\title{
Inorganic Polymers (Geopolymers) as Potential Bioactive Materials
}

by

\author{
Nils Rahner
}

A thesis

submitted to the Victoria University of Wellington in fulfilment of the requirements for the degree of

Master of Science in Chemistry.

Victoria University of Wellington 2009 



\begin{abstract}
The primary aim of this project was to synthesise potassium activated geopolymer composites with bioactivity, and this was realised by adding $10 \mathrm{wt} \%$ of calcium hydroxide, nano-structured calcium silicate or calcium phosphate to the geopolymer matrix. The synthesised samples were cured at $40^{\circ} \mathrm{C}$ then heated to $550^{\circ} \mathrm{C}$ and $600^{\circ} \mathrm{C}$ to reduce their alkalinity. Tensile strength was measured by diametral compression. The effect of exposure to simulated body fluid (SBF) was determined by x-ray diffractometry (XRD), ${ }^{27} \mathrm{Al},{ }^{29} \mathrm{Si}$ and ${ }^{43} \mathrm{Ca}$ nuclear magnetic resonance spectroscopy with magic angle spinning (MAS NMR), $\mathrm{pH}$ measurements, inductively coupled plasma (ICP), scanning electron microscopy (SEM) and energy dispersive $\mathrm{x}$-ray analysis (EDS).

$\mathrm{XRD},{ }^{27} \mathrm{Al}$ and ${ }^{29} \mathrm{Si} \mathrm{MAS} \mathrm{NMR}$ confirmed that all the samples retained their structural characteristics of a true aluminosilicate geopolymer, even after heating and exposure to SBF. EDS examination of the calcium-containing geopolymer composites showed that the calcium distribution was generally homogeneous. Exposure of the geopolymer composites to SBF at body temperature, was used to simulate the behaviour of the geopolymer composites in blood plasma. XRD and SEM/ EDS analysis showed that the geopolymers containing calcium hydroxide and calcium silicate formed hydroxyl apatite (HA) and carbonate hydroxyl apatite (HCA) after their exposure to SBF, indicating a degree of bioactivity. The absorp-
\end{abstract}


tion of calcium and phosphorus from the SBF and the observation of nano crystals rich in these elements provide some evidence of bioactive phases in the composite containing calcium phosphate and the reference geopolymer. The reference and the calcium phosphate geopolymer (both heated to $600^{\circ} \mathrm{C}$ ) produced the lowest $\mathrm{pH}(\approx 8)$ in the SBF.

ICP analysis of the SBF after exposure shows that most of the aluminium remains in the geopolymer structure. The greatest release of aluminium ( $<2.7 \mathrm{ppm}$ after 168 hours) was found for the calcium hydroxide geopolymer (heated to $600^{\circ} \mathrm{C}$ ). Diametral compression testing showed that the strength of the calcium phosphate-containing geopolymer heated to $550^{\circ} \mathrm{C}(4.17 \mathrm{MPa})$ is comparable with that of Bioglass ${ }^{\circledR}(5.56 \mathrm{MPa})$, currently used as a bio-material.

Although none of the composites are ideal in all respects, they show sufficient promise to suggest that with further refinement, geopolymer materials may well be become candidates as bioactive ceramics. 
This Thesis is dedicated to my parents

Brigitte

and

Ewald Rahner

for their outstanding support and encouragement 



\section{Acknowledgments}

I would like to acknowledge and gratefully thank everybody who added their own individual and important part to a successful completion of this work.

Special thanks go to Prof. Kenneth MacKenzie for his outstanding supervision, time consuming support, advice, understanding, sharing his knowledge and also for his personal contact and off-topic conversations. Further thanks go to Aileen MacKenzie, his better half; they were both responsible for my great time during my stay in New Zealand, and also for an easy going start just after my arrival in its capital Wellington.

First contact with Kenneth MacKenzie was initiated by Dr. Martin Schmuecker (DLR - German Aerospace Center); he also supported and advised during this project from overseas. Without him, I would have never made my way to the Victoria University to carry out this project.

Further thanks go to Industrial Research Ltd. (IRL) for providing funding and facilities for this research project through a sub-contract from the Foundation for Research, Science and Technology.

Much appreciated was the input of Ross Fletcher (IRL), his support, advice, encouragement, ideas and the carrying out of the strength measurements, but also that he was always available for a laugh and a chat. 
Thanks also for solving language difficulties and for voluntarily proofreading of this work.

Without the great and warmhearted support of Teresa Gen (VUW) it would have almost been impossible to synthesise the SBF. Thanks are due to her for good times in her lab.

SEM and EDS imaging was carried out with the first-class guidance of David Flynn.

I also like to grateful acknowledge Prof. Mark Smith and Dr. Alan Wong from the University of Warwick (UK) who kindly carried out the natural abundance ${ }^{43} \mathrm{Ca}$ MAS NMR spectroscopy.

I shall not forget the staff of the IRL ceramics group, especially Martin Ryan, and all the other staff-members and students of the Victoria University of Wellington too numerous to name individually, who were also involved in making this work a success.

Last but not least, I wish to give special thanks to my parents. Without their encouragement and extraordinary support from Germany, I would have never started and finished this degree. 


\section{Contents}

Contents vii

List of Figures $\quad$ xiii

List of Tables $\quad$ xvii

\begin{tabular}{lll}
\hline & Introduction & 1
\end{tabular}

2 Literature review 3

2.1 What are geopolymers? . . . . . . . . . . . . . . . . 4

2.1 .1 Characteristics of geopolymers . . . . . . . . 7

2.1 .2 Benefits of geopolymers . . . . . . . . . . . . . . 10

2.2 History and Applications . . . . . . . . . . . . . . . . 10

2.2.1 History of geopolymers . . . . . . . . . . . . . 10

2.2.2 Geopolymer applications and research . . . . . . . . 10

2.3 Bio-Materials . . . . . . . . . . . . . . . . . . . . . 12

2.3 .1 Bioinert materials . . . . . . . . . . . . . . 13

2.3 .2 Resorbable biomaterials . . . . . . . . . . . . 13

2.3 .3 Porous Biomaterials . . . . . . . . . . . . . . . 14

2.3 .4 Bioactive Materials . . . . . . . . . . . . . . . . 14 
2.4 Geopolymers as biomaterials . . . . . . . . . . . . . . 15

2.4 .1 Current State of Art . . . . . . . . . . . . . . . . . . 15

2.5 Project Aims . . . . . . . . . . . . . . . . . . . . . . . . 19

$\begin{array}{lll}3 & \text { Experimental } & 23\end{array}$

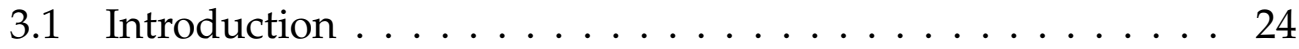

3.1 .1 Reagents .................... 24

3.2 Preparation of raw materials . . . . . . . . . . . . . 24

3.3 Sample Preparation . . . . . . . . . . . . . . . . . . 25

3.3.1 Sample formulation . . . . . . . . . . . . . 25

3.4 Synthesis of the geopolymer specimens . . . . . . . . . . . . 27

$3.4 .1 \quad$ Preparation of the moulds . . . . . . . . . . . 27

3.4.2 Mixing and curing of the geopolymers . . . . . . . 28

3.5 Heat-treatment of geopolymers . . . . . . . . . . . . . . . . . . . 29

3.6 In-Vitro Studies . . . . . . . . . . . . . . . . . . . . 31

3.6.1 Synthesis of simulated body fluid (SBF) . . . . . . . . 31

3.6 .2 In vitro experiments $\ldots \ldots \ldots$. . . . . . . . . . 33

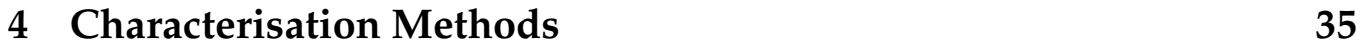

$4.1 \quad$ X-ray Diffractometry $\ldots \ldots \ldots \ldots$

4.1 .1 Introduction . . . . . . . . . . . . 36

4.1 .2 Theoretical background . . . . . . . . . . . 36

$4.1 .3 \quad$ XRD apparatus $\ldots \ldots \ldots \ldots \ldots$

4.1 .4 Sample preparation. . . . . . . . . . . . . . . . . 39

4.1.4.1 Monolithic sample preparation . . . . . . . 39

4.1.4.2 Powder sample preparation . . . . . . . . . 40

4.2 Nuclear Magnetic Resonance Spectroscopy . . . . . . . . . . . 41 
4.2 .1 Introduction $\ldots \ldots \ldots \ldots \ldots \ldots \ldots$. . . . . . 41

4.2 .2 Sample preparation. . . . . . . . . . . . . . . . 43

4.2 .3 NMR spectrometer . . . . . . . . . . . . . . . . . 43

4.3 Scanning Electron Microscopy _. . . . . . . . . . . . . . . . 45

$4.3 .1 \quad$ Secondary electron imaging . . . . . . . . . . . . 47

$4.3 .2 \quad$ Backscattered electron imaging . . . . . . . . . . 47

$4.3 .3 \quad$ SEM/ EDS apparatus . . . . . . . . . . . . . . . 48

4.3 .4 Sample preparation. . . . . . . . . . . . . . . . . . 49

4.4 Compression Testing (Brazil Test) _ . . . . . . . . . . . . . 50

4.4 .1 Introduction . . . . . . . . . . . . . . . . . . . 50

4.5 Inductively Coupled Plasma . . . . . . . . . . . . . . . . 53

4.6 pH studies . . . . . . . . . . . . . . . . . . . . . . . 55

5 Results and Discussion 57

$5.1 \quad$ Strength measurement results . . . . . . . . . . . . . . . 58

$5.2 \quad$ XRD results $\ldots \ldots \ldots \ldots \ldots \ldots$

$5.2 .1 \quad$ XRD patterns of the raw materials . . . . . . . . . 63

5.2 .2 Reference geopolymer . . . . . . . . . . . . . . . 67

5.2 .3 Calcium hydroxide geopolymers . . . . . . . . . . 68

$5.2 .4 \quad$ Calcium silicate geopolymers $\ldots \ldots \ldots$. . . . . . . 73

5.2 .5 Calcium phosphate geopolymers . . . . . . . . . . 75

5.3 MAS NMR results . . . . . . . . . . . . . . . . . . . . . . . 79

$5.3 .1 \quad{ }^{27} \mathrm{Al}$ and ${ }^{29} \mathrm{Si}$ MAS NMR results $\ldots . . . . . . . . . .79$

5.3.1.1 Reference geopolymer . . . . . . . . . . . . 79

5.3 .1 .2 Calcium hydroxide geopolymers . . . . . . . 82

5.3.1.3 Calcium silicate geopolymers . . . . . . . . 86 
5.3.1.4 Calcium phosphate geopolymers . . . . . . 90

5.3.2 ${ }^{34}$ Ca MAS NMR of calcium phosphate geopolymers . . . . . . . . . . . . . . . . 96

$5.4 \quad$ Alteration of the $\mathrm{pH}$ of the $\mathrm{SBF} \ldots \ldots \ldots \ldots$

5.4.1 Behaviour of the reference and calcium phosphate geopolymers in $\mathrm{SBF} \ldots \ldots \ldots . \ldots 99$

5.4.2 Behaviour of the calcium hydroxide geopolymers in SBF . . . . . . . . . . . . . . . . . . . . 101

5.4.3 Behaviour of the calcium silicate geopolymers in SBF 102

5.5 ICP analysis of the SBF after exposure of the geopolymers . . 105

5.5 .1 Phosphorus analysis . . . . . . . . . . . . . 106

5.5 .2 Aluminium analysis . . . . . . . . . . . . . . . 108

5.5 .3 Calcium analysis . . . . . . . . . . . . . . 110

5.5 .4 Silicon analysis $\ldots \ldots \ldots$. . . . . . . . . . . . 112

5.5 .5 Potassium analysis . . . . . . . . . . . . . . . . . 114

5.6 SEM results . . . . . . . . . . . . . . . . . . . . . . . 116

5.6 .1 Reference geopolymer . . . . . . . . . . . . . . 117

5.6.1.1 Before SBF exposure . . . . . . . . . . . 117

5.6 .1 .2 After SBF exposure . . . . . . . . . . . . 121

5.6 .2 Calcium hydroxide geopolymer . . . . . . . . . . . 125

5.6 .2 .1 Before SBF exposure . . . . . . . . . . . 125

5.6 .2 .2 After SBF exposure . . . . . . . . . . 128

5.6 .3 Calcium silicate geopolymer . . . . . . . . . . . . 132

5.6 .3 .1 Before SBF exposure . . . . . . . . . . . . 132

5.6 .3 .2 After SBF exposure . . . . . . . . . . . . . 137

5.6 .4 Calcium phosphate geopolymer. . . . . . . . . . . 142 
$5.6 .4 .1 \quad$ Before SBF exposure . . . . . . . . . . . 142

$5.6 .4 .2 \quad$ After SBF exposure . . . . . . . . . . . . 147

6 Conclusions 153

6.1 Future work . . . . . . . . . . . . . . . . . . . . 157

\begin{tabular}{ll}
\hline Bibliography & 159
\end{tabular} 



\section{List of Figures}

$2.1 \quad$ (Poly-)sialate structural units . . . . . . . . . . . . . . 5

2.2 (Poly-)sialate network structures . . . . . . . . . . . 6

2.3 Typical XRD spectrum of a geopolymer. . . . . . . . . . . 7

2.4 Geopolymer applications . . . . . . . . . . . . . . 9

2.5 Geopolymer implants . . . . . . . . . . . . . . . . . . . . . . 18

3.1 Geopolymer sample . . . . . . . . . . . . . . . . . . . . . . . . . . 29

$4.1 \quad$ X-Ray diffraction by lattice planes . . . . . . . . . . . . . . 37

4.2 NMR: Fourier transformation of FID to frequency domain. . 42

4.3 Chemical shifts of ${ }^{29} \mathrm{Si}$ and ${ }^{27} \mathrm{Al} \mathrm{NMR} \ldots \ldots$. . . . . . . . . . 44

4.4 Test setup for diametral compression testing . . . . . . . . . 51

4.5 DCT-tesing, requirements on the sample . . . . . . . . . . 52

4.6 Emission of electromagnetic radiation . . . . . . . . . . . 53

4.7 ICP-AES process steps . . . . . . . . . . . . . . . . . . 54

5.1 XRD pattern of calcium phosphate . . . . . . . . . . . 63

5.2 XRD pattern of calcium silicate . . . . . . . . . . . . . . 64

5.3 XRD pattern of calcium hydroxide . . . . . . . . . . . . 65

5.4 XRD of halloysite before and after dehydroxylation . . . . . 66 
5.5 XRD: reference geopolymer before and after heating . . . . . 67

5.6 XRD: Ca-hydroxide geopolymer before and after heating . . 68

5.7 XRD: Ca-hydroxide geopolymer, unheated, before and after

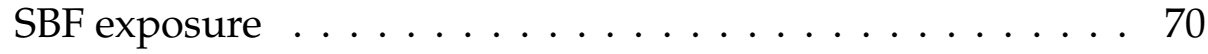

$5.8 \quad$ XRD: Ca-hydroxide geopolymer, $550^{\circ} \mathrm{C}$, before and after SBF exposure ......................... 71

5.9 XRD: Ca-hydroxide geopolymer, $600^{\circ} \mathrm{C}$, before and after SBF exposure . . . . . . . . . . . . . . . 72

5.10 XRD: Ca-silicate geopolymer before and after heating. . . . . 73

5.11 XRD: Ca-silicate geopolymer, $600^{\circ} \mathrm{C}$, before and after SBF exposure .......................... 74

5.12 XRD: Ca-phosphate geopolymer before and after heating . . 75

$5.13{ }^{27} \mathrm{Al}$ MAS NMR, reference geopolymer . . . . . . . . . . . . . . 79

$5.14{ }^{29} \mathrm{Si}$ MAS NMR, reference geopolymers, unheated . . . . . . . 80

$5.15{ }^{29} \mathrm{Si}$ MAS NMR, reference geopolymer, $550^{\circ} \mathrm{C} \ldots$. . . . . . . 81

$5.16{ }^{27} \mathrm{Al}$ MAS NMR, Ca-hydroxide geopolymer . . . . . . . . . . 82

$5.17{ }^{27} \mathrm{Al}$ MAS NMR, Ca-hydroxide geopolymer, $550^{\circ} \mathrm{C} \ldots 83$

$5.18{ }^{29} \mathrm{Si}$ MAS NMR, Ca-hydroxide geopolymer . . . . . . . . . . 84

$5.19{ }^{29} \mathrm{Si}$ MAS NMR, Ca-hydroxide geopolymer, $550^{\circ} \mathrm{C} \ldots \ldots 5$

$5.20{ }^{27} \mathrm{Al}$ MAS NMR, Ca-silicate geopolymer . . . . . . . . . . . 86

$5.21{ }^{27} \mathrm{Al}$ MAS NMR, Ca-silicate geopolymer, $550^{\circ} \mathrm{C} \ldots$. . . . . . 87

$5.22{ }^{29} \mathrm{Si}$ MAS NMR, Ca-silicate geopolymer, $550^{\circ} \mathrm{C} \ldots \ldots 88$

$5.23{ }^{29} \mathrm{Si}$ MAS NMR, Ca-silicate geopolymer, $600^{\circ} \mathrm{C} \ldots$. . . . . . 89

$5.24{ }^{27} \mathrm{Al}$ MAS NMR, Ca-phosphate geopolymer . . . . . . . . . . . 90

$5.25{ }^{27} \mathrm{Al}$ MAS NMR, Ca-phosphate geopolymer, $550^{\circ} \mathrm{C} \ldots . . .91$

$5.26{ }^{29}$ Si MAS NMR, Ca-phosphate geopolymer . . . . . . . . . . . 92 
$5.27{ }^{29} \mathrm{Si}$ MAS NMR, Ca-phosphate geopolymer, $550^{\circ} \mathrm{C} \ldots \ldots$

$5.28{ }^{29} \mathrm{Si}$ MAS NMR, Ca-phosphate geopolymer, $600^{\circ} \mathrm{C}$. . . . . . . 94

$5.29{ }^{43}$ Ca MAS NMR, Ca-phosphate geopolymers before and after SBF exposure . . . . . . . . . . . . . . . . . . . 97

$5.30 \mathrm{pH}$ results, exposure of reference geopolymers . . . . . . . . . 99

5.31 pH results, exposure of Ca-phosphate geopolymers . . . . . . 100

5.32 pH results, exposure of Ca-hydroxide geopolymers . . . . . . 101

$5.33 \mathrm{pH}$ results, exposure of Ca-silicate geopolymers . . . . . . . 102

5.34 ICP: P content in SBF . . . . . . . . . . . . . . 106

5.35 ICP: Al concentration in SBF . . . . . . . . . . . . . . . . . 108

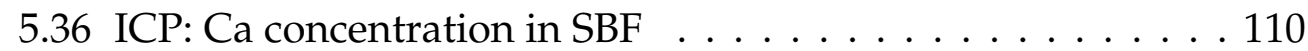

5.37 ICP: Si concentration in SBF . . . . . . . . . . . . . . . 112

5.38 ICP: K concentration in SBF . . . . . . . . . . . . . . . . 114

5.39 SEM: reference geopolymer, x1000, before SBF exposure . . . 117

5.40 SEM: reference geopolymer, x10k, before SBF exposure. . . . 118

5.41 SEM: reference geopolymer, x30k, before SBF exposure . . . . 119

5.42 EDS: reference geopolymer, $600^{\circ} \mathrm{C}$, before SBF exposure . . . 120

5.43 SEM: reference geopolymer, x550, after SBF exposure . . . . . 121

5.44 SEM: reference geopolymer, x5k, after SBF exposure . . . . 122

5.45 SEM: reference geopolymer, x20k, after SBF exposure . . . . . 123

5.46 EDS: reference geopolymer, $600^{\circ} \mathrm{C}$, after SBF exposure . . . . 124

5.47 SEM: Ca-phosphate geopolymer, x550, before SBF exposure. 125

5.48 SEM: Ca-phosphate geopolymer, x15k, before SBF exposure. 126

5.49 EDS: Ca-hydroxide geopolymer, $600^{\circ} \mathrm{C}$, before SBF exposure 127

5.50 SEM: Ca-hydroxide geopolymer, $x 4 k$, after SBF exposure . . 128

5.51 SEM: Ca-hydroxide geopolymer, x20k, after SBF exposure. . 129 
5.52 EDS: Ca-hydroxid geopolymer, $600^{\circ} \mathrm{C}$, after SBF exposure . . 130

5.53 SEM: Ca-silicate geopolymer, x2k, before SBF exposure. . . . 132

5.54 SEM: Ca-silicate geopolymer, x9.5k, before SBF exposure . . 133

5.55 SEM: Ca-silicate geopolymer, x20k, before SBF exposure . . . 134

5.56 EDS: Ca-silicate geopolymer, $600^{\circ} \mathrm{C}$, before SBF exposure . . 135

5.57 SEM: Ca-silicate geopolymer, x4k, after SBF exposure . . . . . 137

5.58 SEM: Ca-silicate geopolymer, $x 11 k$, after SBF exposure . . . . 138

5.59 SEM: Ca-silicate geopolymer, x20k, after SBF exposure . . . . 139

5.60 EDS: Ca-silicate geopolymer, $600^{\circ} \mathrm{C}$, after SBF exposure . . . 140

5.61 SEM: Ca-phosphate geopolymer, x1000, before SBF exposure 142

5.62 SEM: Ca-phosphate geopolymer, x10k, before SBF exposure. 143

5.63 SEM: Ca-phosphate geopolymer, x30k, before SBF exposure. 144

5.64 EDS: Ca-phosphate geopolymer, $600^{\circ} \mathrm{C}$, before SBF exposure 145

5.65 SEM: Ca-phosphate geopolymer, x1000, after SBF exposure . 147

5.66 SEM: Ca-phosphate geopolymer, x10k, after SBF exposure. . 148

5.67 SEM: Ca-phosphate geopolymer, x15k, after SBF exposure. . 149

5.68 EDS: Ca-phosphate geopolymer, $600^{\circ} \mathrm{C}$, after SBF exposure . 150 


\section{List of Tables}

3.1 Geopolymer mixtures . . . . . . . . . . . . . . . . . . 26

3.2 Element ratios of the geopolymer mixtures . . . . . . . . 27

3.3 Molar ratios of the geopolymer mixtures . . . . . . . . . 27

3.4 Heat-treatment schedules . . . . . . . . . . . . . . . . 30

3.5 Ingredients of the SBF $\ldots \ldots \ldots \ldots \ldots \ldots \ldots \ldots$

$4.1 \quad$ ICP-AES detection limits $\ldots \ldots \ldots \ldots \ldots \ldots$

5.1 Tensile strength measurement results . . . . . . . . . . . 58

5.2 Tensile strength comparison with biomaterials . . . . . . . . 61

5.3 Bioactive phases in geopolymers after SBF exposure . . . . 78

$5.4{ }^{43}$ Ca MAS NMR results of Ca-phosphate geopolymers . . . 96

6.1 Summary of the geopolymer properties . . . . . . . . . 155 

Chapter 1

\section{Introduction}


Geopolymers are materials based on a pure aluminosilicate system activated with strong alkali. These materials consist of tetrahedral aluminate and silicate units based on (poly-)sialates (shorthand for silicon-oxoaluminates). A comprehensive overview of these group of materials was recently given by MacKenzie [1]. The expression "geopolymer" was proposed by Davidovits in the 1980's due to their setting mechanism, a polycondensation process under alkaline conditions, similar to organic polymers. Geopolymers have ceramic-like properties but attain their strength and durability at ambient temperatures [2].

Geopolymers are presently used for a variety of applications including heat resistant materials and fire protection. Specialist geopolymers have been developed as biomaterials to replace/ repair damaged animal bones [3] [4].

The term bioactivity applies to biomaterials capable of forming the bone-like phase hydroxyl apatite by interaction with blood plasma. This can be simulated by exposing such materials to simulated body fluid (SBF) under laboratory conditions [5].

This project seeks to explore the concept of the bioactive geopolymer by introducing calcium-based compounds into a geopolymer matrix in order to promote bioactivity. 
Chapter 2

Literature review 


\subsection{What are geopolymers?}

According to Davidovits [2], the formation of geopolymers is a polymerisation process similar to the polycondensation of an organic polymer, and therefore he named the process "geopolymerisation". Since geopolymerisation is exothermic and generally takes place at ambient temperatures, the synthesis of inorganic polymers does not require additional energy to achieve good mechanical properties. However, special conditions such as a controlled water content and high alkalinity are required to attain strength and durability.

During the setting process, (poly-)sialates are formed having a random 3-D network made of tetrahedral $\mathrm{Si}-\mathrm{O}$ and $\mathrm{Al}-\mathrm{O}$ units with $\mathrm{Al}^{3+}$-ions in IV-fold coordination. This produces a negative charge, balanced by alkaliions (potassium or sodium) located in the network cavities [1], [2]. The empirical formula of a (poly-)sialate is:

$$
M_{n}\left[-\left(\mathrm{SiO}_{2}\right)_{z}-\mathrm{AlO}_{2}\right]_{n},{ }_{w} \mathrm{H}_{2} \mathrm{O}
$$

in which " $\mathrm{M}$ " stands for a monovalent cation (e.g. potassium, sodium), " $n$ " indicates the degree of polycondensation and " $\mathrm{z}$ " can take values of 1 , 2 or 3. 
Some (poly-)sialate structures are shown schematically in Figures 2.1 and 2.2 ([1] ], [6]).

Depending on the setting conditions, geopolymers can be crystalline or amorphous when cured under hydrothermal conditions or at ambient temperatures respectively [2].
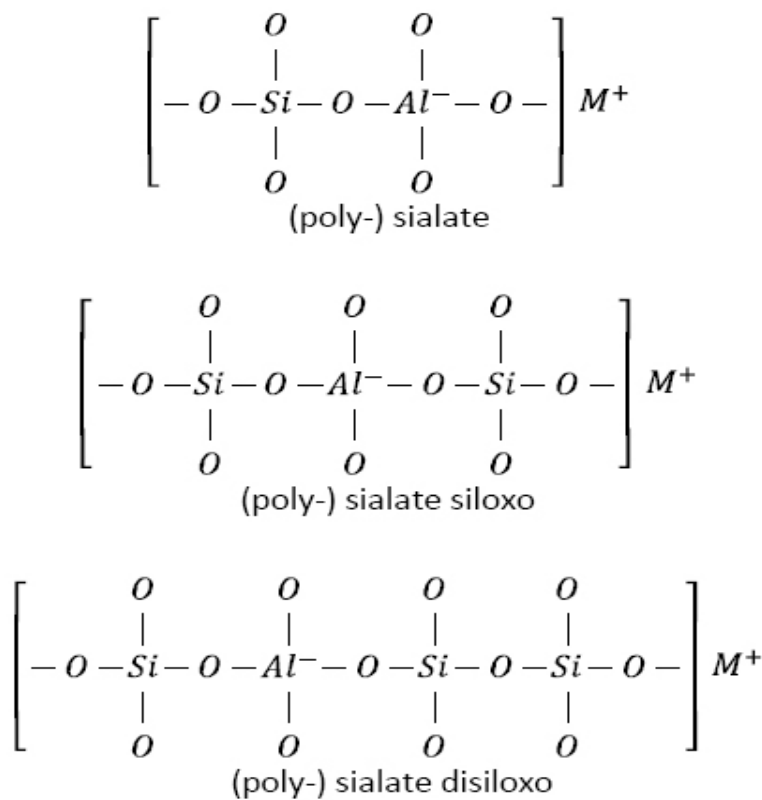

Figure 2.1: (Poly-)sialate structural units [1] 


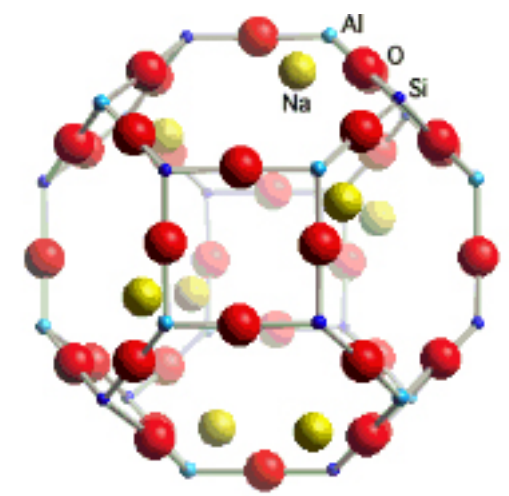

Sodium-Poly(sialate)

Sodalite framework Na-PS

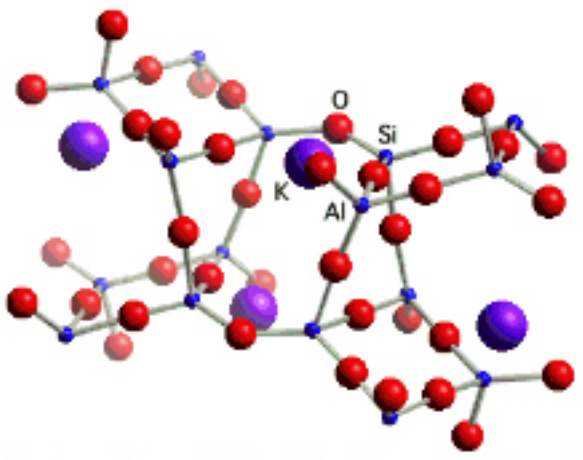

Potassium Poly(sialate-disiloxo)

Sanidine framework K-PSDS

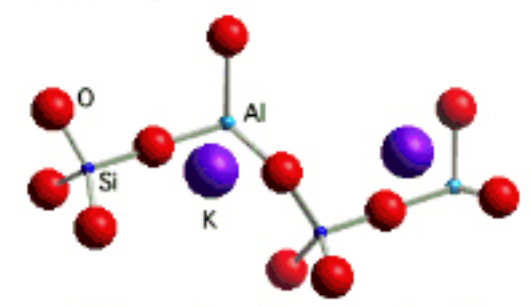

Potassium-Poly(sialate)

Kalsilite framework K-PS
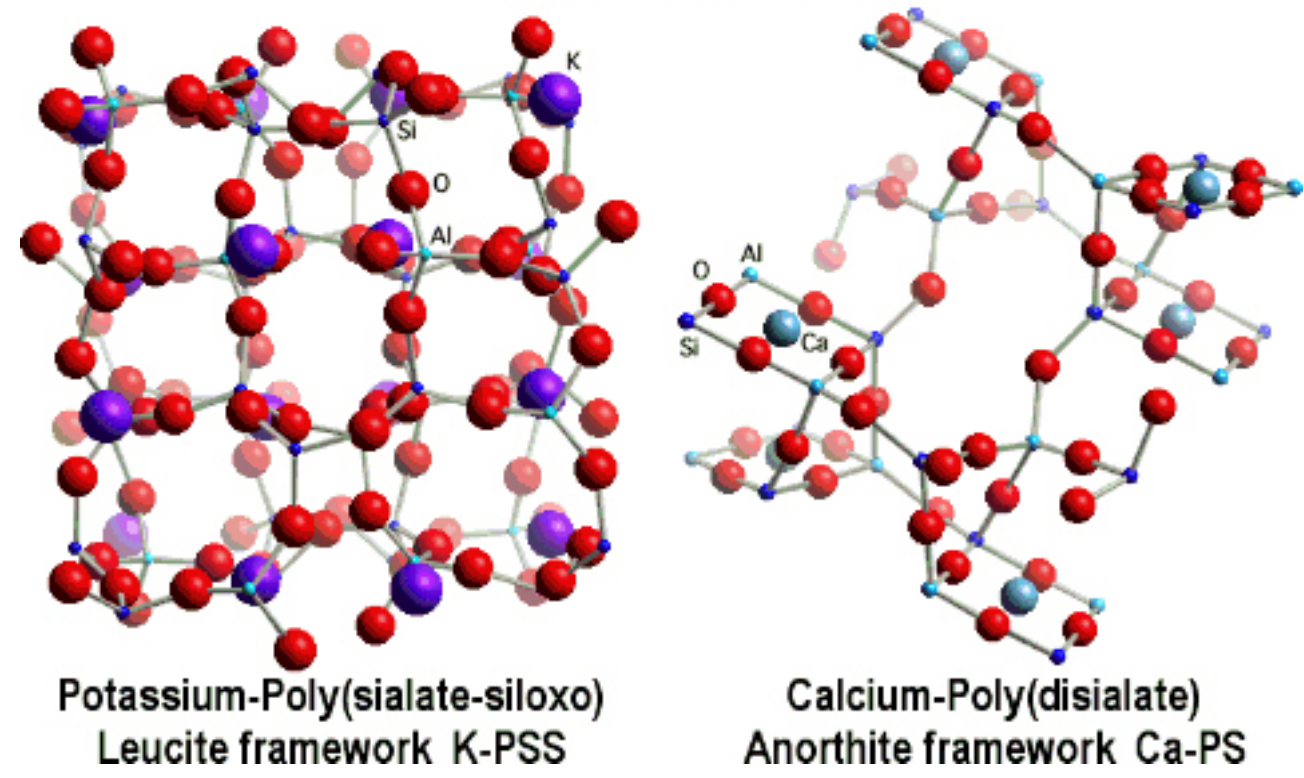

Figure 2.2: (Poly-)sialate network structures [6] 


\subsubsection{Characteristics of geopolymers}

A typical characteristic of geopolymers cured at ambient temperatures is that they are x-ray amorphous. The x-ray diffraction patterns of wellcured geopolymers do not normally show sharp peaks but present a large hump at around 30 degrees $/ 2 \Theta$. A typical pattern is shown in Figure 2.3 The peak labelled " $\mathrm{Q}$ " is a quartz peak, from an impurity in a reactant.

Typical geopolymer XRD spectrum

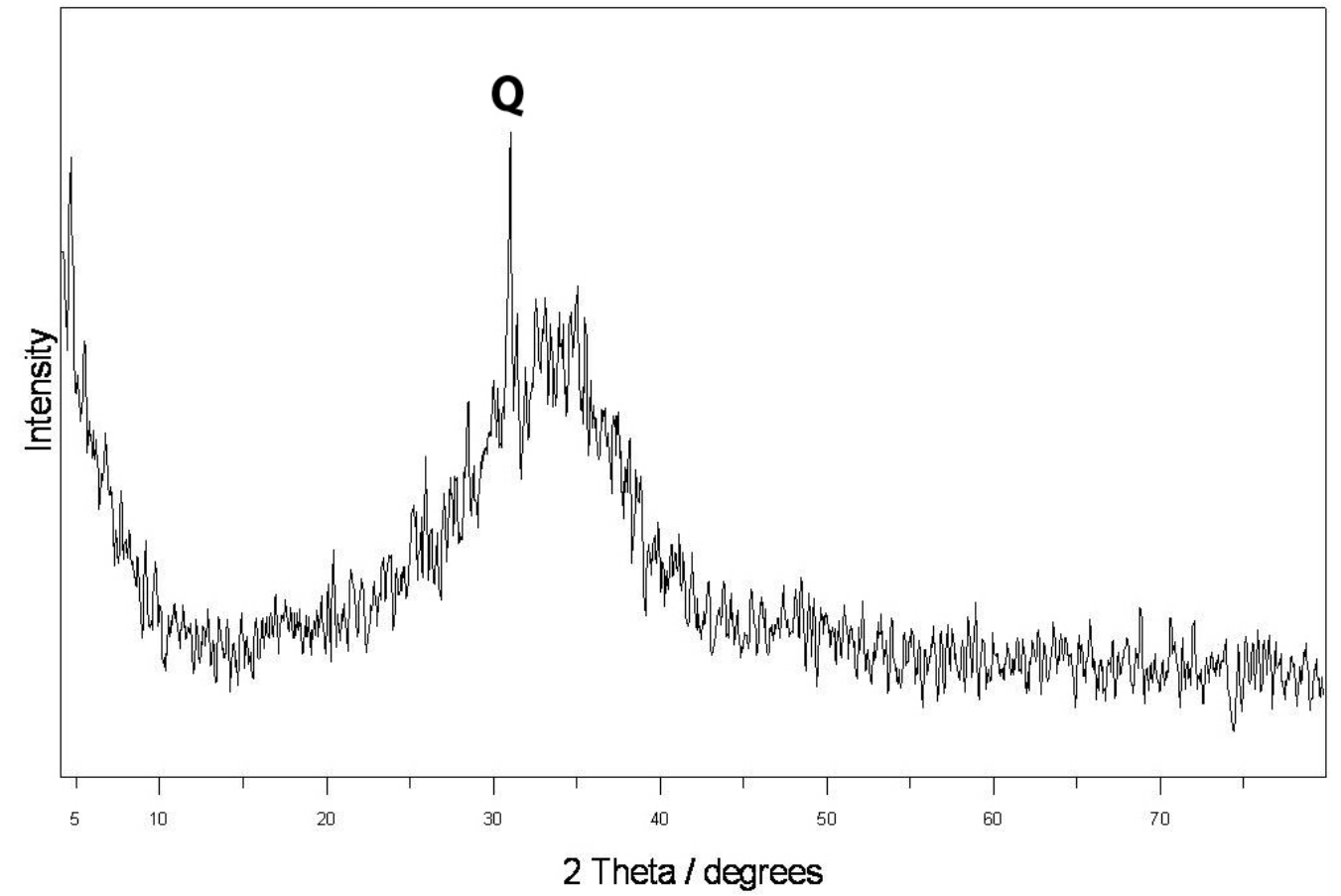

Figure 2.3: Typical XRD spectrum of a geopolymer, $Q=$ quartz impurity

Further, silicon and aluminium in a well cured inorganic polymer must be in 4-fold coordination. Since XRD cannot determine the coordination state of atoms in amorphous materials, solid state nuclear magnetic resonance spectroscopy with magic angle spinning (MAS NMR) must be used 
to provide this information [7].

Geopolymers can be produced with various microstructures in relation to the Al:Si ratio; high aluminium contents lead to three-dimensional structures and high silicon contents lead to two dimensional cross-linked structures. Because of the various microstructures, different mechanical and physical properties can be achieved. Hence, geopolymers are useful for a wide range of applications (Fig. 2.4), e.g. as heat resistant materials (up to $1400^{\circ} \mathrm{C}$ ) [6, 8, 9] and sealants or encapsulation materials. Moreover, because of their properties, geopolymers could also provide a good alternative to conventional plastics or cements [2, 10]. A more recent approach is the application of geopolymers in the field of biomaterials which were successfully implanted in animals [3, 4, 11]. 


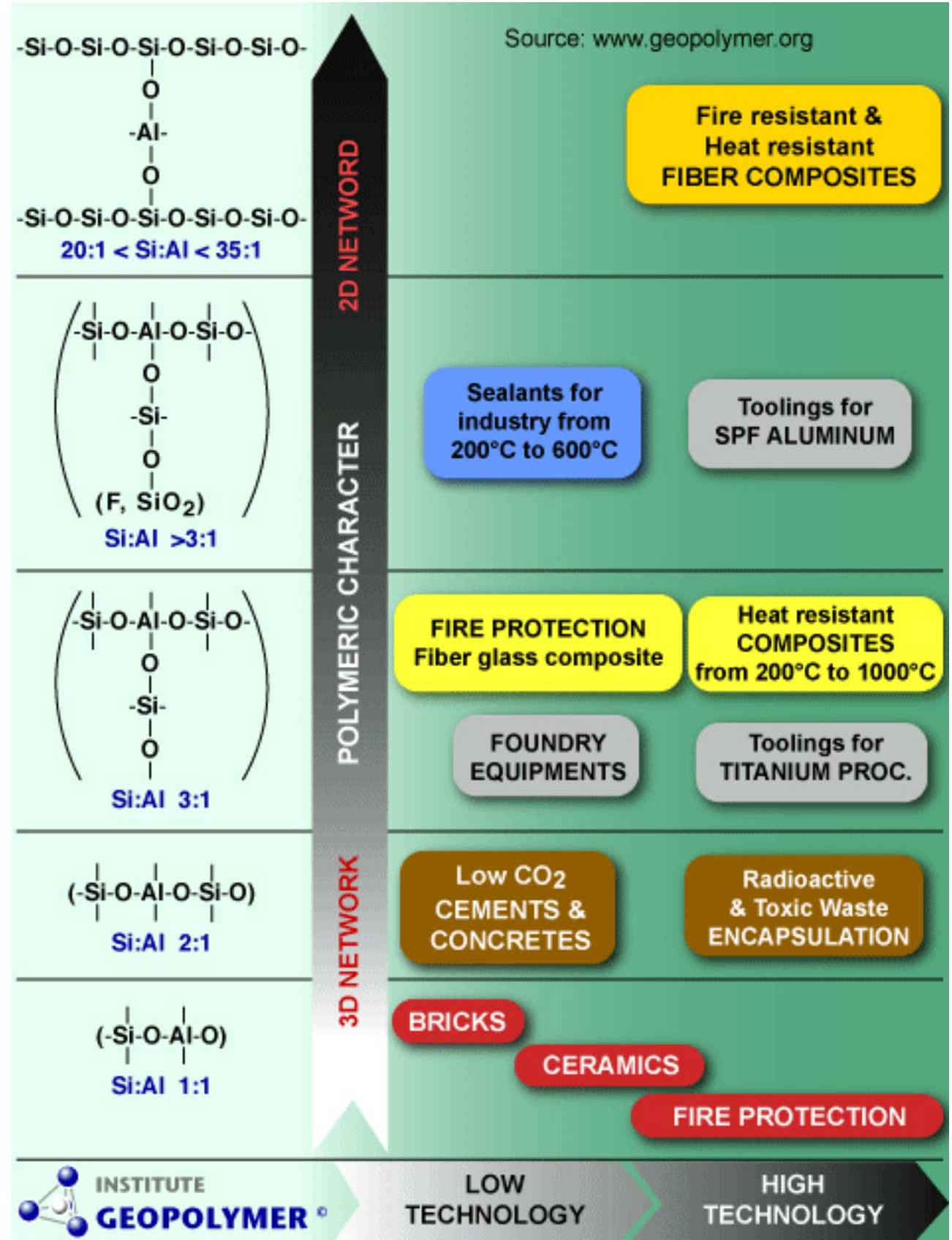

Figure 2.4: Applications of geopolymers related to their network structure [6] 


\subsubsection{Benefits of geopolymers}

The synthesis of geopolymers does not create greenhouse gases and because of this energy efficiency, inorganic polymers have become increasingly attractive. This increasing attraction is not just because of the abovementioned aspects but also because it is generally possible to produce these products using recycled materials. This is another benefit in the context of the current problems of global warming and environmental protection.

\subsection{History and Applications}

\subsubsection{History of geopolymers}

The usage of geopolymers may go back to the Romans and Egyptians, and probably further back to the Babylonians, as they used inorganic compounds mixed with organic matter to produce strong building materials. While there are still disagreements whether or not the Egyptian pyramids were made of geopolymers, it has been confirmed that the network structure of the building blocks matches the definition of inorganic polymers [12].

\subsubsection{Geopolymer applications and research}

A major application, and probably one of the most important ones for geopolymers is fire protection. 
Davidovits and Latapie started extensive research in non-flammable materials after some disastrous fires in France between 1970 and 1973 [10]. They rediscovered the possibility of making ceramic-like materials without firing at temperatures below $100^{\circ} \mathrm{C}$ which had already been observed in the 1930's and reinvented in 1970 by Olsen and Berg et. al, [10] (although without any industrial success).

Due to the intensive research of Davidovits and Legrand, the first fire resistant building materials, containing chipboard panels with a geopolymer coating, were produced in the mid 1970's, thus initiating the geopolymer industry [10]. Ongoing research led to improvements in the materials and broadened their applications within the field of heat protection.

A wider range of applications and improvements were made due to continuous research in the geopolymers field. The properties of geopolymers were exploited, drawing on the fact that they are not only heat resistant but are also highly porous and therefore light weight. Using this knowledge and applying it to the ceramics field, composite geopolymeric materials were developed with improved specific properties, resulting in more technical or advanced applications, for example aeronautical applications, wall insulation for cabins and storage bins, wire insulation and automotive parts [10].

Beside these "high-tech" applications, special geopolymer concretes have been used for repairing runways or motorways because they set and harden quickly and develop a high compressive strength within four hours [10].

Likewise, geopolymers are used for structural and building applications. Flexible inorganic polymer fibre composites can be used to repair 
structures made of stone, bricks or concrete. Such fibre composites are already used in Japan and America to reinforce existing bridges and other buildings but are also used in new constructions in hazardous areas [10]. Another important application is waste encapsulation. It has been reported that it is possible to synthesise geopolymers which trap heavy metals and radioactive materials in their network structures (see also Figure 2.4[6] [13] [14].

\subsection{Bio-Materials}

A general definition of biomaterials is: "Any substance (other than a drug) or combination of substances, synthetic or natural in origin, which can be used for any period of time, as a whole or as a part of a system which treats, augments or replaces any tissue, organ or function of the body." And: "A non-viable material used in a medical device intended to interact with biological systems." [15].

The development of materials suitable for imbedding in humans or animals is one of the recent human discoveries. Since such materials were introduced, life has become more comfortable for e.g. bone fracture patients or patient requiring joint replacements (e.g. hip or shoulder) [16]. Beside metals and metal-composites, ceramics and ceramic-composite materials play an important role for such applications and are called "bio-ceramics". Larry Hench from the University of Florida is one of the best-known scientists involved in inventing bio-ceramics. He discovered numerous ceramics and glasses usable as implants in living tissue. Today, a wide range of his developments are used in operating theatres including the materials Bioglass ${ }^{\circledR}$ and Ceravital ${ }^{\circledR}[17]$. During the last decade, attempts have been 
made to create bio-compatible geopolymers to provide inorganic materials other than ceramics, for use as implants. All bio-ceramics have to form a stable interface with the living host tissue [16] [17]. Presently, there are four types of known bio-ceramics.

\subsubsection{Bioinert materials}

Bioinert materials have the characteristic that they are not biologically or chemically bonded, but physically attached to the living tissue. For this reason there may be movement between the implant and the surrounding tissue which leads to the development of unattached fibrous capsules in both soft and hard tissues. Movement of the implant-tissue interface may lead to malfunction of the implant or the interface-tissue, or both. Due to this relative movement, and depending on the material, the thickness of the non-adherent tissue layer alters significantly. Hence, it is essential that the implants are implanted with the correct load rates and possess suitable properties (e.g. elastic modulus) otherwise clinical failures are likely to occur, e.g. weakening of the implant, stress shielding etc. [16][17].

\subsubsection{Resorbable biomaterials}

The purpose of resorbable implants is to dissolve and be replaced by natural host tissue over time. One advantage is that the body is able to repair itself and reconstruct cell populations, and no artificial substances remain in the body. The use of resorbable materials as implants leads to a very thin or non-existent interface between implant and tissue. While these materi- 
als are relatively weak and therefore limited in their application, they are excellent when only short term performance and low strength is required. Calcium phosphate materials are especially successful for such purposes, e.g. as implants in the jaw or forehead. Resorbable materials act as a support and help to regenerate the damaged body in natural way [16][17].

\subsubsection{Porous Biomaterials}

The use of porous materials provides the possibility for the host tissue to grow into the implant surface or even throughout the whole sample. In effect, this causes a larger interfacial connection area which results in a stronger movement resistance, and therefore reduction of the relative motion between implant and tissue. The interface is established by the growth of living tissue into the pores of the implant and is often called "biological fixation". This type of interfacial connection can manage more complex stress patterns in contrast to implants attaining "morphological fixation". However, there are limitations and certain requirements for these materials, such as the specific pore size necessary for the ingrowth of the living host tissue. Further, interfacial movement cannot be accommodated as it may cut off the blood supply and cause tissue death and inflammation and destruction of the interfacial connection [16] [17].

\subsubsection{Bioactive Materials}

The tissue response of this group of biomaterials when exposed to simulated body fluid (SBF) or implanted in living tissue ranges between that of 
resorbable and bioinert materials. The general definition of bioactive materials is as follows: "A bioactive material is one that elicits a specific biological response at the interface of the material, which results in the formation of a bond between the tissue and the material." [16]

Known bioactive materials form a biologically active hydroxyl-carbonate apatite layer $(\mathrm{HCA})\left[(\mathrm{Ca}, \mathrm{Mg}, \mathrm{Na})_{10}\left(\mathrm{PO}_{4}, \mathrm{CO}_{3}\right)_{6}(\mathrm{OH})_{2}\right]$ that bonds to hard and soft tissue. Substances with bioactive behaviour include calcium silicate, calcium hydroxide $\left(\mathrm{Ca}(\mathrm{OH})_{2}\right)$ or tri-calcium phosphate $\left(\mathrm{Ca}_{3}\left(\mathrm{PO}_{4}\right)_{2}\right)$. This particular bond can also be achieved using bioactive glasses, bioactive glass-ceramics or dense hydroxyl apatite. The important point is that the HCA phase thus formed is equivalent to bone, both chemically and morphologically. The adherent interface formed between implant and surrounding tissue is very strong and can withstand significant mechanical forces. Often the adhesive strength of the interface has an equal or higher cohesive strength than the implant or the tissue. For that reason, failures are likely to occur either in the tissue or the implant material rather than in the interface [16] [17].

\subsection{Geopolymers as biomaterials}

\subsubsection{Current State of Art}

Calcium phosphate cements have been used for bone filling purposes for more than 50 years. Such cements are similar to geopolymers in terms of the setting process, which does not involve heat-treatment. In addition, these cements may be bioactive as well as biodegradable, which means 
that they may be replaced by natural bone. However, calcium phosphate cements do not have good mechanical properties and can only be used under low load conditions, such as the forehead or jaw [18].

Relatively new products in the field of biomaterials applications are materials based on amorphous silicate network structures. These network structures are similar to those of inorganic polymers, suggesting that they may well be classified as such. Compared to calcium phosphate cements, geopolymers have better mechanical properties and may be used where load resistance is required. However, as yet, they have only restricted uses in biomedical applications because of their aluminium content and the possibility of leaching out "free" aluminium. However, Yap et al. [19] reported that the release of aluminium ions is controversial and that low concentrations of aluminium can actually be beneficial and stimulate the proliferation of osteoblasts and new bone formation, and for determining the in-vivo bio-compatibility. However, Yap [19], Geyer [20] and Hantson [21] reported that high concentrations of aluminium $(<2 \mathrm{ppm})$ led to brain diseases. For safety, the release of aluminium-ions should be minimized or suppressed. In addition, geopolymers are very alkaline ( $\mathrm{pH} 10$ - 14) by contrast to the $\mathrm{pH}$ of the body $(7-7.5)$ and therefore difficult to use as biomaterials.

Nevertheless, current research shows that it is possible to use geopolymers as biomaterials and these have been successfully implanted in living tissue [3] [4] [11] .

In 2005, Oudadesse et al. [11] investigated a standard geopolymer such as used for applications such as fireproof interior panels or marine structural composites. This had a high Si:Al ratio to minimise the aluminium 
content. No additives were used to make the inorganic polymers bioactive or biocompatible in any way. Additionally, heat processing at temperatures between $250^{\circ} \mathrm{C}$ and $625^{\circ} \mathrm{C}$ was used to reduce the geopolymer alkalinity and increase its porosity. "In-vitro" and "in-vivo" studies were carried out using a geopolymer heated to $500^{\circ} \mathrm{C}$, since this showed the best results in terms of $\mathrm{pH}$ and the most strongly bonded aluminium in the network structure. The studies were successful with regard to the stability of the material both after exposure to SBF and also after implantation in living tissue. However, the geopolymers chosen may not be bioactive, as no growth of HCA or other bioactive phases was reported [11].

Martin et al. [4] used geopolymer compositions which provided good mechanical properties but contained additional substances which are well known for their bio-compatibility, namely hydroxyl apatite (HA) and tricalcium phosphate (TCP). The aim was to create porous geopolymers compatible with living tissue. Pure HA and TCP as well as a mixture of both were used as additives in the aluminium silicates for the experiments. To increase the porosity and to lower the sample $\mathrm{pH}$ to about 7 , the samples were heat treated to $500^{\circ} \mathrm{C}$. They were later implanted in rabbits and left for various times to analyse the behaviour of the materials when exposed to living tissue. All of the synthesised geopolymers were accepted by the organism without causing inflammation or encapsulation effects. Bonding to bone was inferred from the penetration of bone into the implants. Figure 2.5 shows an example of in vivo studies; the top image presents the implant immediately after implantation, the bottom image 30 days after implantation [4]. 

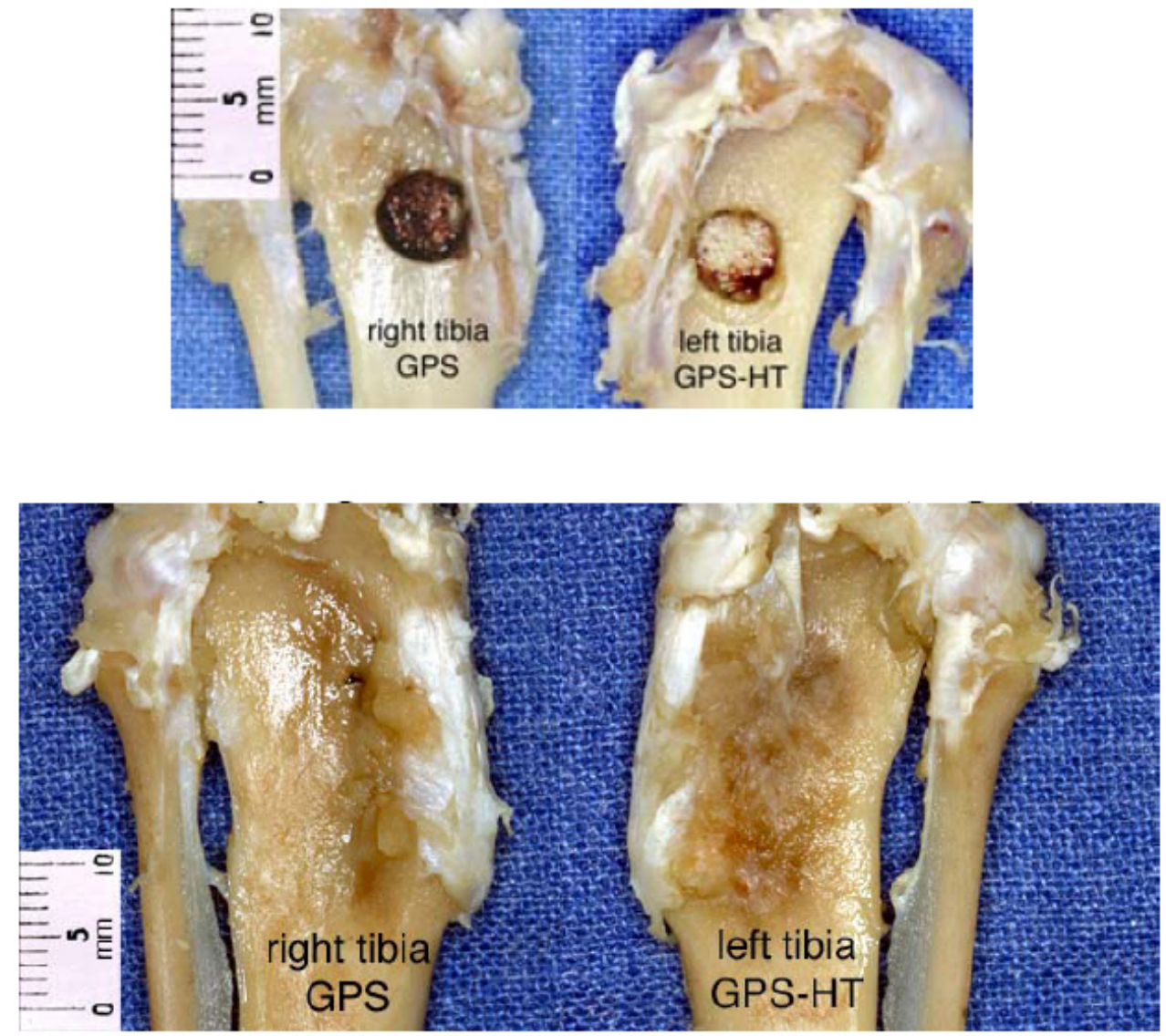

Figure 2.5: Geopolymer implants: 0 (top) and 30 days (bottom) after implantation [4]

More recent studies carried out by Oudadesse et al. [3] examined the behaviour of bioactive geopolymers. These focussed on geopolymer compositions with a zeolite-like structure and used hydroxyl apatite (HA) and tri-calcium phosphate (TCP) or a mixture of both as additives to make them bio-compatible. Aluminosilicates were mixed and synthesised in three steps:

1. Potassium silicate solution was depolymerised by adding potassium hydroxide 
2. Dehydrated kaolinite was mixed with this solution, distilled water was added to optimise homogenisation. This mixture was left at $-10^{\circ} \mathrm{C}$ for 24 hours in a sealed mould to produce a polycondensed aluminosilicate.

3. Hydroxyl apatite, tri-calcium phosphate or biphasic HA-TCP was added to the geopolymer mix, homogenised and re-sealed for curing.

The highly alkaline specimens were heat treated to $250^{\circ} \mathrm{C}$ and $500^{\circ} \mathrm{C}$ to reduce their $\mathrm{pH}$ values and to create a certain degree of porosity. "Invitro" studies were carried out to determine the material behaviour when exposed to liquids, and "in vivo" experiments were executed to check whether or not the materials are suitable as biomaterials in terms of leaching out of aluminium and acceptance by the host tissue. Oudadesse et al. reported that they successfully made materials which were accepted by host bone and provided good mechanical properties. Further, neither inflammation or encapsulation of the surrounding tissue occurred nor leaching out of harmful elements from the sample was recorded [3].

In conclusion, current research suggests that it is possible to synthesise materials with biocompatible behaviour suitable as implants in living tissue.

\subsection{Project Aims}

This project is focussed on synthesising bio-geopolymer(s) as potential bioactive materials based on previous studies and suggestions by Prof. 
Kenneth MacKenzie (supervisor of this work) [22]. By combining the good mechanical properties of inorganic polymers with the bioactive behaviour of substances such as calcium hydroxide, nano structured calcium silicate and calcium phosphate, we can develop a durable implant.

In contrast to previous experiments carried out by Oudadesse [3, 11] and Martin [4], this work aims to create an in-situ geopolymer containing calcium and possibly phosphorus, synthesised in a one-step process rather than in two or more steps. It has been reported that calcium and phosphorus can be successfully incorporated in inorganic polymers without disturbing the typical properties of a true geopolymer (producing an amorphous network structure as well as aluminium and silicon in tetrahedral sites) [22] [23].

Of the two geopolymerisation activators, potassium and sodium, potassium provides the lowest alkalinity (approximately $\mathrm{pH} 12$ ), although this is still too high for a biological system. But it is possible to lower the alkalinity using the least possible potassium hydroxide necessary for the geopolymerisation process to occur. Further, heat-treatment of geopolymers above $250^{\circ} \mathrm{C}$ has been reported to lower the $\mathrm{pH}$ significantly. This thermal treatment causes a dehydroxylation of the material. Subsequently, a diminution of the quantities of protons occurs that reduces the alkalinity. As a side effect the aluminium can be stabilised in the network structure [11], and may therefore also be used.

The Al:Si ratios in a geopolymer can vary widely (Figure 2.4), thus a geopolymer composition with low aluminium content will be chosen to minimise the risk of releasing aluminium.

To verify that the typical geopolymer characteristics and properties are 
present, several analysis methods will be used, including x-ray diffractometry (XRD), tensile strength measurements (Brazil test method), solid state ${ }^{27} \mathrm{Al},{ }^{29} \mathrm{Si}$ and ${ }^{43} \mathrm{Ca}$ nuclear magnetic resonance spectroscopy with magic angle spinning (MAS NMR) and scanning electron microscopy (SEM) with energy dispersive spectroscopy (EDS).

To determine whether or not the synthesised samples are bioactive and if the alkalinity meets the requirements, "in vitro" experiments in simulated body fluid will be performed viz. $\mathrm{pH}$ measurements, SEM, EDS, $\mathrm{XRD}$ and inductively coupled plasma (ICP), analysis of the soaking solution.

The present study will attempt to synthesise bioactive geopolymers that contain $10 \mathrm{wt} \%$ of bioactive substances in the bulk material. The added components will be calcium hydroxide $\left(\mathrm{Ca}(\mathrm{OH})_{2}\right)$, nano structured calcium silicate $\left(\mathrm{CaSi}_{1.67} \mathrm{O}_{3.75}\right)$ or calcium phosphate $\left(\mathrm{Ca}_{3}\left(\mathrm{PO}_{4}\right)_{2}\right)$, giving geopolymers that harden and cure.

Studies have shown that it is possible to make aluminosilicate geopolymers containing tetrahedral phosphate [24]. Further, it is possible to put calcium into aluminosilicate geopolymers, either as the hydroxide, phosphate or as an amorphous silicate. ${ }^{43} \mathrm{Ca}$ MAS NMR studies have been carried out on these compounds [24]. The calcium phosphate geopolymer develops HCA precursors after 1 and 7 days exposure to SBF [22].

Studies of aluminosilicate materials as potential implants are only in their early stages but the initial results are sufficiently promising to encourage further research with the expectation that materials with good bioactivity might be produced [4]. 

Chapter 3

Experimental 


\subsection{Introduction}

Synthesis of geopolymers involves material preparation and begins with the determination of suitable geopolymer formulations. This chapter describes the different preparation steps in detail.

\subsubsection{Reagents}

Reactants for the preparation of the inorganic polymers are listed below.

- aluminosilicate raw material (halloysite) (IMERYS, PREMIUM)

- calcium phosphate (BDH reagent grade)

- calcium hydroxide (BDH reagent grade)

- nano structured calcium silicate $\left(\mathrm{CaSi}_{1.67} \mathrm{O}_{3.75} \bullet 3 \mathrm{H}_{2} \mathrm{O}\right)(\mathrm{VUW}$, PatentNo: WO/2006/078176)

- potassium hydroxide $(\mathrm{KOH})(\mathrm{BDH}$ reagent grade)

- potassium silicate solution (K66, INEOS Silicas, Ltd. UK)

\subsection{Preparation of raw materials}

Thermal pre-treatment of halloysite is necessary to secure proper curing behaviour and the formation of true geopolymers. This method was used because it gives the best results compared with other treatments reported elsewhere [25]. Calcination of the halloysite was carried out in heat resistant containers in an electric furnace (Arum Products NZ). The containers 
were not completely filled and were also loosely covered to minimise the effects of explosive loss of water.

Dehydroxylation was carried out at $600^{\circ} \mathrm{C}$ for 12 hours at a heating rate of $5{ }^{\circ} \mathrm{C} / \mathrm{min}$ followed by unforced cooling to room temperature.

To ensure that only the fine fraction of the powder was used in the geopolymer synthesis for good homogeneity, the bigger grains were separated using an automatic sieve shaker (Retsch, Germany) and two sieves (500 and 180 microns).

\subsection{Sample Preparation}

\subsubsection{Sample formulation}

To prepare geopolymers that set and harden, attention must be paid to the ratios of $\mathrm{Al}: \mathrm{Si}, \mathrm{K}: \mathrm{Si}$ and $\mathrm{H}_{2} \mathrm{O}: \mathrm{K}_{2} \mathrm{O}$. A geopolymer formulation which had been successfully used for previous in-vitro studies was used as a basis [22]. This material was reproduced, then the amount of alkaline compounds was progressively reduced to a minimum to produce a material with low alkalinity. Attempts were made to use less water and the least potassium hydroxide necessary to produce a geopolymer with good strength.

The actual synthesis of the inorganic polymer samples is described in detail in section 3.4 .

The hardness of the sample was initially tested by scratching the surface with a fingernail. The formulations soft enough to be scratched were rejected. Once a usable mix was created, it was modified further by adding 
the calcium compounds (calcium hydroxide, calcium silicate and calcium phosphate). The addition of these compounds made it necessary to introduce further slight adjustments to the original formulation to produce workable compositions which set and harden. Various trial and error experiments resulted in the best working geopolymer compositions which were used for all experiments and are listed in Table 3.1.

Samples containing $10 \mathrm{wt} \%$ added calcium hydroxide, calcium silicate and calcium phosphate are designated N1, N6 and N13 respectively, whereas the control samples without calcium additives are labelled N11.

Table 3.1: Geopolymer mixtures, values are $w t \%$

\begin{tabular}{||l||c||c||c||c||}
\hline \hline Ingredients & N1 & N6 & N11 & N13 \\
\hline \hline Halloysite & 40.6 & 30.6 & 43.0 & 42.2 \\
\hline Water & 20.3 & 33.7 & 19.2 & 17.5 \\
\hline Potassium hydroxide & 9.1 & 13.1 & 5.9 & 9.0 \\
\hline Potassium silicate (K66) & 30.0 & 22.6 & 31.9 & 31.3 \\
\hline \hline Calcium hydroxide & 10.0 & & & \\
\hline Calcium silicate & & 10.0 & & \\
\hline Calcium phosphate & & & & 10.0 \\
\hline \hline
\end{tabular}


The corresponding element and molar ratios, can be found in Table 3.2 and Table 3.3 respectively.

Table 3.2: Element ratios of the geopolymer mixtures

\begin{tabular}{||l||c||c||c||c||}
\hline \hline Ratios & N1 & N6 & N11 & N13 \\
\hline \hline Si $:$ Al & 2.9 & 2.9 & 2.9 & 2.9 \\
\hline K : Si & 0.6 & 0.9 & 0.4 & 0.5 \\
\hline $\mathbf{K}: \mathbf{A l}$ & 1.6 & 2.6 & 1.1 & 1.5 \\
\hline $\mathbf{H}_{2} \mathbf{O}: \mathbf{A l}$ & 29.6 & 47.7 & 28.0 & 27.0 \\
\hline \hline
\end{tabular}

Table 3.3: Molar ratios of the geopolymer mixtures

\begin{tabular}{||l||c||c||c||c||}
\hline \hline Ratios & $\mathbf{N 1}$ & $\mathbf{N 6}$ & $\mathbf{N 1 1}$ & $\mathbf{N 1 3}$ \\
\hline \hline $\mathrm{SiO}_{2}: \mathbf{A l}_{2} \mathbf{O}_{3}$ & 3.24 & 3.24 & 3.24 & 3.24 \\
\hline $\mathbf{K}_{2} \mathbf{O}: \mathbf{S i O}_{2}$ & 0.26 & 0.42 & 0.19 & 0.25 \\
\hline $\mathbf{H}_{2} \mathbf{O}: \mathbf{K}_{2} \mathbf{O}$ & 18.79 & 18.56 & 24.39 & 17.77 \\
\hline \hline
\end{tabular}

\subsection{Synthesis of the geopolymer specimens}

\subsubsection{Preparation of the moulds}

The $30 \mathrm{~mm}$ diameter and $25 \mathrm{~mm}$ high cylindrical plastic moulds were thoroughly cleaned and a light coat of petroleum jelly applied to the internal surfaces. The moulds have removable bases to facilitate sample removal. 


\subsubsection{Mixing and curing of the geopolymers}

The reagents were weighed separately using a two-place top loading laboratory balance.

Powder chemicals such as dehydroxylated halloysite and the additives were weighed first, followed by the water and potassium hydroxide $(\mathrm{KOH})$. The calculated amount of distilled water was measured into a plastic beaker. The $\mathrm{KOH}$ was then weighed and dissolved in the water, using eye protection and latex gloves. The reaction of $\mathrm{KOH}$ with water produces heat which may cause boiling. After the $\mathrm{KOH}$ was completely dissolved, potassium silicate solution (K66) was added using a plastic pipette and the solution was stirred well. Finally, the dehydroxylated halloysite was added and stirred well to achieve a well homogenised mixture which is pourable. At this stage, the calcium-containing substances were added. Thorough mixing and homogenising was essential to distribute the additive well throughout the mixture.

The resulting liquid geopolymer mixture was poured into the greased moulds, compacted and de-aired using a sieve shaker. For large sample numbers a vibrating table was found to be useful for this task. As soon as no more bubbles appeared on the surface of the liquid mixture the moulds were put in sealed plastic bags to ensure a controlled water content for the setting process.

The sealed moulds were placed in a curing room controlled at $40^{\circ} \mathrm{C}$ and cured for 14 - 20 hours. The samples were then demoulded and returned to the curing room for an additional 7 - 10 days, in sealed plastic bags. A fully cured geopolymer sample is shown in Figure 3.1 . 


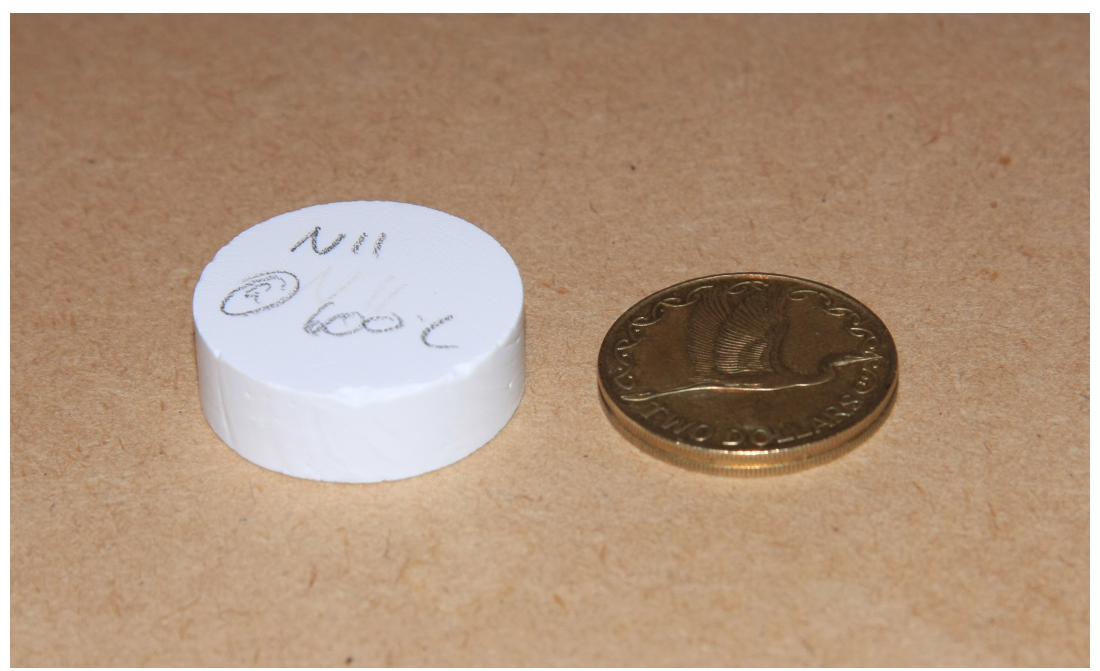

Figure 3.1: Sample of a fully cured reference geopolymer heated to $600^{\circ} \mathrm{C}$ compared to a New Zealand two-dollar coin

The top and bottom surfaces of the fully cured samples were ground flat and plane-parallel. These samples were the starting materials for further treatments described in the following sections.

\subsection{Heat-treatment of geopolymers}

Since heat-treatment of geopolymer samples is a possible means of reducing the alkalinity as mentioned in section 2.4.1, the cured samples were heated to $550^{\circ} \mathrm{C}$ and $600^{\circ} \mathrm{C}$. The furnace was switched off and allowed to cool to room temperature with the door closed throughout.

For the heat processing, the pool of samples was divided three ways for each geopolymer composition, with one third of the samples remaining unheated. Due to variations in the compositions, some samples were found to require different heating rates to prevent cracking, but the maxi- 
mum temperature remained the same for every geopolymer composition, as listed in Table 3.4

Table 3.4: Heating schedules for heat-treatment to $550^{\circ} \mathrm{C}$ (top) and $600^{\circ} \mathrm{C}$ (bottom)

\begin{tabular}{||c||c||c||c||c||c||}
\hline \hline Sample & N1 & N6 & N11 & N13 & \\
\hline \hline $\begin{array}{c}\text { T1 }-\mathrm{T} 2 \\
\left({ }^{\circ} \mathrm{C}\right)\end{array}$ & $\begin{array}{c}\text { time } \\
(\mathrm{min})\end{array}$ & $\begin{array}{c}\text { time } \\
(\mathrm{min})\end{array}$ & $\begin{array}{c}\text { time } \\
(\mathrm{min})\end{array}$ & $\begin{array}{c}\text { time } \\
(\mathrm{min})\end{array}$ & $\begin{array}{c}\text { heat rate } \\
(\mathrm{K} / \mathrm{min})\end{array}$ \\
\hline \hline RT - 100 & 70 & 70 & 70 & 70 & 1.1 \\
\hline $100-100$ & 60 & 60 & 60 & 60 & 0.0 \\
\hline $100-550$ & 130 & 130 & 130 & 130 & 3.5 \\
\hline $550-550$ & 360 & 360 & 360 & 360 & 0.0 \\
\hline \hline \hline Sample & N1 & N6 & N11 & N13 & \\
\hline \hline $\begin{array}{c}\text { T1 }-\mathrm{T} 2 \\
\left({ }^{\circ} \mathrm{C}\right)\end{array}$ & $\begin{array}{c}\text { time } \\
(\mathrm{min})\end{array}$ & $\begin{array}{c}\text { time } \\
(\mathrm{min})\end{array}$ & $\begin{array}{c}\text { time } \\
(\mathrm{min})\end{array}$ & $\begin{array}{c}\text { time } \\
(\mathrm{min})\end{array}$ & $\begin{array}{c}\text { heat rate } \\
(\mathrm{K} / \mathrm{min})\end{array}$ \\
\hline \hline RT - 100 & 70 & 70 & 70 & 70 & 1.1 \\
\hline $100-100$ & 60 & 60 & 60 & 60 & 0.0 \\
\hline $100-600$ & 130 & 130 & 130 & 130 & 3.5 \\
\hline $600-600$ & 360 & 360 & 360 & 360 & 0.0 \\
\hline \hline
\end{tabular}




\subsection{In-Vitro Studies}

An accepted way to determine the bioactivity of substances is to expose them to simulated body fluid (SBF). SBF is a solution which reacts with materials to form the bone-like compound apatite $\left[(\mathrm{Ca}, \mathrm{Mg}, \mathrm{Na})_{10}\left(\mathrm{PO}_{4}\right.\right.$, $\left.\left.\mathrm{CO}_{3}\right)_{6}(\mathrm{OH})_{2}\right]$ [26]. The ion compositions and concentrations of SBF are chosen to be as identical to those of blood plasma as possible. Conventional simulated body fluid (1.5 SBF) was chosen because it has a very good (long term) stability at slightly elevated temperatures and is also highly active [26]. It also has the advantage that it does not form calcite when samples are exposed to it, although calcite may have already been present in some of the synthesised geopolymer samples.

Since a supplier of SBF could not be located, the SBF was synthesised, and stored according to published instructions [26] [27].

\subsubsection{Synthesis of simulated body fluid (SBF)}

The synthesis of the SBF requires a clean, dust free environment. Apparatus used for mixing, stirring and storage must be sterilised. The components of SBF are soluble salts and ultra pure water. Ultra pure water is demineralised water containing only $\mathrm{H}_{2} \mathrm{O}$ that contains $\mathrm{H}^{+}$and $\mathrm{OH}^{-}$in equilibrium. It is important to carefully add the ingredients in a particular order (Tab. 3.5).

Ultra-pure water in a suitable beaker is warmed to $36.5^{\circ} \mathrm{C}$ and continuously stirred. The previously weighed compounds listed in Table 3.5 are carefully added one at a time and allowed to dissolve before the next 
Table 3.5: Ingredients and order of addition for $2000 \mathrm{ml}$ of 1.5 SBF

\begin{tabular}{||c|c|c||}
\hline \hline Order & Reagent & amount \\
\hline \hline 0 & Ultra-pure water & $1500 \mathrm{ml}$ \\
\hline 1 & $\mathrm{NaCl}$ & $23.988 \mathrm{~g}$ \\
\hline 2 & $\mathrm{NaHCO}_{3}$ & $1.050 \mathrm{~g}$ \\
\hline 3 & $\mathrm{KCl}$ & $0.672 \mathrm{~g}$ \\
\hline 4 & $\mathrm{~K}_{2} \mathrm{HPO}_{4} \bullet 3 \mathrm{H}_{2} \mathrm{O}$ & $0.684 \mathrm{~g}$ \\
\hline 5 & $\mathrm{MgCl}_{2} \bullet 6 \mathrm{H}_{2} \mathrm{O}$ & $0.916 \mathrm{~g}$ \\
\hline 6 & $1 \mathrm{kmol}^{3} \mathrm{~m}^{3} \mathrm{HCl}$ & $120 \mathrm{ml}$ \\
\hline 7 & $\mathrm{CaCl}_{2}$ & $0.834 \mathrm{~g}$ \\
\hline 8 & $\mathrm{Na}_{2} \mathrm{SO}_{4}$ & $0.214 \mathrm{~g}$ \\
\hline 9 & $\left(\mathrm{CH}_{2} \mathrm{OH}\right)_{3} \mathrm{CNH}$ & $18.172 \mathrm{~g}$ \\
\hline 10 & $1 \mathrm{kmol}_{2} / \mathrm{m}^{3} \mathrm{HCl}$ & $\begin{array}{c}\text { appropriate amount } \\
\text { for adjusting } \mathrm{pH} \text { to } 7.4\end{array}$ \\
\hline \hline
\end{tabular}

is added. The $\mathrm{pH}$ is continuously checked using a $\mathrm{pH}$ meter. Addition of the tris-buffer (reagent 9) must be done little by little to avoid sudden $\mathrm{pH}$ increase. The $\mathrm{pH}$ is then adjusted to 7.4 using $1 \mathrm{kmol} / \mathrm{m}^{3} \mathrm{HCl}$ delivered from a pipette. The prepared solution was transferred to a 2.0 litre volumetric flask and cooled to $20^{\circ} \mathrm{C}$, then adjusted to $2000 \mathrm{ml}$ using ultrapure water and shaken well. This final solution is placed in polyethylene bottles and stored in a refrigerator at 5 to $10^{\circ} \mathrm{C}$ until required. 


\subsubsection{In vitro experiments}

In vitro experiments were carried out using a temperature-controlled water bath, adjusted to $37.5^{\circ} \mathrm{C} \pm 0.5^{\circ} \mathrm{C}$ and checked frequently to ensure a stable temperature. No specific treatment of the samples was necessary, although it was important that they were free of dust or any other loose grinding material. The samples were placed in plastic sample jars and covered with approximately $50 \mathrm{ml}$ of SBF. The containers were then closed and placed in the water bath for various times.

To determine whether the specimen had interacted with the SBF, samples of the specimen were taken out after various times and analysed. After removal from the solution, they were dried with a soft tissue and the XRD patterns of the exposed surfaces were recorded and described in section 4.1 . The $\mathrm{XRD}$ results are reported in section 5.2 .

Scanning electron microscopy (SEM) and electron dispersive spectroscopy (EDS) was also carried out using a JEOL microscope (see section 4.3) to determine alteration of the sample surface that may be undetectable by XRD. The SEM results are reported in section 5.6.

Solid state nuclear magnetic resonance spectroscopy (MAS NMR) (section 4.2) was used to monitor any changes in the ${ }^{27} \mathrm{Al},{ }^{29} \mathrm{Si}$ or ${ }^{43} \mathrm{Ca}$ environments during the in-vitro experiments.

The $\mathrm{pH}$ of the SBF during the experiments was recorded frequently using a portable $\mathrm{pH}$-meter to determine the sample behaviour when exposed to $\mathrm{SBF}$, as described in section 4.6

Changes of the SBF composition during soaking were analysed by ICP (section 4.5) carried out by a commercial analytical laboratory. 



\section{Chapter 4}

\section{Characterisation Methods}

This chapter introduces and briefly describes the analytical methods used to determine the properties of the samples e.g., strength, phase composition and structure. 


\subsection{X-ray Diffractometry}

\subsubsection{Introduction}

X-ray diffractometry (XRD) is an important tool for the characterisation of crystalline materials. Using XRD, crystallographic phases can be identified and quantitatively determined in materials such as metals, clays, ceramics or mineral mixtures [28].

$\mathrm{XRD}$ is based on the diffraction of $\mathrm{x}$-rays from crystalline phases containing long-range order; therefore it cannot be used as a characterisation method for amorphous phases with diffuse scattering patterns. Amorphous phases in such materials appear as broad humps and a raised background rather than well defined peaks. However, the presence of a broad amorphous hump allows this technique to indicate the presence of the amorphous inorganic polymers. Any partially reacted crystalline phases still present in inorganic polymers may also be detected as unusual peaks, or as peaks related to mineral phases present as impurities in the reactants.

\subsubsection{Theoretical background}

When an x-ray beam interacts with a crystalline substance the reflection of the beam results in a characteristic diffraction pattern of intensities at particular diffraction angles. Since each crystalline material produces its unique diffraction pattern, each crystalline phase can be identified or determined within a substance containing multiple crystalline phases. X-ray patterns of pure substances are thus like fingerprints.

$\mathrm{XRD}$ analysis is based on the principles of $\mathrm{x}$-ray diffraction by a diffrac- 
tion grating. Suitable "gratings" for $x$-ray beams are the planes of atoms in the crystal structures of crystalline phases. Without any diffraction effects, the incidence of a primary $x$-ray beam onto a sample volume would produce scattering in all directions. Diffraction redistributes intensity from the whole scattering field into distinct directions, between which the intensity drops drastically. The directions in which the reflections can be observed depend on the intervals between the lattice planes scattering $x$-ray beams and interference of the scattering by scattering from neighbouring lattice planes (Fig 4.1] [29].

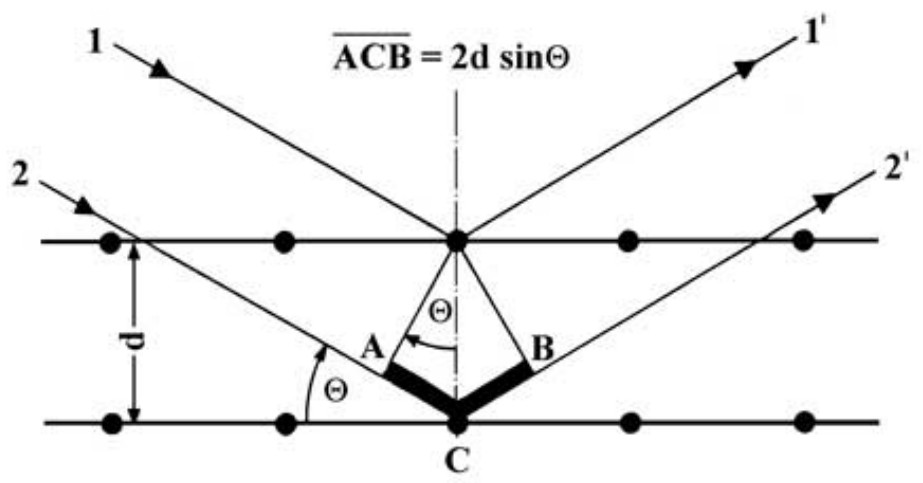

Figure 4.1: X-Ray diffraction by lattice planes [29]

Reflections can only occur where the path of the beam scattered by the lower of the two planes is longer by an integer number of wavelengths than the path length of the beam scattered by the upper plane, visualised in Figure 4.1. This is described by Bragg's law (equation 4.1).

$$
n \lambda=2 d \sin \Theta
$$

In which " $n$ " is an integer, " $\lambda$ " is the radiation wavelength, " $d$ " is the distance between the planes and " $\Theta$ " is half the angle through which the 
incident beam is diffracted [28] [30].

\subsubsection{XRD apparatus}

The present samples were analysed using two slightly different diffractometers. One is used exclusively for powders whereas the other one may also be used for monolithic samples with flat surfaces. The sample preparation of both powder and monolithic specimens is described in section 4.1.4.

Diffractometer 1 is a Philips PW 1700 series Bragg-Brentano diffractometer with a PW 1729 generator, a PW 1050 goniometer of $173 \mathrm{~mm}$ radius, automatic divergence and 1 degree fixed anti scatter slits, a $0.2 \mathrm{~mm}$ receiving slit and graphite diffracted beam monochromator. The detector is a xenon-filled proportional counter.

Diffractometer 2 is a hybrid, but can be described as a Philips PW 3700 series Bragg-Brentano diffractometer with a PW 1729 generator, a PW 1050 goniometer of $173 \mathrm{~mm}$ radius and independent theta and two-theta drives, fixed 1 degree divergence and anti scatter slits, a $0.2 \mathrm{~mm}$ receiving slit and graphite diffracted beam monochromator. The detector is a xenon-filled proportional counter. A benefit of this machine is that monolithic samples may be analysed using special sample holders.

Both diffractometers use cobalt $\mathrm{K}$ alpha ( $\mathrm{Co} \mathrm{K} \alpha$ ) radiation (weighted wavelength $\bar{\alpha}=1.79026 \AA$ ). The generator settings are a $40 \mathrm{kV}$ excitation potential with a current of $35 \mathrm{~mA}$ for long fine focus tubes. Since Co K $\alpha$ radiation is used, the diffraction patterns presented in this thesis may not be compared directly with results published elsewhere using $\mathrm{Cu} \mathrm{K} \alpha$ radi- 
ation.

The programs typically used were scans of 25 minutes or 5 hours and 25 minutes long, extending from 4 degrees to 80 degrees $2 \Theta$. For the 25-minute program, the counting time was one second per point, giving a sampling interval of 0.05 degrees whereas the longer program counted for 13 minutes per point with the same sampling interval. Both were "continuous" scans and therefore averaged over the 0.05 interval, assigning the count to the interval midpoint (thus the 4.00 degree point is actually an average from 3.975 to 4.025 degrees).

\subsubsection{Sample preparation}

Analysing a specimen to determine the phases present requires an even and flat sample surface on the diffractometer axis. Using the above diffractometers it is possible to analyse both powder and monolithic samples.

\subsubsection{Monolithic sample preparation}

Some experiments required the examination of sample surfaces for phases present after synthesis, or changes after a treatment. The surface to be exposed to the x-ray beam must be coplanar with the top of the sample holder. To achieve this, plasticine was used as a flexible fixing substance, with the benefits of easy height and angular adjustment of the sample and easy removal. Using this system and suitable sample holders, specimens of various heights and diameters may be analysed within the limitations of the diffractometer dimensions. 


\subsubsection{Powder sample preparation}

Phase analysis of powders using $\mathrm{x}$-ray diffraction requires thorough sample preparation. To prevent contamination of the samples and misleading results, it is essential to work in a clean environment. The starting materials may be solid pieces which must be powdered using a mortar. Ideally the particles should not be larger than about $5 \mu \mathrm{m}$; a good indication of sufficient fineness is when the powder feels floury. The sample holder was filled with a slight excess of powder which was then compressed using a clean glass microscope slide. It is important that the powder is only pushed down; sliding or turning the glass slide across the powder bed should be avoided to prevent preferred orientation of crystals. To check if the powder is attached to the holder, it can be gently tipped. If the powder remains in the sample holder with its surface coplanar, it is ready to be x-rayed.

If only a very small amount of sample is available, aluminium sample holders with a flat glass or quartz inlay are used but special sample preparation is necessary. Such samples are firstly ground, then suspended in a suitable liquid to create a slurry; distilled water was used for the present work but other liquids may also be applicable. The slurry is applied thinly to the top of the inlay of the sample holder. After drying, the sample is ready for the analysis. 


\subsection{Nuclear Magnetic Resonance Spectroscopy}

\subsubsection{Introduction}

Solid state nuclear magnetic resonance spectroscopy (NMR) is a relatively new method for investigating solid materials. As a complementary technique to XRD analysis, NMR provides information not available from $\mathrm{x}$ ray diffractometry especially for amorphous materials in which the atomic states of specific atoms can be examined.

NMR is a rf (radio frequency) spectroscopy and exploits the nuclear spin of specific nuclei to determine factors such as their coordination state and bonding to surrounding atoms. When nuclei with a nuclear spin are placed in a strong magnetic field, the energy levels of the different spin states separate. In the strong magnetic field, the nuclear spin has an associated magnetic moment and therefore the nucleus spins around an axis which precesses to the axis of the magnetic field at a specific frequency (Larmor frequency) characteristic of that nuclide. The sample is then irradiated with a pulse of plane polarised rf radiation at the Larmor frequency, causing a tipping of the spin system with respect to the magnetic field axis. At the end of the pulse, the spin system returns to its original axis with a characteristic time constant and the emission of a decaying pulse. Since the nucleus of an atom is shielded from the applied magnetic field by its surrounding electrons, this changes the emitted frequency slightly by an amount called the chemical shift. This emitted frequency is detected by 
a coil surrounding the sample as a decaying voltage and is called free induction decay (FID) which is transformed from the time domain to the frequency domain using Fourier transformation (Fig. 4.2) [31].

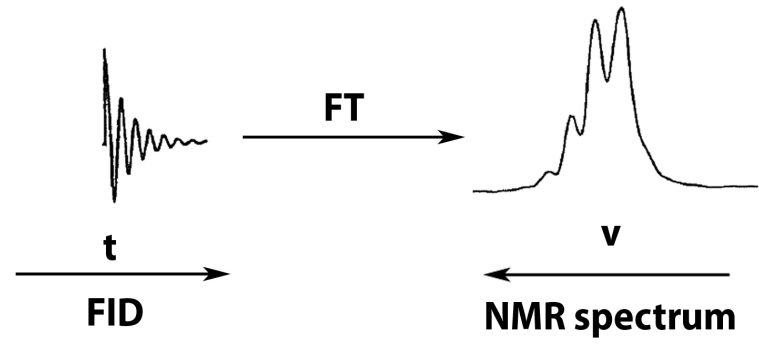

Figure 4.2: Fourier transformation of a free induction decay (FID) in the time domain to an NMR spectrum in the frequency domain [31]

Solid state NMR spectra are broadened due to a number of interactions including dipole moments and, in quadrupole nuclides, quadrupole moments [7]. Some of these broadening effects can be cancelled out by spinning the sample at high speeds (up to $20000 \mathrm{rev} \mathrm{s}^{-1}$ ) at an angle of $54.7^{\circ}$ to the magnetic field axis (called the "magic angle"). This technique is known as magic angle spinning - MAS and produces sharp peaks in the spectra of solids.

However, not all elements possess nuclei suitable for NMR spectroscopy. Nuclei to be analysed must have a nuclear spin and must occur with good natural abundance. The two main factors of the chemical environment affecting the resonance positions in NMR spectra are the coordination state and the nature of the coordinating ligand.

These environment changes can influence the chemical shifts signifi- 
cantly. The ranges of chemical shifts of ${ }^{29} \mathrm{Si}$ and ${ }^{27} \mathrm{Al}$ in various environments are shown in Figure 4.3 [7] [31].

\subsubsection{Sample preparation}

NMR spectra are acquired using similar powder samples as used for $\mathrm{x}-$ ray diffraction. It is most important that the powders are ground fine and oven dried to $90^{\circ} \mathrm{C}$. High spinning speeds and residual water cause the sample to solidify in the rotor. The powder is gently tamped into the rotor in layers and the rotor cap fitted.

\subsubsection{NMR spectrometer}

${ }^{29} \mathrm{Si}$ and ${ }^{27} \mathrm{Al}$ solid state nuclear magnetic resonance spectroscopy with magic angle spinning was carried out at $11.7 \mathrm{~T}$ using a BRUKER Avance 500 spectrometer and Doty MAS probes spun at approximately $6 \mathrm{kHz}$ for ${ }^{29} \mathrm{Si}$ and $10-12 \mathrm{kHz}$ for ${ }^{27} \mathrm{Al}$. The experimental conditions used for ${ }^{29} \mathrm{Si}$, ${ }^{27} \mathrm{Al}$ and ${ }^{43} \mathrm{Ca}$ were as follows:

${ }^{29} \mathrm{Si} \mathrm{NMR}$ was carried out at a frequency of $99.926 \mathrm{MHz}$, using a $6 \mu \mathrm{s}$ $(\pi / 10)$ pulse and a 30 second delay, the spectra being referenced to tetramethyl silane (TMS).

${ }^{27} \mathrm{Al}$ NMR was carried out at a spectrometer frequency of $130.224 \mathrm{MHz}$, using a $1 \mu \mathrm{s}(\pi / 10$ pulse for solution) and a one second delay, the spectra being referenced to $\mathrm{Al}\left(\mathrm{H}_{2} \mathrm{O}\right)_{6}^{3+}$.

In the Physics Department, University of Warwick, UK, ${ }^{43}$ Ca natural abundance MAS NMR spectra were acquired at $14.1 \mathrm{~T}$ using a Chem Mag- 

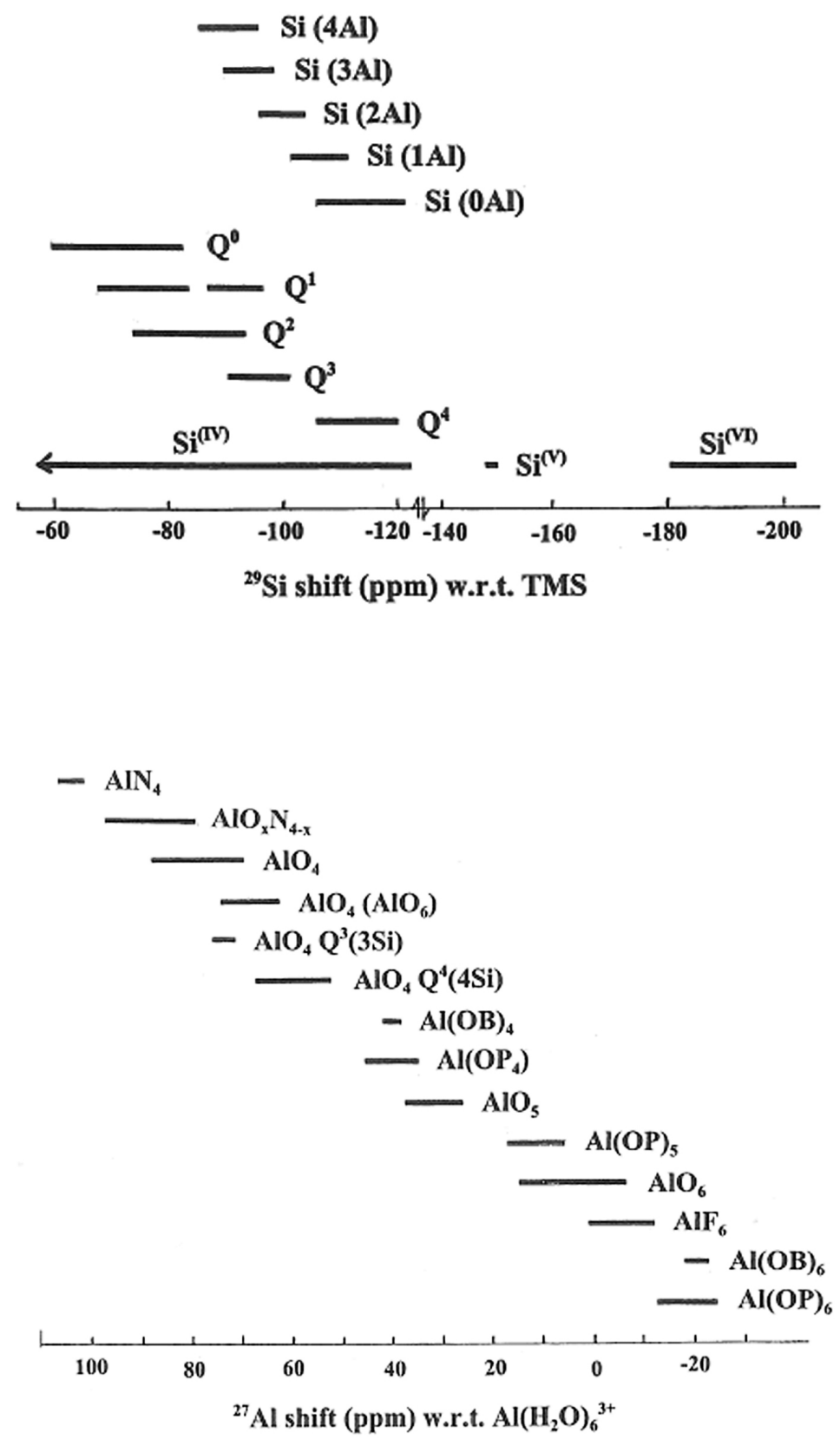

Figure 4.3: Chemical shifts of ${ }^{29} \mathrm{Si}$ and ${ }^{27} \mathrm{Al}$ in various coordination states and environments, [32], [33]. 
netics spectrometer. The spectrometer frequency was $40.388 \mathrm{MHz}$ and the Varian $9.5 \mathrm{~mm}$ MAS probe was spun at $3.5 \mathrm{kHz}$ for approximately 16 hours. A 3.5 - $4 \mu \mathrm{s}$ ( $\pi / 9$ pulse for solution) RAPT single pulse sequence was used with a delay of 0.5 to 4 seconds whereas the delay of 0.5 seconds results in the best signal to noise ratio. The spectra were recorded with between 59,227 to 117,824 scans and referenced to saturated $\mathrm{CaCl}_{2}$ solution.

\subsection{Scanning Electron Microscopy}

Electron microscopes using electron beams rather than light give an immense improvement in resolution. This improvement is due to the fact that the wavelength of electron beams is approximately $10^{5}$ times less than the wavelength of light. Electrons can be influenced in their orbital characteristics by interaction with magnetic or electric fields. In electron microscopes such fields act as the refractive medium and function as the collector lenses (objective and condenser lens) in optical microscopes.

This technology has led to the development of transmission electron microscopy (TEM) and scanning electron microscopy (SEM). TEMs have a resolution barrier of about 0.1 to $0.2 \mathrm{~nm}$ and can provide information about the inner structure of translucent objects whereas SEMs have the potential to display solid surfaces in three dimensions. In terms of magnifications, scanning electron microscopes fill the gap between TEMs and optical systems. However, the actual resolution and the maximum magnification of TEMs and SEMs is strongly dependent on the samples and their preparation. 
Scanning electron microscopes have a very good depth of field and can therefore deliver images of rough surfaces with good resolution. Due to the large depth of field, the images appear to be three dimensional. Nevertheless, sample preparation plays an important role if high magnification with high resolution is required. Because of its universal applicability, uncomplicated sample preparation and ease of interpreting the images, scanning electron microscopy is a very popular technique. In addition to displaying images, scanning electron microscopes provide the possibility of analysing micro areas. This technique is called energy dispersive $\mathrm{x}$-ray fluorescence spectroscopy (EDS). Such analyses are carried out by scattering the sample surface with electromagnetic radiation that excites the atoms in the matter. Relaxation of the excited atoms leads to an emission of for each atom specific $x$-ray radiation that is detected to identify the atoms present in the specimen [34].

An important difference from optical microscopes is the way the image is produced. Optical systems provide direct imaging, but SEMs display indirect images; hence the signal production and signal processing systems are separated. SEM images are artificial copies of a sample surface arising from interactions of electrons with the specimen surface using a concentrated electron beam (the primary electron beam) which rasters the target. This produces secondary signals such as secondary and backscattered electrons which are used to control the brightness modulation of a cathode ray tube (CRT) on which the image appears. The scan coil in the microscope produces a line-by-line scanning of the target surface by the primary electron beam. Because of the interactions of primary electrons with the sample surface, secondary signals develop which are collected 
by detectors. Line-by-line scanning therefore produces a copy of the sample surface as a row of signals transmitted serially. Areas emitting high concentrations of secondary electrons appear as bright spots on the screen whereas areas that provide only low secondary electron emission remain dark. The chronological separation of the electric signals allows the signal processing ("brightness" and "contrast") to be altered. Thus, rough to very smooth surfaces can be displayed by adjusting the contrast and brightness.

Magnification of target surfaces arises from the fact that various size areas are rastered but the information gained from these areas are always projected on to the same screen size, e.g. $10 \times 10 \mathrm{~cm}$. Thus, a surface area of $5 \times 5 \mathrm{~mm}$ results in a 20-times magnification, but a surface area of $10 \times$ $10 \mu \mathrm{m}$ would be magnified 10,000 times [34].

Analysis of geopolymer samples was carried out using SEM in various modes, including secondary electron imaging and backscattered mode.

\subsubsection{Secondary electron imaging}

Secondary electrons are excited by electrons incident on the sample. Since only a very small area generates such electrons, the image is hardly affected and therefore the best resolution can be obtained in this mode [35].

\subsubsection{Backscattered electron imaging}

The backscattered mode detects highly energetic electrons re-emitted from the sample surface after being scattered within the specimen. In this mode, 
spots appear brighter or darker depending on the atomic number of the elements present. Generally speaking, the heavier the element or the higher the atomic number of the element, the brighter it appears on the screen [35].

Areas of interest of a sample are exposed to a focussed highly energetic beam of electrons, protons or x-rays. The atoms present have unexcited electrons (or electrons in ground state) in their electron shells. The highly energetic beam excites these electrons and forces them into a higher energy level (higher shell) which causes an electron gap. This gap is filled by another electron from a higher energy level (higher shell). The energy difference between these two shells is expressed by the emission of specific $\mathrm{x}$-ray radiation characteristic of the energy difference. Every element has a specific x-ray radiation if its electrons are excited in this way which can therefore be used as a "fingerprint" or unique identifier.

\subsubsection{SEM/ EDS apparatus}

The scanning electron microscope used was a JEOL JSM-6500F with a Schottky-type field emission gun (T-FE gun) and a $\mathrm{Zr} / \mathrm{O}$ tungsten emitter.

EDS conditions were used exclusively with an accelerating voltage of $15 \mathrm{kV}$, a probe current of 15 (coarse value approximately $5 \times 10^{-9} \mathrm{~A}$ ) and a working distance of $10 \mathrm{~mm}$.

The backscattered electrons are detected using a retractable BE detector (JEOL SM-54031) and for EDS analysis a JEOL EX-23000BU ED x-ray analyser. 


\subsubsection{Sample preparation}

Sample preparation of specimens for scanning electron microscopy involves coating the surface with an electrically conductive material that can be grounded to avoid surface charging by accumulation of a static electric charge. Conductive samples may not need special preparation other than cleaning but coating can improve the resolution, especially for elements of low atomic number.

Non-conductive materials such as ceramics or geopolymers require coating of their surfaces with an ultra-thin layer (few $\mathrm{nm}$ ) of conductive material, for example, gold, platinum, silver or carbon. Depending on the coating substance, the layers are applied using low vacuum sputtering or high vacuum evaporation.

The coating material must be chosen to meet the specific demands of the sample. If high magnification with good resolution is the aim, carbon may not be satisfactory as it tends to form ball-shaped structures on sample surfaces. Commonly used materials for such purposes may be gold or platinum. Nevertheless, carbon is a good choice for analysis in the backscattered mode, since backscattered electrons can penetrate lighter materials.

Where EDS analysis is required, coating with heavy elements should be avoided since EDS mapping is done in the backscattered mode. When light elements are used as a coating material the electron beam can penetrate to the sample and interact to generate the signal. If heavy substances (e.g. gold) are used it is likely that a large number of secondary electrons will be generated within the coating layer, suppressing the secondary elec- 
trons generated at greater depth i.e. at the sample surface.

The inorganic polymer samples were prepared and coated with carbon for backscattered electron imaging as well as for electron dispersive element analysis.

Gold and platinum coatings were used for high resolution imaging in the SEI-mode to display fine structure in the samples. The thickness of the platinum and gold coating layers was initially $8 \mathrm{~nm}$ but could be adjusted up to $18 \mathrm{~nm}$ depending on charging. The carbon coating layers were $6 \mathrm{~nm}$ initially but were increased to $16 \mathrm{~nm}$ to reduce surface charging.

\subsection{Compression Testing (Brazil Test)}

\subsubsection{Introduction}

The aim of implants is to replace bones or parts of bony structures, and therefore their major function is to support the body weight as bones do. However, specific applications require certain mechanical characteristics i.e. implants used for legs must withstand higher loads compared to implants used for ears.

To determine the mechanical strength of materials, several methods have been established, including 3 or 4-point bending, direct and indirect tensile strength measurements. Although these all measure tensile strengths, the results are not always comparable because different effective volumes and stress distributions may be involved. Thus, it should always be noted which method has been used when making comparisons with published results. 
The diametral compression strength test or Brazil test was chosen for this study because it is commonly used to determine the tensile strength of brittle materials such as concretes or ceramics. The experimental setup is simple and similar to that used for axial compression. In addition, the sample shape can be kept very simple and specimens do not need to be attached to the testing machine. Compared with other test methods, only a small amount of the sample is exposed to the applied force. However, the maximum tensile strength is not limited to the surface of the sample and failure can be initiated from the internal areas [36], [37].

Tensile strength determination by the Brazil test is carried out on cylindrical samples with plane-parallel ends. The specimen is placed between two flat platens and compressed across its diameter, shown schematically in Figure 4.4 [37].

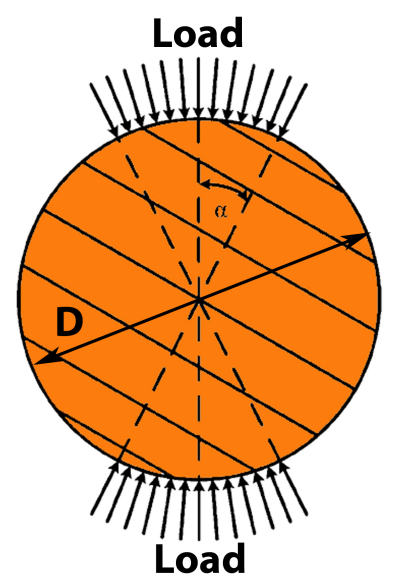

Figure 4.4: Schematic diagram of the test setup for diametral compression testing [37]

However, diametral tensile strength is limited to materials with mechanical properties such as linear elasticity, elastically isotropic, homogeneous and stronger in shear and compression than in tension. These 
properties are characteristic of ceramics. If a material does not meet these requirements it is not suitable for examination by diametral compression because it may fail before the load which causes tensile failure can be applied.

The tensile strength is calculated using equation 4.2

$$
\sigma=\frac{2 P}{\pi D t}
$$

Where, " $P$ " is the applied load, " $D$ " is the diameter and " $t$ " is the thickness of the specimen [38].

Tests were carried out on cylindrical specimens with plane-parallel ends as illustrated in Figure 4.5[37].

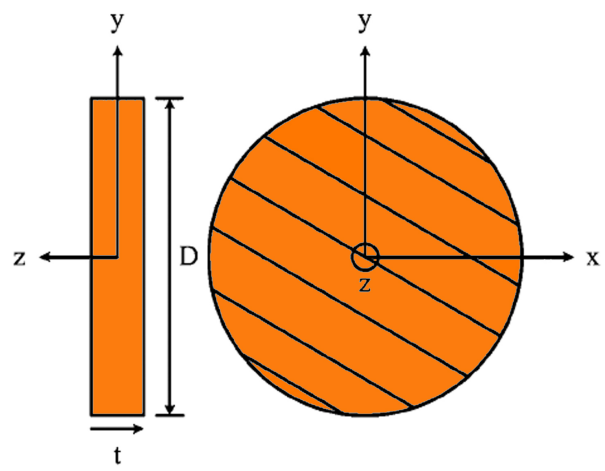

Figure 4.5: Requirements on the samples regarding the preparation 37]

The tests were carried out using a calibrated/ certificated Instron Universal testing machine with a maximum load capacity of $250 \mathrm{kN}$. The load was applied with a cross-head speed of $1 \mathrm{~mm} /$ minute. 


\subsection{Inductively Coupled Plasma}

Examination of composition changes of the simulated body fluid was carried out using inductively coupled plasma atomic emission spectroscopy (ICP-AES). This analytical spectroscopy uses the emission of electromagnetic radiation $(\mathrm{h} \nu)$ in the vacuum ultraviolet (VUV) range $(120-185 \mathrm{~nm})$ of excited atoms relaxing to the ground state, as shown in Figure 4.6 [39]. Due to their specific atomic mass, each atom emits its unique electromagnetic radiation. Detection of VUV radiation requires an environment free of air, commonly an argon atmosphere.

EXCITED STATE

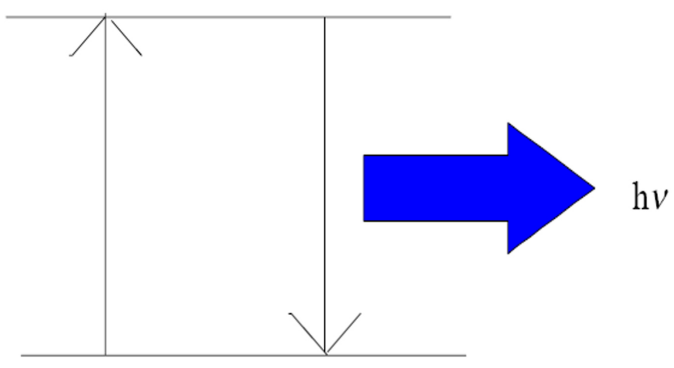

GROUND STATE

Figure 4.6: Emission of electromagnetic radiation after relaxing of an excited atom to its ground state [39].

ICP-AES is used to identify elements and to determine their concentrations in the sample. This involves three steps, the formation of the atoms, their excitation and the emission of electromagnetic radiation. However, before an atom is excited it must be separated from the other attached 
atoms so it can emit its unique radiation.

The excitation source for ICP-AES analysis is an analytical plasma with a temperature between $600-8000 \mathrm{~K}$, which is an electrically neutral, and highly ionised gas consisting of ions, electrons and atoms. Figure 4.7illustrates the steps by which an aqueous phase is analysed by ICP-AES [39].

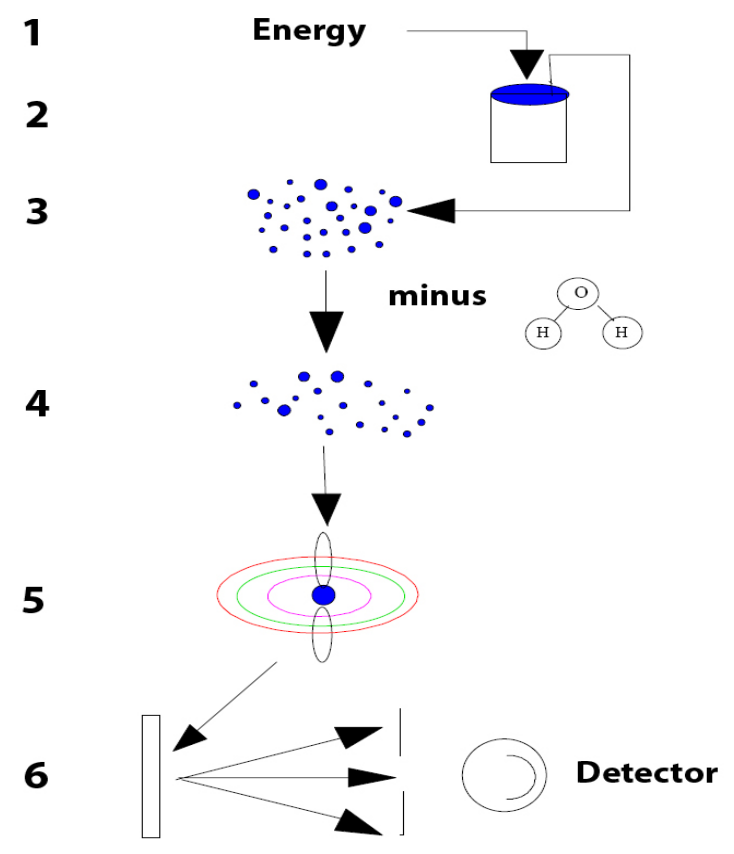

Figure 4.7: Steps in the analysis of an aqueous sample by ICP-AES [39]

The liquid sample is transformed to an aerosol (2), then water is driven off and the remaining solids and liquid compounds are converted to gases (3). In stage 4 atomisation occurs in a plasma by breaking the molecular bonds in gaseous molecules forming atoms. Excitation and emission of the characteristic wavelength takes place in step 5 and is detected in step 6 [39]. 
The accuracy of the results is $\pm 10 \%$ of the measured values, the detection limits are listed in Table 4.1, both quoted by the analytical laboratory.

Table 4.1: ICP-AES detection limits

\begin{tabular}{|l|l||}
\hline \hline Aluminium & $0.005 \mathrm{ppm}$ \\
\hline Calcium & $0.01 \mathrm{ppm}$ \\
\hline Phosphorus & $0.01 \mathrm{ppm}$ \\
\hline Potassium & $0.01 \mathrm{ppm}$ \\
\hline Silicon & $0.005 \mathrm{ppm}$ \\
\hline \hline
\end{tabular}

\section{$4.6 \mathrm{pH}$ studies}

An important part of this work was to determine $\mathrm{pH}$ changes in the simulated body fluid when geopolymers are soaked in it. Cured specimens in various states (unheated, heated to $550^{\circ} \mathrm{C}$ and $600^{\circ} \mathrm{C}$ ) were exposed to SBF for various times and changes in the $\mathrm{pH}$ of the fluid were monitored by frequent measurements. Within the first two hours measurements were made every five to 10 minutes, then the intervals increased to 30 minutes between two and four hours, that followed by a further increase of the measurement intervals to hourly and twice daily intervals throughout the rest of the experiment.

The $\mathrm{pH}$ measurements were carried out using a portable $\mathrm{pH}$-meter (RS V5969, accuracy: $\pm 0.03 \mathrm{pH}$ ) which was calibrated with buffer solutions of pH 7 and pH 9. 

Chapter 5

Results and Discussion 


\subsection{Strength measurement results}

Diametral compression strength measurements were carried out only on the initial fully cured samples, namely, unheated, heated to $550^{\circ} \mathrm{C}$ and $600^{\circ} \mathrm{C}$. Specimens exposed to SBF were not tested because of the small number of samples available which would have led to statistically unsatisfactory results.

The average measured tensile strengths of the tested specimens are shown in Table (5.1).

Table 5.1: Tensile strength measurement results of geopolymer samples, (values) are standard deviations

\begin{tabular}{|c|c|c|c|}
\hline & unheated & heated $550^{\circ} \mathrm{C}$ & heated $600^{\circ} \mathrm{C}$ \\
\hline Sample & $\begin{array}{l}\text { Tensile strength } \\
\qquad(\mathrm{MPa})\end{array}$ & $\begin{array}{c}\text { Tensile strength } \\
\qquad(\mathrm{MPa})\end{array}$ & $\begin{array}{c}\text { Tensile strength } \\
(\mathrm{MPa})\end{array}$ \\
\hline Reference & $2.49(0.19)$ & $2.05(0.90)$ & $1.22(0.68)$ \\
\hline Ca-hydroxide & $3.97(0.99)$ & $0.64(0.38)^{1}$ & $1.46(0.69)$ \\
\hline Ca-silicate & $1.00(0.39)$ & $\varlimsup^{2}$ & $1.38(0.32)$ \\
\hline Ca-phosphate & $2.86(0.44)$ & $4.17(1.21)^{3}$ & $1.73(0.77)$ \\
\hline
\end{tabular}

The highest mean strengths of the unheated samples were shown by the calcium hydroxide-containing samples, measured on 10 samples, followed by the calcium phosphate-containing samples and reference geopolymers (3.97, 2.86 and $2.49 \mathrm{MPa})$ respectively. The weakest samples were 
those containing calcium silicate, with a tensile strength of $1 \mathrm{MPa}$.

The results of samples heated to $550^{\circ} \mathrm{C}$ should be viewed with caution, especially for the geopolymers containing calcium hydroxide and calcium silicate. Strength tests on calcium silicate-containing samples heated to $550^{\circ} \mathrm{C}$ could not be carried out because they broke during the heattreatment. Heating of the geopolymers to $550^{\circ} \mathrm{C}$ and $600^{\circ} \mathrm{C}$ removes the structural (hydroxyl) water content. This typically leads to shrinkage of the material that may cause internal stresses. If the materials are hydrophilic - as in the present work - an exposure to air and therefore humidity causes reabsorption of water. This can lead to a critical expansion of the samples and may involve mechanical failure including crack development or even destruction of specimens.

The lowest tensile strengths $(0.64 \mathrm{MPa})$ are shown by the samples containing calcium hydroxide possibly because the samples had developed surface cracks prior to testing. The reference geopolymer samples showed tensile strengths of $2.05 \mathrm{MPa}$, while $4.17 \mathrm{MPa}$ was recorded for the samples containing calcium phosphate; however, these values are based on only 5 samples. All other strength tests were carried out on 14 to 18 samples.

A possible explanation for the higher strengths of the calcium phosphate-containing sample is because of phosphate bonding, known to occur in alumina ceramics and cements [40]. It has been reported that phosphorus can be incorporated in the network structure of geopolymers and may lead to higher strengths of the geopolymers [1] [22].

Strength measurements on the samples heated to $600^{\circ} \mathrm{C}$ show a relatively narrow distribution. The results range from 1.22 to $1.73 \mathrm{MPa}$ for the reference and the calcium phosphate-containing geopolymers respec- 
tively, whereas the calcium hydroxide and calcium silicate-containing samples show tensile strengths of 1.46 and $1.38 \mathrm{MPa}$ respectively.

A clear trend of the strength measurements with heating temperature is shown only by the reference geopolymer, which becomes weaker with increasing temperature. The strengths of the other samples fluctuate according to their calcium compounds and heating temperature, possibly because the samples were examined within different periods after removal from the furnace or curing room. The unheated geopolymers were tested almost immediately after removal from the curing room whereas the heattreated geopolymers were not tested directly after being taken out of the furnace. Since the as-synthesised geopolymers appear to be hydrophilic, they were kept in sealed plastic bags to avoid rehydration until required for testing.

Table 5.2 shows the a collection of the tensile strengths of other bioceramics and bone compared with one of the results measured in this project. 
Table 5.2: Comparison of the tensile strengths of various bio-ceramics and bone, test method unknown unless labelled ${ }^{\dagger}$.

\begin{tabular}{||l|l||c||}
\hline \hline Material & $\begin{array}{l}\text { Tensile strength } \\
(\mathrm{MPa})\end{array}$ & Reference \\
\hline \hline Bone & $60-160$ & {$[41]$} \\
\hline Cancellous bone & 3 & {$[42]$} \\
\hline Hydroxyl apatite & 80 & {$[42]$} \\
\hline Bioglass ${ }^{\circledR}$ & 42 & {$[42]$} \\
\hline Bioglass ${ }^{\circledR}$ & 5.54 (SD 0.529) & {$[43]^{+}$} \\
\hline Bioglass ${ }^{\circledR} /$ polyethylene ${ }^{*}$ & 10.15 & {$[42]$} \\
\hline Bioglass ${ }^{\circledR} /$ polysulfone ${ }^{*}$ & 1.5 & {$[42]$} \\
\hline $\begin{array}{l}\text { Apatite-wollastonite glass-ceramic / } \\
\text { polyethylene* }{ }^{*}\end{array}$ & 14.87 & {$[42]$} \\
\hline Ca-phosphate geopolymer $($ H550) & 4.17 (SD 1.21) & + \\
\hline \hline \multicolumn{2}{|c}{${ }^{*}:$ Diametral compression testing } \\
\hline
\end{tabular}


Direct comparison of the tensile strengths of the materials listed in Table 5.2 is still inappropriate because of the unknown nature of the testing method. As mentioned in section 4.4, there are various methods for determining the tensile strengths of materials in which the tested volume of the specimen and hence the results can vary, e.g. the two values for Bioglass ${ }^{\circledR}$ shown in Table 5.2 are very different. The result from the unknown testing method [42] is much higher than that from the diametral compression test (DCT) [43] (42 and 5.54 MPa respectively). Therefore, it is likely that dissimilar methods were used and that the Brazil test (DCT) used in this work provides generally lower strength measurements.

Extending these observations to the geopolymer results shown in Table 5.1 and 5.2 suggests that their strengths results comparable with those of the materials known to have been determined by DCT. Specifically, the strength of Bioglass ${ }^{\circledR}$ [43] and the calcium phosphate-containing geopolymer, both measured using diametral compression testing do not differ greatly, although the geopolymer shows a slightly lower value.

The strongest samples (calcium phosphate-containing geopolymer heated to $550^{\circ} \mathrm{C}$ ) has a tensile strength comparable to that of Bioglass ${ }^{\circledR}$ tested by the same method, although the lower strengths of the other calcium-containing geopolymers are still comparable with those of Bioglass $₫ /$ polysulfone composite. 


\subsection{XRD results}

\subsubsection{XRD patterns of the raw materials}

The raw materials were examined by XRD to determine whether or not they change during the setting process i.e. undergo reaction, or if they remain in the product structure after synthesis.

The XRD diffraction pattern of calcium phosphate (Fig. 5.1) shows it to be a purely crystalline material consisting of calcium hydrogen phosphate hydroxide (PDF No. 00-046-0905) and calcium phosphate phases (PDF No. 00-017-0499). Peaks labelled CP/CPH are present in both phases, calcium phosphate and calcium hydrogen phosphate hydroxide.

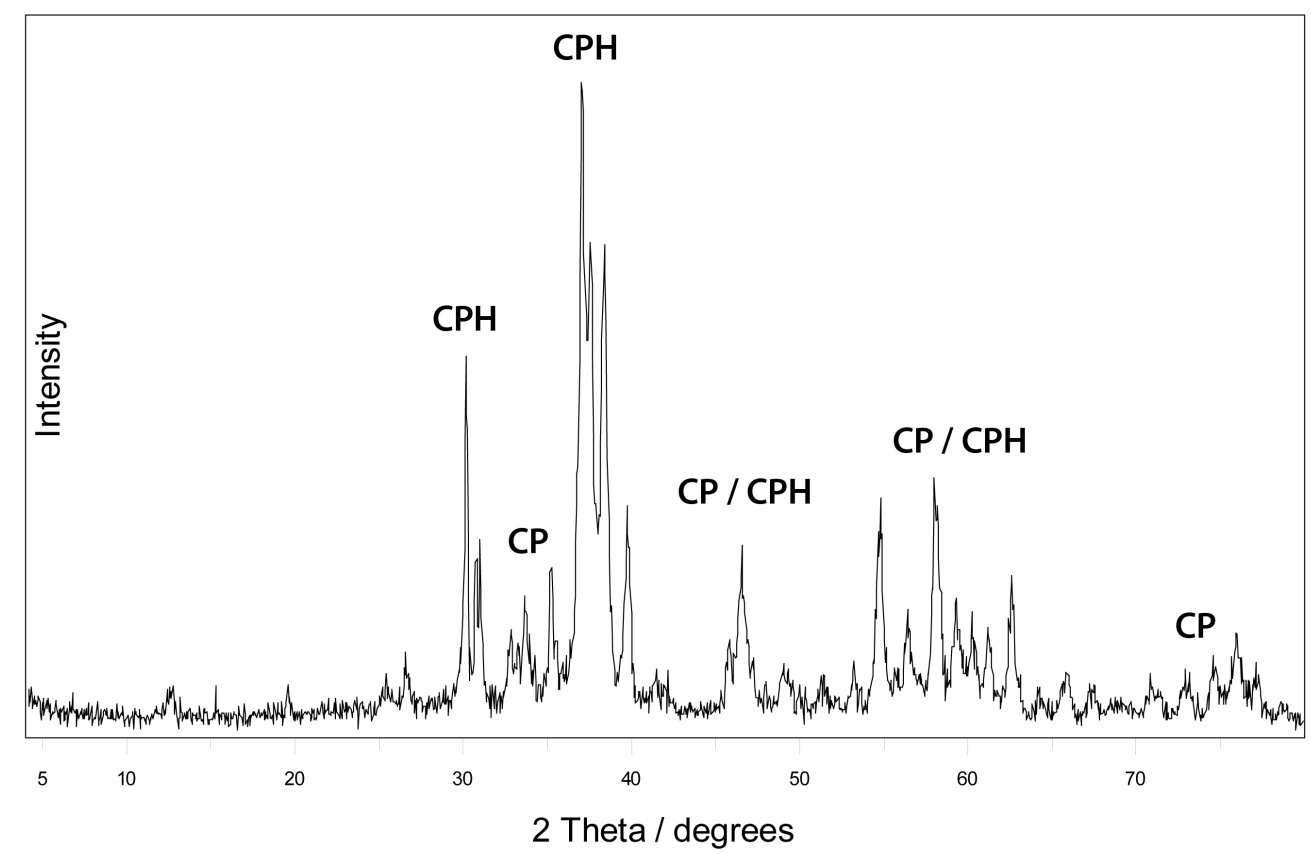

Figure 5.1: $X R D$ pattern of calcium phosphate; $C P H=$ calcium hydrogen phosphate hydroxide, $\mathrm{CP}=$ calcium phosphate 
XRD shows the nano-structured calcium silicate starting material to contain poorly crystalline calcium silicate hydrate (PDF No. 00-033-0306) (Fig. 5.2).

\section{Calcium silicate as received}

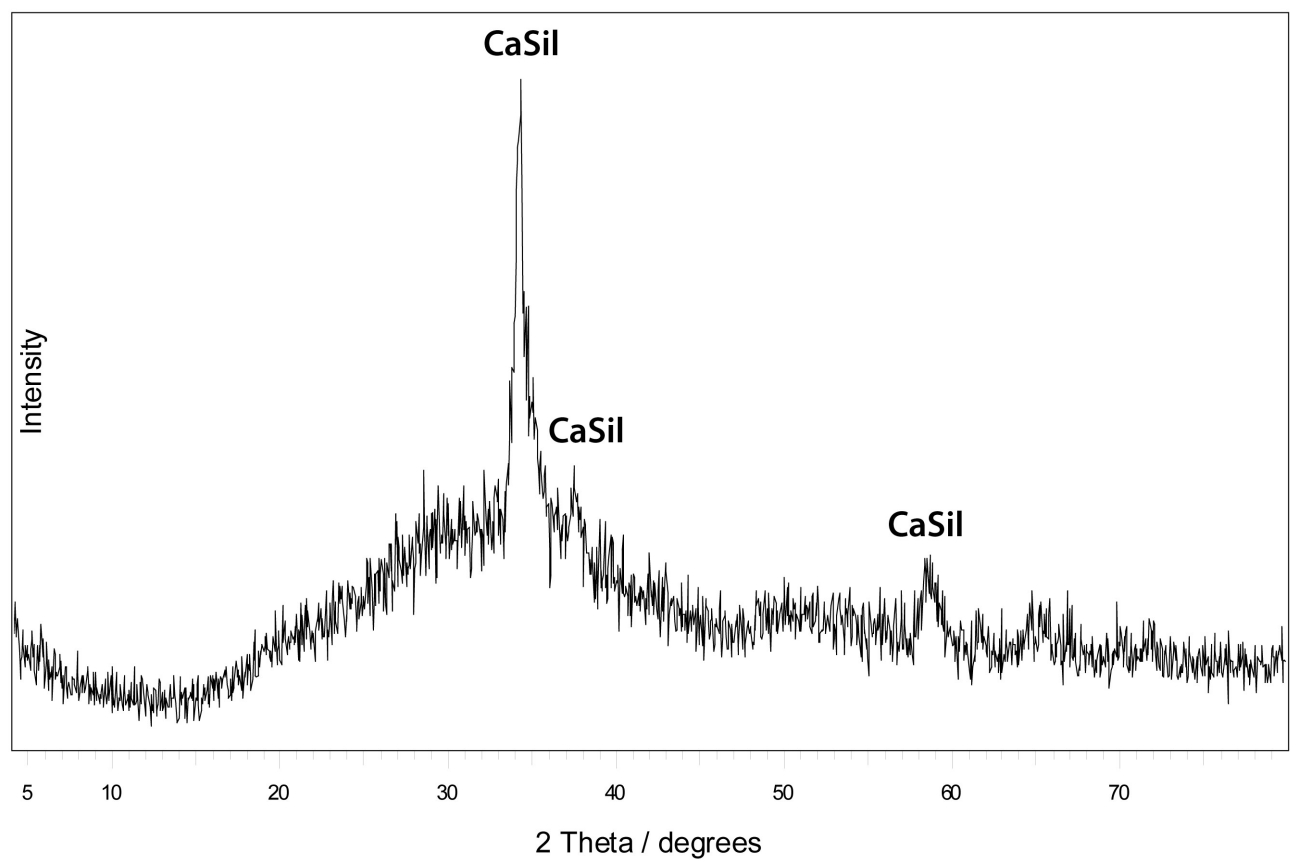

Figure 5.2: $X R D$ pattern of calcium silicate; CaSil = calcium silicate 
The x-ray diffraction pattern of the calcium hydroxide starting material, Figure 5.3, shows it to be highly crystalline calcium hydroxide, portlandite (PDF No. 00-44-1481).

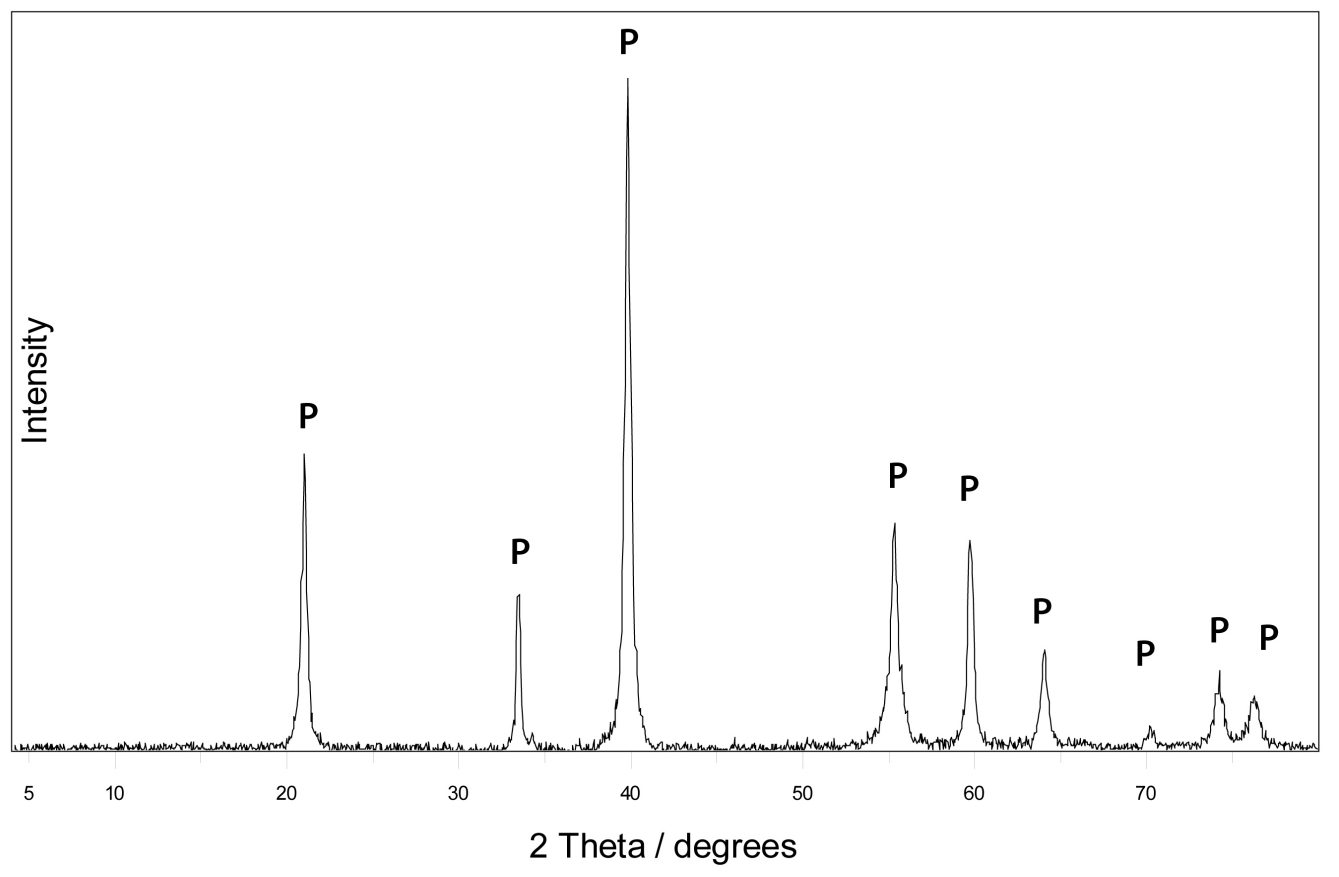

Figure 5.3: $X R D$ pattern of calcium hydroxide; $P=$ portlandite 
Dehydroxylation of the halloysite results in the destruction of the clay structure (Fig. 5.4).

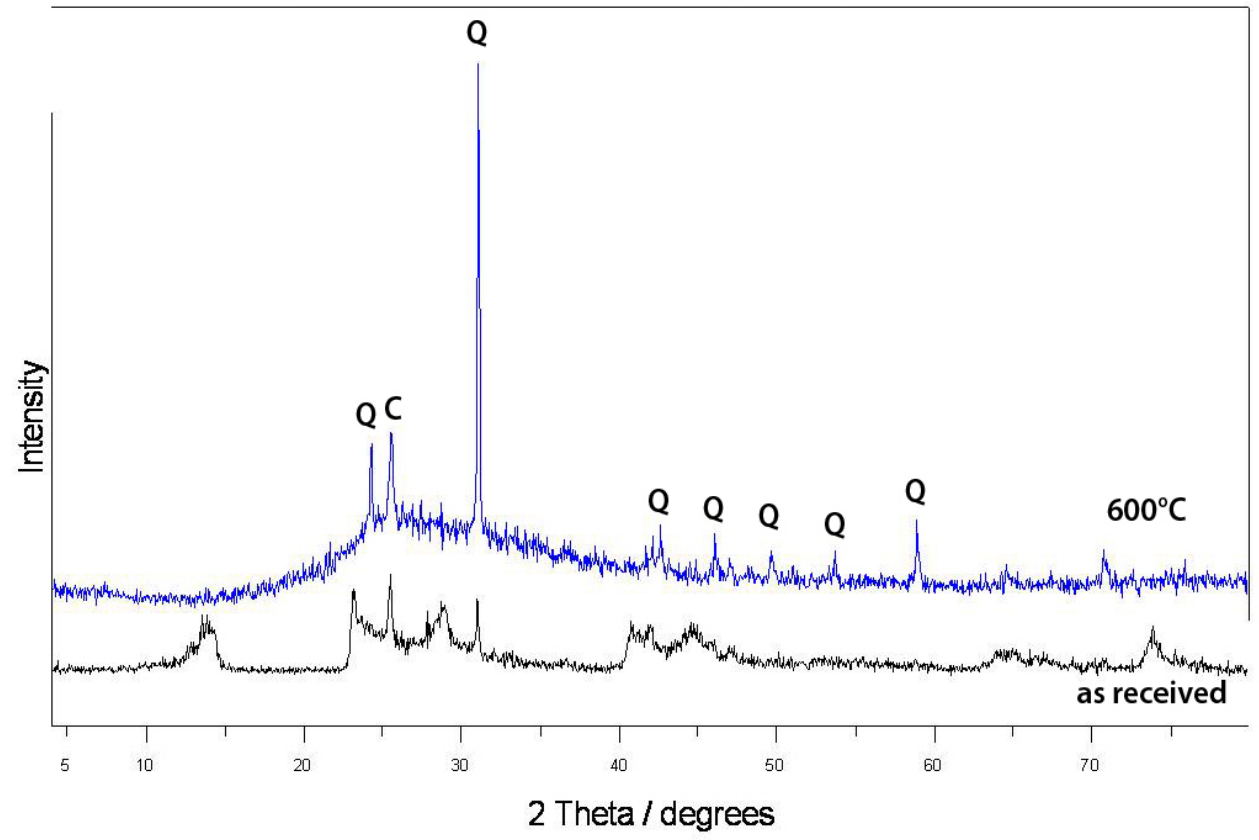

Figure 5.4: XRD patterns of halloysite as received (bottom) and after dehydroxylation (top), $Q=$ quartz,$C=$ cristobalite

Quartz (PDF No. 00-046-1045) and possibly cristobalite (PDF No. 00039-1425) are probably impurities in the original halloysite, although some of the quartz could be converted to cristobalite upon heating. The unlabelled peaks of the lower pattern (as received) indicate the halloysite prior to dehydroxylation.

Thus, the dehydroxylated halloysite and calcium silicate starting materials are more or less x-ray amorphous, but contain some crystalline phases, (Fig. 5.2 and 5.4), whereas the calcium hydroxide and calcium phosphate show sharp, well-defined peaks (Fig. 5.15.3). 


\subsubsection{Reference geopolymer}

The x-ray diffraction patterns of the geopolymer without added calcium compounds, unheated and heated to $550^{\circ} \mathrm{C}$ and $600^{\circ} \mathrm{C}$ do not show significant differences, apart from a small unidentified peak appearing at about $362 \Theta /$ degrees after heating at $600^{\circ} \mathrm{C}$ (Fig. 5.5). The only crystalline peaks present are impurities from the dehydroxylated halloysite, the quartz (PDF No. 00-046-1045) and cristobalite (00-039-1425).

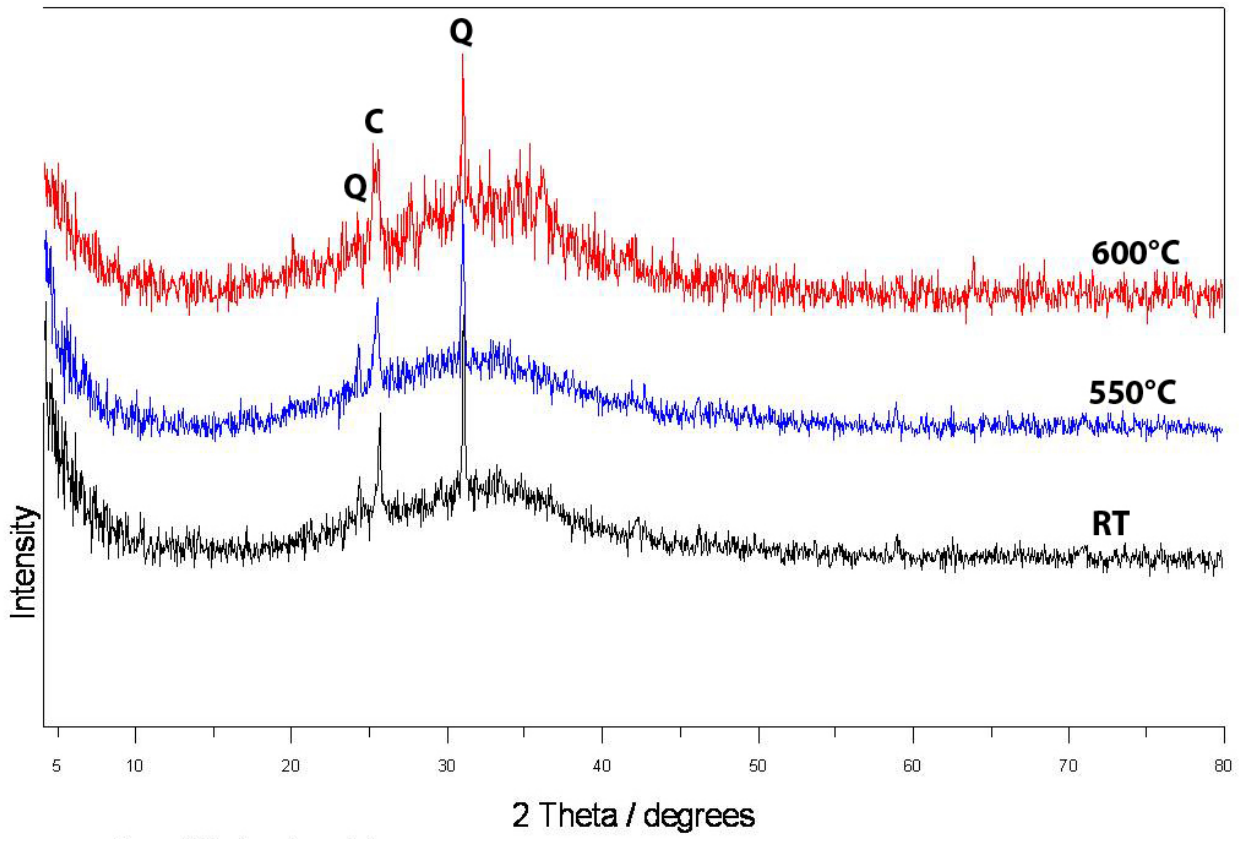

Figure 5.5: XRD patterns of the reference geopolymer before and after heating, $Q=$ quartz,$C=$ cristobalite

Exposure of these geopolymers to SBF produces no change in the XRD patterns. 


\subsubsection{Calcium hydroxide geopolymers}

The synthesised calcium hydroxide-containing geopolymers in general show the X-ray amorphous XRD patterns typical of geopolymers, both before and after heating. The added crystalline calcium hydroxide could not be detected by XRD diffractometry, however it is still present in the material in the form of x-ray amorphous nano-crystals shown by SEM and EDS analysis in section 5.6.2.

The calcium hydroxide-containing geopolymers after synthesis and heating to $550^{\circ} \mathrm{C}$ show similar XRD patterns whereas the XRD pattern of the sample heated to $600^{\circ} \mathrm{C}$ is slightly different (Fig. 5.6).

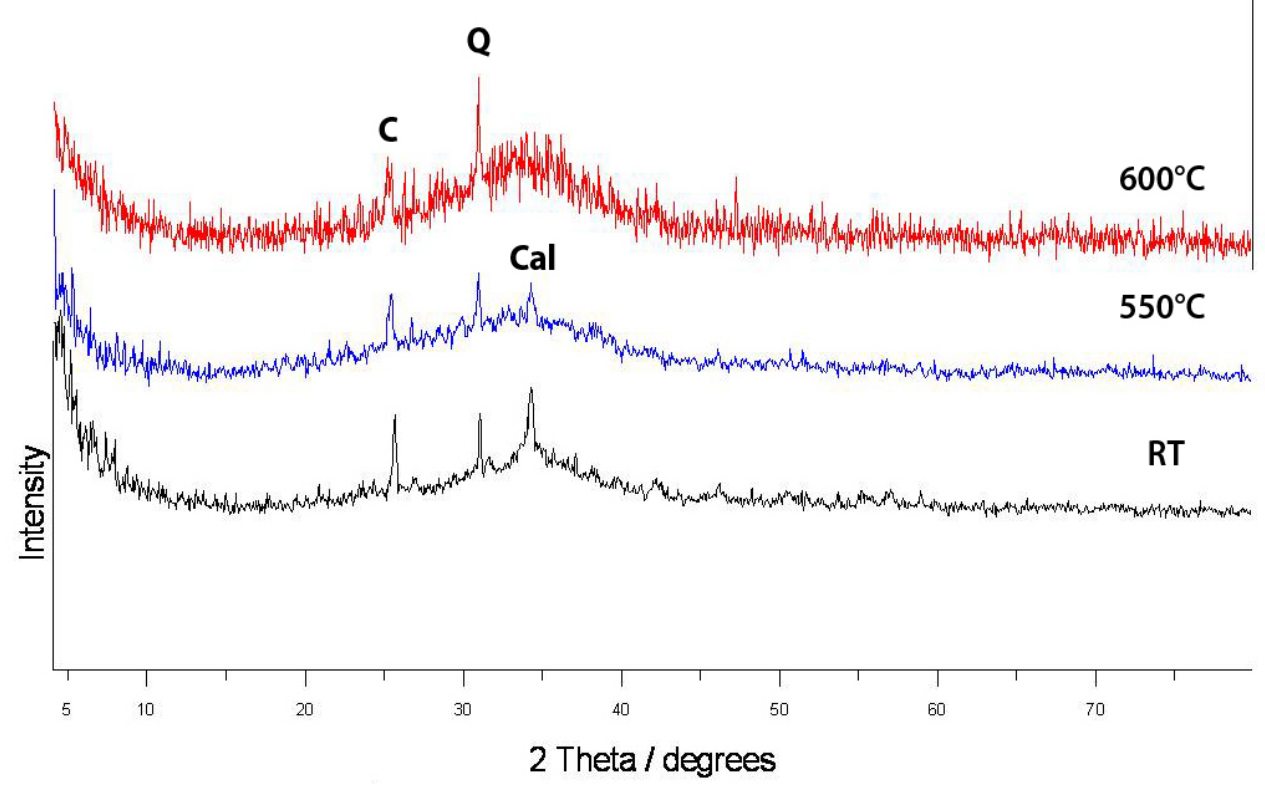

Figure 5.6: XRD patterns of calcium hydroxide-containing geopolymers before and after heating. $Q=$ quartz,$C=$ cristobalite, $\mathrm{Cal}=\mathrm{CaCO}_{3}$

All the samples contain residual quartz (PDF No. 00-046-1045)) and 
cristobalite (PDF No. 00-039-1425) whereas heating to $600^{\circ} \mathrm{C}$ leads to an increase of the amorphous phase, indicated by the increased size of the hump at $342 \Theta /$ degrees and the loss of the calcite peaks (PDF No. 01-072-1937) which are present in the samples unheated and heated to $550^{\circ} \mathrm{C}$ (Fig. 5.6). The calcite probably arises from atmospheric carbonation forming nano-structured particles. The continuously degradation of the calcite with increasing of the heating temperature may be explained by the thermal destruction of nano-structured calcite at lower temperatures with reduced activating energy compared with bulk calcite, reported by Yue et al. [44], and thus very finely divided invisible for x-ray diffractometry. 
X-ray diffraction of an unheated calcium hydroxide-containing geopolymer after exposure to SBF for four weeks (Fig. 5.7) presents a much larger and sharper calcite peak (PDF No. 01-072-1937).

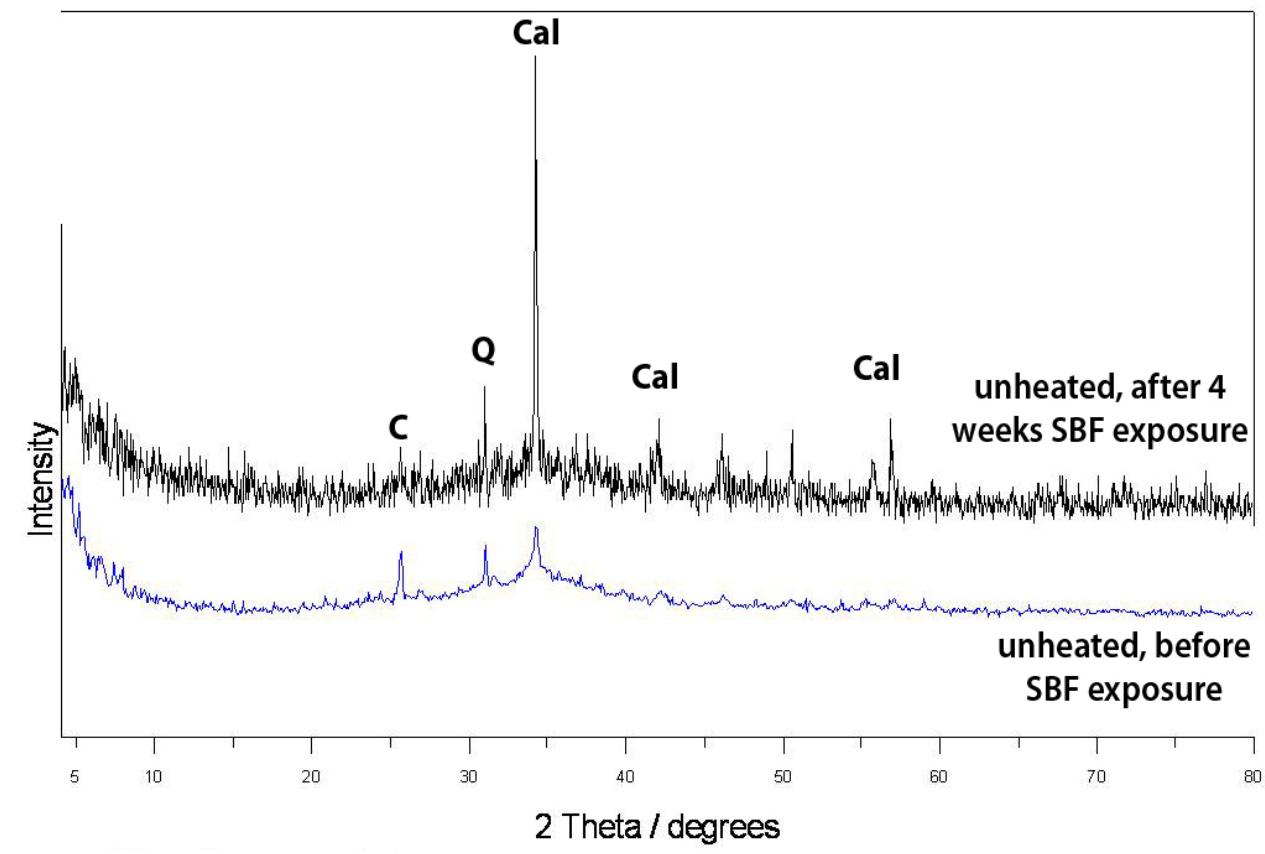

Figure 5.7: XRD spectra of calcium hydroxide-containing geopolymers before and after SBF exposure. $Q=$ quart,$C=$ cristobalite,$C a l=$ calcite

The Calcite in this case probably arises from reaction with the sodium bicarbonate ions in the simulated body fluid. 
The calcium hydroxide-containing samples heated to $550^{\circ} \mathrm{C}$ (Fig. 5.8) and $600^{\circ} \mathrm{C}$ (Fig. 5.9) have similar XRD patterns before and after the invitro exposure experiments.

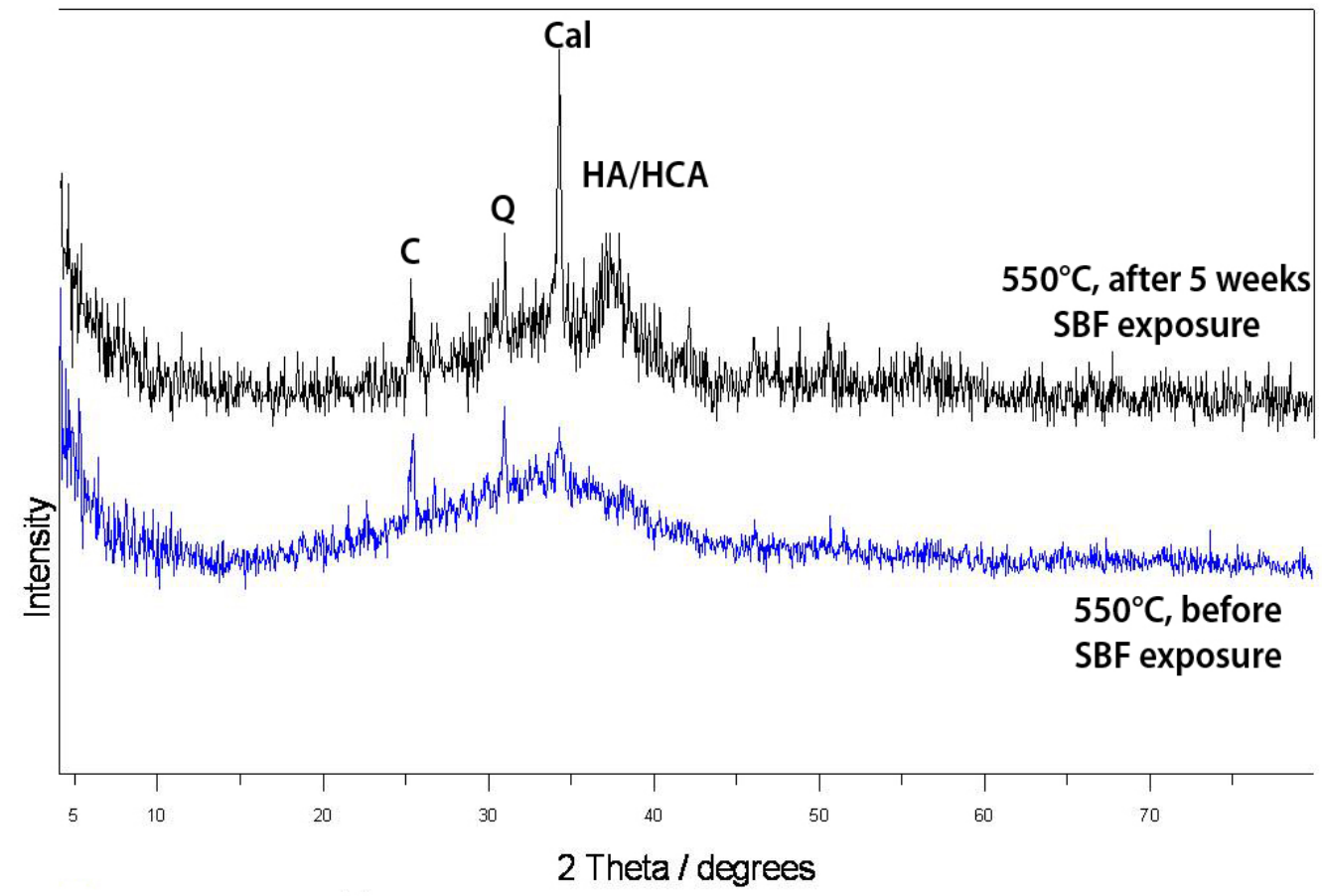

Figure 5.8: XRD patterns of calcium hydroxide-containing geopolymer $\left(550^{\circ} \mathrm{C}\right)$ before and after SBF exposure. $Q=$ quartz,$C=$ cristobalite,$C a l=$ calcite,$H A=$ hydroxyl apatite, $H C A=$ hydroxyl carbonate apatite

Both show evidence of reaction with the SBF to form hydroxyl apatite (PDF No. 00-009-0432) and hydroxyl carbonate apatite (PDF No.00-0190272) phases after an exposure time of four weeks (Fig. 5.9) and five weeks (Fig. 5.8). The two crystalline impurity phases cristobalite and quartz remain unchanged by the heating and exposing to SBF. The specimen heated to $550^{\circ} \mathrm{C}$ (Fig. 5.8) contains well-crystallised calcite in addition to the two other poorly crystalline phases HA and HCA, all of which have formed 
during the in-vitro exposure experiment.

The XRD patterns of a calcium hydroxide-containing sample heated to $600^{\circ} \mathrm{C}$ before and after exposure to simulated body fluid are shown in Figure 5.9. The formation of HA and HCA in this sample upon exposure is more advanced, as induced by the greater intensity of the representative $\mathrm{x}$-ray peak and the lack of a calcite reflection. Thus, this sample appears to be a good candidate for a bioactive geopolymer.

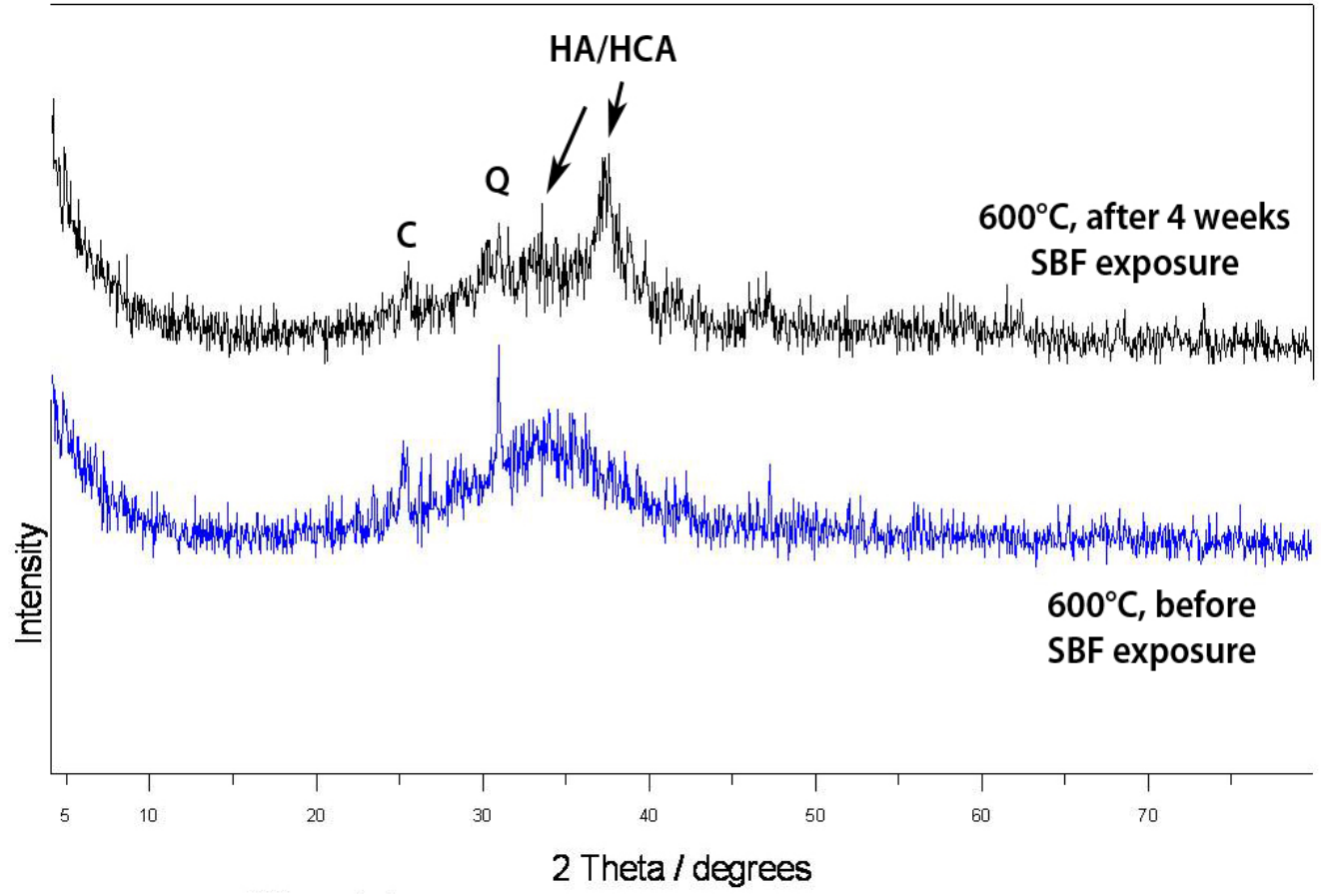

Figure 5.9: $X R D$ spectra of calcium hydroxide-containing geopolymers $\left(600^{\circ} \mathrm{C}\right)$ before and after SBF exposure. $Q=$ quartz,$C=$ cristobalite,$C a l=$ calcite,$H A=$ hydroxyl apatite, $H C A=$ hydroxyl carbonate apatite 


\subsubsection{Calcium silicate geopolymers}

The calcium silicate-containing geopolymers show very similar XRD patterns regardless of the heat-treatment. They all containing the broad hump typical of a geopolymer together with crystalline quartz and cristobalite impurity phases (Fig. 5.10).

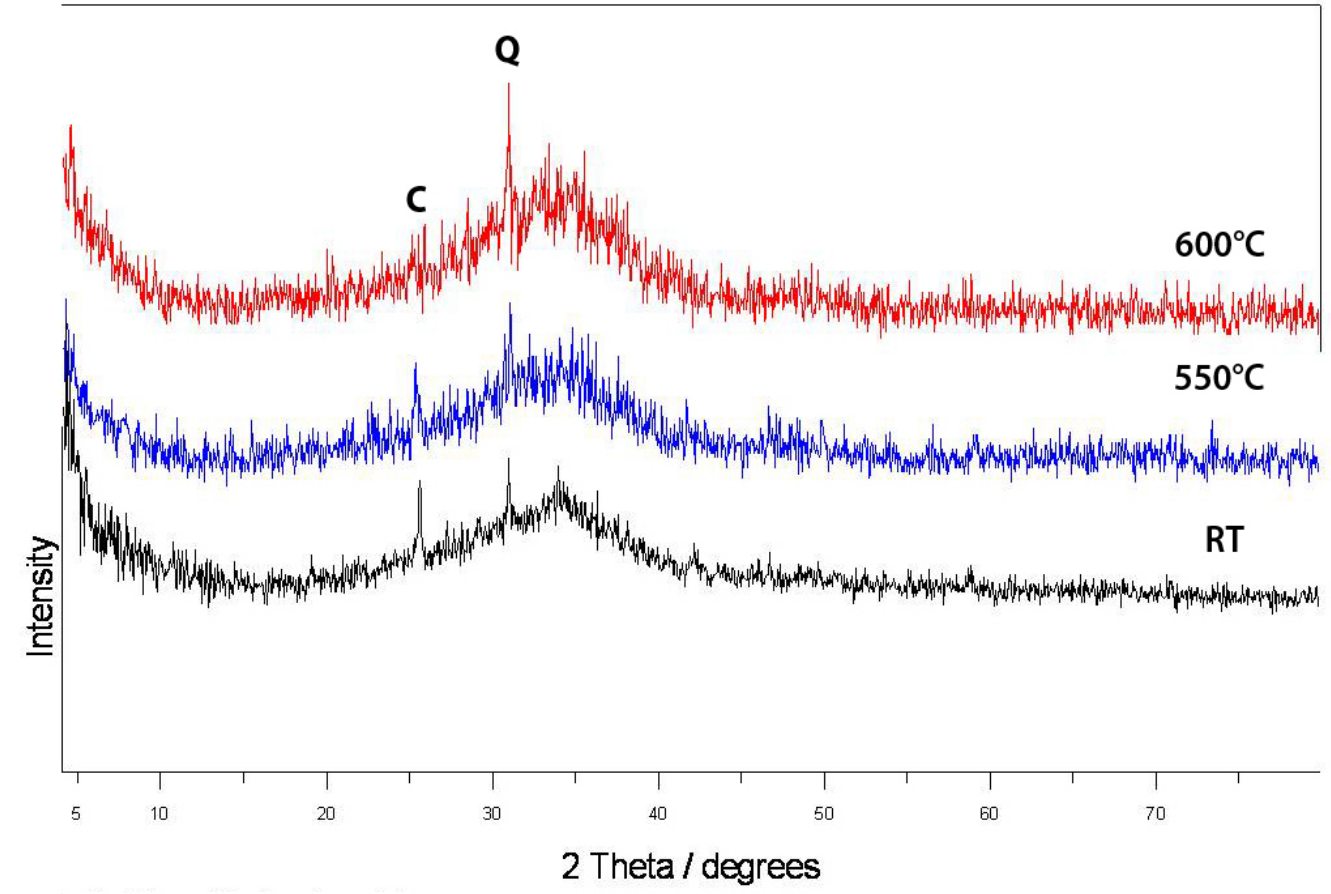

Figure 5.10: XRD patterns of calcium silicate-containing geopolymers before and after heating. $Q=$ quartz, $C=$ cristobalite

In-vitro exposure experiments of samples, both unheated and heated to $550^{\circ} \mathrm{C}$, show no change after exposure to simulated body fluid. 
Specimens heated to $600^{\circ} \mathrm{C}$ show the formation of two possible forms of poorly crystalline hydroxyl apatites (PDF No. 01-082-1944 and 01-0894405) after four weeks of SBF exposure (Fig. 5.11), quartz and cristobalite impurities are still present.

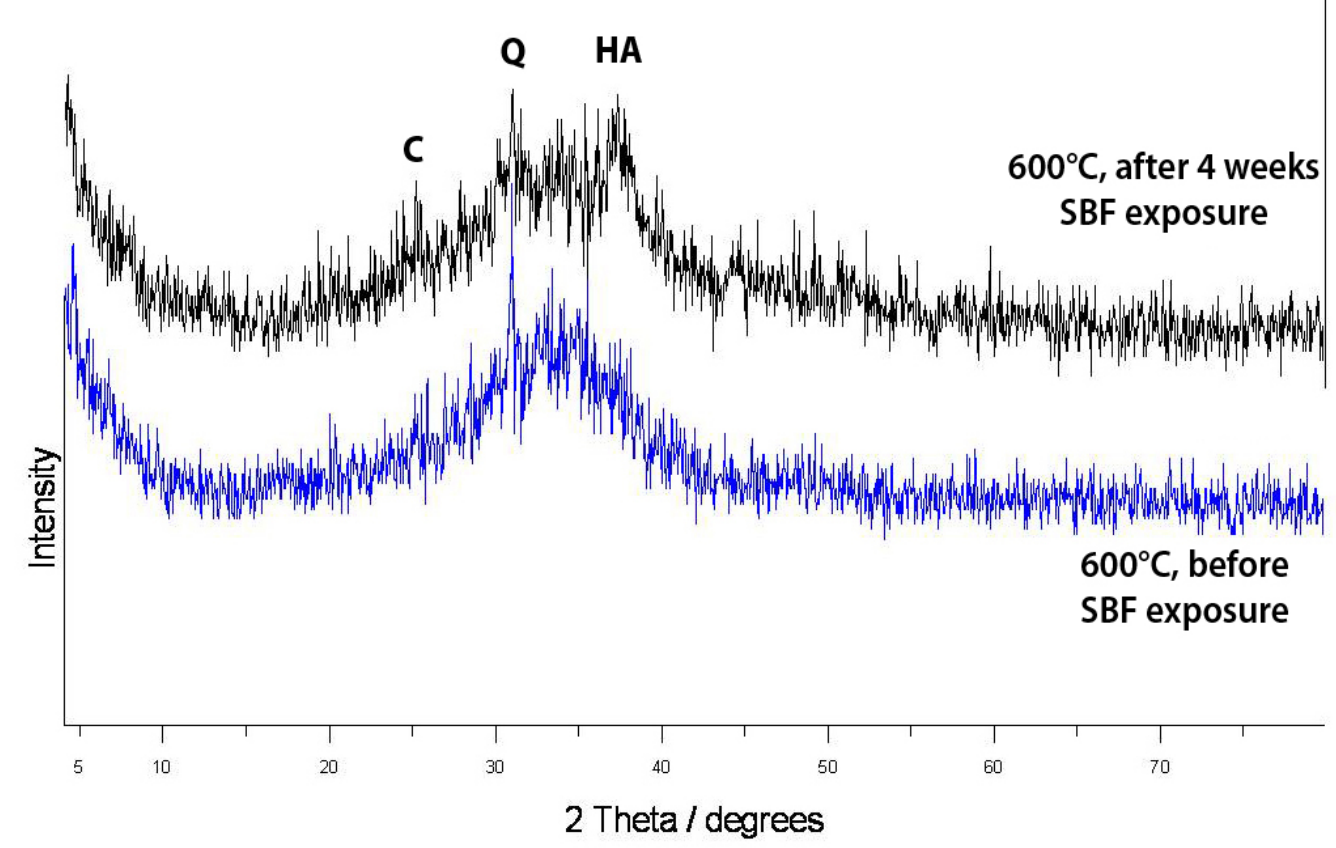

Figure 5.11: XRD patterns of calcium silicate-containing geopolymers $\left(600^{\circ} \mathrm{C}\right)$ before and after SBF exposure; $Q=$ quartz,$C=$ cristobalite, $H A=$ hydroxyl apatite 


\subsubsection{Calcium phosphate geopolymers}

The geopolymers containing calcium phosphate all show typical x-ray amorphous geopolymer diffraction patterns, in both heated and unheated samples (Fig. 5.12).

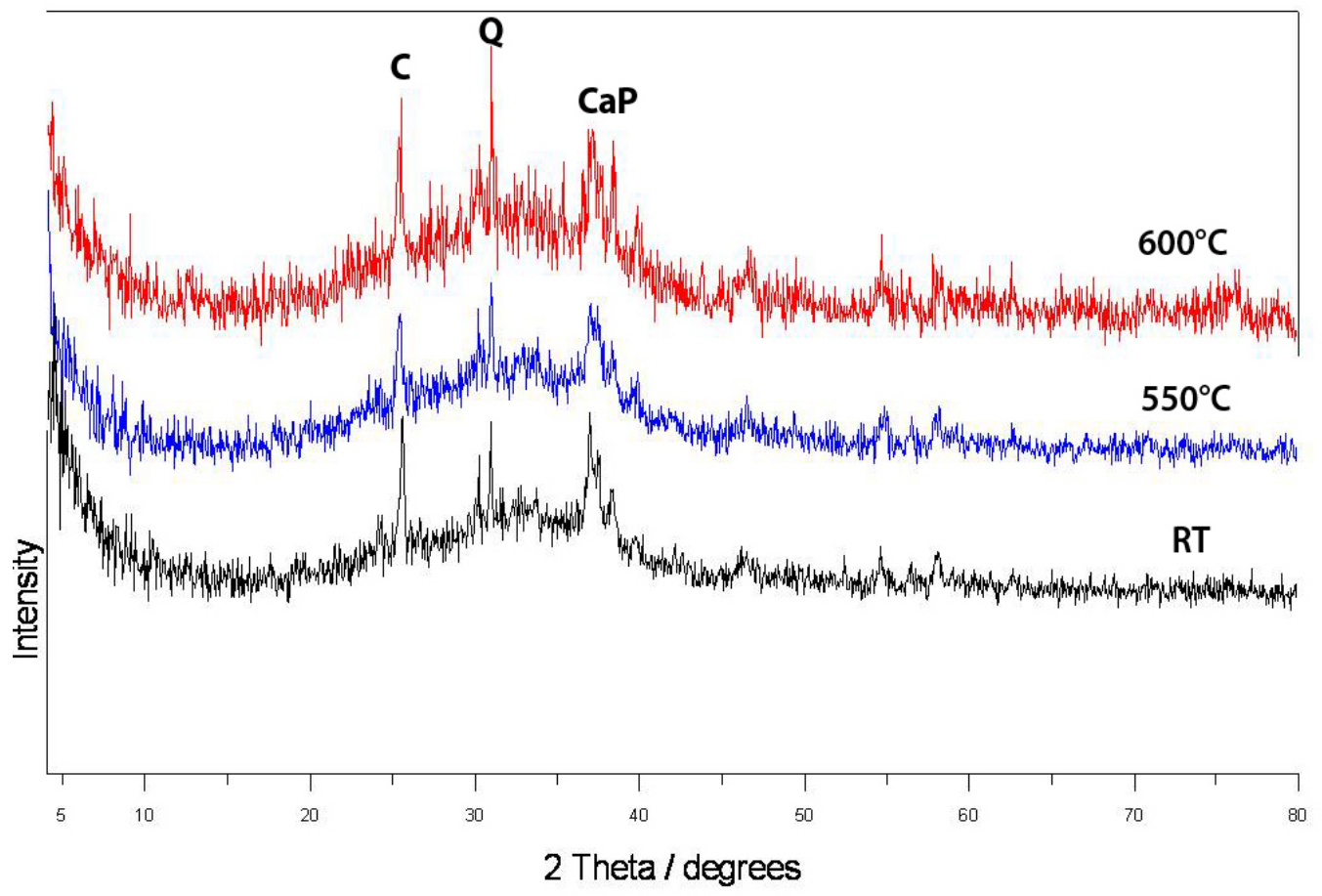

Figure 5.12: XRD patterns of calcium phosphate-containing geopolymers before and after heating. $Q=$ quartz,$C=$ cristobalite,$C a P=$ calcium hydrogen phosphate hydroxide

In addition to the amorphous geopolymer feature, all the patterns contain sharp peaks of quartz and cristobalite impurities and calcium hydrogen phosphate hydroxide (PDF No. 00-046-0905).The in-vitro exposure experiments produce no new peaks in the XRD patterns. However, in the pattern of the geopolymer heated to $600^{\circ} \mathrm{C}$, the $\mathrm{CaP}$ peaks appears slightly more intense possibly due to formation of another calcium phos- 
phate phase, such as hydroxyl apatite or carbonate hydroxyl apatite. Analysis of this sample by SEM showed the formation of small crystals after 7 weeks of SBF exposure, section 5.6.4.

To summarise the XRD results, all the samples show the $\mathrm{x}$-ray amorphous feature of a typical geopolymer, with superimposed crystalline phases corresponding to quartz and cristobalite impurities, and the calcium compounds where these are present. Heating to $550^{\circ} \mathrm{C}$ and $600^{\circ} \mathrm{C}$ produces little change in the XRD pattern, apart from the loss of calcite from the calcium hydroxide-containing sample at $600^{\circ} \mathrm{C}$.

After exposure to SBF, the geopolymers containing calcium hydroxide and calcium silicate heated to $550^{\circ} \mathrm{C}$ and $600^{\circ} \mathrm{C}$ show the formation of the bioactive phases hydroxyl apatite and carbonate hydroxyl apatite. The hydroxyl apatite or carbonate hydroxyl apatite are not detected by XRD as they may be present in insufficient quantities or be of very poor crystallinity (x-ray amorphous).

In-vitro exposure experiments of the reference geopolymer without calcium compounds produced no evidence of the formation of bioactive compounds regardless of the heat-treatment. Neither the heated or unheated calcium phosphate-containing geopolymers show any obvious changes in the XRD patterns, after in-vitro SBF exposure experiments. However, under the alkaline conditions of geopolymerisation, the added calcium phosphate is identified by XRD as calcium hydrogen phosphate hydroxide. Since the XRD patterns of hydroxyl apatite and carbonate hydroxyl apatite and calcium hydrogen phosphate hydroxide are practically indistinguishable, the possible formation of hydroxyl apatite or hydroxyl carbonate apatite during the in-vitro experiments cannot be ruled out. 
Thus, bioactive compounds are shown by XRD to be formed under in-vitro conditions in samples containing calcium hydroxide and nanostructured calcium silicate, especially in the former sample heated to $600^{\circ} \mathrm{C}$. The similarity of the XRD patterns of the phosphate compound formed in the geopolymers containing calcium phosphate before SBF exposure and hydroxyl apatite or hydroxyl carbonate apatite makes it impossible to determine whether the sample has interacted with the SBF. Geopolymers without added calcium compounds do not form bioactive compounds with SBF. These findings are summarised in Table 5.3 .

The presence of calcium is important for effective bioactivity. According to a personal communication [45], it was stated that the most recent information is that both, calcium and silicon play an essential role in activating the genes that turn on the body's regenerative processes. The optimum concentration for calcium is $60 \mathrm{ppm}$ and for silicon is $20 \mathrm{ppm}$ [45]. 
Table 5.3: Presence of bioactive phases (HA/ HCA) found in geopolymers after SBF exposure.

\begin{tabular}{|c|c|c|}
\hline Geopolymer & heating temperature & HA / HCA \\
\hline \multirow{3}{*}{ Reference } & unheated & absent \\
\hline & $550^{\circ} \mathrm{C}$ & absent \\
\hline & $600^{\circ} \mathrm{C}$ & absent \\
\hline \multirow{3}{*}{ Calcium hydroxide } & unheated & absent \\
\hline & $550^{\circ} \mathrm{C}$ & present \\
\hline & $600^{\circ} \mathrm{C}$ & strongly present \\
\hline \multirow{3}{*}{ Calcium silicate } & unheated & absent \\
\hline & $550^{\circ} \mathrm{C}$ & absent \\
\hline & $600^{\circ} \mathrm{C}$ & present \\
\hline \multirow{3}{*}{ Calcium phosphate } & unheated & * \\
\hline & $550^{\circ} \mathrm{C}$ & * \\
\hline & $600^{\circ} \mathrm{C}$ & * \\
\hline
\end{tabular}

*: Cannot be determined (see text) 


\subsection{MAS NMR results}

\subsection{1 $\quad{ }^{27} \mathrm{Al}$ and ${ }^{29} \mathrm{Si}$ MAS NMR results}

\subsubsection{Reference geopolymer}

The ${ }^{27} \mathrm{Al}$ MAS NMR spectrum of the unheated reference geopolymer (Fig. 5.13 is very similar to the samples heated to $550^{\circ} \mathrm{C}$ and $600^{\circ} \mathrm{C}$. In-vitro exposure experiments for seven weeks does not change the ${ }^{27} \mathrm{Al}$ MAS NMR spectrum of these materials.

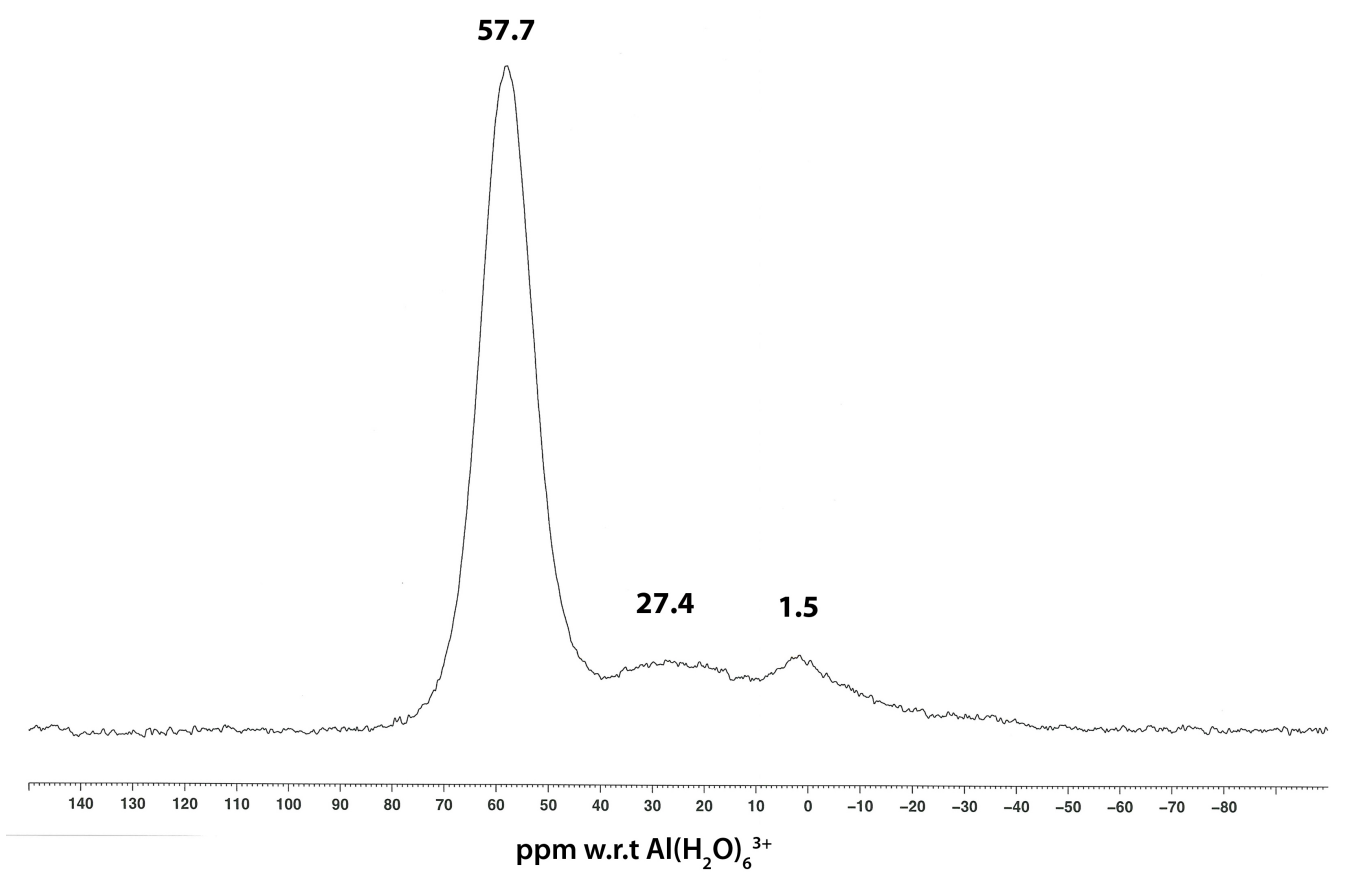

Figure 5.13: $11.7 T^{27}$ Al MAS NMR of the reference geopolymer, unheated.

The major ${ }^{27} \mathrm{Al}$ peak at $57.7 \mathrm{ppm}$ arises from tetrahedral $\mathrm{AlO}_{4}$ and the peaks at 27.4 and $1.5 \mathrm{ppm}$ correspond to aluminium in 5-coordination $\left(\mathrm{AlO}_{5}\right)$ and 6-coordination $\left(\mathrm{AlO}_{6}\right)$ respectively. These sites are typically 
found in the meta-halloysite starting material, and hence probably due to a small amount of unreacted meta-halloysite, indicating an incomplete geopolymerisation process eventually due to insufficient amounts of alkaline materials or water, or both.

The ${ }^{29} \mathrm{Si}$ MAS NMR spectra (Fig. 5.14) are all very similar. They all containing a major peak at about $-92 \mathrm{ppm}$ arising from tetrahedral silicon in predominantly $\mathrm{Q}_{4}(3 \mathrm{Al})$ units and a shoulder at $-106 \mathrm{ppm}$ arises from unreacted quartz impurity, indicating $\mathrm{Q}^{4}(0 \mathrm{Al})$.

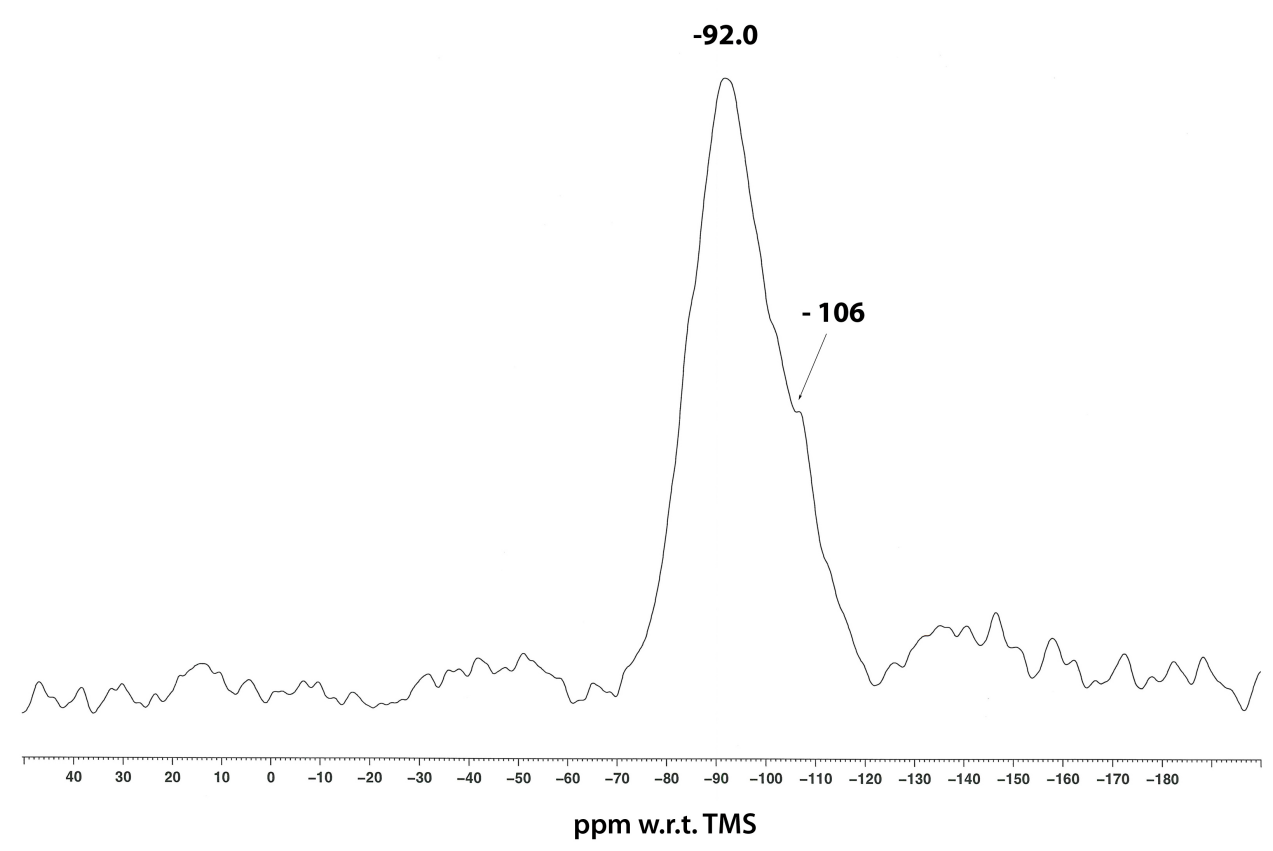

Figure 5.14: $11.7 \mathrm{~T}^{29}$ Si MAS NMR spectrum of the reference geopolymer, unheated. 
The ${ }^{29} \mathrm{Si}$ spectrum of the sample heated to $550^{\circ} \mathrm{C}$ differs in that the shoulder is absent (Fig. 5.15), and that the main peak at -92.8 is relatively broad, suggesting that other $\mathrm{Q}^{4}$ Si-units such as $\mathrm{Q}^{4}(4 \mathrm{Al})$ and $\mathrm{Q}^{4}(2 \mathrm{Al})$ are present under the spectral lineshape.

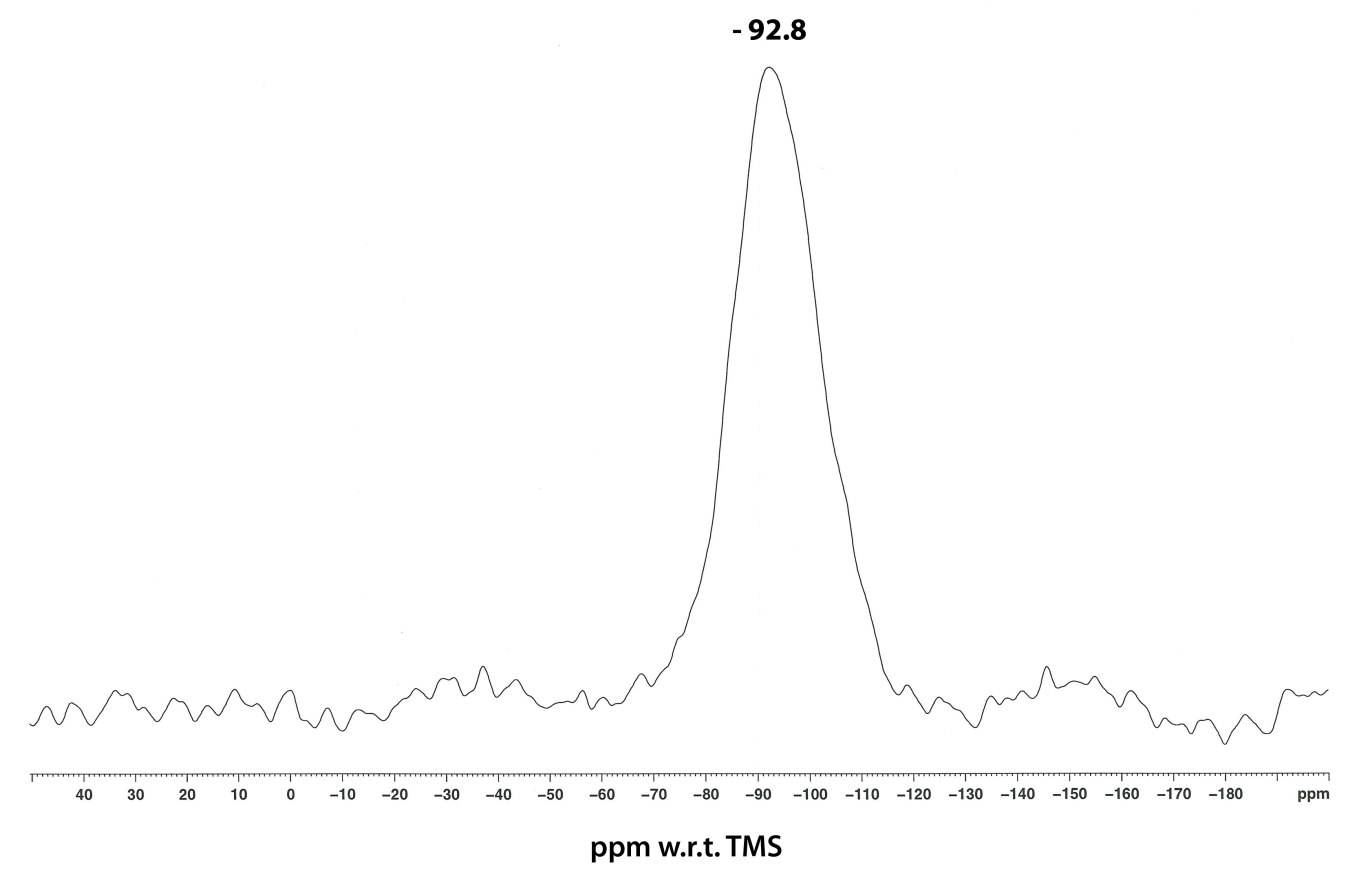

Figure 5.15: $11.7 T{ }^{29}$ Si MAS NMR spectrum of the reference geopolymer heated to $550^{\circ} \mathrm{C}$. 


\subsubsection{Calcium hydroxide geopolymers}

Figure 5.16 shows the ${ }^{27} \mathrm{Al}$ MAS NMR spectrum of an unheated calcium hydroxide-containing geopolymer.

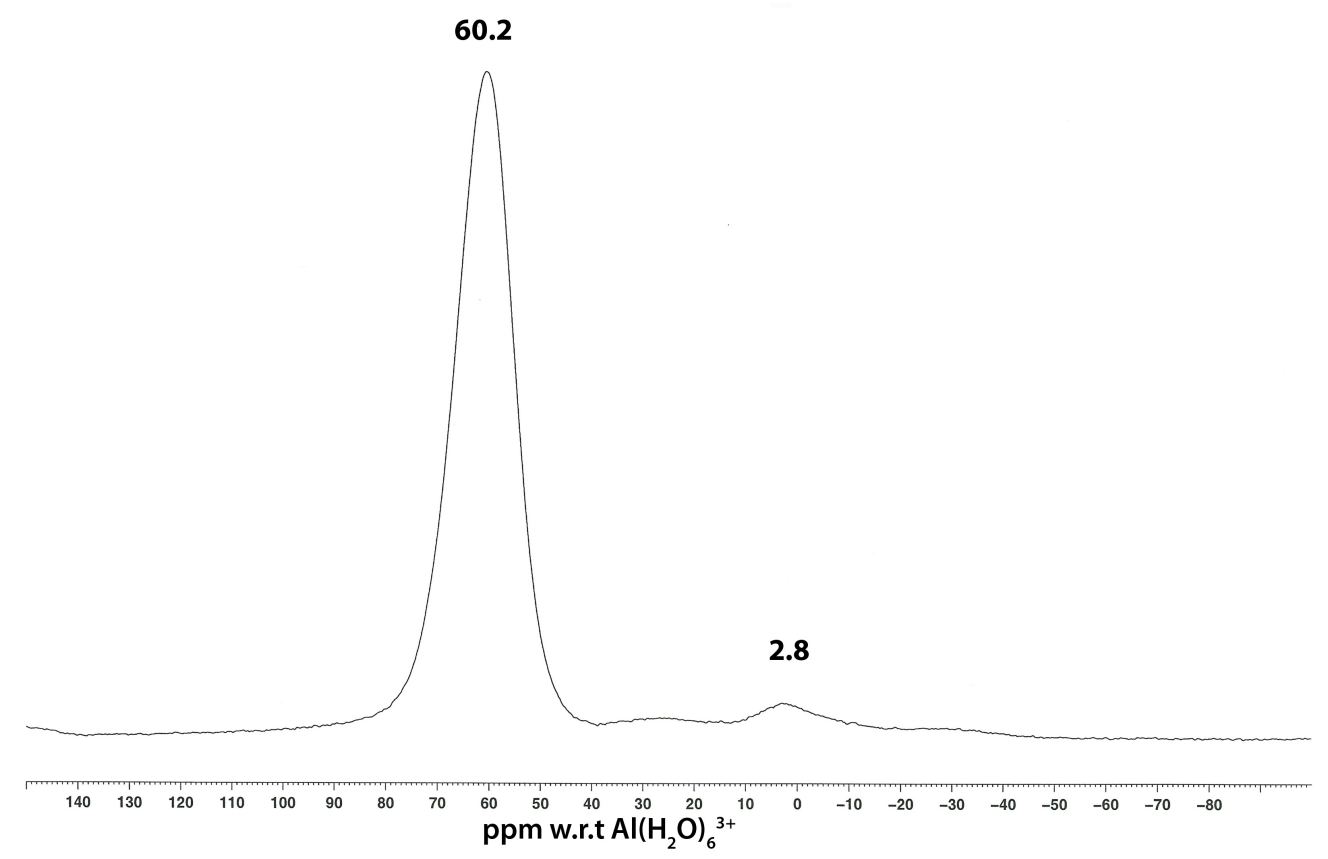

Figure 5.16: $11.7 \mathrm{~T}^{27} \mathrm{Al}$ MAS NMR spectrum of the 10wt\% calcium hydroxidecontaining geopolymer, unheated.

The ${ }^{27} \mathrm{Al}$ spectrum of the sample before and after the exposure to simulated body fluid remains unchanged, both spectra being shown in Figure 5.16 .

The major peak at $60.2 \mathrm{ppm}$ arises from the presence of aluminium in tetrahedral sites $\left(\mathrm{AlO}_{4}\right)$, and the small hump visible at $2.8 \mathrm{ppm}$ shows that a small amount of 6-coordinated aluminium $\left(\mathrm{AlO}_{6}\right)$ is also present in the geopolymer, probably due to unreacted meta-halloysite. The small feature at $28 \mathrm{ppm}$ is in the correct position for $\left(\mathrm{AlO}_{5}\right)$, but is too minor to 
be significant.

Heating the calcium hydroxide-containing geopolymers to $550^{\circ} \mathrm{C}$ and $600^{\circ} \mathrm{C}$ changes the ${ }^{27} \mathrm{Al}$ MAS NMR spectra only slightly. The broad octahedral feature is no longer visible, the major peak at $58.3 \mathrm{ppm}$ indicating only tetrahedral aluminium (Fig. 5.17), indicating an improved ideal geopolymer structure due to the absence of 5- and 6- coordinated aluminium. Invitro exposing experiments do not change these ${ }^{27} \mathrm{Al}$ MAS NMR spectra.

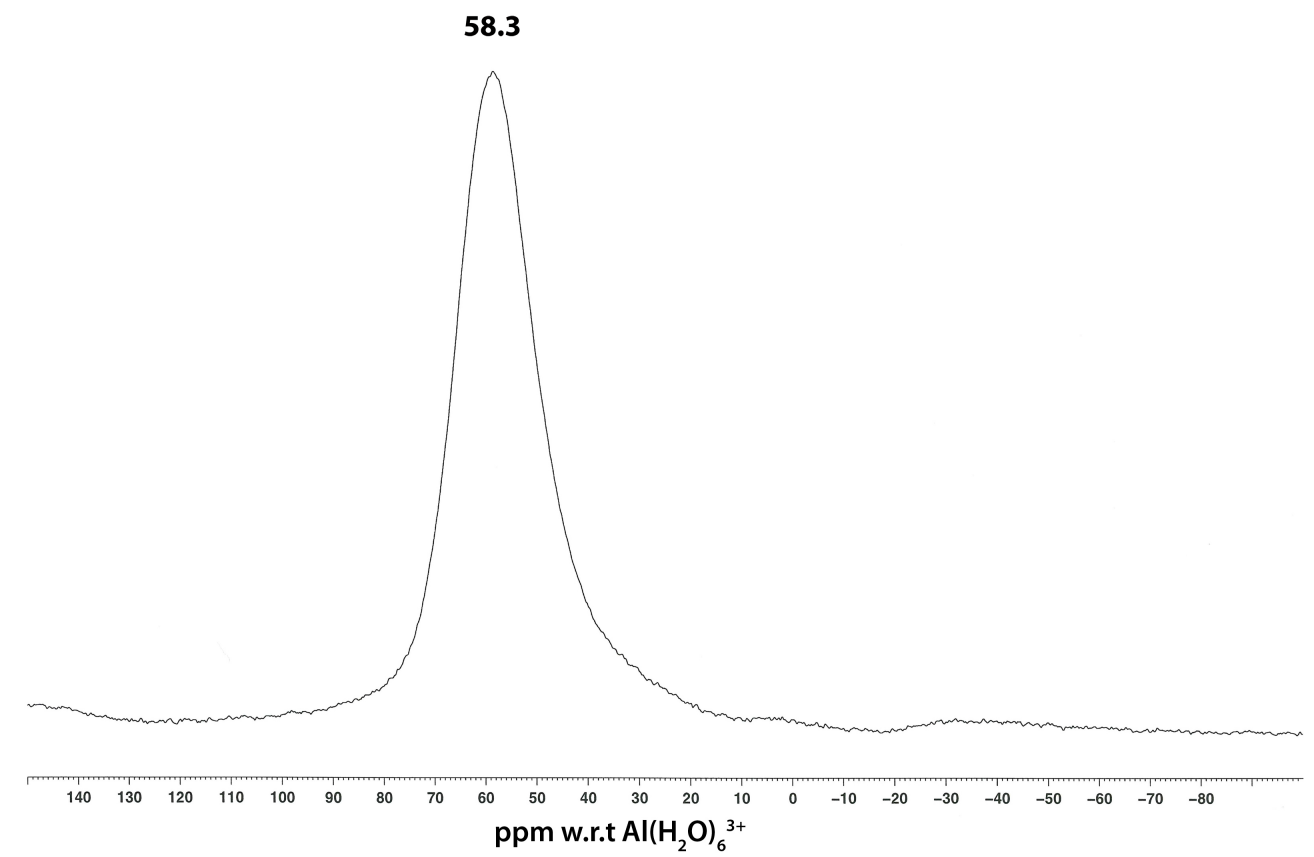

Figure 5.17: $11.7 \mathrm{~T}^{27} \mathrm{Al}$ MAS NMR spectrum of the 10wt\% calcium hydroxidecontaining geopolymer heated to $550^{\circ} \mathrm{C}$. 
The ${ }^{29} \mathrm{Si}$ spectrum of the unheated calcium hydroxide-containing geopolymers is shown in Figure 5.18 .

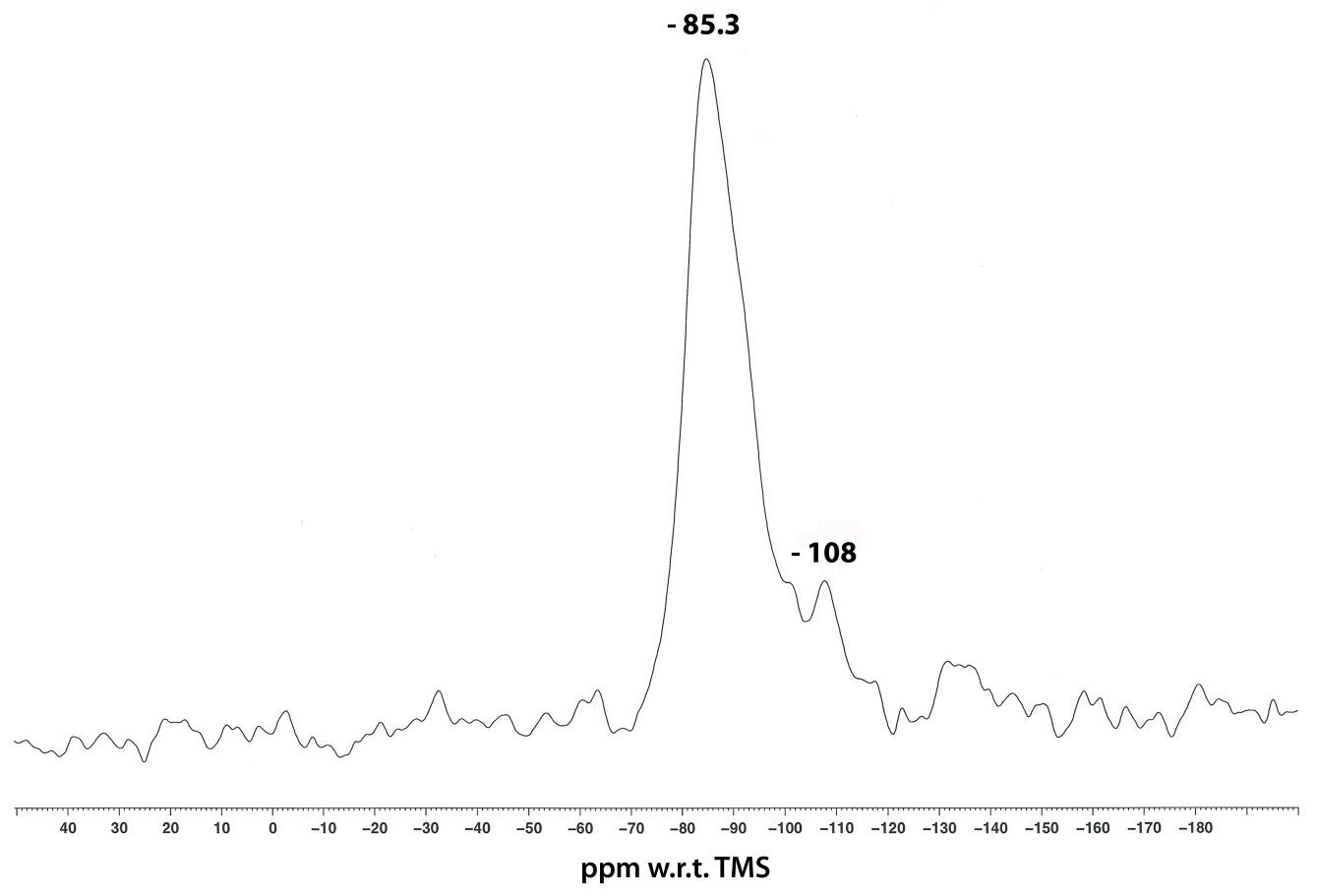

Figure 5.18: $11.7 \mathrm{~T}{ }^{29}$ Si MAS NMR spectrum for the 10wt\% calcium hydroxidecontaining geopolymer cured at room temperature.

The major peak at $-85.3 \mathrm{ppm}$ is in the general vicinity of a typical ${ }^{29} \mathrm{Si}$ geopolymer resonance (-90 ppm), normally assigned to $\mathrm{Q}^{4}(3 \mathrm{Al})$ units [24]. The small downfield shift of this resonance has also been reported in geopolymer samples containing calcium hydroxide [24] and may be due either to the effect of the calcium or to a greater degree of saturation by aluminium, producing $\mathrm{Q}^{4}(4 \mathrm{Al})$ and $\mathrm{Q}^{4}(3 \mathrm{Al})$ units. The small peak at 108 ppm is due to the unreacted $\mathrm{SiO}_{2}$ (quartz) impurity and arises from silicon in $\mathrm{Q}^{4}(0 \mathrm{Al})$. The ${ }^{29} \mathrm{Si}$ spectrum of the unheated calcium hydroxidecontaining geopolymer is unchanged by the in-vitro experiments. 
Calcium hydroxide-containing geopolymers heated to $550^{\circ} \mathrm{C}$ and $600^{\circ} \mathrm{C}$ (Fig. 5.19) show variations in their ${ }^{29} \mathrm{Si}$ MAS NMR spectra.

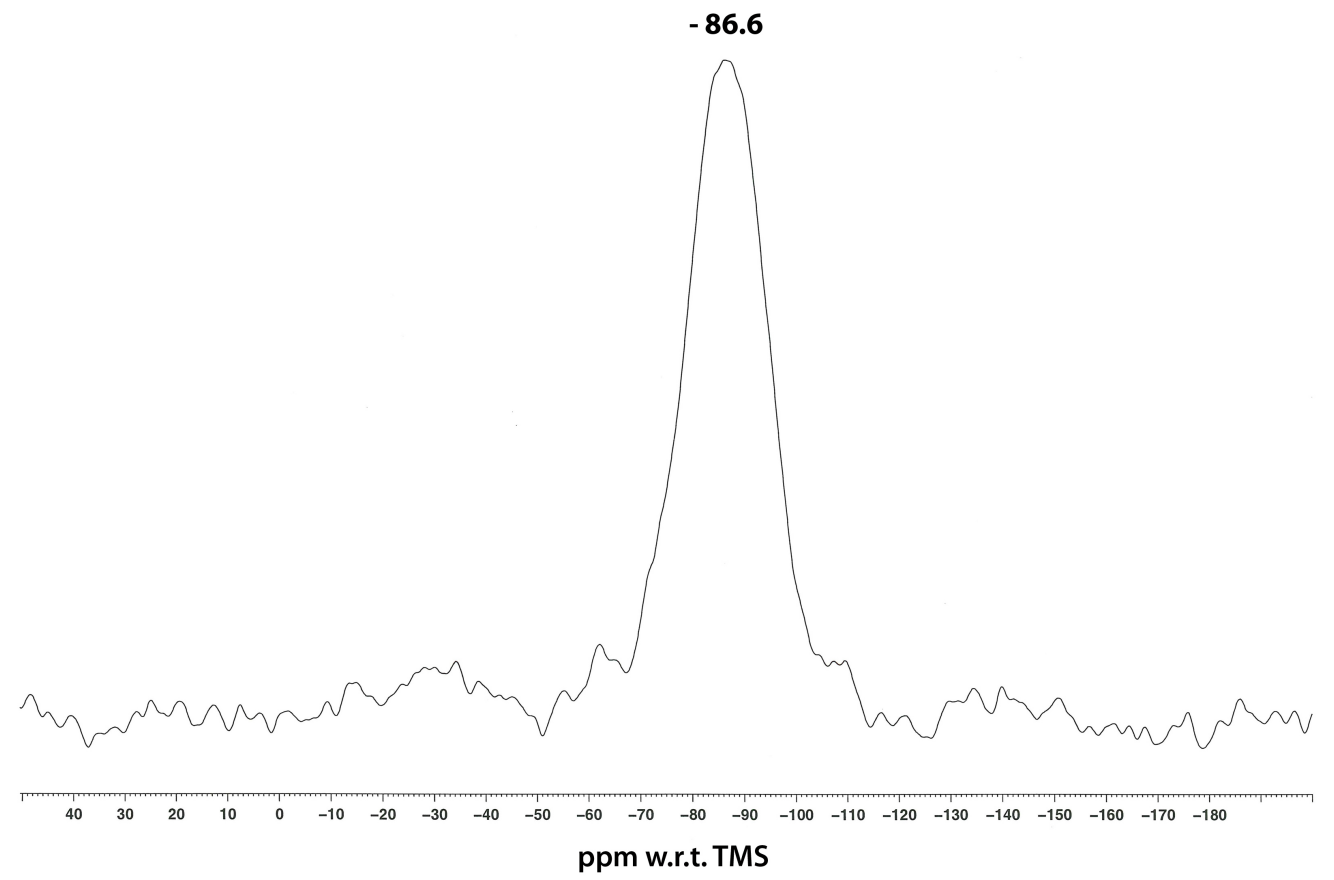

Figure 5.19: $11.7 \mathrm{~T}{ }^{29} \mathrm{Si}$ MAS NMR spectrum of the 10wt\% calcium hydroxidecontaining geopolymer heated to $550^{\circ} \mathrm{C}$.

Compared to the unheated geopolymer the main ${ }^{29} \mathrm{Si}-\mathrm{NMR}$ peak at $86.6 \mathrm{ppm}$ of the samples heated to $550^{\circ} \mathrm{C}$ and $600^{\circ} \mathrm{C}$ appears to be broader. Thus, the shoulder arising from quartz at -108 ppm, if present in Fig. 5.18 , is obscured by the noise. However, in Fig. 5.19 because of the broadening effect the present quartz impurity at $-108 \mathrm{ppm}$ only appears as a small shoulder and not as a proper peak but is still there.

The major peak at $-86.6 \mathrm{ppm}$ (Fig. 5.19) indicates tetrahedral silicon in $\mathrm{Q}^{4}(4 \mathrm{Al})$ and possibly $\mathrm{Q}^{4}(3 \mathrm{Al})$. In-vitro exposing to $\mathrm{SBF}$ does not change the ${ }^{29} \mathrm{Si}$ MAS NMR spectra significantly, and their major peak is probably 
again due to $\mathrm{Q}^{4}(4 \mathrm{Al})$ and $\mathrm{Q}^{4}(3 \mathrm{Al})$ units. Thus, both the ${ }^{27} \mathrm{Al}$ and the ${ }^{29} \mathrm{Si}$ MAS NMR spectra of the calcium hydroxide-containing geopolymers are consistent with those of normal geopolymers, and are unchanged by either heating or exposure to SBF.

\subsubsection{Calcium silicate geopolymers}

Calcium silicate-containing geopolymers cured at room temperature without additional heat-treatment have similar ${ }^{27} \mathrm{Al}$ MAS NMR spectra to that of shown in Figure 5.20, both before and after the in-vitro exposing experiments.

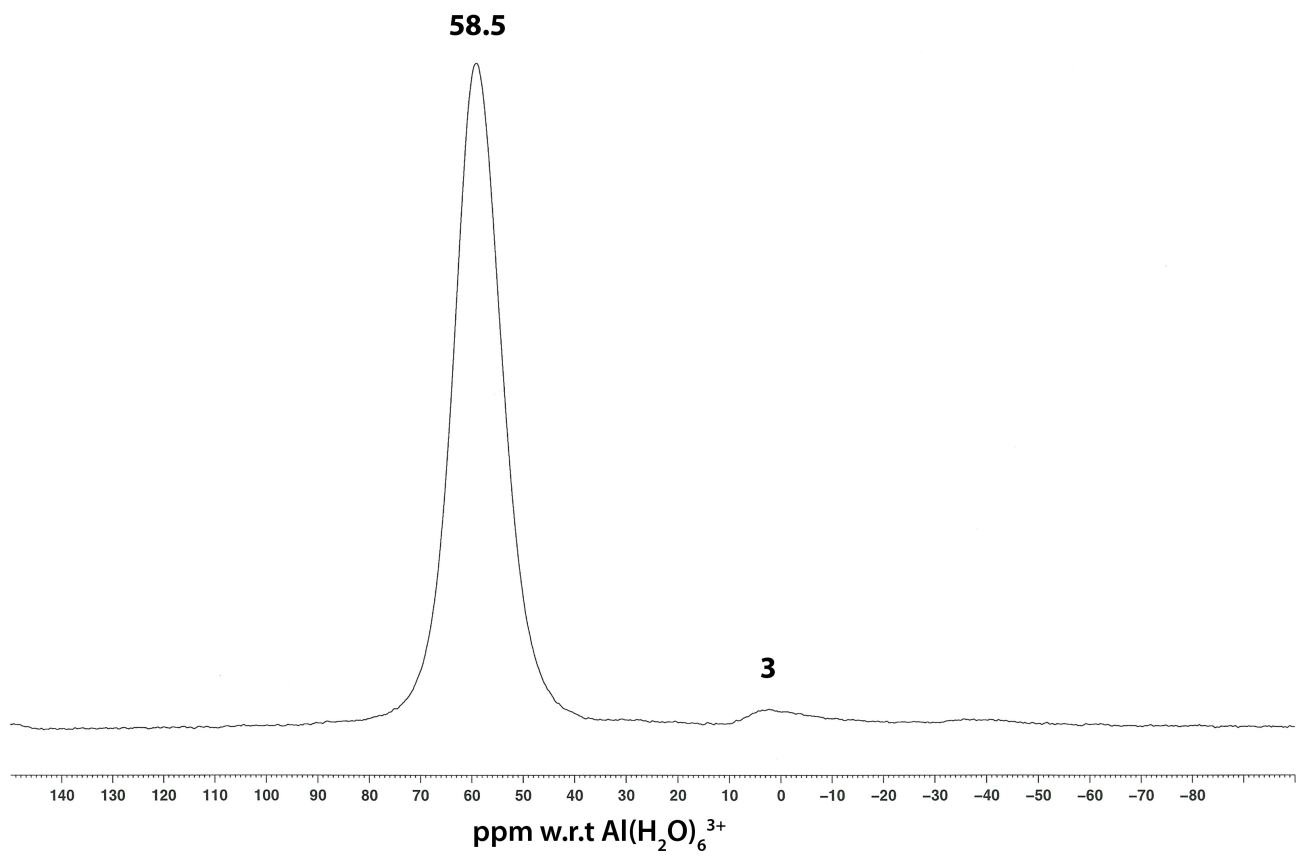

Figure 5.20: $11.7 \mathrm{~T}^{27} \mathrm{Al}$ MAS NMR spectrum of a 10wt\% calcium silicate-containing geopolymer cured at room temperature.

The sharp peak at $58.5 \mathrm{ppm}$ arises from tetrahedral aluminium $\left(\mathrm{AlO}_{4}\right)$, 
while the small hump at $3 \mathrm{ppm}$ arises from a very small amount of 6coordinated aluminium $\left(\mathrm{AlO}_{6}\right)$ arising from unreacted meta-halloysite.

The ${ }^{27} \mathrm{Al}$ MAS NMR spectra of geopolymers containing calcium silicate after heating to $550^{\circ} \mathrm{C}$ and $600^{\circ} \mathrm{C}$ are very similar and are represented by Figure 5.21 (spectrum of the sample heated to $550^{\circ} \mathrm{C}$ ). They show only a sharp peak at about $57 \mathrm{ppm}$, indicating aluminium in solely tetrahedral coordination. The absence of 5- and 6-coordinated aluminium indicates an improvement of the ideal geopolymer structure after heating.

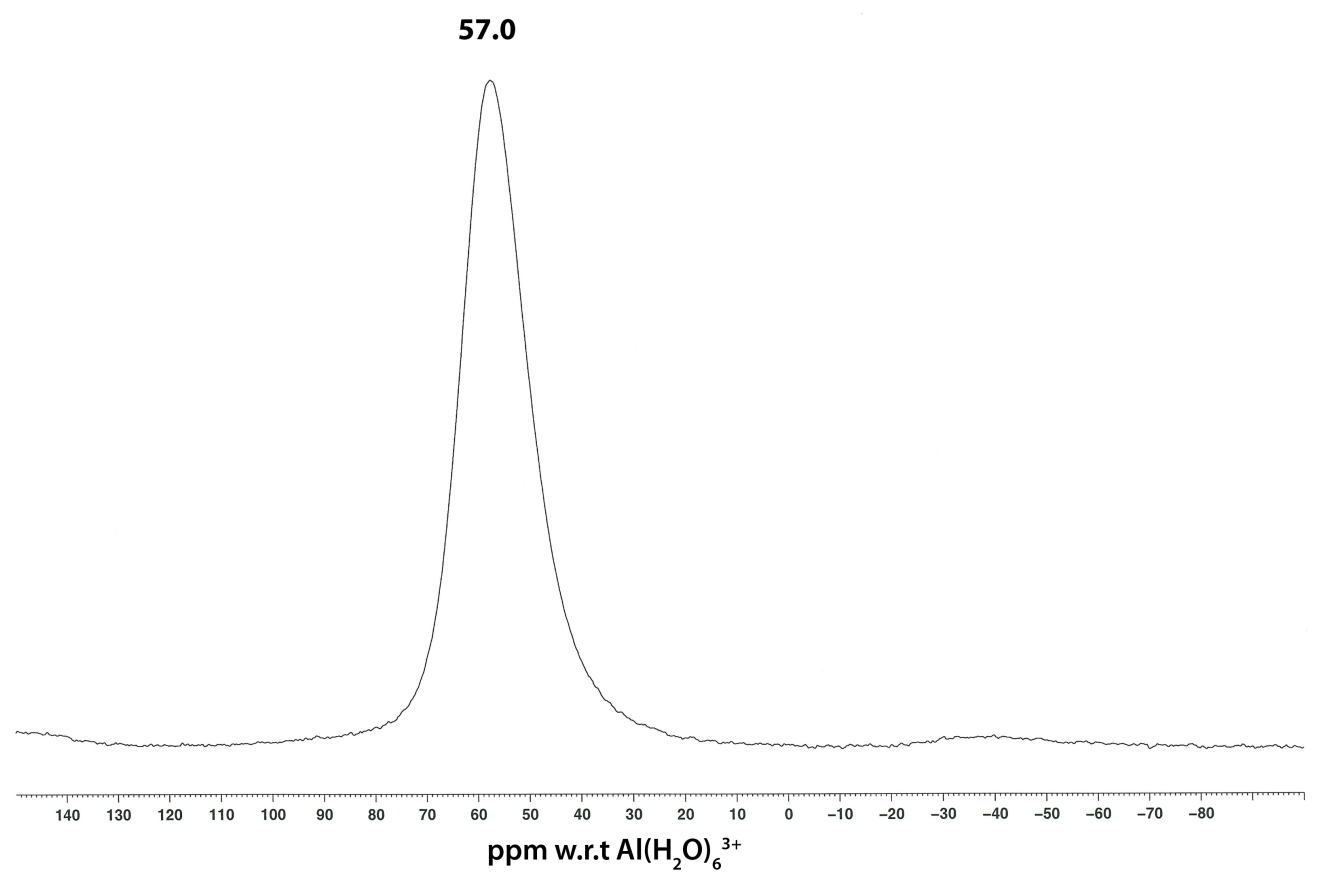

Figure 5.21: $11.7 \mathrm{~T}^{27} \mathrm{Al}$ MAS NMR spectrum of a geopolymer containing $10 \mathrm{wt} \%$ calcium silicate, after heating to $550^{\circ} \mathrm{C}$.

Exposure to simulated body fluid does not change the coordination state of the aluminium which remains tetrahedral $\left(\mathrm{AlO}_{4}\right)$, similar to the 
spectrum shown in Figure 5.21.

The ${ }^{29}$ Si MAS NMR spectra of geopolymers containing nano structured calcium silicate unheated, heated to $550^{\circ} \mathrm{C}$ and $600^{\circ} \mathrm{C}$ prior to the in-vitro exposure experiments show comparable results, regardless of the heating temperature. A similar spectrum is shown also by the unheated calcium silicate geopolymer after the in-vitro exposure to SBF. Figure 5.22 is representative of those spectra, showing a major peak at -90.2 ppm typical of a geopolymer with silicon in $\mathrm{Q}^{4}(3 \mathrm{Al})$ and possibly $\mathrm{Q}^{4}(4 \mathrm{Al})$ sites.

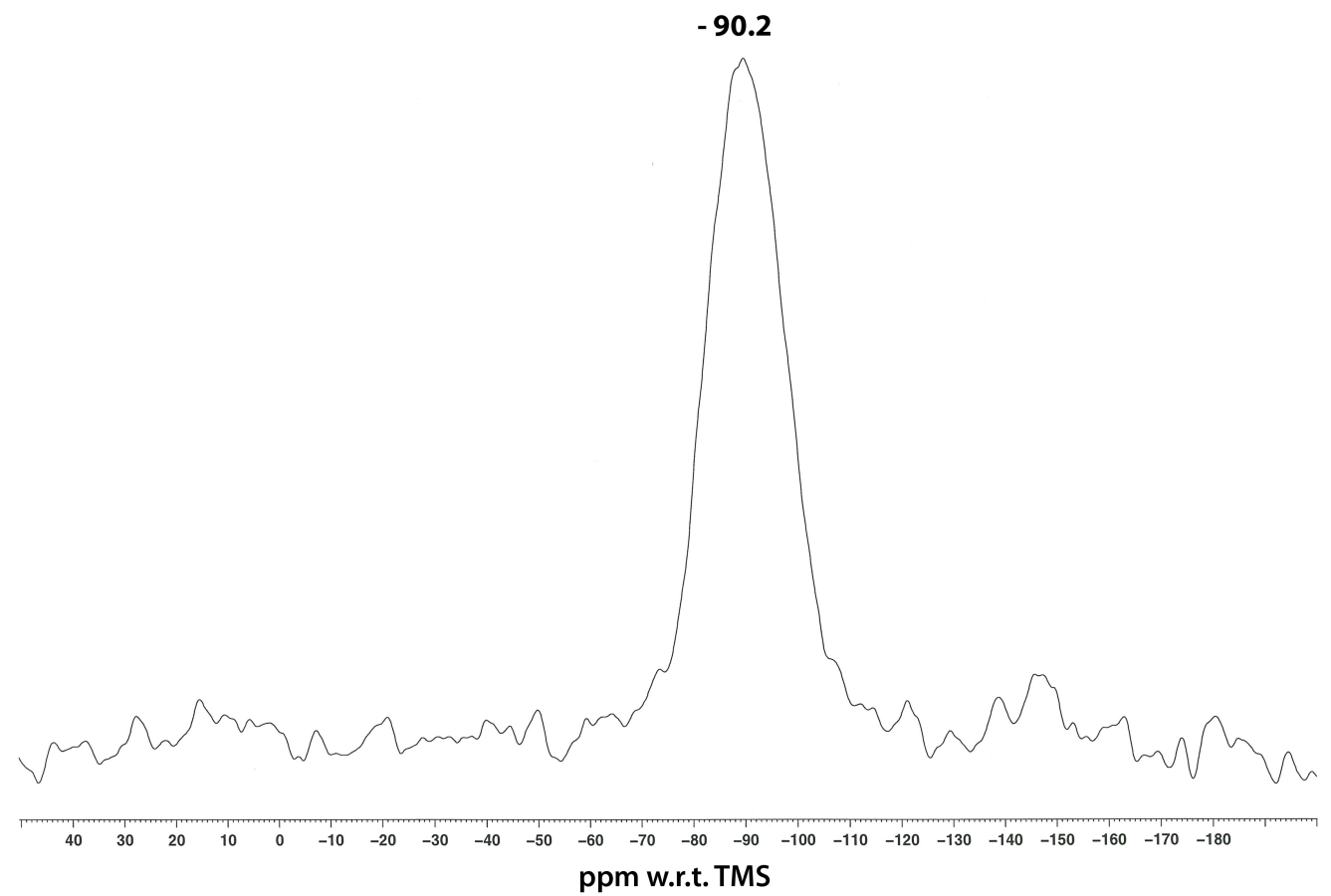

Figure 5.22: $11.7 \mathrm{~T}^{29}$ Si MAS NMR spectrum of a 10wt\% calcium silicate-containing geopolymer heated to $550^{\circ} \mathrm{C}$. 
Geopolymers containing calcium silicate heated to $550^{\circ} \mathrm{C}$ and $600^{\circ} \mathrm{C}$ show slightly altered ${ }^{29} \mathrm{Si}$ MAS NMR spectra after exposure to SBF for 5 and 7 weeks, with evidence of shoulders at -94 and -104 ppm (Fig. 5.23). The large peak at about $-90.6 \mathrm{ppm}$ is typical of a geopolymer $\mathrm{Q}^{4}(3 \mathrm{Al})$ or $\left(\mathrm{Q}^{4}(4 \mathrm{Al})\right)$ environment. The shoulder at $-94 \mathrm{ppm}$ is due to a silicon unit less saturated in aluminium, such as $\mathrm{Q}^{4}(2 \mathrm{Al})$, and the shoulder at -104 ppm may arise from $\mathrm{Q}^{4}(1 \mathrm{Al})$ units containing even less aluminium coordinated in the aluminosilicate units.

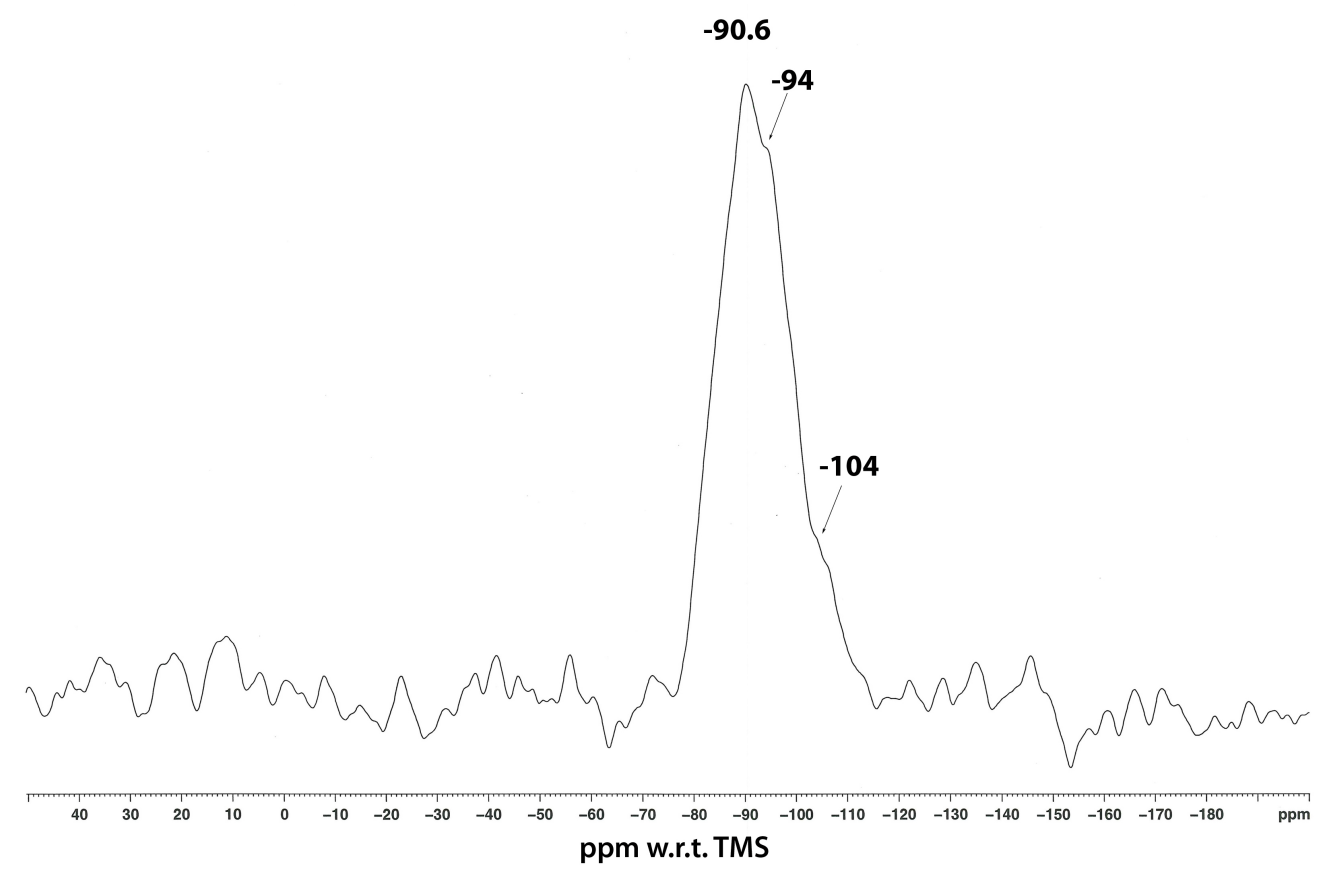

Figure 5.23: $11.7 T{ }^{29}$ Si MAS NMR spectrum of a $10 w t \%$ calcium silicate-containing geopolymer heated to $600^{\circ} \mathrm{C}$, after 7 weeks SBF exposure. 


\subsubsection{Calcium phosphate geopolymers}

A typical ${ }^{27} \mathrm{Al}$ MAS NMR spectrum of an unheated geopolymer containing $10 \mathrm{wt} \%$ calcium phosphate both before and after in-vitro exposure to simulated body fluid is shown in Figure 5.24 .

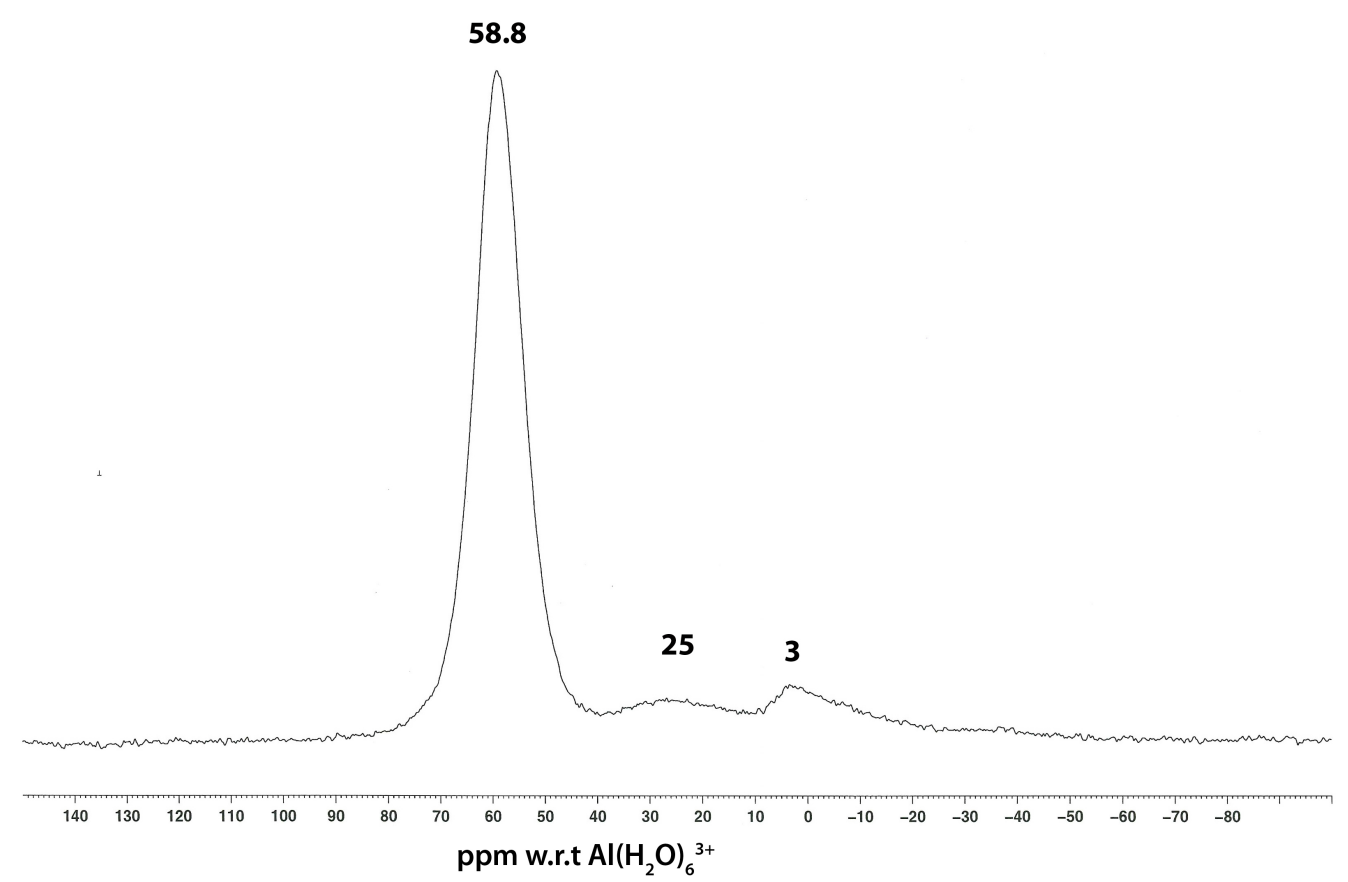

Figure 5.24: $11.7 \mathrm{~T}^{27} \mathrm{Al}$ MAS NMR spectrum of an unheated $10 w \mathrm{w} \%$ calcium phosphate-containing geopolymer.

The large peak at $58.8 \mathrm{ppm}$ is due to tetrahedral aluminium $\left(\mathrm{AlO}_{4}\right)$ and the two smaller features at 25 and 3 ppm arise from small amounts of 5and 6-coordinated aluminium, probably from unreacted meta-halloysite. 
The ${ }^{27} \mathrm{Al}$ spectra of $10 \mathrm{wt} \%$ calcium phosphate-containing geopolymers heated to $550^{\circ} \mathrm{C}$ and $600^{\circ} \mathrm{C}$ are unchanged by the in-vitro exposure experiments. A typical spectrum is shown in Figure 5.25

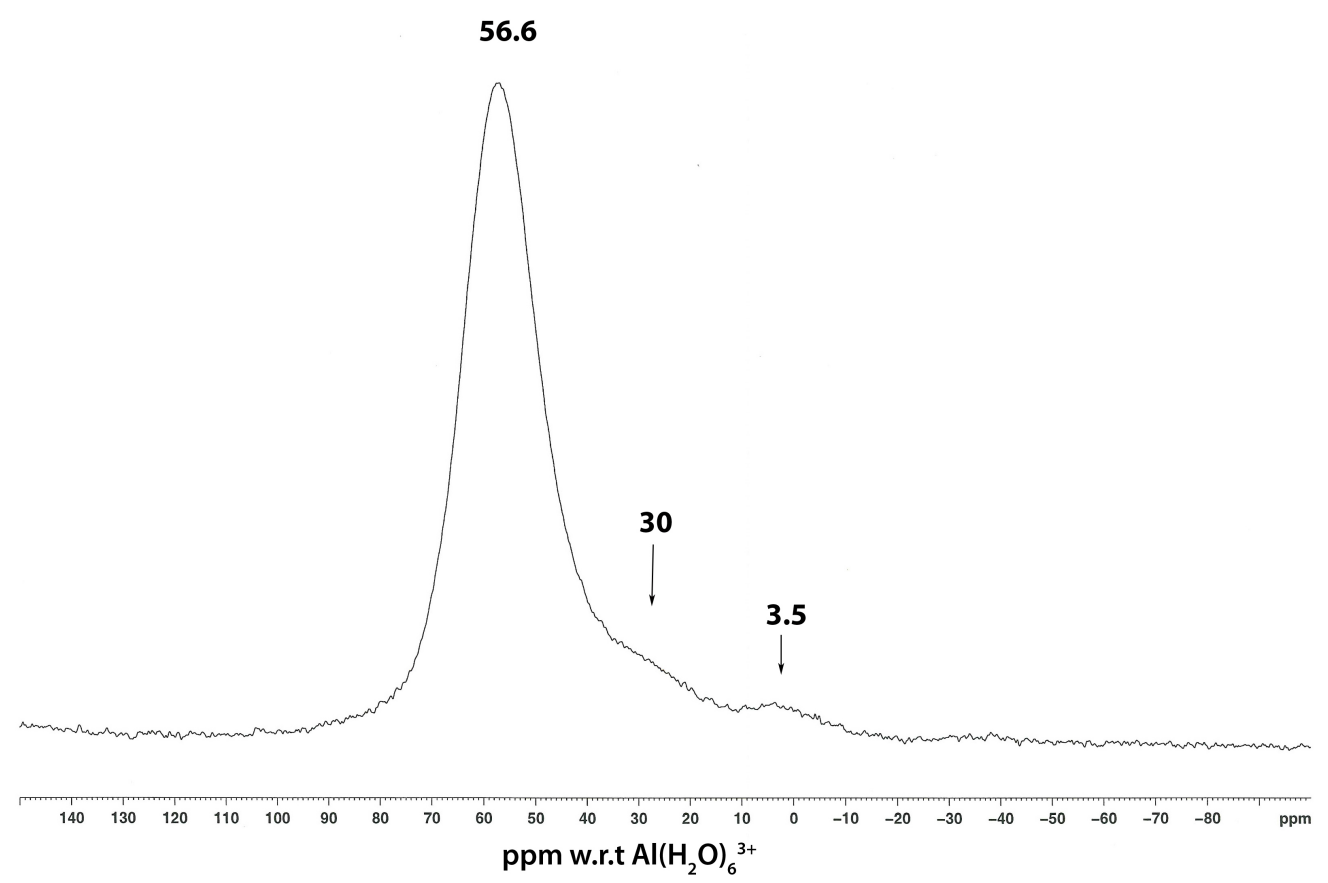

Figure 5.25: $11.7 \mathrm{~T}{ }^{27} \mathrm{Al}$ MAS NMR spectrum of the $10 \mathrm{wt} \%$ calcium phosphatecontaining geopolymer heated to $550^{\circ} \mathrm{C}$.

The main peak at $56.6 \mathrm{ppm}$ due to 4-coordinated aluminium appears to be broader with a small downfield shift compared to the main peak in Figure 5.24. This probably arises from the still incomplete reaction of the meta-halloysite, indicated by the poorly resolved peaks at 30 and $3.5 \mathrm{ppm}$. The broadening effect is probably due to an aluminium-phosphate phase $\left(\mathrm{Al}\left(\mathrm{PO}_{4}\right)\right)$. 
The ${ }^{29}$ Si MAS NMR spectrum of the unheated sample (Fig. 5.26), has its major peak at -90.5 ppm indicating 4-coordinated silicon in $\mathrm{Q}^{4}(3 \mathrm{Al})$ units typical of a geopolymer. The small peak at about -107 ppm arises from unreacted silica $\left(\mathrm{Q}^{4}(0 \mathrm{Al})\right.$ and $\mathrm{Q}^{4}(1 \mathrm{Al})$ sites $)$, probably due to the quartz impurity. The shoulder on the major peak at about -100 ppm may indicate the presence of silicon in $\mathrm{Q}^{4}(1 \mathrm{Al})$ and $\mathrm{Q}^{4}(2 \mathrm{Al})$ sites. Similar results were found for samples both before and after exposure to SBF, which show ${ }^{29} \mathrm{Si}$ spectra similar to Figure 5.26 .

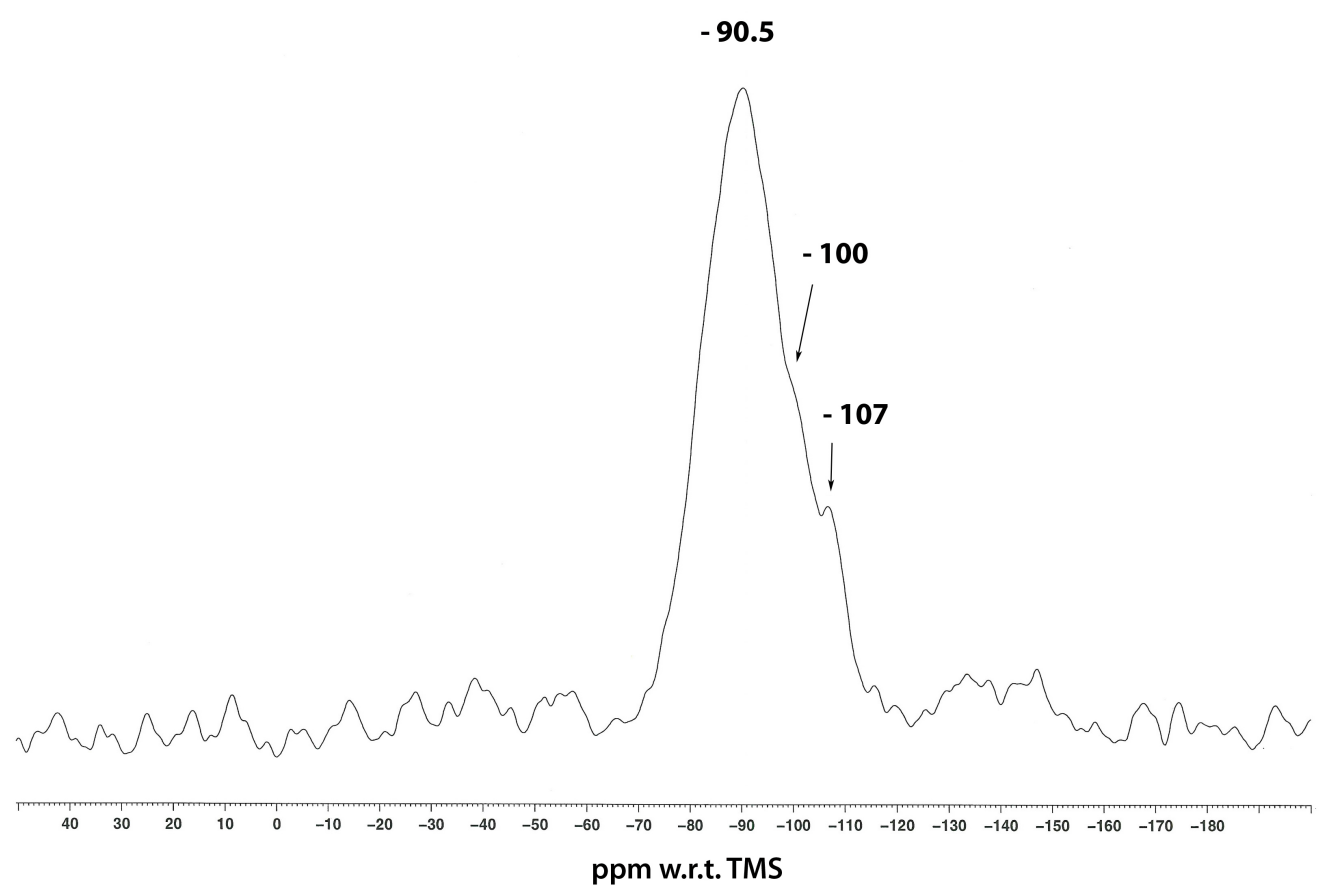

Figure 5.26: $11.7 \mathrm{~T}^{29}$ Si MAS NMR spectrum of a geopolymer containing $10 w t \%$ calcium phosphate. 
The ${ }^{29} \mathrm{Si}$ MAS NMR spectra of calcium phosphate-containing geopolymers heated to $550^{\circ} \mathrm{C}$ and $600^{\circ} \mathrm{C}$ prior to exposure to simulated body fluid (Fig. 5.27), are slightly different to the ${ }^{29} \mathrm{Si}$ MAS NMR spectrum of the unheated sample (Fig: 5.26).

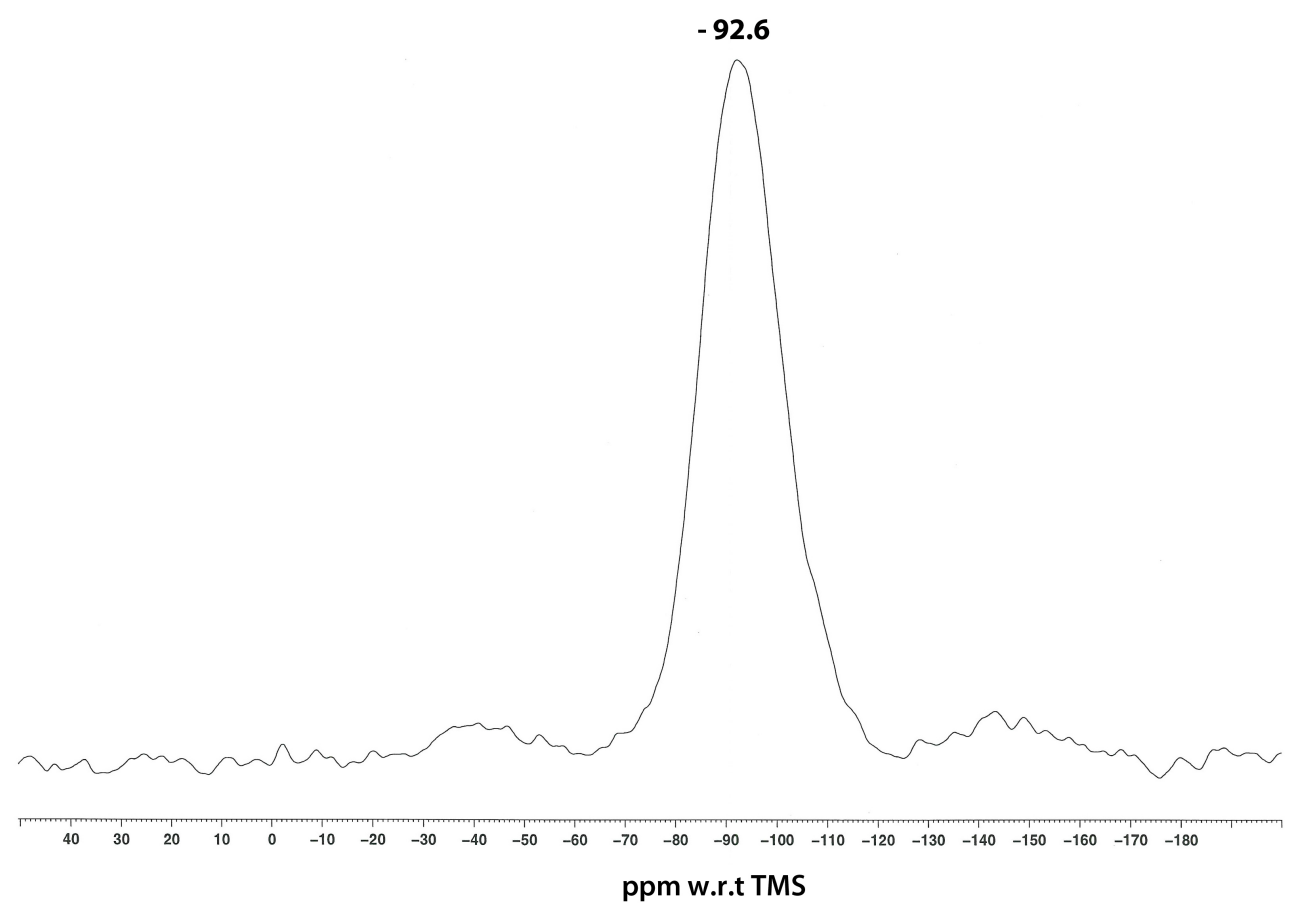

Figure 5.27: $11.7 T{ }^{29}$ Si MAS NMR spectrum of the geopolymer containing 10wt\% calcium phosphate heated to $550^{\circ} \mathrm{C}$.

The single peak at -92.6 ppm is typical of predominantly $\mathrm{Q}^{4}(3 \mathrm{Al})$ geopolymer units. A similar ${ }^{29}$ Si MAS NMR spectrum is found for the sample heated to $550^{\circ} \mathrm{C}$ after exposure to SBF. 
However, as shown in Figure 5.28, after the in-vitro exposure experiments of the calcium phosphate-containing geopolymer heated to $600^{\circ} \mathrm{C}$, the ${ }^{29}$ Si MAS NMR spectrum appears slightly different from that of the unexposed geopolymer, showing a sharp peak at -93.7 ppm and slight shoulders at $-100 \mathrm{ppm}$ and $-107 \mathrm{ppm}$. These features indicate the presence of silicon in predominantly $\mathrm{Q}^{4}(3 \mathrm{Al})$ sites, together with some unreacted meta-halloysite and quartz impurities (silicon in $\mathrm{Q}^{4}(2 \mathrm{Al}), \mathrm{Q}^{4}(1 \mathrm{Al})$ and $\left.\mathrm{Q}^{4}(0 \mathrm{Al})\right)$, .

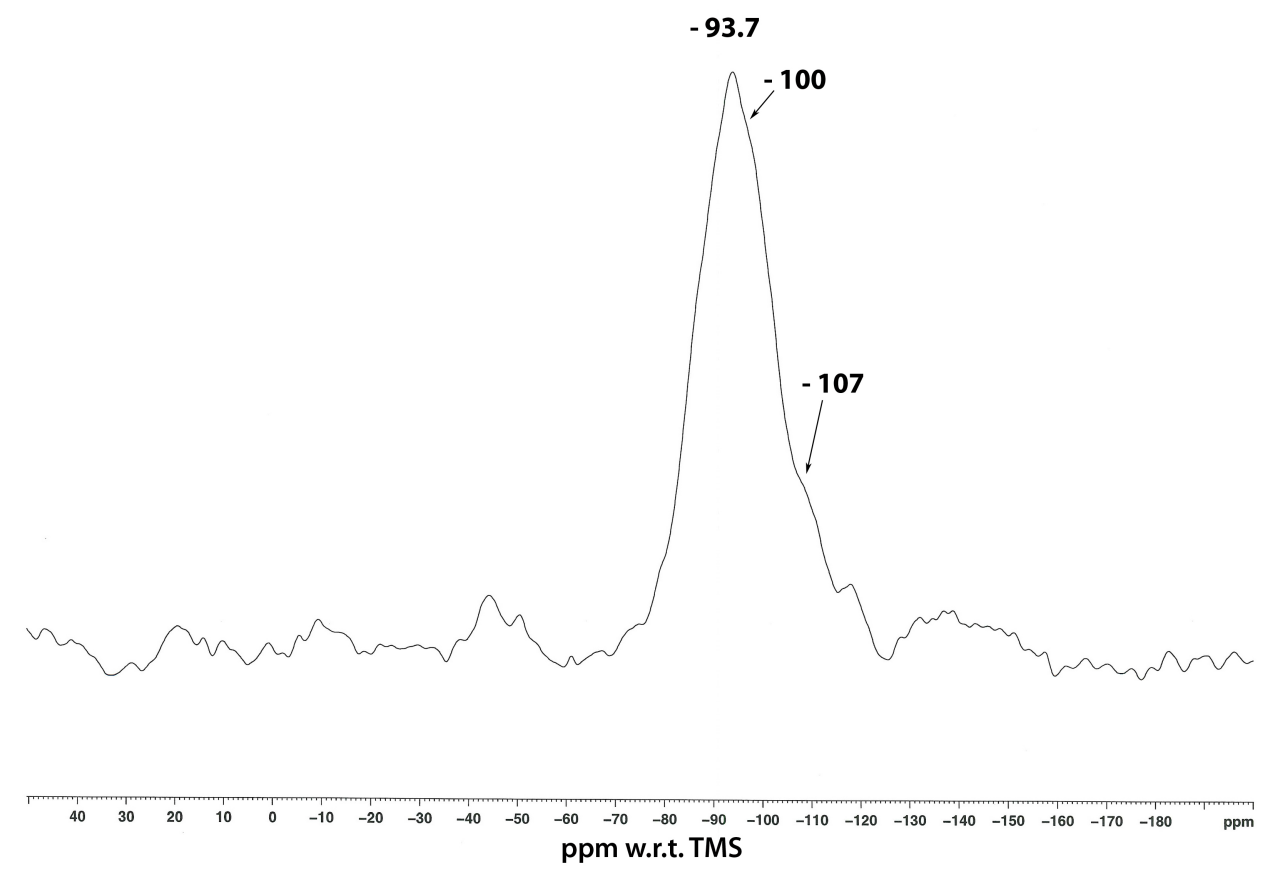

Figure 5.28: $11.7 \mathrm{~T}{ }^{29} \mathrm{Si}$ MAS NMR spectrum of the $10 \mathrm{wt} \%$ calcium phosphatecontaining geopolymer heated to $600^{\circ} \mathrm{C}$, after seven weeks SBF exposure. 


\section{Summary}

- ${ }^{27} \mathrm{Al}$ MAS NMR and ${ }^{29} \mathrm{Si}$ MAS NMR of all the geopolymers show the presence of tetrahedral aluminium and silicon.

- Heating the samples to $550^{\circ} \mathrm{C}$ and $600^{\circ} \mathrm{C}$ to lower their $\mathrm{pH}$ does not affect the geopolymer structure.

- Exposure to simulated body fluid does not change the geopolymer structure of any of the samples. 


\subsection{2 $\quad{ }^{34}$ Ca MAS NMR of calcium phosphate geopolymers}

This section presents the natural abundance ${ }^{43} \mathrm{Ca}$ MAS NMR results for all the geopolymers containing $10 \mathrm{wt} \%$ of calcium phosphate, including the unheated sample, samples heated to $550^{\circ} \mathrm{Cand} 600^{\circ} \mathrm{C}$, and these samples after the in-vitro exposure experiments. The ${ }^{34} \mathrm{Ca}$ MAS NMR spectra are shown in Figure 5.29, and the peak positions and additional information listed in Table 5.4 .

Table 5.4: ${ }^{43} \mathrm{Ca} M A S$ NMR shifts of the centre-of-gravity $\left(\delta_{C O G}\right)$ of calcium phosphatecontaining geopolymers, uncertainties in brackets.

\begin{tabular}{||l||c||c||c||}
\hline \hline Sample & $\delta_{C O G}(\mathrm{ppm})$ & peak width (Hz) & no. of scans \\
\hline \hline unheated & $-11(4)$ & $1260(100)$ & 59227 \\
\hline $\begin{array}{l}\text { unheated, } \\
4 \text { weeks SBF exposure }\end{array}$ & $-11(4)$ & $1600(100)$ & 108585 \\
\hline heated $550^{\circ} \mathrm{C}$ & $-4(4)$ & $1500(100)$ & 117824 \\
\hline $\begin{array}{l}\text { heated } 550^{\circ} \mathrm{C}, \\
4 \text { weeks SBF exposure }\end{array}$ & $-4(4)$ & $1000(100)$ & 113617 \\
\hline heated $600^{\circ} \mathrm{C}$ & $-7(4)$ & $1400(100)$ & 116903 \\
\hline $\begin{array}{l}\text { heated } 600^{\circ} \mathrm{C}, \\
4 \text { weeks SBF exposure }\end{array}$ & $-7(4)$ & unmeasured & 106798 \\
\hline \hline
\end{tabular}

All the ${ }^{43} \mathrm{Ca}$ MAS NMR spectra show almost identical results before SBF exposure. However, there are slight variations in the peak positions (Tab. 5.4); the ${ }^{43} \mathrm{Ca}$ peak of the unheated geopolymer is at about $-5 \mathrm{ppm}$ 


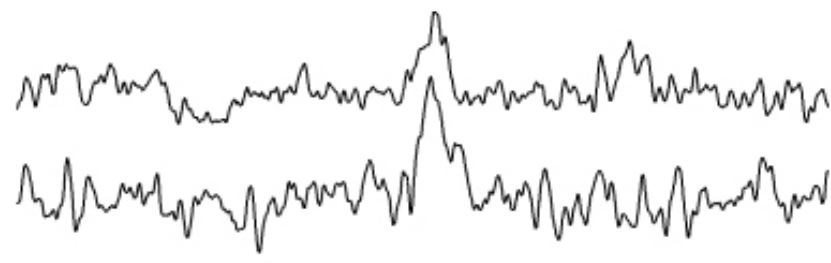

unheated, before

SBF exposure

unheated, 4 weeks

SBF exposure

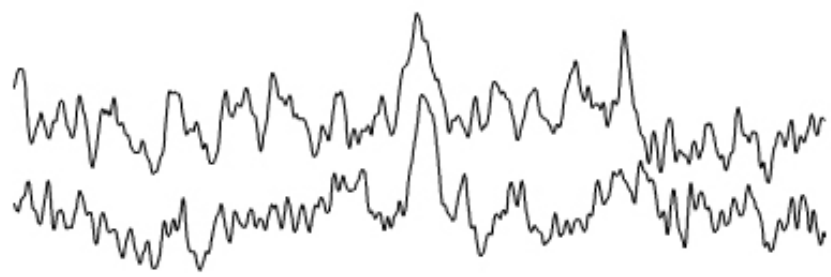

$550^{\circ} \mathrm{C}$, before

SBF exposure

$550^{\circ} \mathrm{C}, 4$ weeks

SBF exposure

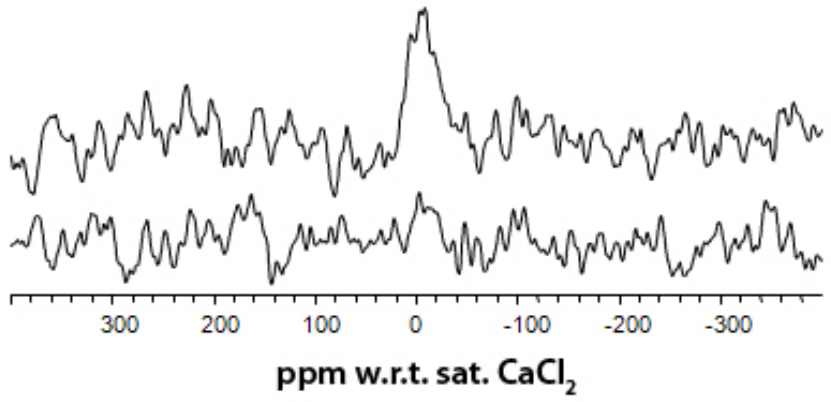

$600^{\circ} \mathrm{C}$, before

SBF exposure

$600^{\circ} \mathrm{C}, 4$ weeks

SBF exposure

Figure 5.29: $14.1 T^{43} \mathrm{Ca}$ MAS NMR spectra of calcium phosphate-containing geopolymers before and after SBF exposure

while it is about $-10 \mathrm{ppm}$ in both the heated samples. The quality of these spectra (noise and broadness) reflects the extreme difficulty in obtaining natural abundance ${ }^{34} \mathrm{Ca}$ NMR spectra (the natural abundance of ${ }^{34} \mathrm{Ca}$ is $0.135 \%$ ). Therefore, these peak positions represent the centre-of-gravity $\left(\delta_{C O G}\right)$ of the resonance. These peak positions are very similar to those previously published for samples containing 30 and $50 \mathrm{wt} \%$ calcium phosphate (-6 to -7 ppm [24]).

Since the number of scans in each case is very similar, the peak heights 
should provide an approximate indication of the amount of calcium detected in each sample. These show that apart from the sample heated to $600^{\circ} \mathrm{C}$ and exposed to SBF, the amounts of calcium (and their peak positions) are unchanged by heating or SBF exposure. In the case of the sample heated to $600^{\circ} \mathrm{C}$ and exposed to SBF, the absence of calcium suggests it must have leached out of the material. Another possible reason for its disappearance is that it is distributed over a large number of sites corresponding to a number of environments, as in a gel. This gel is not calcium-silicate-hydrate (C-S-H) gel, however, since this has a peak of similar widths to the present spectra, but centred at $14.6 \mathrm{ppm}$ [24].

This result is peculiar and cannot be explained by ICP analysis nor by SEM/ EDS observations. ICP analysis (section5.5) shows that the calcium phosphate-containing geopolymer absorbs the calcium of the simulated body fluid. EDS analysis of an identical sample shows the presence of calcium, distributed mostly homogeneously (section 5.6.4).

\subsection{Alteration of the $\mathrm{pH}$ of the SBF}

The $\mathrm{pH}$ values of the simulated body fluid, during the in-vitro exposure experiments, changed significantly within the first four hours of all experiments, then became stable. All the in-vitro experiments began at $\mathrm{pH}$ of 7.4 . 


\subsubsection{Behaviour of the reference and calcium phosphate geopolymers in SBF}

Exposure to SBF of the reference geopolymer and calcium phosphate-containing geopolymer samples resulted in similar $\mathrm{pH}$-development patterns, shown in Figure 5.30 for the reference geopolymer and Figure 5.31 for the calcium phosphate-containing geopolymer.

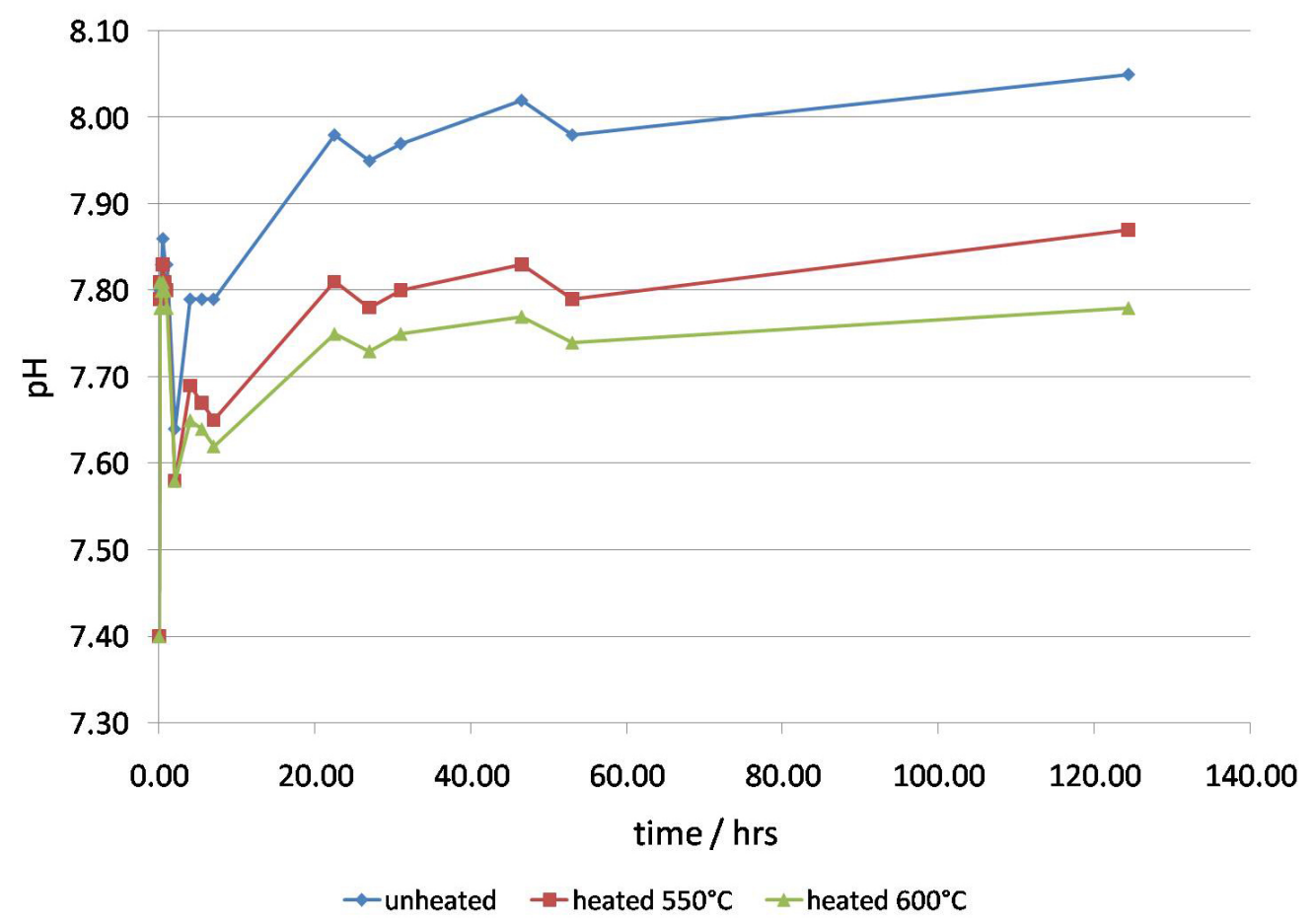

Figure 5.30: Changes of the $p H$ of the SBF during exposure of the reference geopolymers.

The highest $\mathrm{pH}$ values of the SBF solution were recorded for the unheated reference and calcium phosphate-containing samples $(\approx 8$ and 8.2 respectively). In-vitro exposure experiments on the reference and calcium phosphate-containing geopolymers heated to $550^{\circ} \mathrm{C}$ produced $\mathrm{pH}$ values 


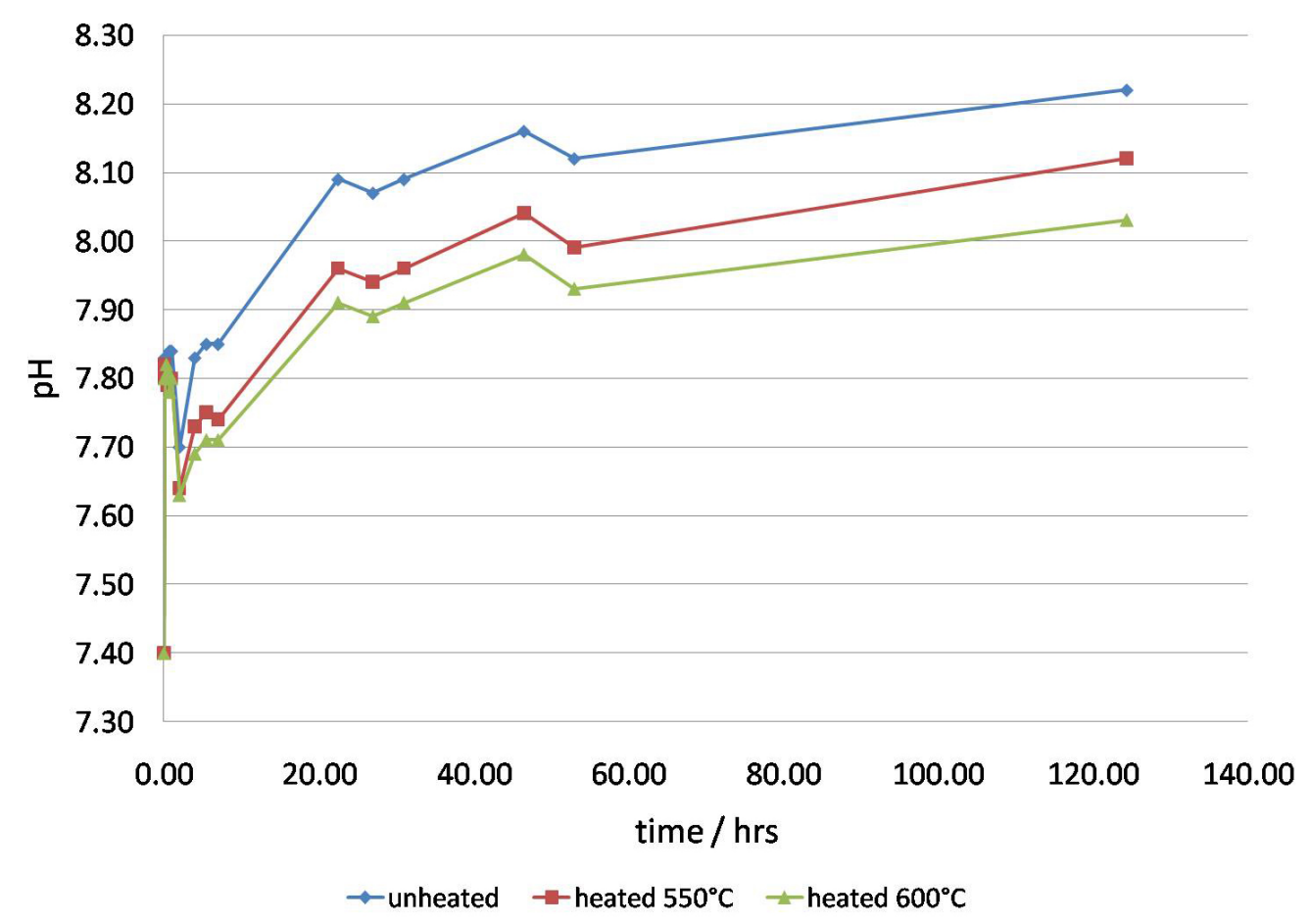

Figure 5.31: Changes of the $p H$ of the SBF during exposure of the calcium phosphatecontaining geopolymers.

of 7.9 and 8.1 respectively. The measured $\mathrm{pH}$ of the solution containing samples heated to $600^{\circ} \mathrm{C}$ decreased only slightly by $\mathrm{pH}$ of 0.1 . All these solutions showed a slight increase in the $\mathrm{pH}$ between 4 and 30 hours. Thereafter, the $\mathrm{pH}$ of the simulated body fluid of the reference geopolymer heated to $600^{\circ} \mathrm{C}$ remained stable $(\approx 7.8)$, but all the other fluids showed a further small increase of the $\mathrm{pH}$ of approximately 0.1 units until the end of the experiments after 125 hours. 


\subsubsection{Behaviour of the calcium hydroxide geopolymers in SBF}

The $\mathrm{pH}$ of the simulated body fluid during in-vitro exposure experiments of calcium hydroxide-containing geopolymers is shown in Figure 5.32 .

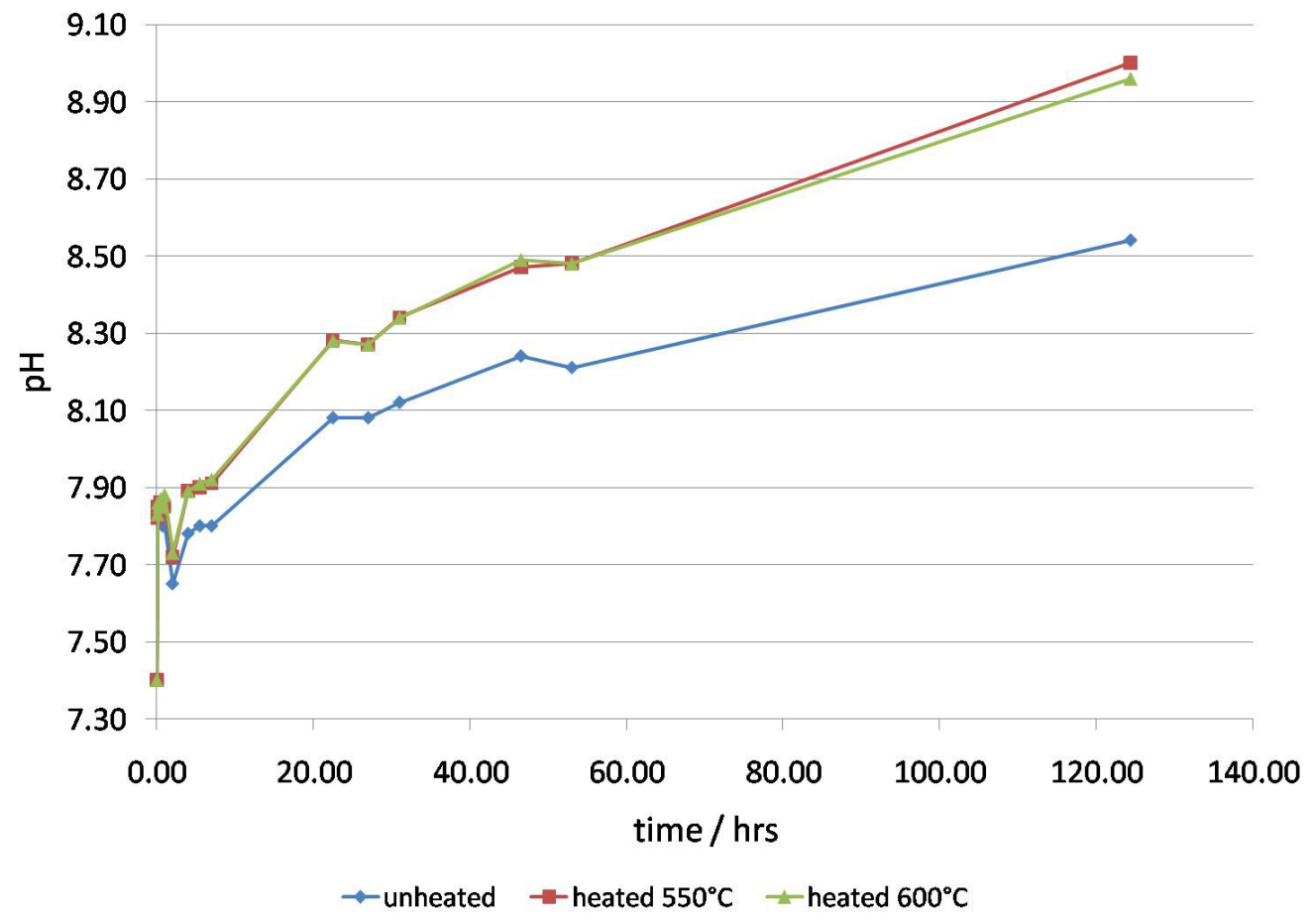

Figure 5.32: Changes of the $p H$ of the SBF during exposure of the calcium hydroxidecontaining geopolymers.

Samples heated to $550^{\circ} \mathrm{C}$ and $600^{\circ} \mathrm{C}$ affected the solution equally and produced slightly higher $\mathrm{pH}$ values $(\approx 9)$ compared with the unheated sample $(\approx 8.5)$. The curves are almost parallel in the early stages and increase more steeply during the first 24 hours to $\mathrm{pH} 8$ and 8.3 for the unheated and heated samples respectively. This is followed by a steady 
increase of the $\mathrm{pH}$, reaching values of $\approx 9$ and 8.5 after 125 hours, when the experiments were stopped.

\subsubsection{Behaviour of the calcium silicate geopolymers in SBF}

The $\mathrm{pH}$ changes of the SBF during in-vitro exposure experiments of calcium silicate-containing geopolymers are shown in Figure 5.33 .

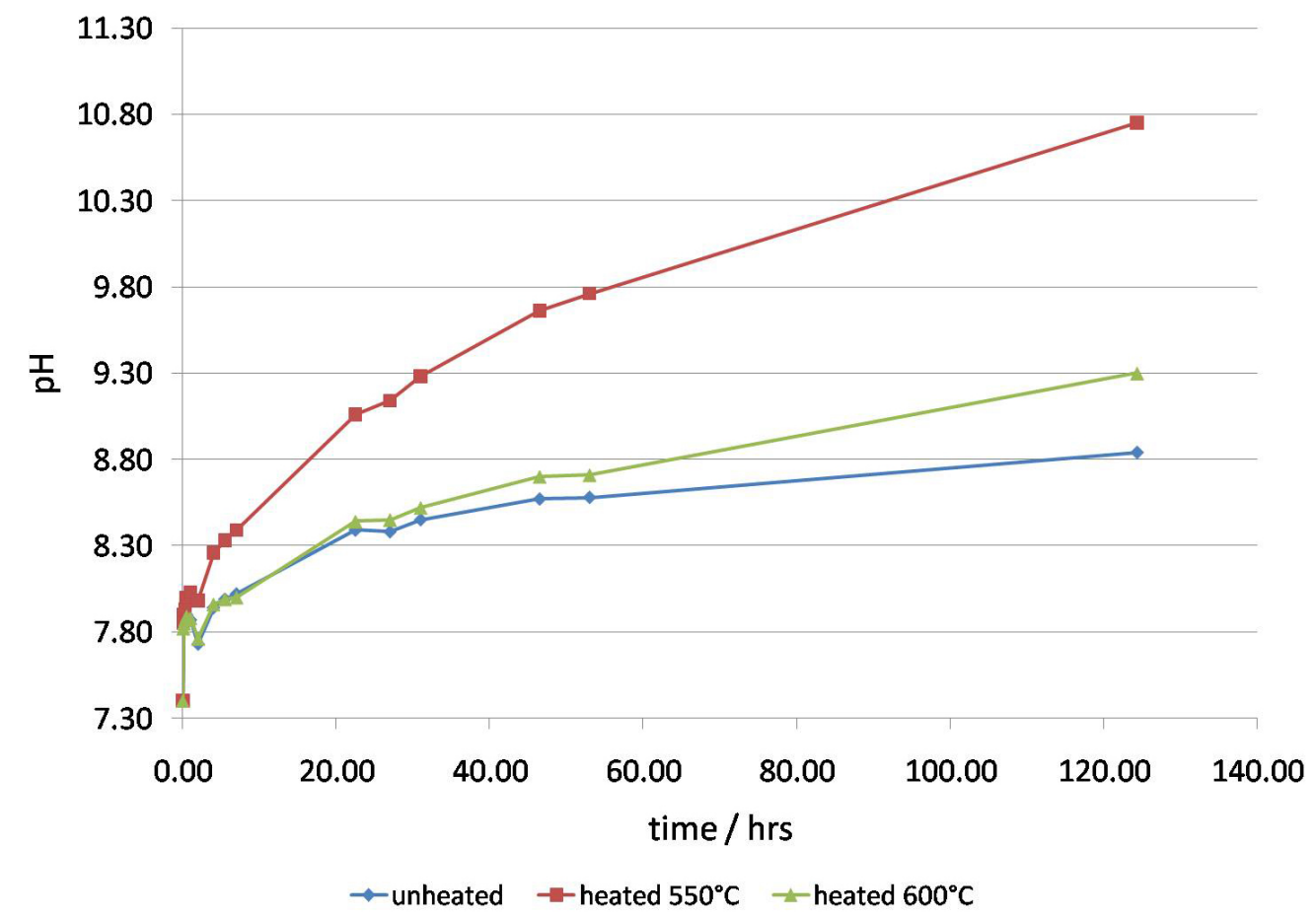

Figure 5.33: Changes of the $p H$ of the SBF during exposure of the nano structured calcium silicate-containing geopolymers.

The unheated sample and the sample heated to $600^{\circ} \mathrm{C}$ behave similarly, producing $\mathrm{pH}$ values of approximately 8.8 and 9.3 respectively, after 125 
hours. The solution of these exposed samples produce a significant increase in the $\mathrm{pH}$ within the first 24 hours followed by a slower increase until the experiments were ended after 125 hours. The $\mathrm{pH}$ of the SBF solution containing the sample heated $550^{\circ} \mathrm{C}$ behaves differently, showing a steadily increasing $\mathrm{pH}$ to 9.8 after 53 hours of exposure, followed by a slower $\mathrm{pH}$ increase to $\approx 10.8$ until the ending of the experiment. However, this $\mathrm{pH}$ behaviour might be due to the fact that the sample broke into two pieces when initially exposed to the SBF.

All the diagrams of the $\mathrm{pH}$-measurements presented in this section show minor fluctuations in the $\mathrm{pH}$ during the experiments. These trends can probably be referred to the re-calibration of the $\mathrm{pH}$-meter before each measurement. The fluctuations are within the $\mathrm{pH}$-meter's accuracy $( \pm 0.03$ $\mathrm{pH}$ ) and can be left unattended. This phenomenon is most noticeable in Figures 5.30 and 5.31 due to the $\mathrm{pH}$-scale used here.

Immersion of all the geopolymers in SBF led to reaction between the material and the solution. The samples containing calcium hydroxide and nano-structured calcium silicate underwent the most obvious reaction. The calcium hydroxide-containing geopolymers released a considerable quantity of gas, which was possibly air present in the pores of the samples being displaced by the SBF solution. This led to the development of minor cracks whereas the geopolymers containing calcium silicate not only released gas bubbles but fell to pieces. Minor gas release without cracking of the sample was noticed for the reference geopolymer and the geopolymer containing calcium phosphate after their immersion in simulated body fluid. 
These observations may explain the higher $\mathrm{pH}$ values measured for the samples containing calcium hydroxide and calcium silicate, since cracking of the samples leads to an increased sample surface and thus a larger area exposed to the SBF. The significantly higher alkalinity of the SBF produced by the exposure of the calcium silicate-containing geopolymers may also be explained by the higher content of alkaline potassium hydroxide (section 3.3.1).

The lower $\mathrm{pH}$ values measured when calcium phosphate geopolymers were exposed can also be explained by the solubility of the calcium phosphate in alkaline conditions in aqueous media reported by Hench [16]. He quoted that the stable calcium phosphate phase at $\mathrm{pH}>4.2$ is hydroxyl apatite. Unhydrated, high-temperature calcium phosphate phases, such as tri-calcium phosphate, interact with water, or body fluids at $37^{\circ} \mathrm{C}$ to form hydroxyl apatite. Thus, the solubility of a tri-calcium phophate (TCP) surface approaches the solubility of hydroxyl apatite and decreases the $\mathrm{pH}$ of the solution [16].

According to these results, the reference geopolymer and the calcium phosphate-containing geopolymer both show that an increase in the heating temperature results in a lowering of the $\mathrm{pH}$. Similar results have been reported previously showing that $\mathrm{pH}$-values of approximately 7 can be achieved in geopolymers heated to $500^{\circ} \mathrm{C}$ (Oudadesse et al. [11], [3]). However, different geopolymer powder compositions and distilled water were used for their experiments, which are therefore not directly comparable.

The reference and the calcium phosphate-containing geopolymer heated to $600^{\circ} \mathrm{C}$ showed the best results, in terms of both $\mathrm{pH}$ and material 
stability when exposed to SBF. Both materials provide the lowest $\mathrm{pH}$ of all the samples $(\approx 8)$. The calcium-phosphate containing geopolymer was chosen for further studies by ${ }^{43}$ Ca MAS NMR (section 5.3.2).

\subsection{ICP analysis of the SBF after expo- sure of the geopolymers}

Results of inductively coupled plasma analysis are shown in this section. The simulated body fluid to which geopolymers heated to $600^{\circ} \mathrm{C}$ were exposed was chosen for this work. It should be noted that the simulated body fluid was renewed every two weeks but was analysed weekly. The analysed elements were calcium $(\mathrm{Ca})$, phosphorus $(\mathrm{P})$, silicon $(\mathrm{Si})$, aluminium ( $\mathrm{Al})$ and potassium (K). 


\subsubsection{Phosphorus analysis}

As shown in Figure 5.34, all samples absorb the phosphorus present in the simulated body fluid during the in-vitro experiment.

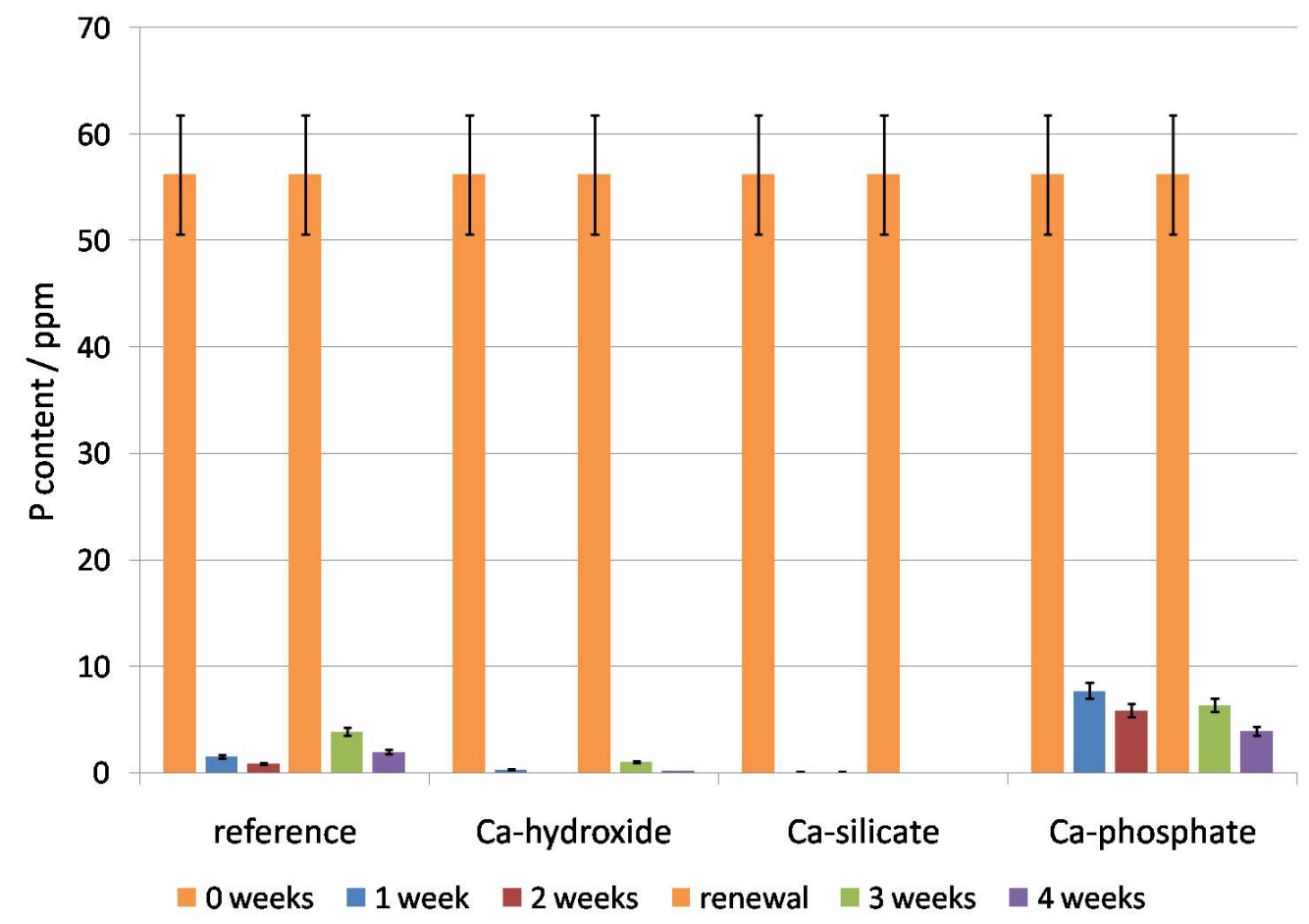

Figure 5.34: ICP results of phosphorus content in SBF after various exposure times.

The original content of phosphorus in the simulated body fluid is drastically reduced after one and two weeks exposure time regardless of the calcium compound in the geopolymer. In the first two weeks, the calcium hydroxide and calcium silicate geopolymer composites absorbed almost all of the phosphorus, but 1 - 6 ppm of phosphorus remained in the solution to which the reference and the calcium phosphate geopolymer were exposed. After renewal of the SBF, the phosphorus present after the second two weeks of exposure is slightly higher than the amount of phos- 
phorus absorbed in the first two weeks, but the rate of absorption is also slightly higher than in the first two weeks; the phosphorus present in the SBF decreased by at least $50 \%$ to $60 \%$ in the second exposure period by comparison with a $25 \%$ to $30 \%$ decrease during the first two weeks. This increase in the absorption of phosphorus may be due to changes in the material during the first exposure period. The possibility of a change in the structure, cannot be excluded e.g. an increase in the porosity or the formation of a calcium phosphate phase (section 5.2.3 and 5.2.4) which would deplete the phosphorus in solution. However, the formation of new phases in the reference geopolymer and the calcium phosphate-containing geopolymer was not confirmed by $\mathrm{x}$-ray diffraction. 


\subsubsection{Aluminium analysis}

The results of the ICP analysis for the aluminium contents of the simulated body fluid are shown in Figure 5.35

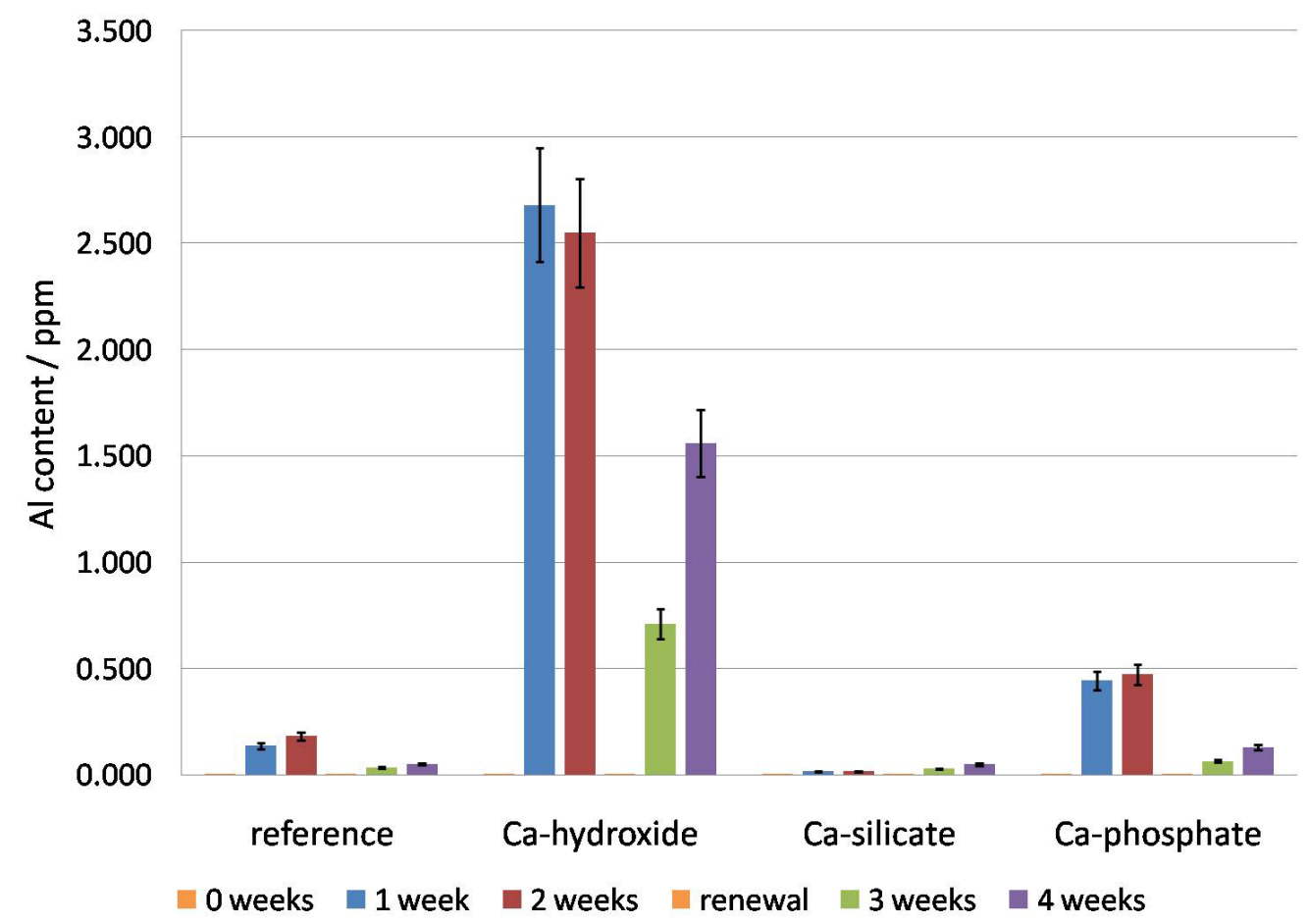

Figure 5.35: Aluminium concentration in SBF after exposure of the various geopolymers for various times.

This shows all the geopolymers release some aluminium during exposure, and although aluminium is not detectable in the SBF (orange bar absent) the calcium hydroxide geopolymer releases considerably more aluminium than the other geopolymers. In case of the calcium hydroxide geopolymer, more aluminium is released into the SBF after the first week $(\approx 2.7 \mathrm{ppm})$ than during the second week $(\approx 2.5 \mathrm{ppm})$. This drop in the aluminium content may be due to reabsorption by the geopolymer. How- 
ever, renewing the SBF after the second week produces a steady increase in the aluminium released, a trend also seen in the other geopolymers.

The lowest results in terms of aluminium release were found for the calcium silicate-containing geopolymers, in which traces of aluminium, ( 0.015 and $0.016 \mathrm{ppm})$ could be detected after one and two weeks exposure time, respectively. However, renewal of the SBF led to the leaching of slightly higher amounts of aluminium (0.027 and $0.049 \mathrm{ppm})$ during the following two weeks.

Similar trends are seen in the behaviour of the reference geopolymer and the calcium phosphate-containing geopolymer. Most aluminium is released after the first two weeks, only slight differences being seen after one week. After replacement of the SBF, the aluminium concentrations increased only slightly possibly because most of the soluble aluminium was removed within the first two-week period.

The aluminium concentrations removed from these samples by the SBF are relatively low. However, it has been reported by Hantson that aluminium concentrations of less than $0.1 \mathrm{ppm}$ in cerebrospinal fluid (CSF), after use of an aluminium-containing cement led to serious brain diseases [21]. Thus, because it has also been reported by Yap that minor release of aluminium is beneficial for new bone formation and to determine the biocompatibility, the literature on aluminium toxicity in humans is contradictory [19]. 


\subsubsection{Calcium analysis}

The results of the Ca analysis of the SBF are shown in Figure 5.36 .

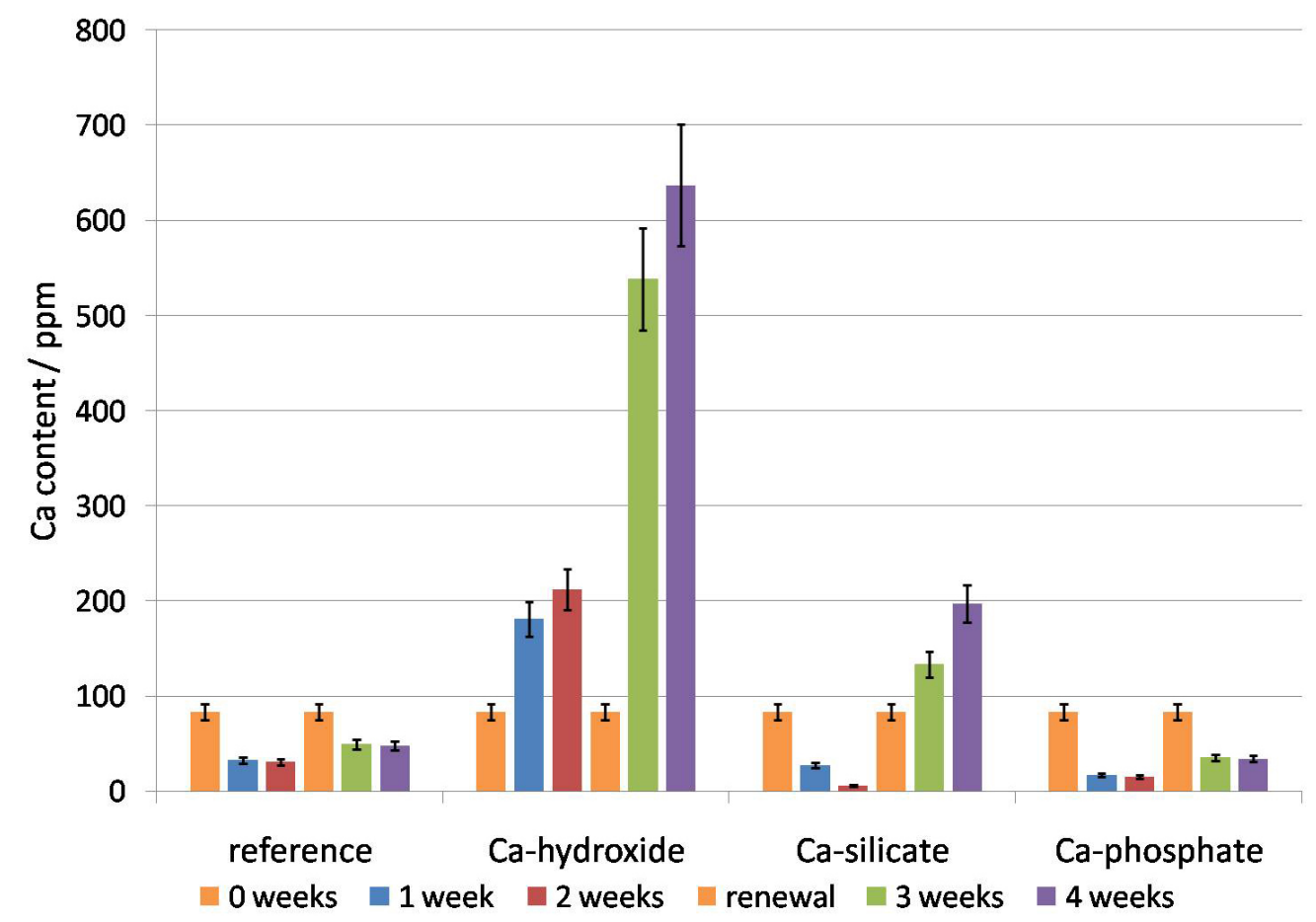

Figure 5.36: Calcium concentration in SBF after exposure of the various geopolymers for various times.

The calcium silicate-containing geopolymer absorbs calcium during the first two weeks of the in-vitro experiment, indicated by the reduced calcium concentration in the SBF. After renewing the solution, the same geopolymer apparently re-releases calcium to the solution, evidenced by the relative increase of the calcium content of the SBF. This unusual behaviour could indicate the formation of an insoluble calcium compound or x-ray amorphous gel on the surface of the sample (or the absorption of $\mathrm{Ca}^{2+}$ from the solution by the geopolymer during the initial exposure 
period. When the concentration of $\mathrm{Ca}^{2+}$ is subsequently increased by the renewal of the $\mathrm{SBF}$, the equilibrium is disturbed and the reaction is reversed.

Exposure of calcium hydroxide containing geopolymers leads to an increase of calcium in the SBF throughout the experiment. Replacing the SBF leads to an even quicker increase in the calcium concentration, the calcium content was about $200 \mathrm{ppm}$ after one to two weeks, increasing to > 500 $600 \mathrm{ppm}$ after one and two weeks since the solution was changed.

The reference geopolymer and the calcium phosphate-containing geopolymer both show similar behaviour when exposed to simulated body fluid. The calcium concentration in the solution decreases throughout the experiment, although the geopolymer containing calcium phosphate takes up more calcium. During the first two weeks before the replenishment of the SBF, the calcium concentrations decreased to 30 and $15 \mathrm{ppm}$ for the reference and the calcium phosphate-containing geopolymers respectively. The concentrations of calcium in the SBF during the second stage of the exposure experiments dropped to 48 and $34 \mathrm{ppm}$ for the reference geopolymer and the geopolymer containing calcium phosphate respectively. Thus, the reference sample and that containing calcium phosphate both remove calcium from the SBF, whereas the geopolymer containing calcium hydroxide releases calcium to the SBF. The behaviour of the geopolymer containing calcium silicate is intermediate between these extremes initially removing the calcium from the SBF, then releasing it when the $\mathrm{Ca}^{2+}$ content is renewed. 


\subsubsection{Silicon analysis}

The results of ICP analysis of the simulated body fluid for silicon show that $4.4 \mathrm{ppm}$ of silicon is present in the original SBF solution (Fig. 5.37).

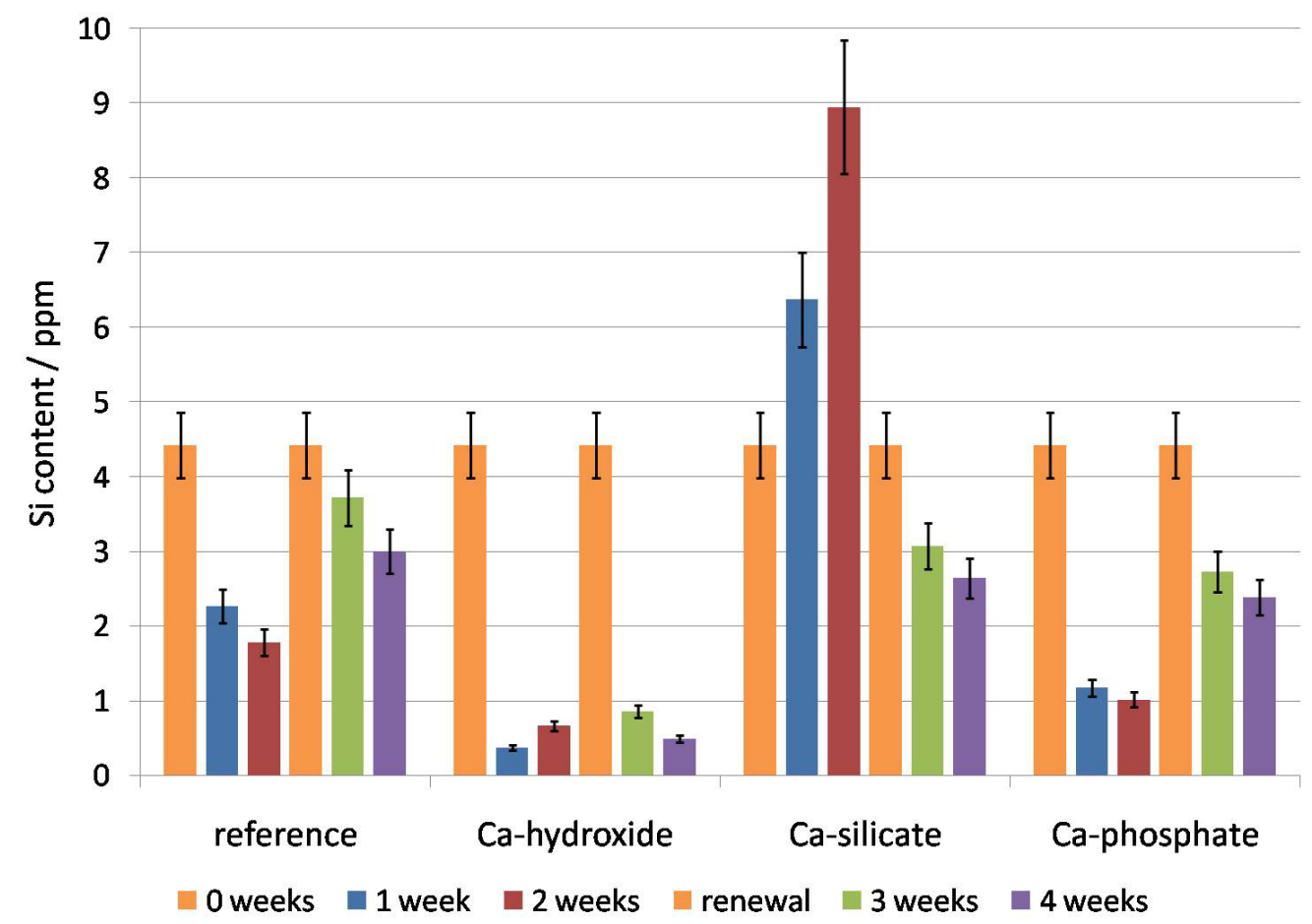

Figure 5.37: Silicon concentration in SBF after exposure of the various geopolymers for various times.

Since silicon is not part of the original formulation of the SBF, this must be an impurity, either present in one of the reagents or leached from the glass volumetric flask used to adjust the SBF volume.

Apart from the calcium silicate-containing sample, all samples absorb silicon from the solution, evidenced by the decreased amount of silicon. However, this absorption varies between the samples, the calcium hydroxide geopolymer taking up the most silicon and leaving $<1$ ppm silicon, 
regardless of whether or not the SBF was changed.

The reference geopolymer and the calcium phosphate-containing geopolymer show similar results whereas the calcium phosphate geopolymer absorbs about 1 ppm more silicon. Both geopolymers absorbed less silicon after the SBF had been changed, showing values of 3 and $2.3 \mathrm{ppm}$ for the reference and the calcium phosphate-containing geopolymer respectively, two weeks after the SBF change. This reduced absorption might be due to an increased saturation of silicon in the geopolymer sample.

The calcium silicate geopolymer releases silicon to the SBF, increasing the silicon concentration to about 6.3 and 9 ppm after one and two weeks respectively. Changing the SBF led to the absorption of silicon during the second stage of the experiment, during which the silicon concentration dropped from $4.4 \mathrm{ppm}$ to about 3.1 and $2.6 \mathrm{ppm}$ one and two weeks after the change of the solution.

Thus, of all geopolymers, only that containing nano-structured calcium silicate releases silicon to the SBF, possibly due to the presence of leachable silicate in this sample. The other samples are stable to silicon-containing solutions, but will absorb small amounts of available silicon, possibly by surface absorption.

Solubility data for HA and HCA in SBF at this $\mathrm{pH}$ are unavailable, neither has the solubility of calcium silicate in SBF been reported in the literature. However, an indication that the extent of leaching of both $\mathrm{Ca}$ and $\mathrm{Si}$ from the inorganic polymer materials is provided by the present experimental elemental concentrations in the SBF after the leaching experiment. 


\subsubsection{Potassium analysis}

The ICP results of the potassium analyse of the simulated body fluid are shown in Figure 5.38 .

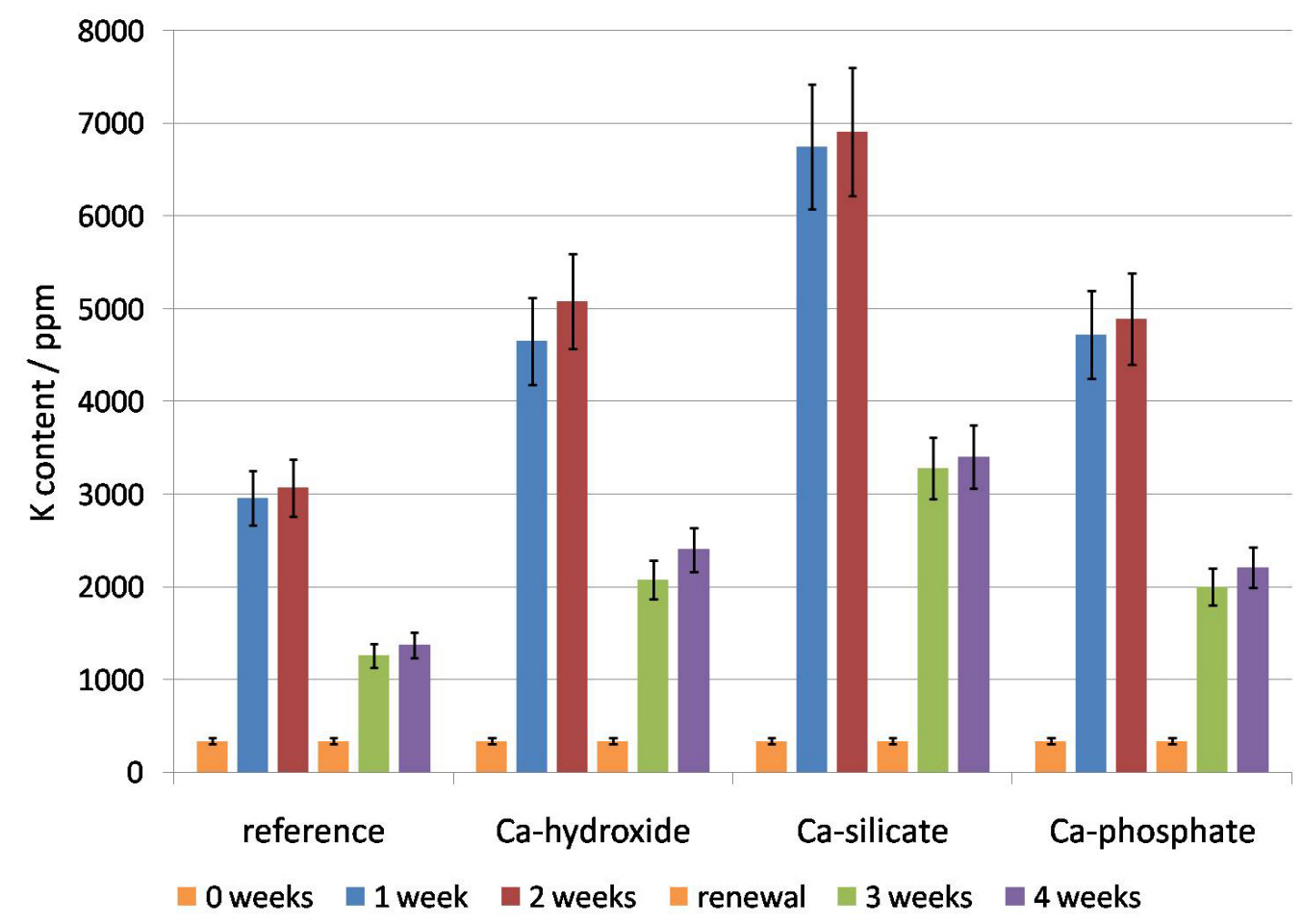

Figure 5.38: Potassium concentration in SBF after exposure of the various geopolymers for various times.

Potassium is leached from all the geopolymers increasing the potassium concentration of the SBF from its original value of about $340 \mathrm{ppm}$. After the change of simulated body fluid, the release of potassium drops by at least $50 \%$.

The highest amount of potassium is released by the calcium silicatecontaining geopolymer during the first two weeks. During this period, 
the potassium concentration reduced about 6800 - $6900 \mathrm{ppm}$ dropping to 3300 and 3400 ppm 1 - 2 weeks after the change of SBF.

The geopolymers containing calcium phosphate and calcium hydroxide show almost identical results. Both geopolymers increased the potassium concentration in the SBF up to about $5000 \mathrm{ppm}$ after the first two weeks but this concentration then decreased to about 2300 ppm two weeks after renewal of the SBF.

The lowest level of potassium into the SBF occurred with the reference geopolymer. Only $3000 \mathrm{ppm}$ potassium was leached out during the first two weeks, dropping further to about $1400 \mathrm{ppm}$ after change of the simulated body fluid.

Since potassium is associated with the presence of alkalinity in the geopolymers, these results correlate with the $\mathrm{pH}$ measurements presented in section 5.4. The $\mathrm{pH}$ measurements showed that the calcium silicatecontaining geopolymer produced the highest alkalinity, followed by the calcium silicate and calcium phosphate-containing geopolymers and the reference geopolymer respectively. Although the calcium hydroxide and the calcium phosphate geopolymers show almost identical leaching of potassium, the $\mathrm{pH}$ of the calcium hydroxide is slightly higher than that of the former ( $\mathrm{pH} 8.9$ and 8 respectively) possibly due to the additional content of the alkaline compound calcium hydroxide. 


\subsection{SEM results}

In this section, scanning electron images of geopolymers heated to $600^{\circ} \mathrm{C}$, before and after in vitro experiments are presented and interpreted.

Secondary electron imaging (SEI) was used for high resolution with a large depth of field whereas backscattered electron imaging (COMPO) was used for EDS analysis.

Generally, imaging of the synthesised geopolymers was often difficult as many of the specimens were charging causing a bright appearance of the sample without contrast. To minimise these issues various coating materials such as platinum, carbon and gold, and coatings of several layers were tried.

Carbon coating (12 nm thickness) was found not to be helpful in the SEI mode but was used for EDS analysis and imaging in backscattered mode. One of the better solutions for imaging in SEI mode was to use a relative thick layer of platinum or gold (18+ nm thickness). 


\subsubsection{Reference geopolymer}

\subsubsection{Before SBF exposure}

Scanning electron microscopy images of the reference geopolymer prior to SBF exposure show a typical geopolymer micro structure [46], [8]. Figure 5.39 gives an overview of an area of the sample surface after heating at $600^{\circ} \mathrm{C}$, the bright area on the right indicating charging problems. The few scratches on the surface remain after the grinding process.

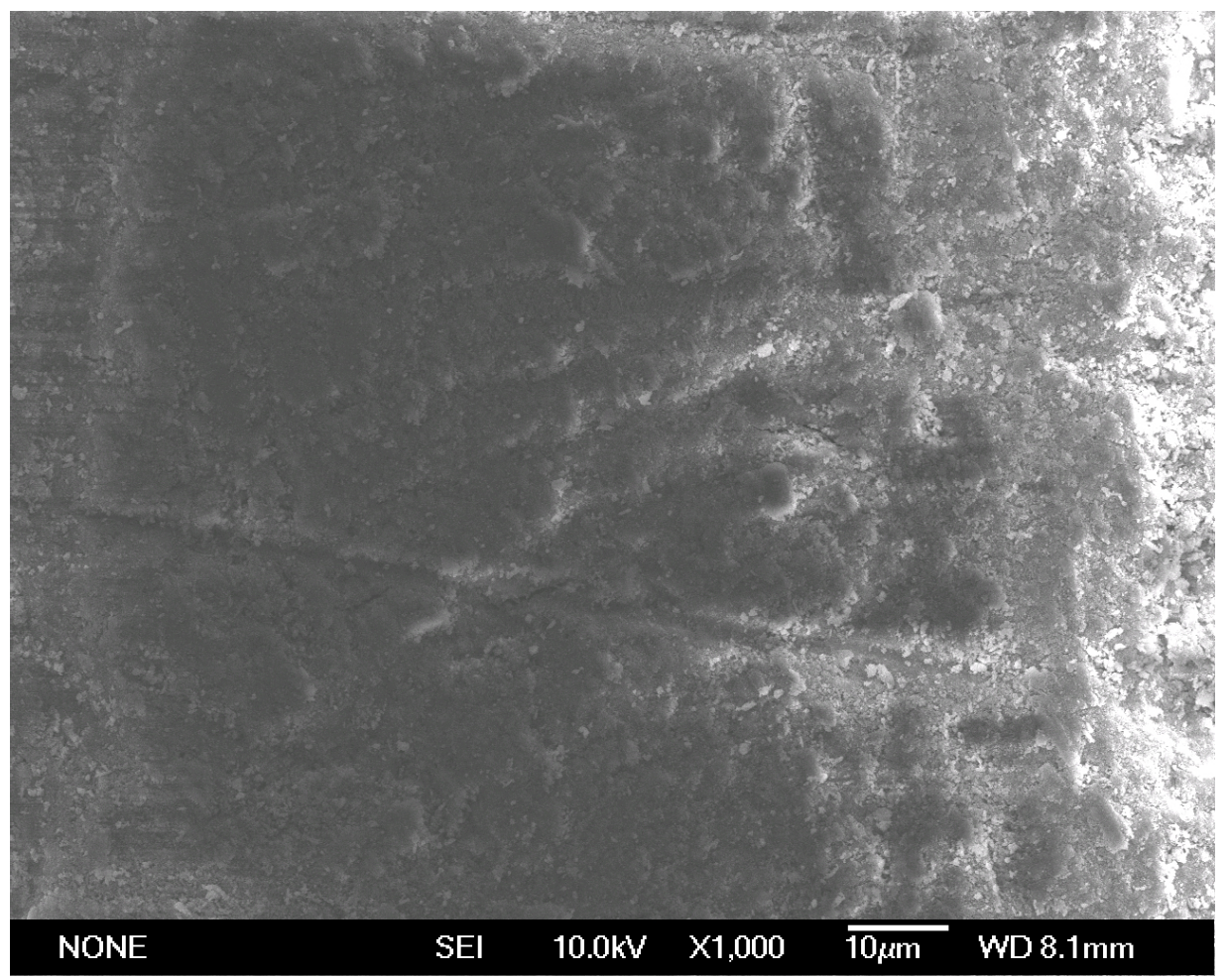

Figure 5.39: SEM micrograph of the reference geopolymer heated to $600^{\circ} \mathrm{C}, x 1000$. 
At higher magnifications (Fig. 5.40), a nanoporous structure and fine ball-like agglomerates become visible. The agglomerates vary in sizes between $<100 \mathrm{~nm}$ to $>1 \mu \mathrm{m}$. The bright spots are due to charging of the sample.

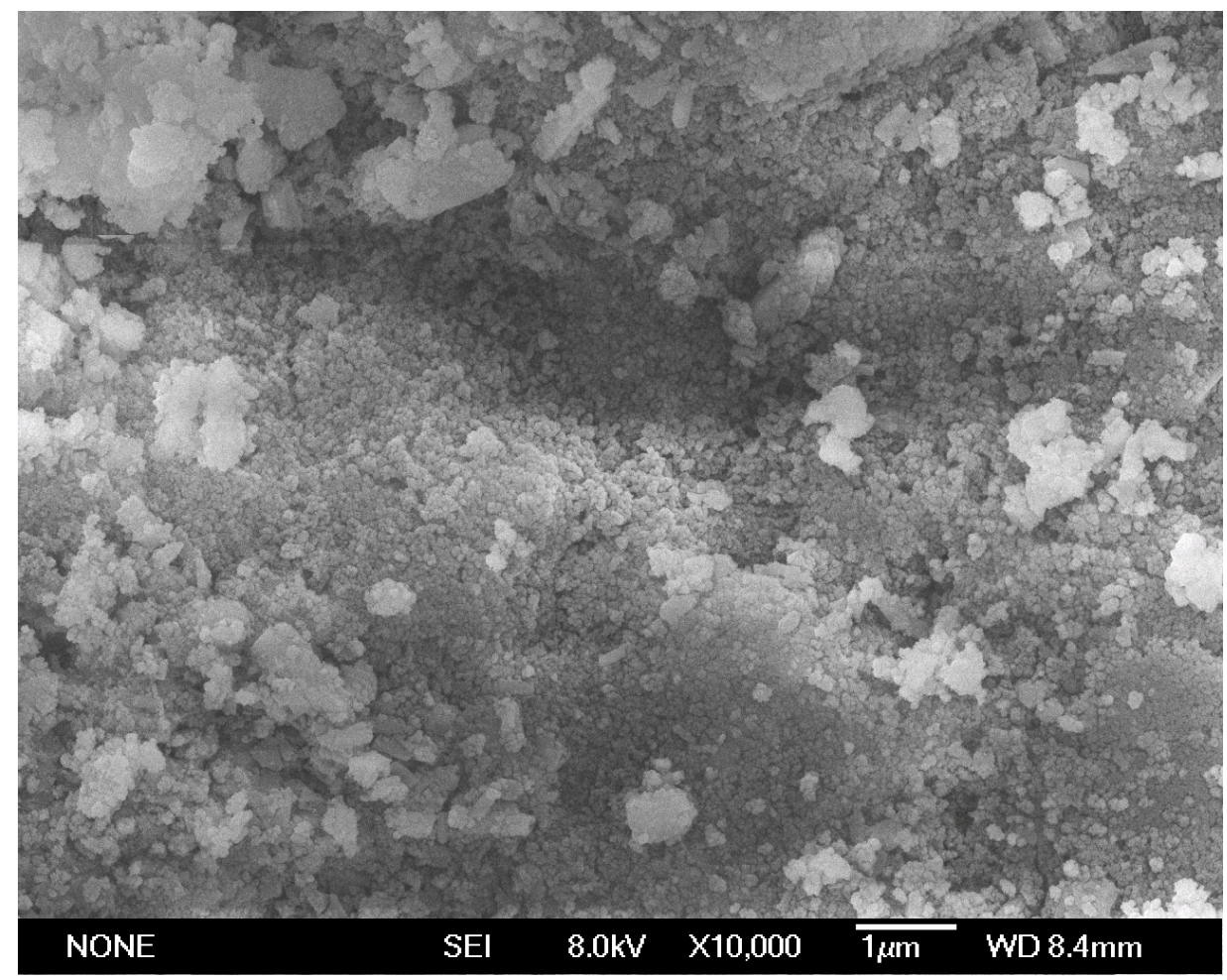

Figure 5.40: SEM micrograph of the reference geopolymer heated to $600^{\circ} \mathrm{C}, x 10 \mathrm{k}$. 
At a still higher magnification $(x 30,000)$ (Fig. 5.41) small ball shaped particles and a fine porous network can be seen. The single particles forming the agglomerates are sized 20 - $50 \mathrm{~nm}$ whereas the main pore network consists of pores $<10 \mathrm{~nm}$ but with a few larger pores of 100 to $200 \mathrm{~nm}$.

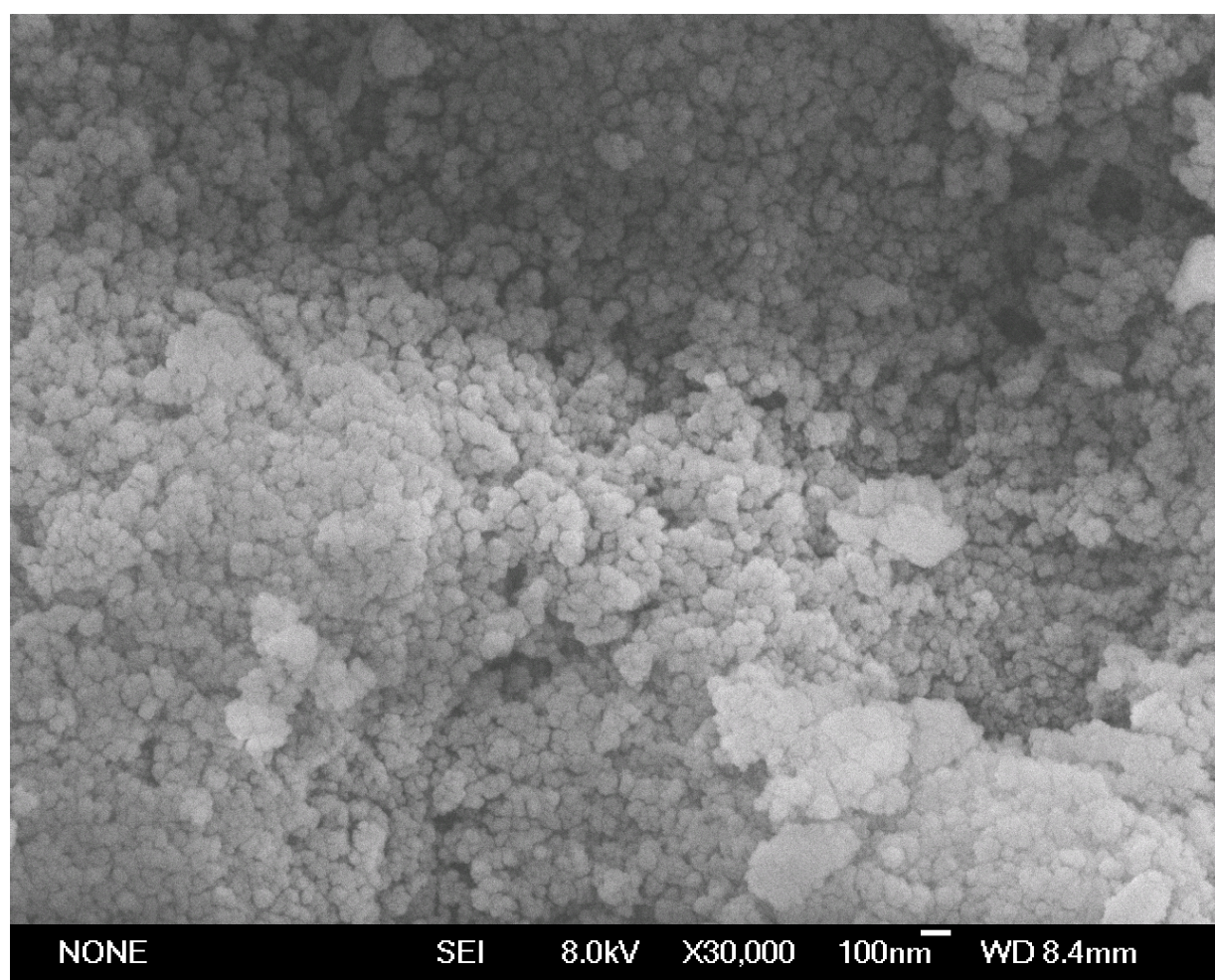

Figure 5.41: SEM micrograph of the reference geopolymer heated to $600^{\circ} \mathrm{C}, x 30 \mathrm{k}$.

EDS analysis of the reference geopolymer sample (Fig. 5.42) shows the presence of some areas with higher potassium concentrations. Aluminium and silicon are well distributed throughout the material. The concentrations of potassium are difficult to explain because the potassium-compounds were completely dissolved before the other reagents were added, followed by thorough stirring to a homogeneous paste. This result suggests a separation of the potassium from the aluminosilicate and the sep- 


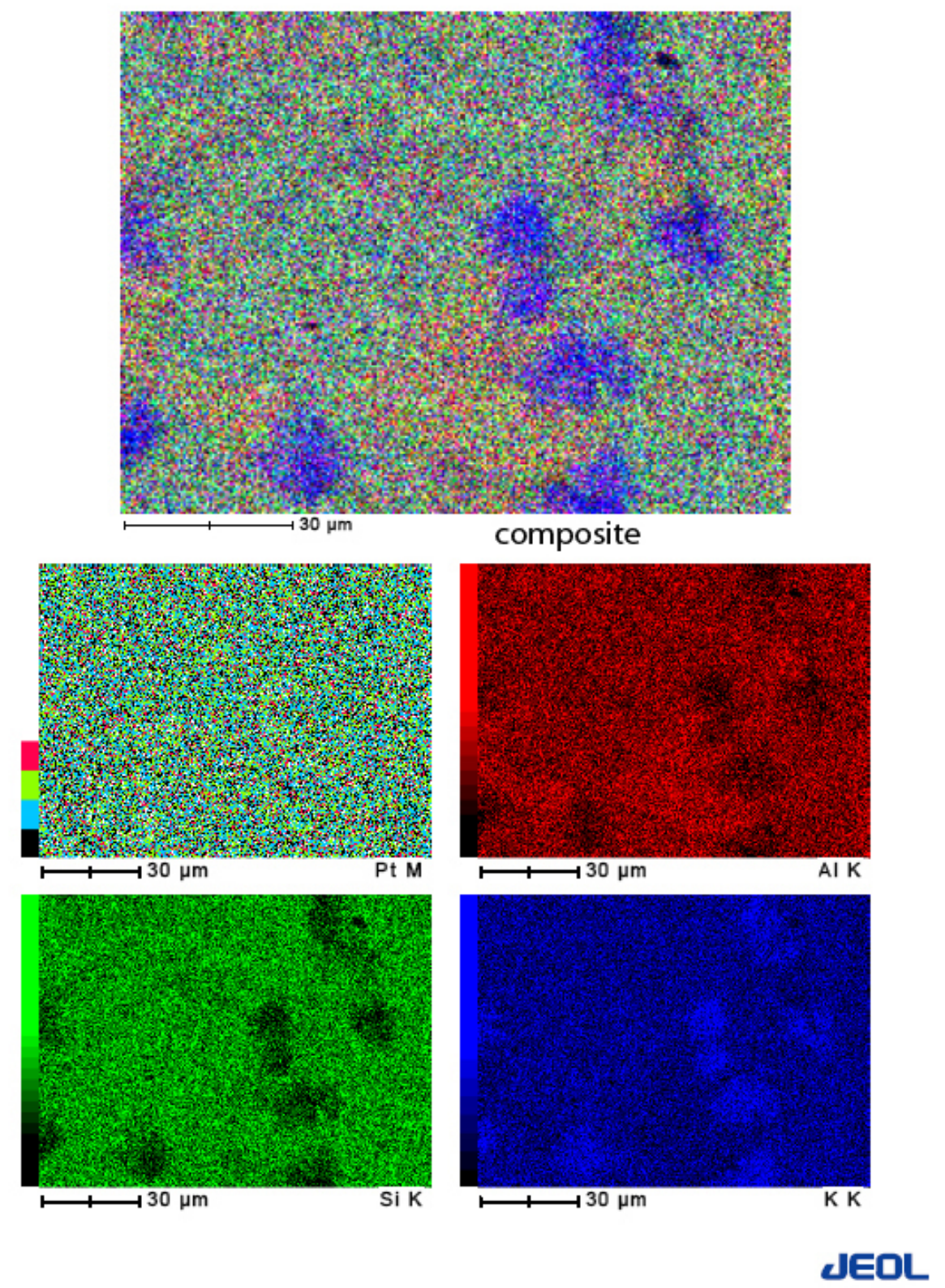

Figure 5.42: EDS element maps of the reference geopolymer heated to $600^{\circ} \mathrm{C}, x 1000$.

aration of a potassium-rich phase on heating. The precise composition of this phase is unknown as no EDX analyses of these potassium-rich regions 
were made.

\subsubsection{After SBF exposure}

Exposure of the heated reference geopolymer to SBF affects the micro structure slightly, as illustrated in the following images.

Figure 5.43 shows large 40 to $50 \mu \mathrm{m}$ agglomerates (marked 1), together with smaller $(<10 \mu \mathrm{m})$ agglomerates (marked 2). The cracks developed during the in-vitro exposure experiment because they were not present prior to exposure to simulated body fluid.

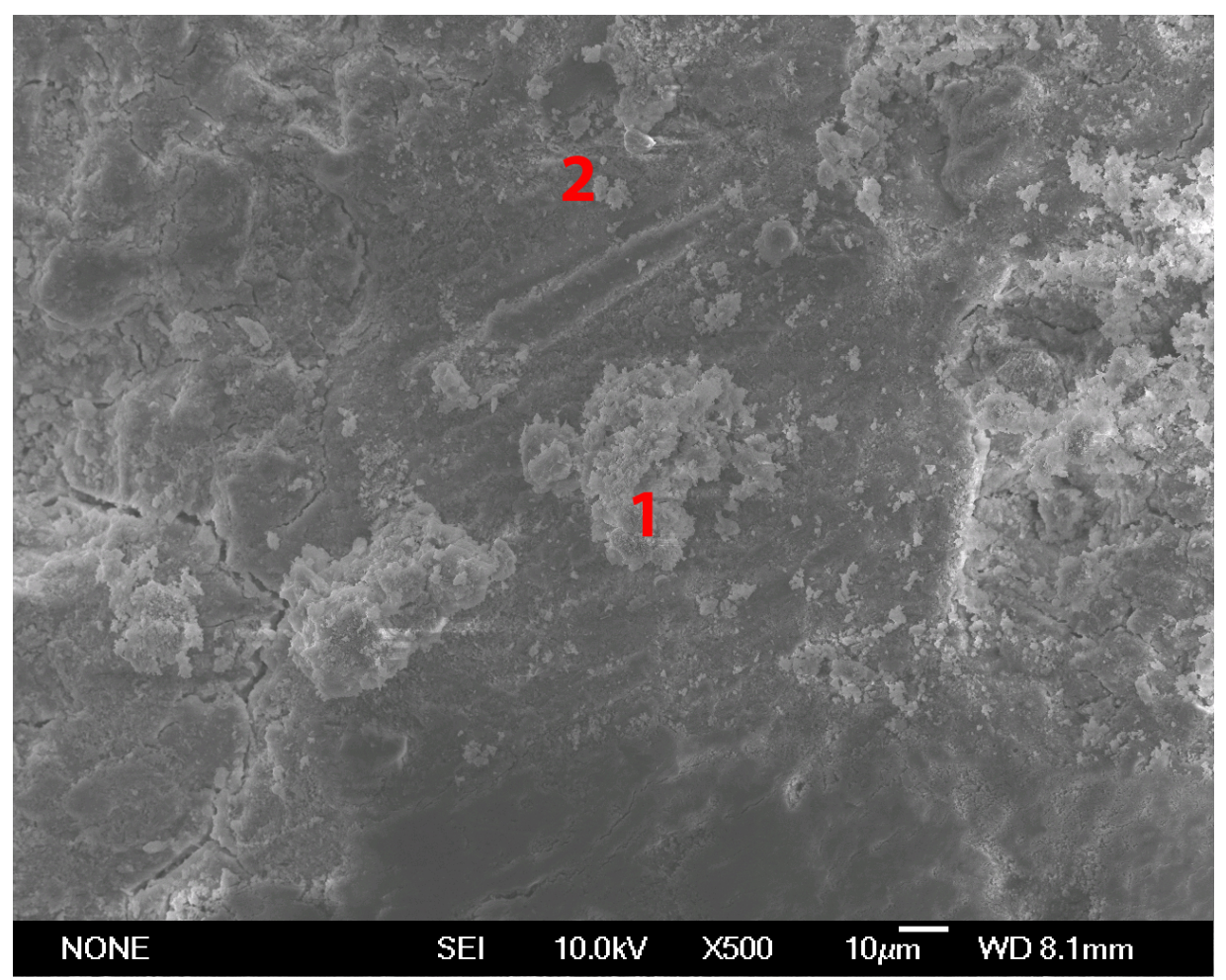

Figure 5.43: SEM micrograph of the reference geopolymer heated to $600^{\circ} \mathrm{C}, 7$ weeks $S B F$ exposure, $x 550$. 
Images taken at higher magnifications (Fig. 5.44 and 5.45) show that, in addition to the agglomerates, crystals (marked 3) have formed. These crystals are up to $1.5 \mu \mathrm{m}$ in length and are thin and spiky. They are randomly distributed, but absent from parts of the sample.

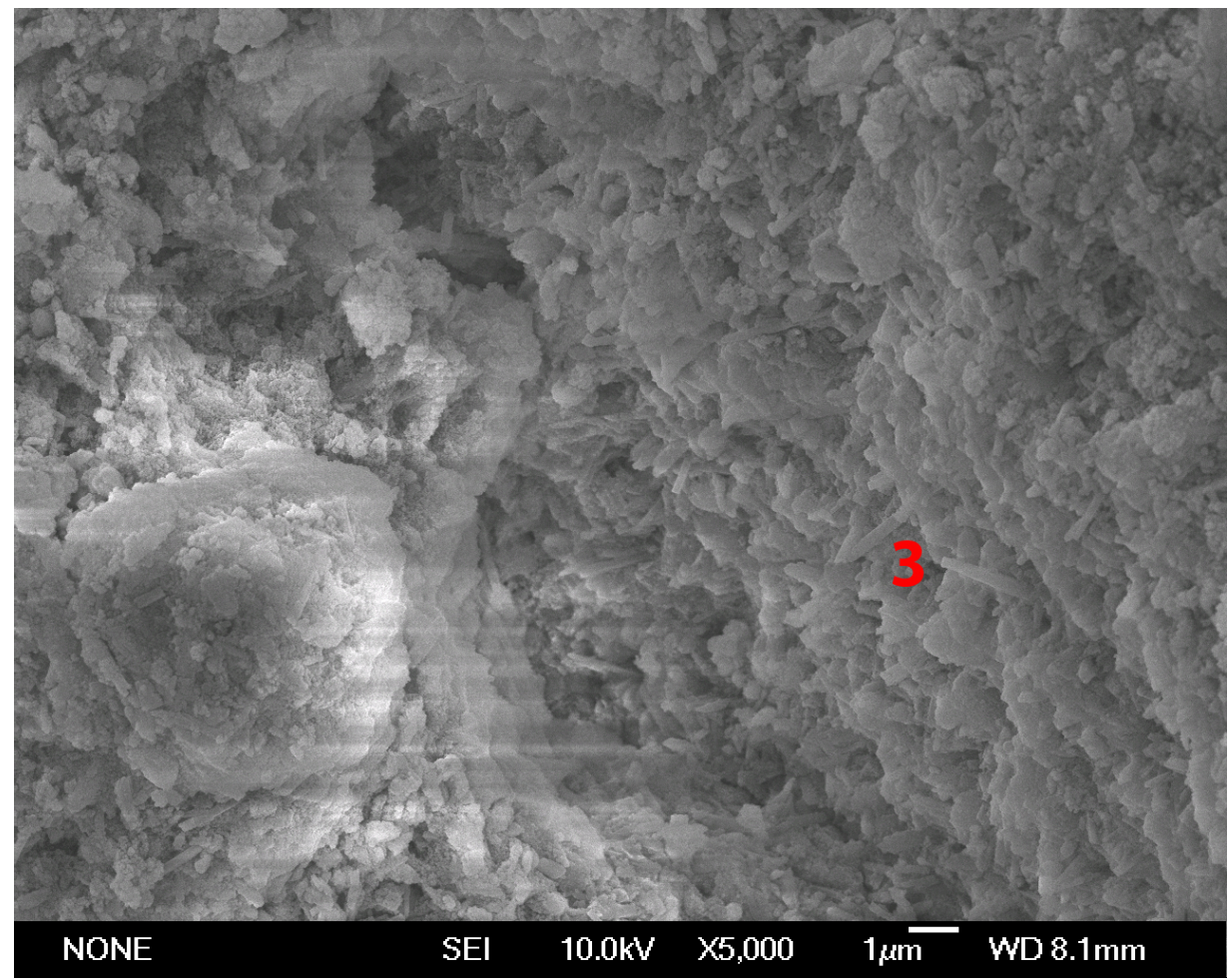

Figure 5.44: SEM micrograph of the reference geopolymer heated to $600^{\circ} \mathrm{C}, 7$ weeks $S B F$ exposure, $x 5000$.

In the areas where crystals are present the material structure seems to have changed; the surface of the agglomerates and the areas surrounding the crystals appear completely disordered. However, other areas are not affected by exposure of the geopolymer to simulated body fluid and remain unchanged. 


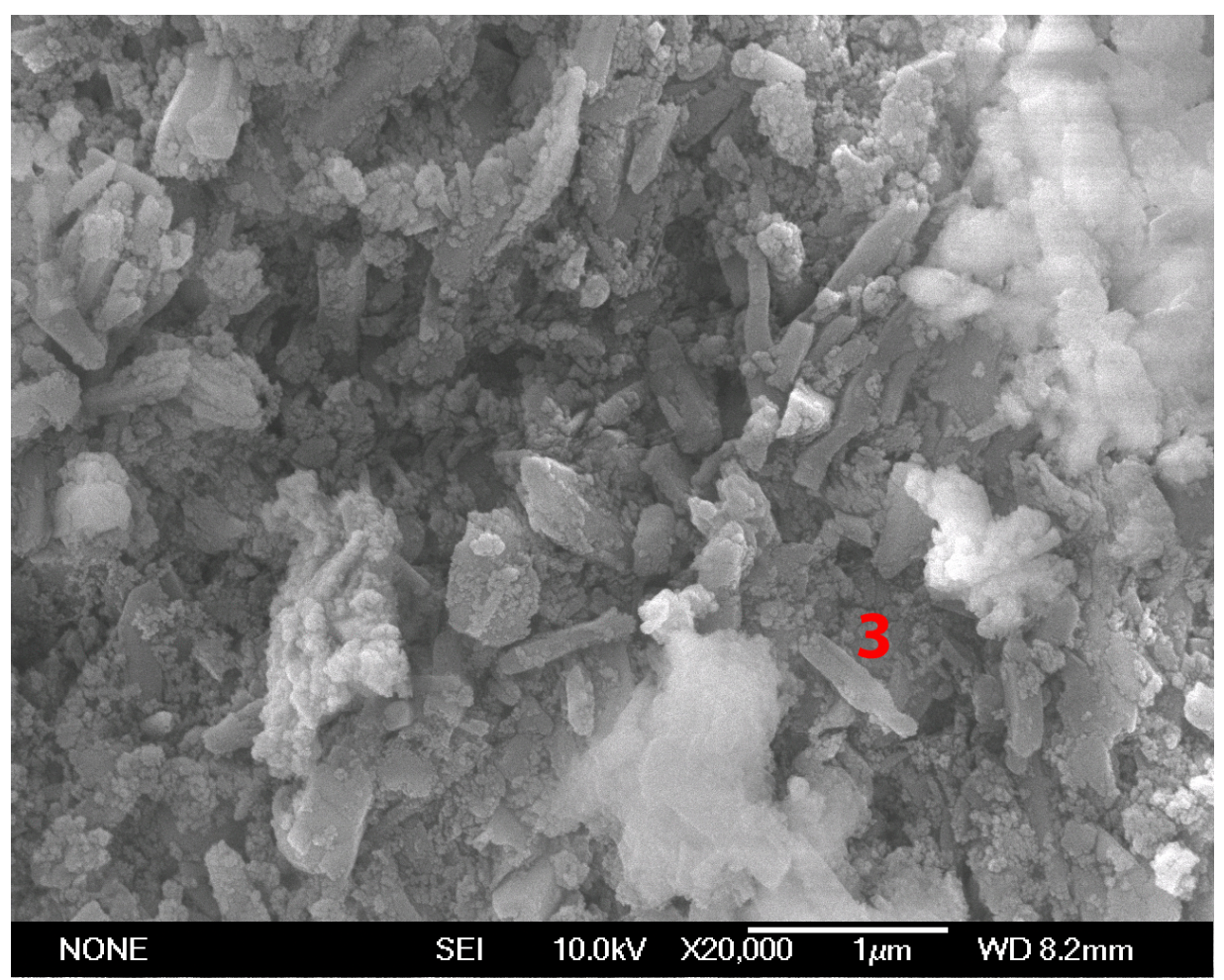

Figure 5.45: SEM micrograph of the reference geopolymer heated to $600^{\circ} \mathrm{C}, 7$ weeks $S B F$ exposure, $x 20 k$.

EDS mapping of the reference geopolymer after the in-vitro experiment is shown in Figure 5.46. Phosphorus (blue), silicon (green) and aluminium (red) are homogeneously distributed throughout the whole sample. However, the newly formed crystals could not be analysed by EDS because all areas where such crystals were present appeared to be in an unfavourable position for the electron beam. Since the reference geopolymer absorbs both calcium and phosphorus from the simulated body fluid it is possible that the needles are composed of a calcium phosphate phase, but this could not be confirmed by EDS nor by x-ray diffraction. 

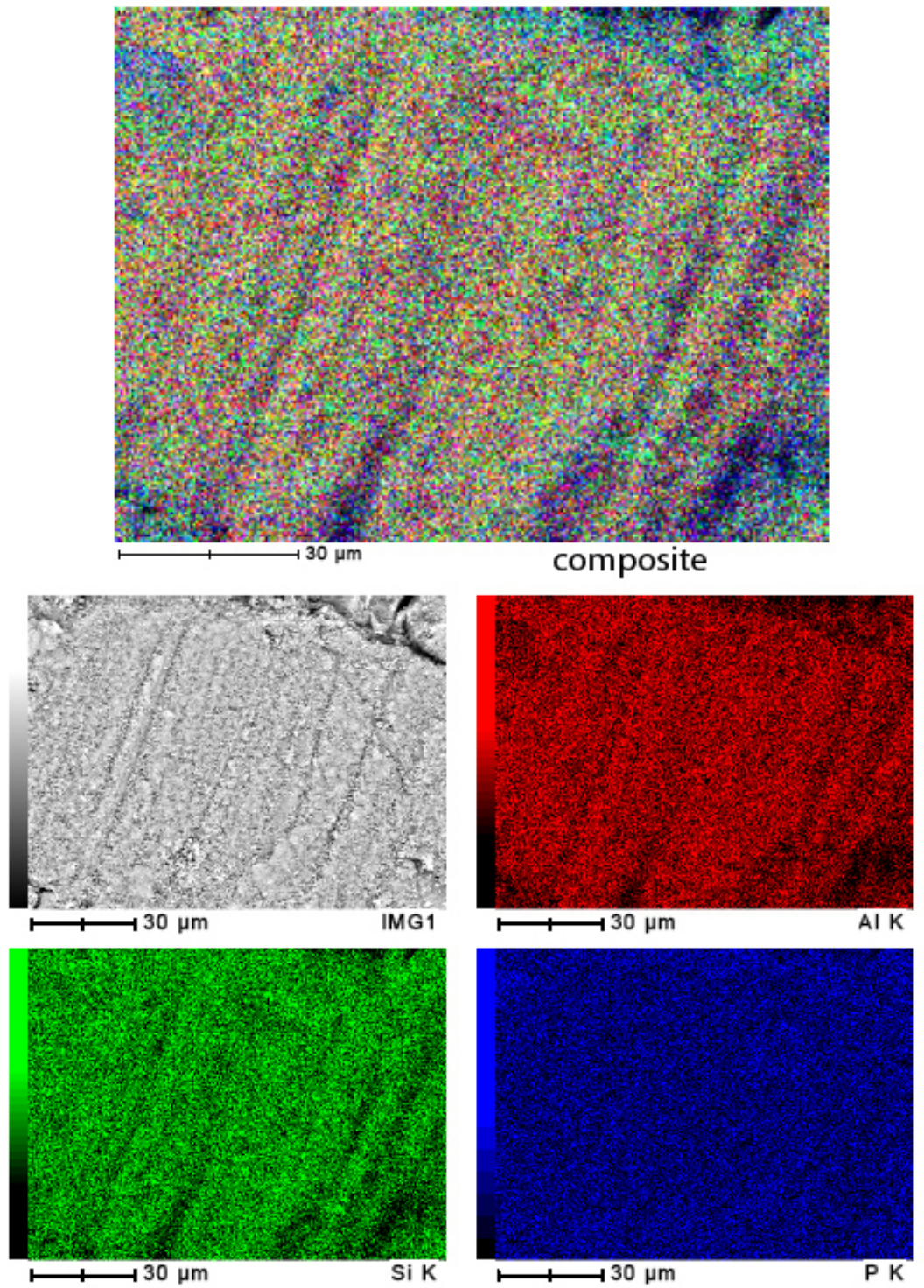

JEOL

Figure 5.46: EDS element maps of the reference geopolymer heated to $600^{\circ} \mathrm{C}, 7$ weeks SBF exposure, $x 1000$. 


\subsubsection{Calcium hydroxide geopolymer}

\subsubsection{Before SBF exposure}

Scanning electron micrographs and element mappings of the calcium hydroxide-containing geopolymer heated to $600^{\circ} \mathrm{C}$ prior to in-vitro exposure to SBF are shown in this section.

Main features of the calcium hydroxide-containing geopolymer are variously sized thin needles (marked 1 in Fig. 5.47), pores and agglomerations (marked 2). The needles are randomly ordered and are 100 - 200 nm long, and 1 - $10 \mathrm{~nm}$ thick.

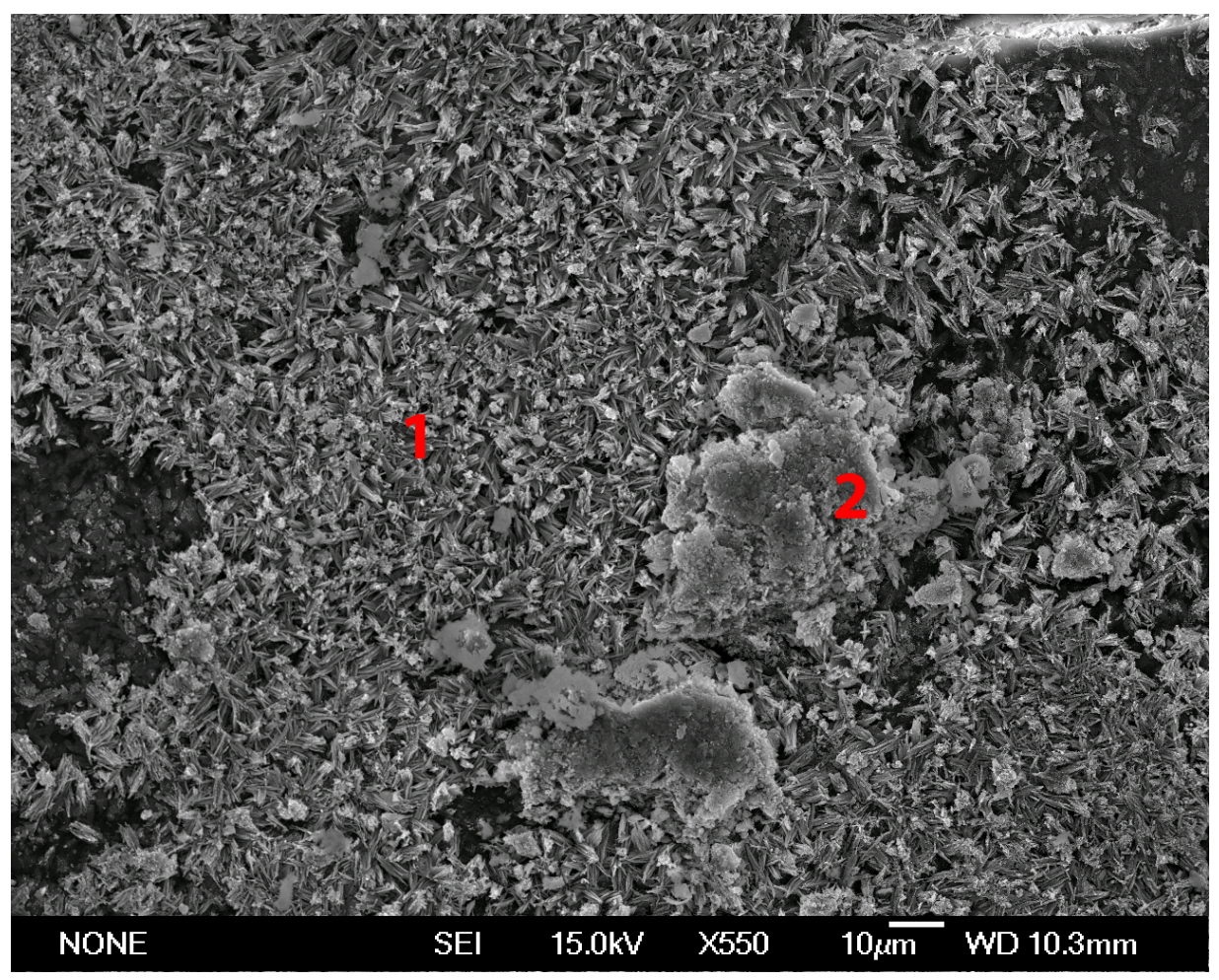

Figure 5.47: SEM micrograph of calcium hydroxide geopolymer, heated to $600^{\circ} \mathrm{C}, x 550$. 
At higher magnification $(x 15,000)$, a needle-rich area (Fig. 5.48) shows the presence of longer and shorter needles together with other random morphologies. The agglomerated regions look like clusters of ball-shaped material and appear much more dense than the surrounding needles.

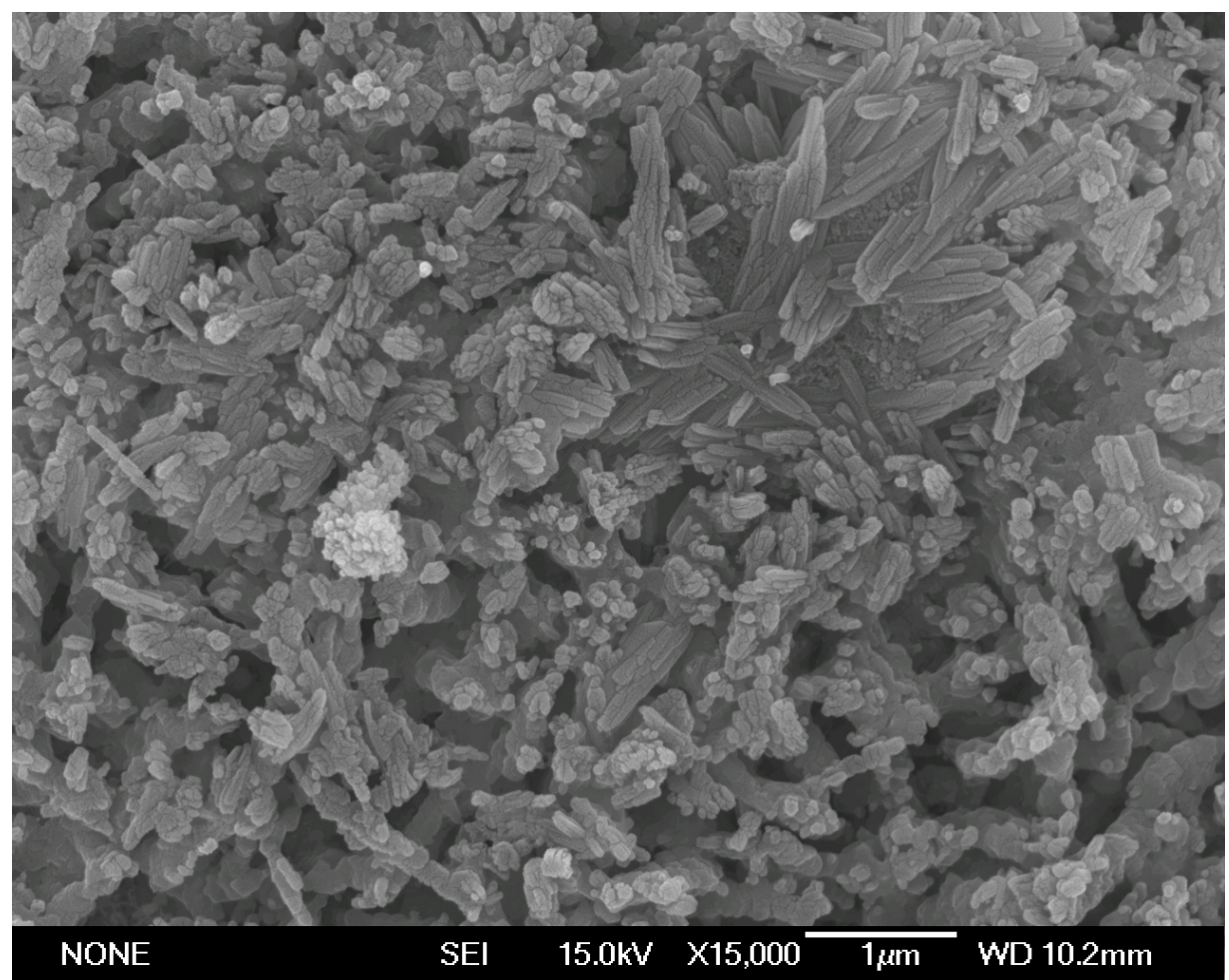

Figure 5.48: SEM micrograph of calcium hydroxide geopolymer, heated to $600^{\circ} \mathrm{C}, x 15 \mathrm{k}$.

EDS analysis of the sample area of Figure 5.49 shows that the needles are rich in calcium (blue) whereas the agglomerated areas contain silicon and aluminium, indicated by the yellow coloured areas in the top image. Although there are areas rich in elements typical of geopolymers, together with other calcium rich areas, the calcium is homogeneously distributed throughout the material.

XRD patterns of the calcium hydroxide-containing geopolymers show 

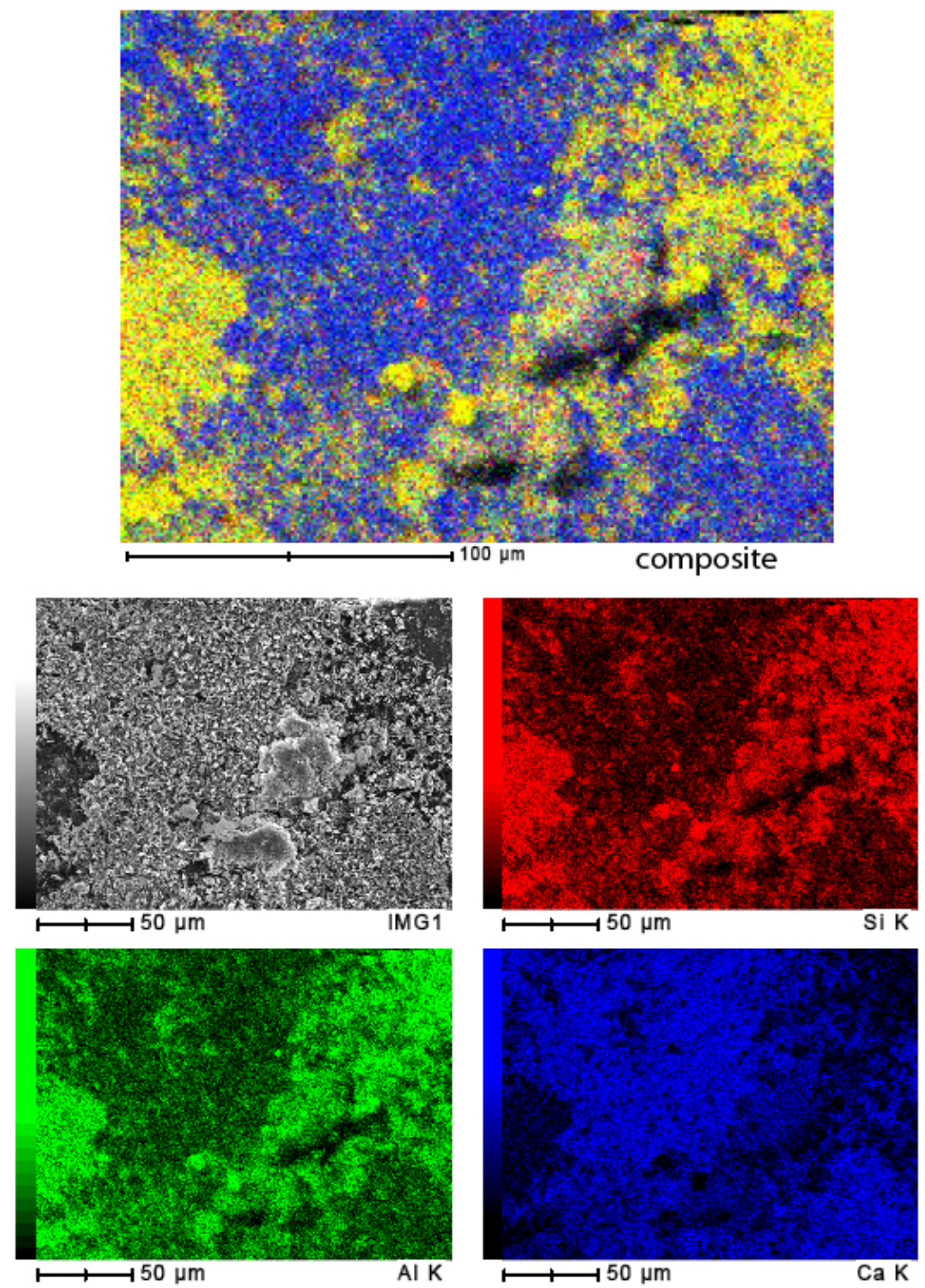

JEOL

Figure 5.49: EDS elemental maps of calcium hydroxide geopolymer, heated to $600^{\circ} \mathrm{C}$.

them to be more amorphous after heating to $600^{\circ} \mathrm{C}$. SEM observations of the same type of specimen (Figs. 5.47, 5.48) show that there are fine, randomly ordered nano-crystals present. Thus, heating to $600^{\circ} \mathrm{C}$ may have 
lead to a formation of x-ray amorphous nano-crystals which may explain their more amorphous nature, since the formation of the nano-crystals takes place upon heating to $600^{\circ} \mathrm{C}$ but not at lower temperatures.

\subsubsection{After SBF exposure}

The calcium hydroxide geopolymer after exposure to simulated body fluid for seven weeks shows different SEI and EDS results. The micro structure appears much finer and more homogeneous after the exposure to SBF (Fig. 5.50).

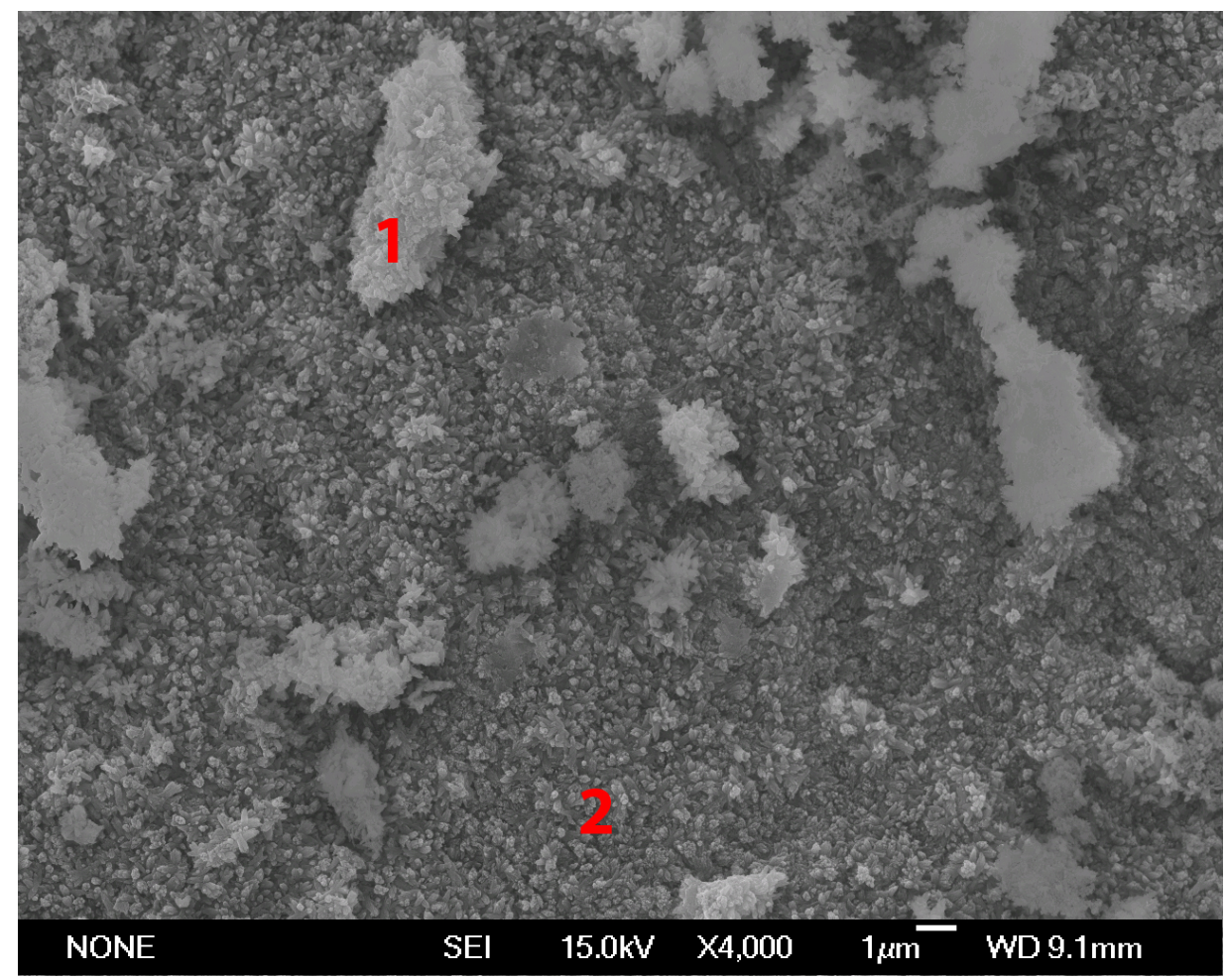

Figure 5.50: SEM micrograph of calcium hydroxide geopolymer, heated to $600^{\circ} \mathrm{C}, 7$ weeks SBF exposure $x 4000$. 
The number of crystal needles (2) appear to be reduced and the agglomerated regions (1) have been transformed and covered in a crystalline substance.

Figure 5.51 shows that two types of structures are present; larger flaky crystals and small agglomerates. The pores seem to be more homogeneously distributed and appear to be internally connected.

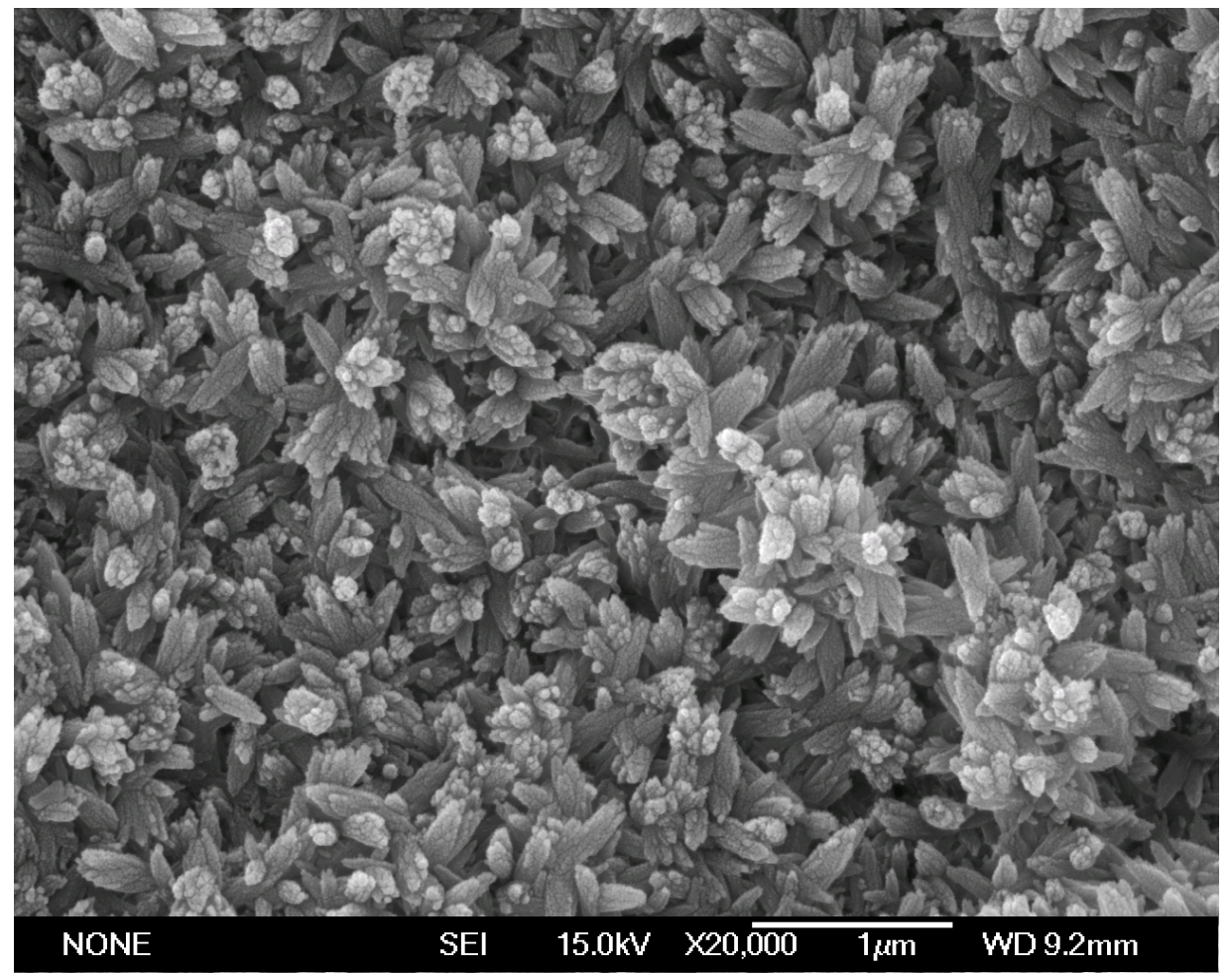

Figure 5.51: SEM micrograph of calcium hydroxide geopolymer, heated to $600^{\circ} \mathrm{C}, 7$ weeks SBF exposure, $x 20 k$

The flaky crystals are between $0.2-0.6 \mu \mathrm{m}$ long and $\approx 0.1-0.2 \mu \mathrm{m}$ thick and of spiky shape. The smaller crystals have a more ball-shaped structure and are less than $0.2 \mu \mathrm{m}$ in size. The pores-size is difficult to judge, as the sample is not polished and the pores are internally connected. However, 
the visible pores range in sizes from about $0.5 \mu \mathrm{m}$ to less than $100 \mathrm{~nm}$.

EDS analysis of the area of Figure 5.50 is shown in Figure 5.52.

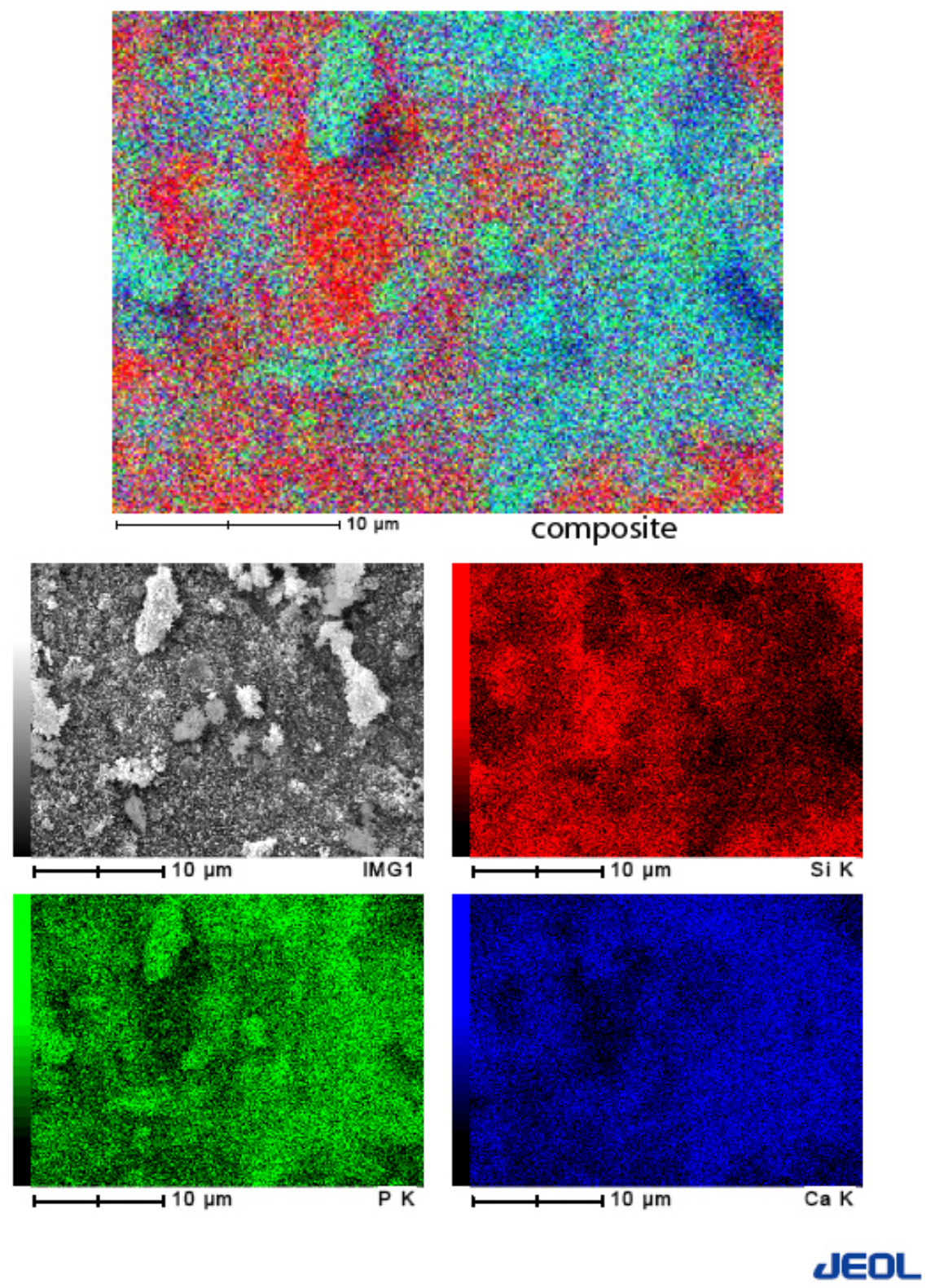

Figure 5.52: EDS elemental map of calcium hydroxide geopolymer, heated to $600^{\circ} \mathrm{C}, 7$ weeks SBF exposure 
The calcium and phosphorus (blue and green areas respectively in the elemental map) are well distributed throughout the sample. Further, the larger composite image shows that calcium and phosphorus occur together (greenish blue areas) whereas there are still areas dominated by the geopolymer (red).

Since the phosphorus was not initially present in the material, it has been absorbed from the simulated body fluid. ICP analysis (section 5.5) shows that the calcium hydroxide-containing geopolymers absorb almost all of the phosphorus present in the simulated body fluid. Since calcium and phosphorus are present in the same regions it appears that a calcium phosphate phase has formed during the exposure time to simulated body fluid. X-ray diffraction (section 5.2) confirmed that the two calcium phosphate phases formed after four weeks exposure to simulated body fluid were hydroxyl apatite and hydroxyl carbonate apatite, both bioactive calcium phosphate phases. 


\subsubsection{Calcium silicate geopolymer}

\subsubsection{Before SBF exposure}

The SEM micrograph shows that the micro structure of calcium silicatecontaining geopolymers (Fig. 5.53) is relatively fine and porous. Two different types of material structures are visible; one looks like large agglomerations of large particles whereas the other shows a very fine porous texture (Fig. 5.53).

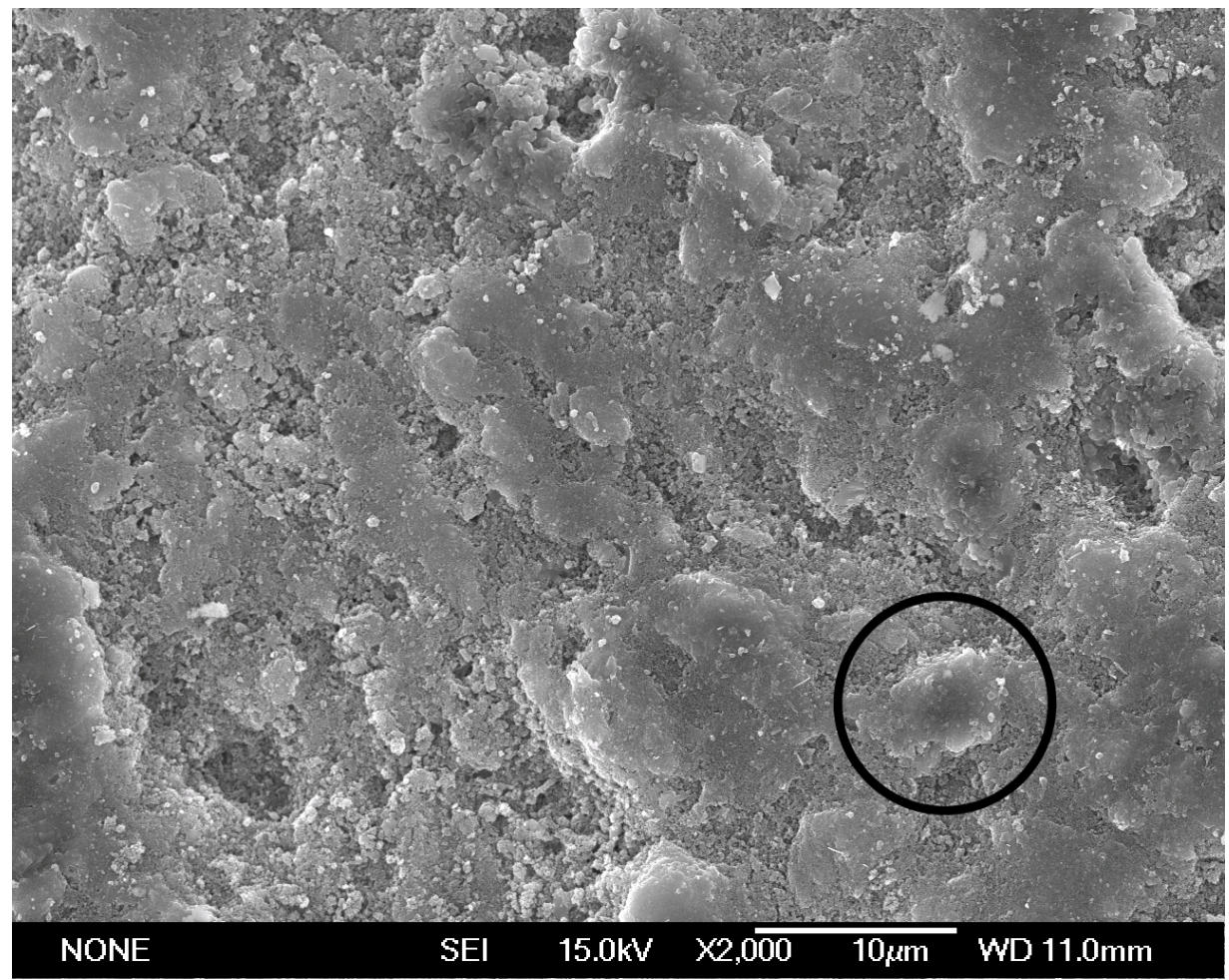

Figure 5.53: Calcium silicate containing geopolymer heated to $600^{\circ} \mathrm{C}, x 2000$ 
At higher magnifications (Fig. 5.54), it can be seen that the pores are in the nanometer range and are homogeneously distributed throughout the material. The artefact in the center of this image is one of the agglomerations, circled in the previous image and seems to be slightly different from the surrounding material, being $5-6 \mu \mathrm{m}$ in diameter and apparently less porous. EDS analysis (Fig. 5.56) shows that the circled area is rich in calcium whereas the surrounding areas are rich the elements aluminium and silicon, typical of geopolymers.

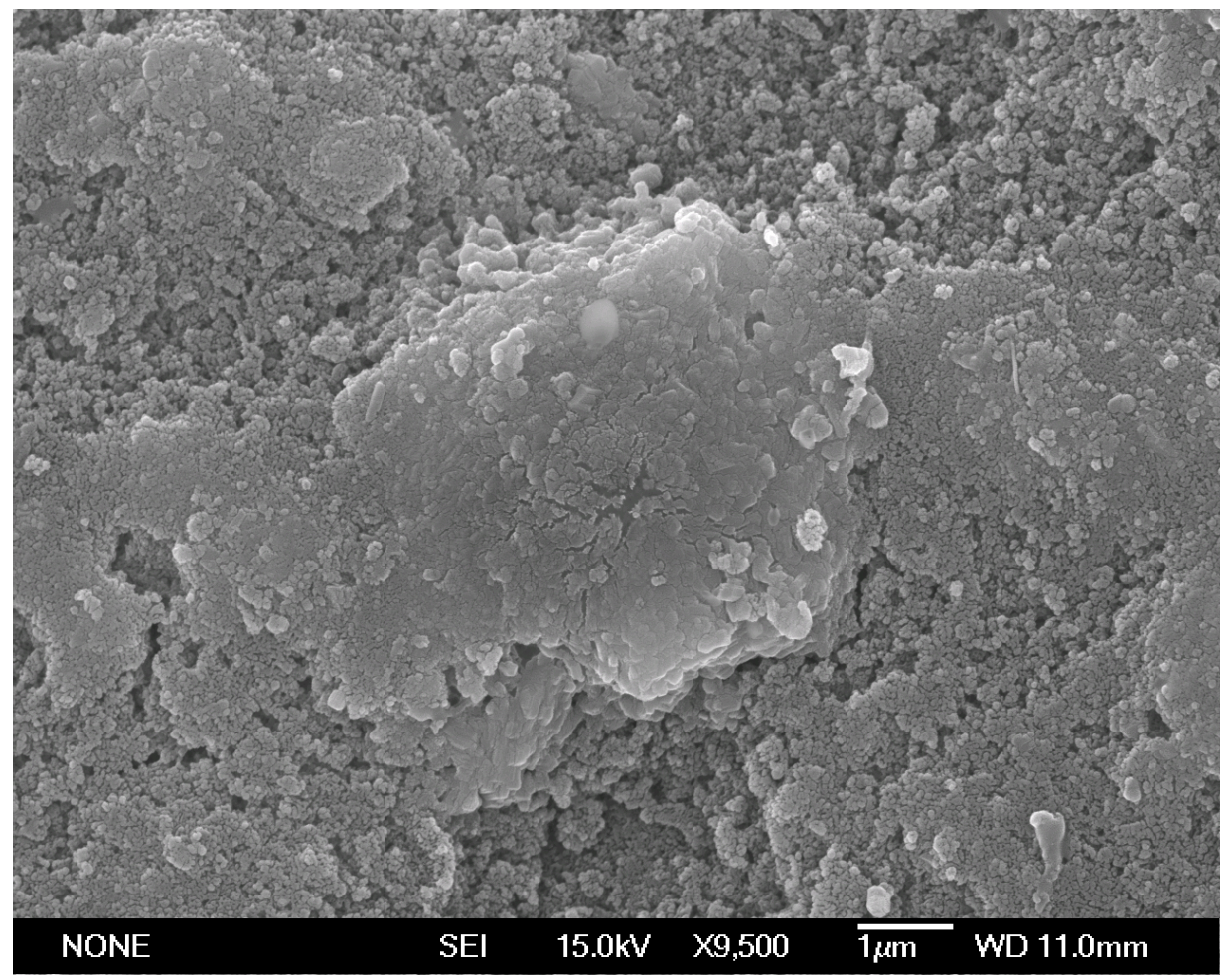

Figure 5.54: SEM micrograph of calcium silicate-containing geopolymer heated to $600^{\circ} \mathrm{C}, x 9500$ 
At still higher magnifications $(x 20,000)$, the areas rich in aluminium and silicon (Fig. 5.55) show a nano-porous network with pore sizes of 10 - $100 \mathrm{~nm}$. The geopolymer particles range in size between 10 - $150 \mathrm{~nm}$. The brighter parts visible in the image are due to charging of the sample surface.

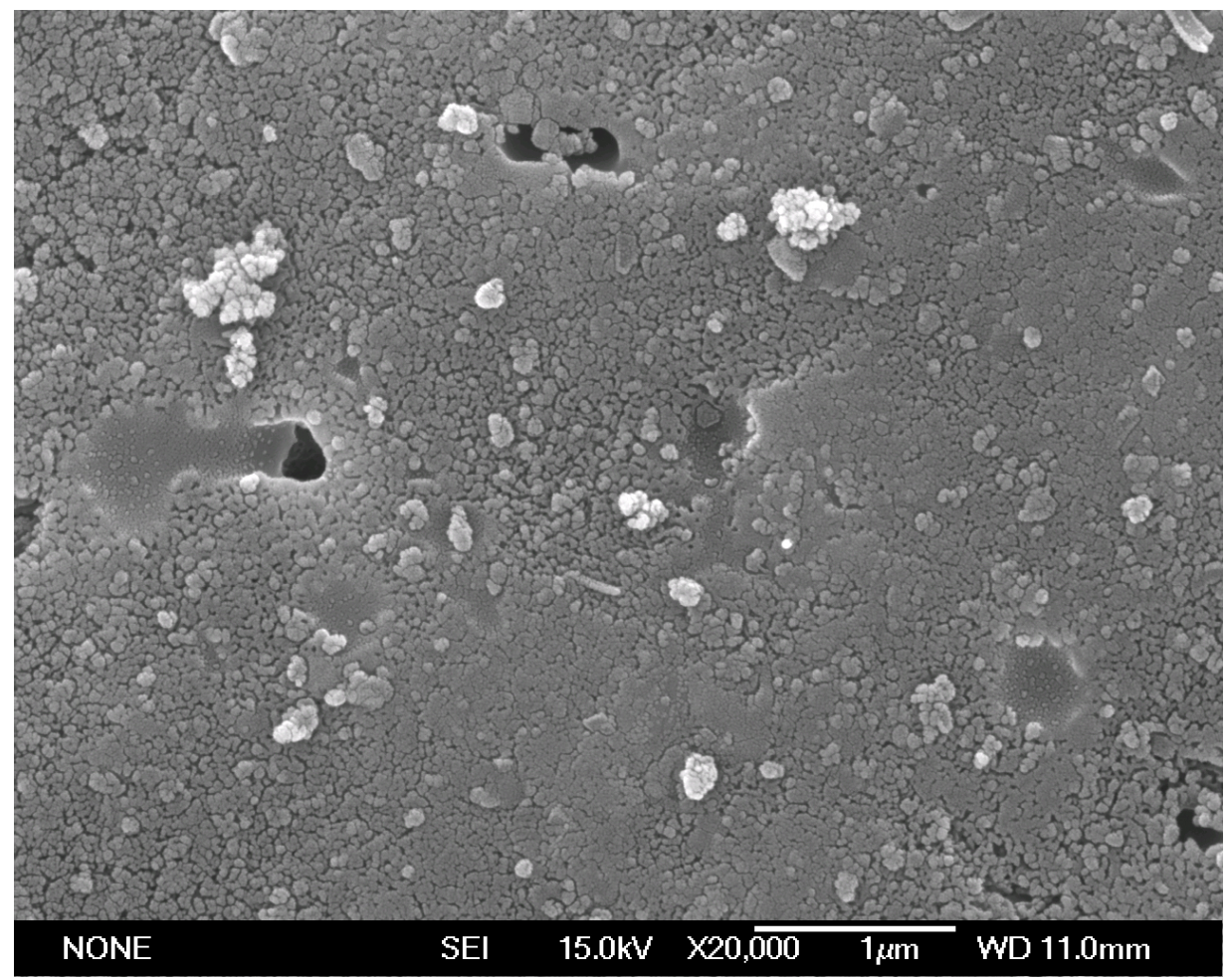

Figure 5.55: SEM micrograph of calcium silicate-containing geopolymer heated to $600^{\circ} \mathrm{C}, x 20 \mathrm{k}$ 
EDS analysis of the area shown in Figure 5.53 is shown in Figure 5.56.

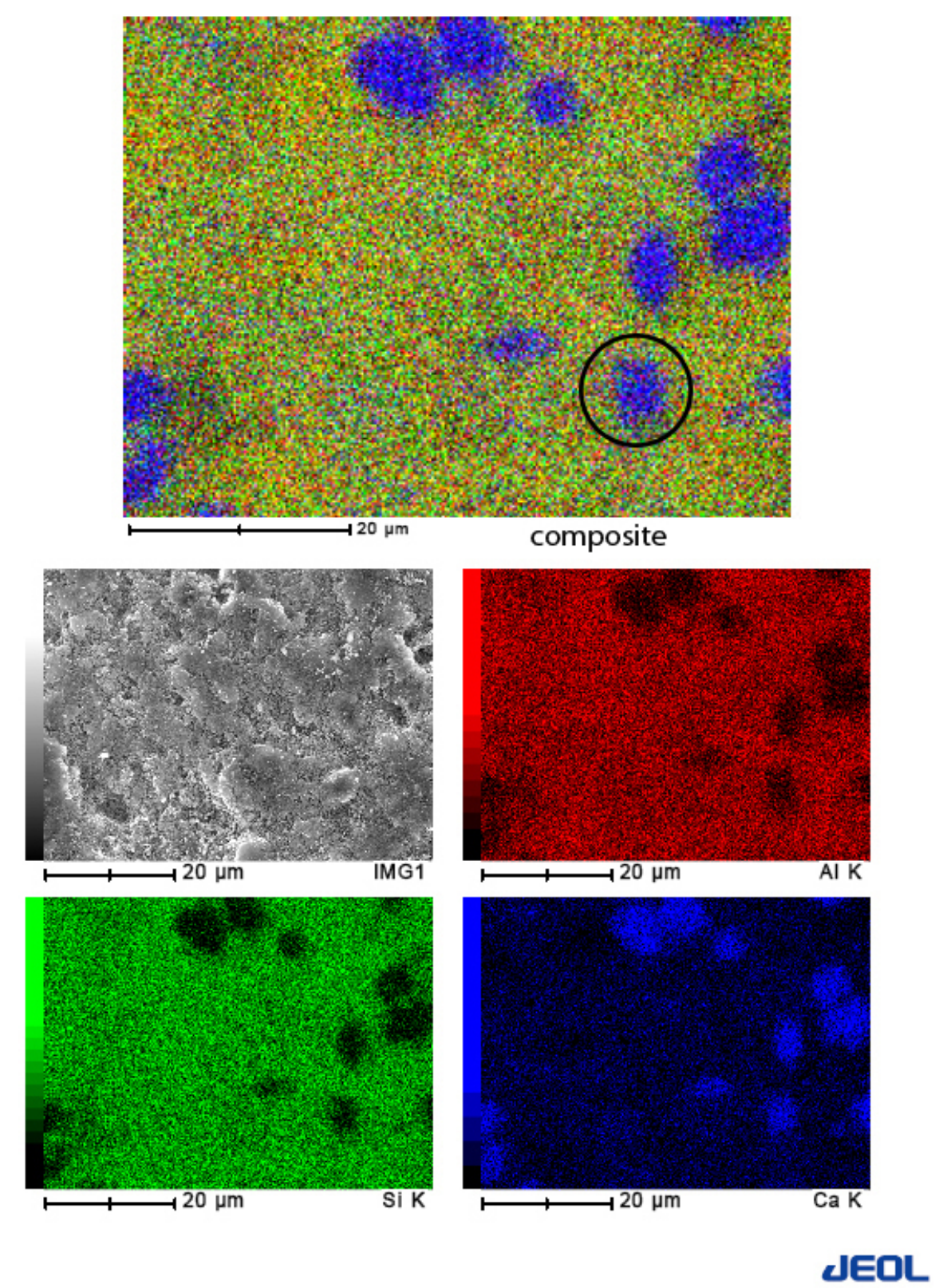

Figure 5.56: EDS elemental maps of calcium silicate-containing geopolymer heated to $600^{\circ} \mathrm{C}, x 2000$ 
The distribution of calcium throughout the sample is not homogeneous, the blue spots in the top image indicating calcium rich areas. However, because calcium silicate was the additive to the geopolymer, calcium and silicon rich areas should occur in conjunction, rather than areas rich in calcium alone. Because only calcium is concentrated in certain parts of the sample, the silicon may have entered the geopolymer structure. This possibility is supported by the NMR results (section 5.3.1.3). The calcium rich areas may therefore correspond to calcium hydroxide. 


\subsubsection{After SBF exposure}

Exposure of the calcium silicate-containing geopolymer to simulated body fluid for seven weeks produced clear changes in the micro structure. The SEM image taken at 4000 times magnification (Fig. 5.57) shows that regular square shaped-crystals (1) have formed and partially cover the sample surface. The crystals range in size from $0.3-5 \mu \mathrm{m}$. Sponge-like structures (2) and agglomerated areas (3) are also present, similar to those in the sample prior to exposure to simulated body fluid.

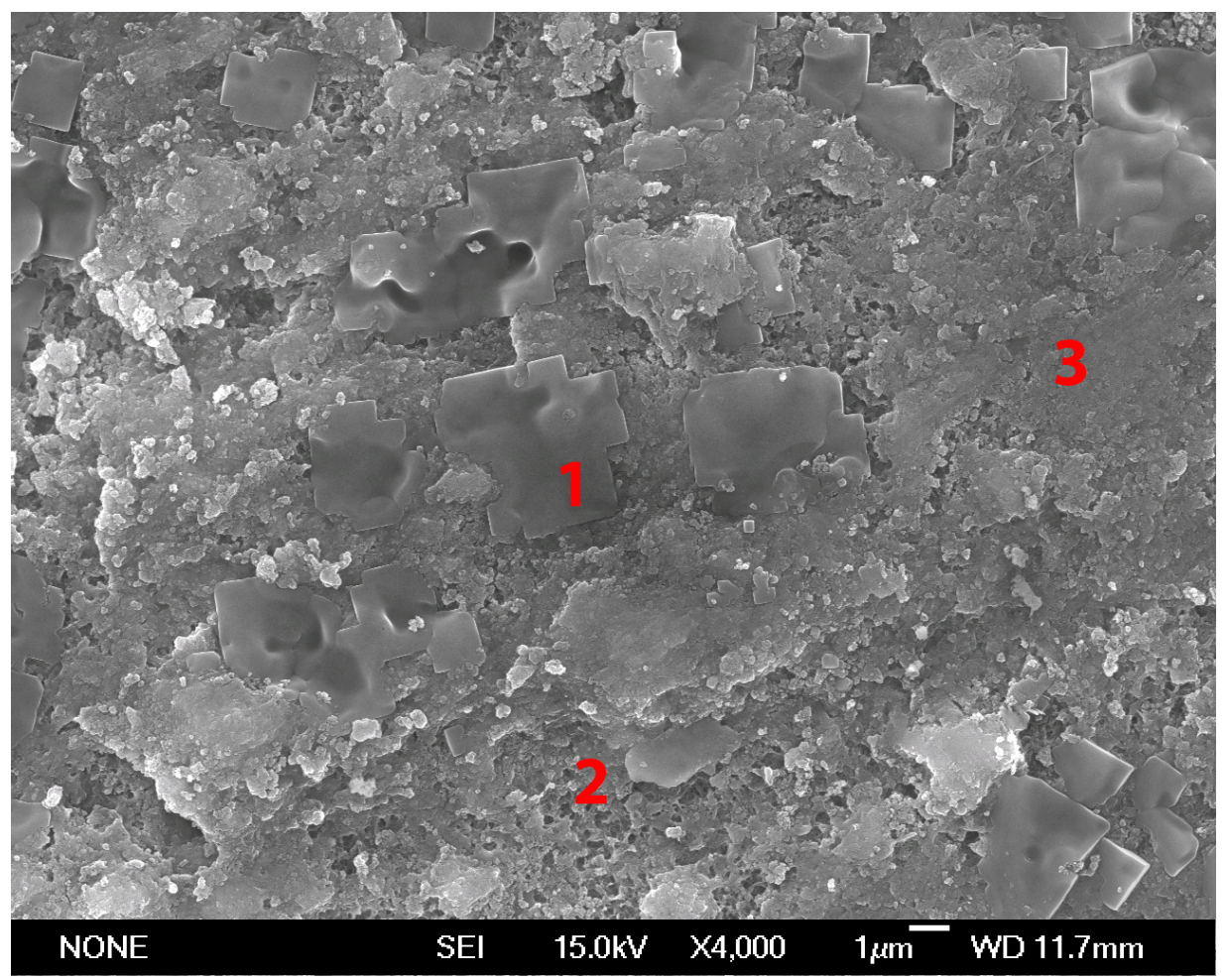

Figure 5.57: SEM micrograph of calcium silicate-containing geopolymer heated to $600^{\circ} \mathrm{C}, 7$ weeks SBF exposure, $x 4000$ 
At higher magnifications (Fig. 5.58), the sponge-like texture contains intra-connected pores and agglomerated small round particles. The pores range in size from $50-0.5 \mu \mathrm{m}$ whereas the agglomerated particle size range between $100 \mathrm{~nm}$ and $1 \mu \mathrm{m}$.

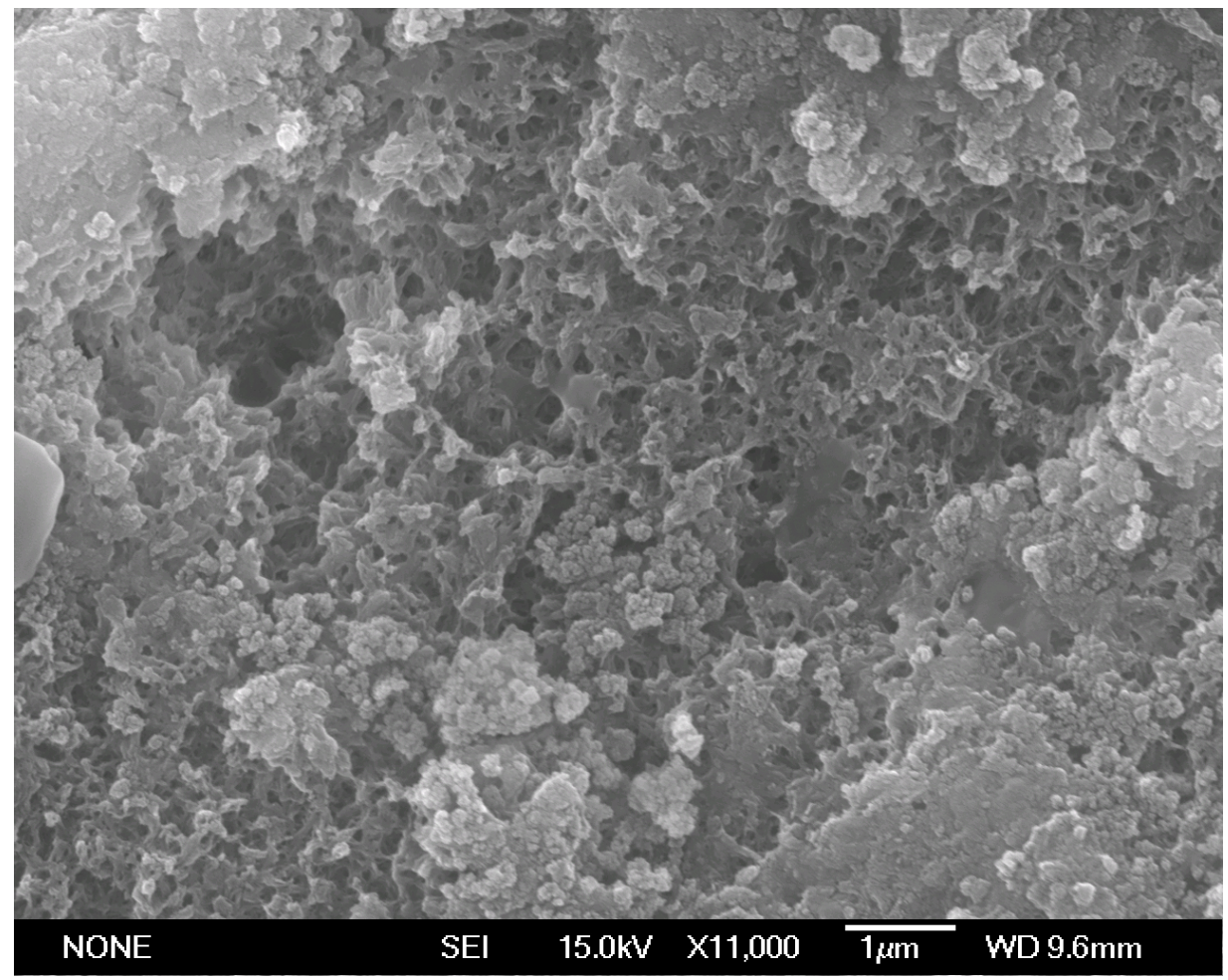

Figure 5.58: SEM micrograph of calcium silicate-containing geopolymer heated to $600^{\circ} \mathrm{C}, 7$ weeks SBF exposure, $x 11 \mathrm{k}$ 
A more detailed image of an agglomerated area is shown in Figure 5.59. revealing fine particles $20-300 \mathrm{~nm}$ in size that comprise the agglomerates. These particles contain very small white dots whose origin could not be determined.

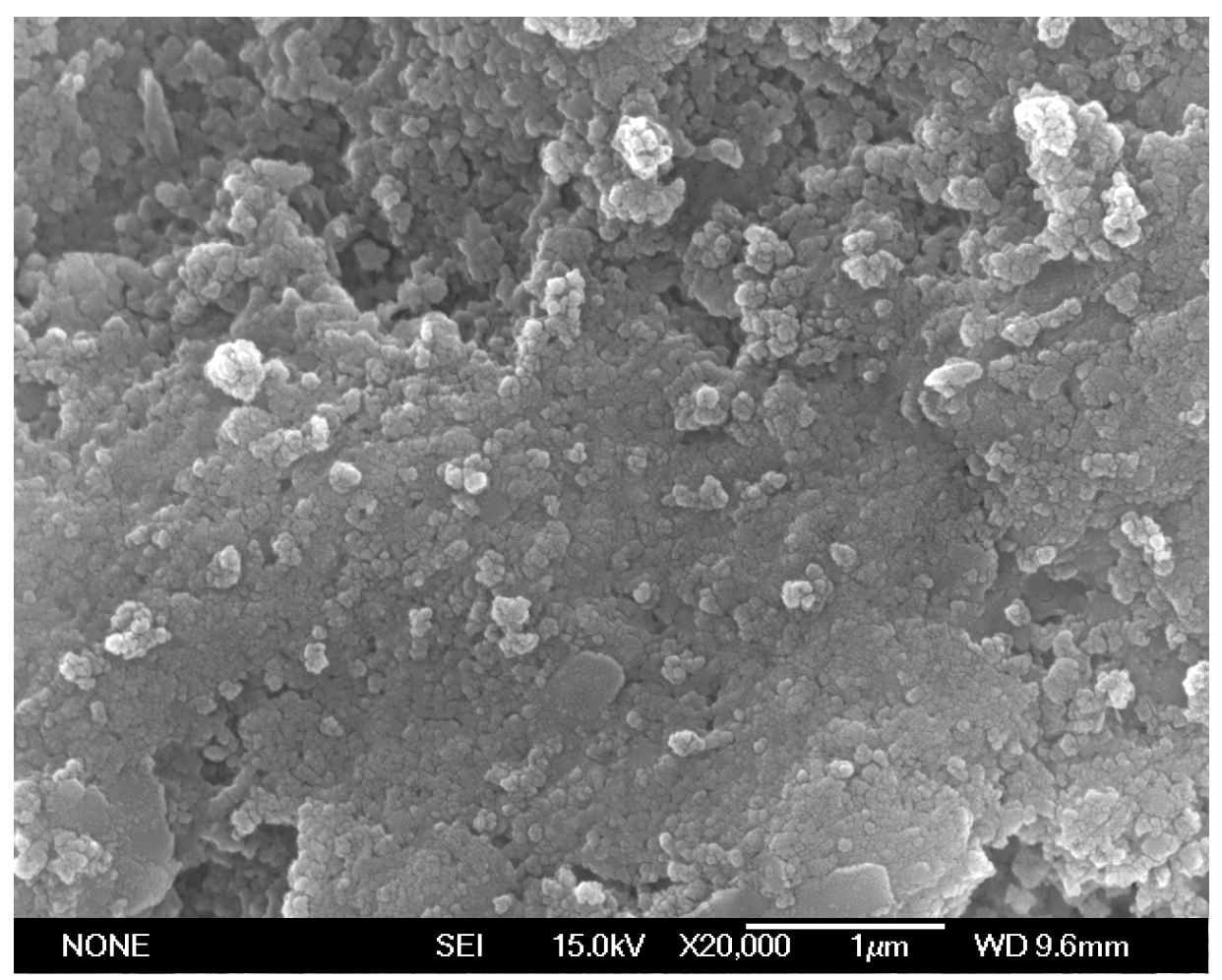

Figure 5.59: SEM micrograph of calcium silicate-containing geopolymer heated to $600^{\circ} \mathrm{C}, 7$ weeks SBF exposure, $x 20 \mathrm{k}$ 
EDS analysis of of the sample area of Figure 5.57 is shown in Figure 5.60

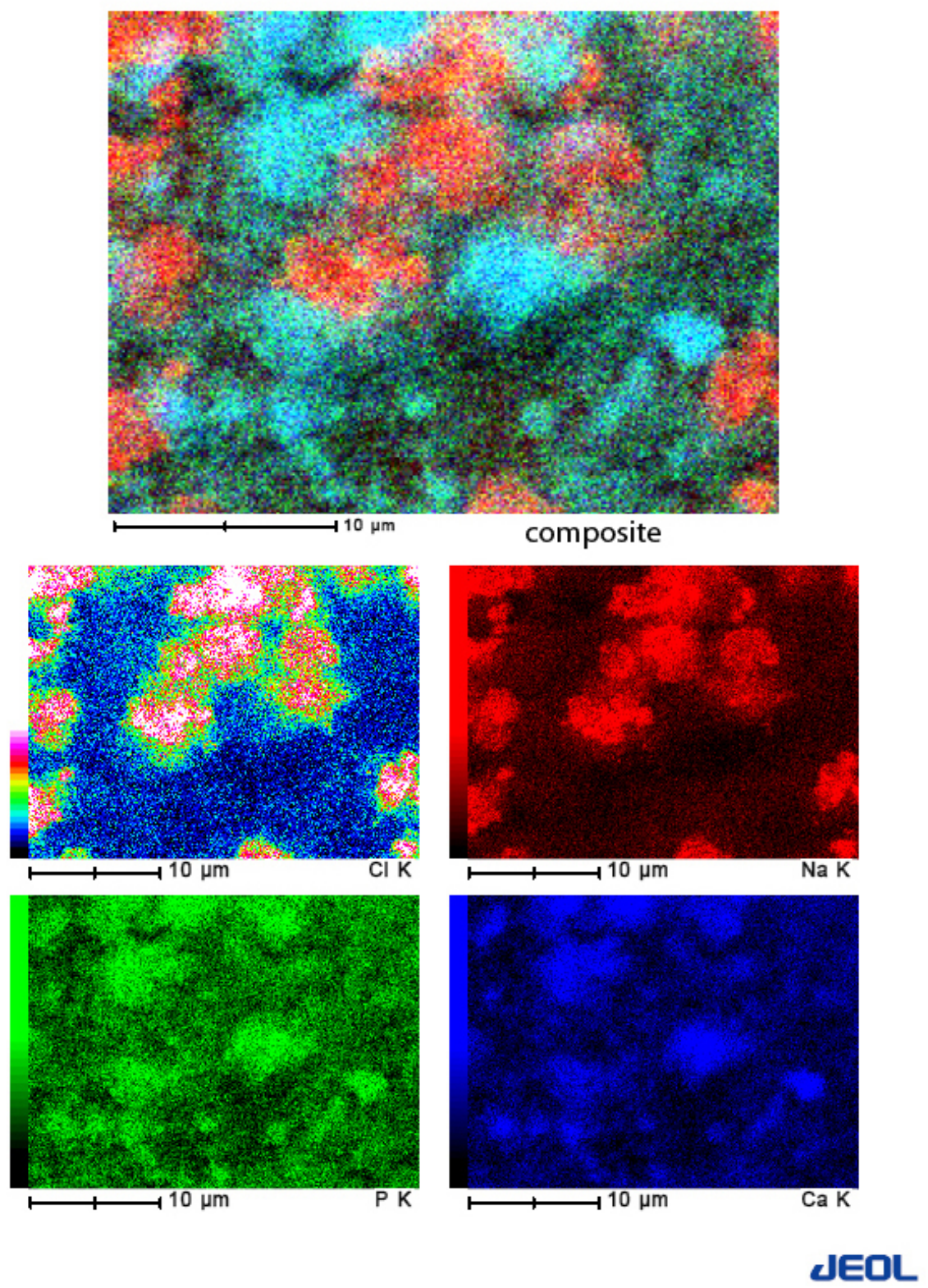

Figure 5.60: Element maps of calcium silicate-containing geopolymer heated to $600^{\circ} \mathrm{C}, 7$ weeks SBF exposure, $x 4000$ 
Chlorine is imaged in multicolour whereas sodium, calcium and phosphorus are displayed in red, blue and green respectively. The EDS mapping identifies the square-shaped crystals as sodium chloride (indicated in red in the composite image). The greenish blue areas representing calcium phosphate and the darker parts of the composite image are the geopolymer elements (silicon and aluminium). The sodium chloride has crystallised from the SBF, nucleating on the underlying crystal aggregates.

To summarise, the calcium silicate added to the geopolymer mixture appears to have added silicon to the geopolymer structure during the setting process. The resulting calcium rich regions become associated with phosphorus during exposure to simulated body fluid, forming calcium phosphate identified as hydroxyl apatite by x-ray diffraction. Hydroxyl apatite is a material which is well known for its bio-compatibility and as a resorbable biomaterial [16] whose formation could explain the microstructural changes observed here. ICP analysis shows that the phosphorus in the simulated body fluid is almost completely assimilated by the geopolymer whereas calcium is firstly absorbed but then released. This behaviour might be explained by the initial formation of a resorbable calcium phosphate phase such as hydroxyl apatite, followed by the degradation of this phase when the $\mathrm{Ca}^{2+}$ concentration is increased upon the addition of fresh SBF. 


\subsubsection{Calcium phosphate geopolymer}

\subsubsection{Before SBF exposure}

Geopolymer samples containing calcium phosphate heated to $600^{\circ} \mathrm{C}$ analysed by SEM at relatively low magnifications show darker and lighter regions (Fig. 5.61). The lighter regions arise from charging of the sample.

The scratches visible in this micrograph developed during grinding of the sample after the curing process. The other smoother areas may also be an artefact of the grinding process.

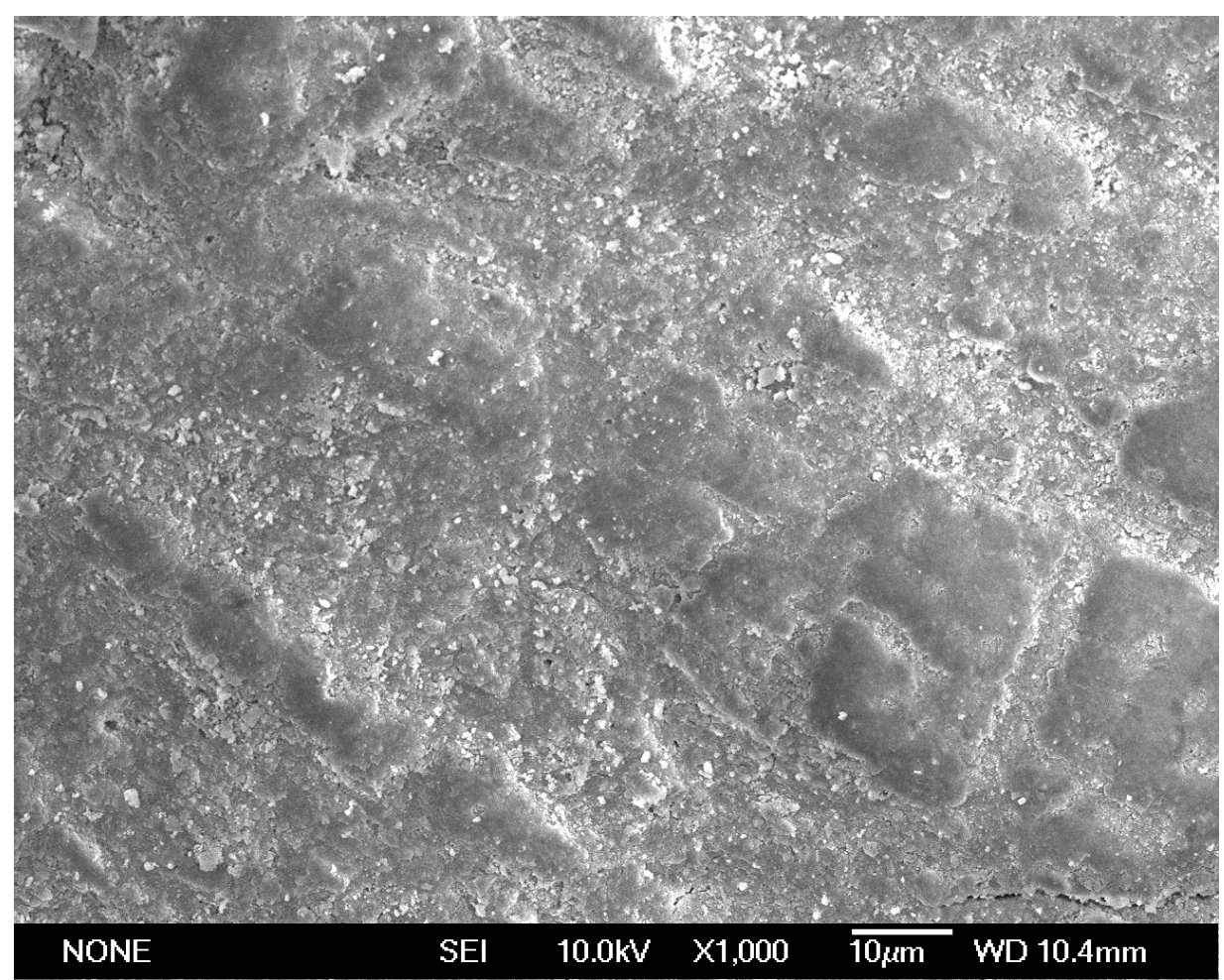

Figure 5.61: SEM micrograph of the calcium phosphate-containing geopolymer, heated to $600^{\circ} \mathrm{C}, x 1000$. 
Micro cracks of about $50-60 \mathrm{~nm}$ and a ball-like texture become visible at higher magnification (Fig. 5.62). The particles are about 50 - 100 $\mathrm{nm}$ in size and form agglomerates ranging from approximately 200 - 500 $\mathrm{nm}$ in size. Some parts of the geopolymer seem to be more textured with higher porosity and larger pores, which are however smaller than the particles themselves. Charging problems are evidenced by the bright white appearance of the agglomerations.

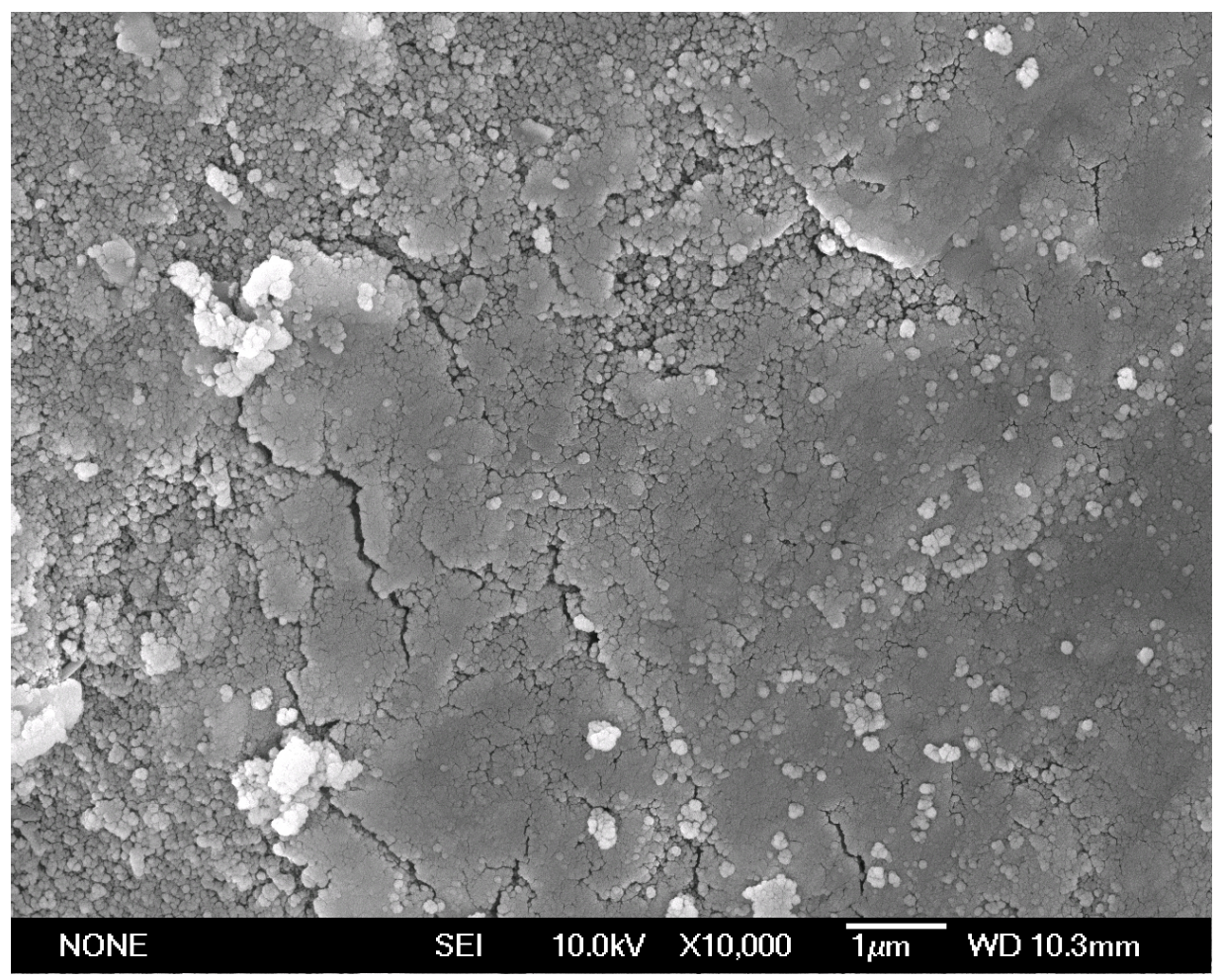

Figure 5.62: SEM micrograph of the calcium phosphate-containing geopolymer, heated to $600^{\circ} \mathrm{C}, x 10 \mathrm{k}$. 
A higher magnification image of this sample is shown in Figure 5.63 . This shows that the particles are agglomerates of even finer particles ranging in size from $30-140 \mathrm{~nm}$. The visible micro cracks are less than $70 \mathrm{~nm}$ wide and are randomly distributed, possibly accounting for the porosity. However, the pore structure and pore size cannot be determined.

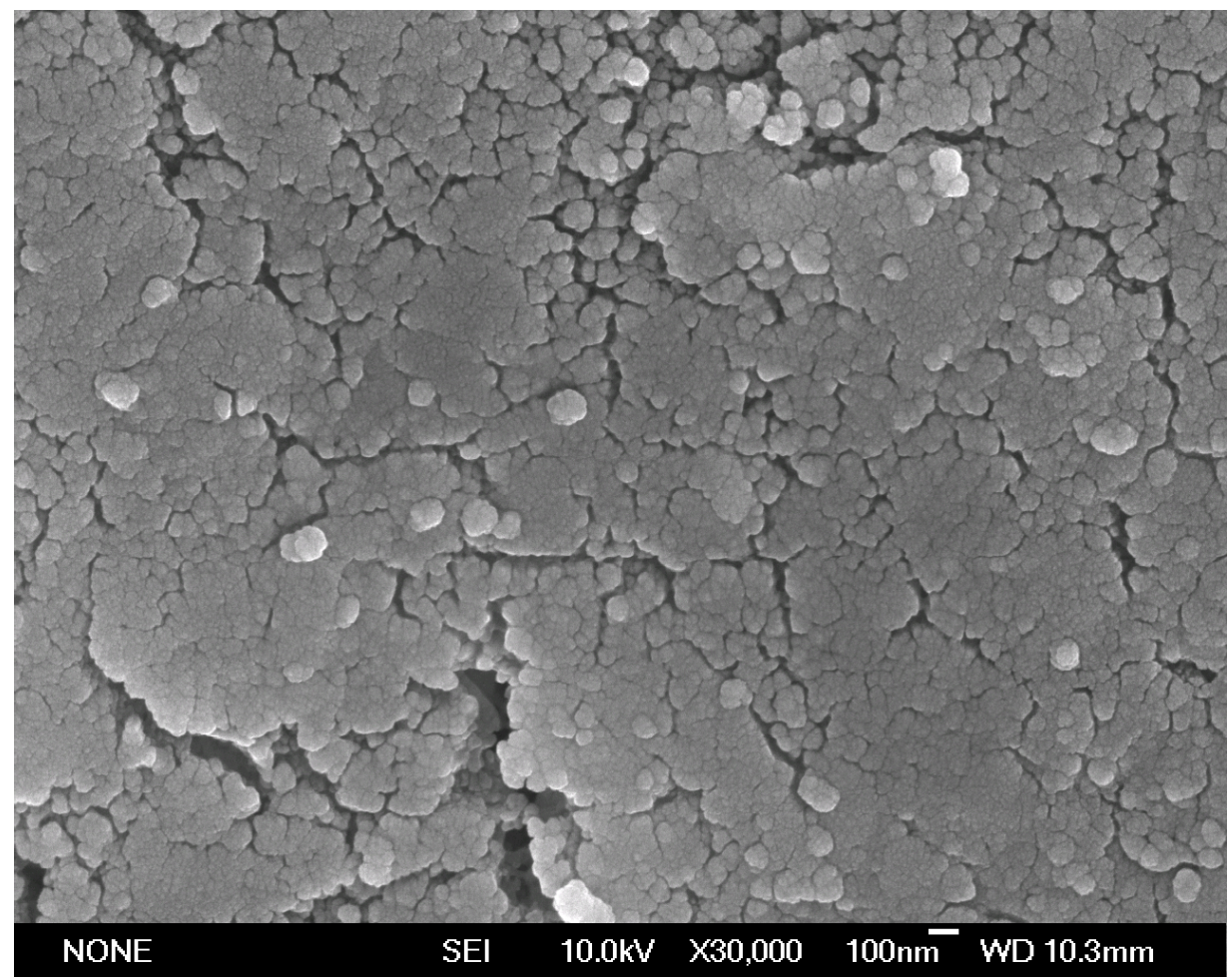

Figure 5.63: SEM micrograph of the calcium phosphate geopolymer, heated to $600^{\circ} \mathrm{C}$, $x 30 k$. 
Element mapping of the calcium phosphate geopolymer (Fig. 5.64) shows inhomogeneities in the of element distribution.
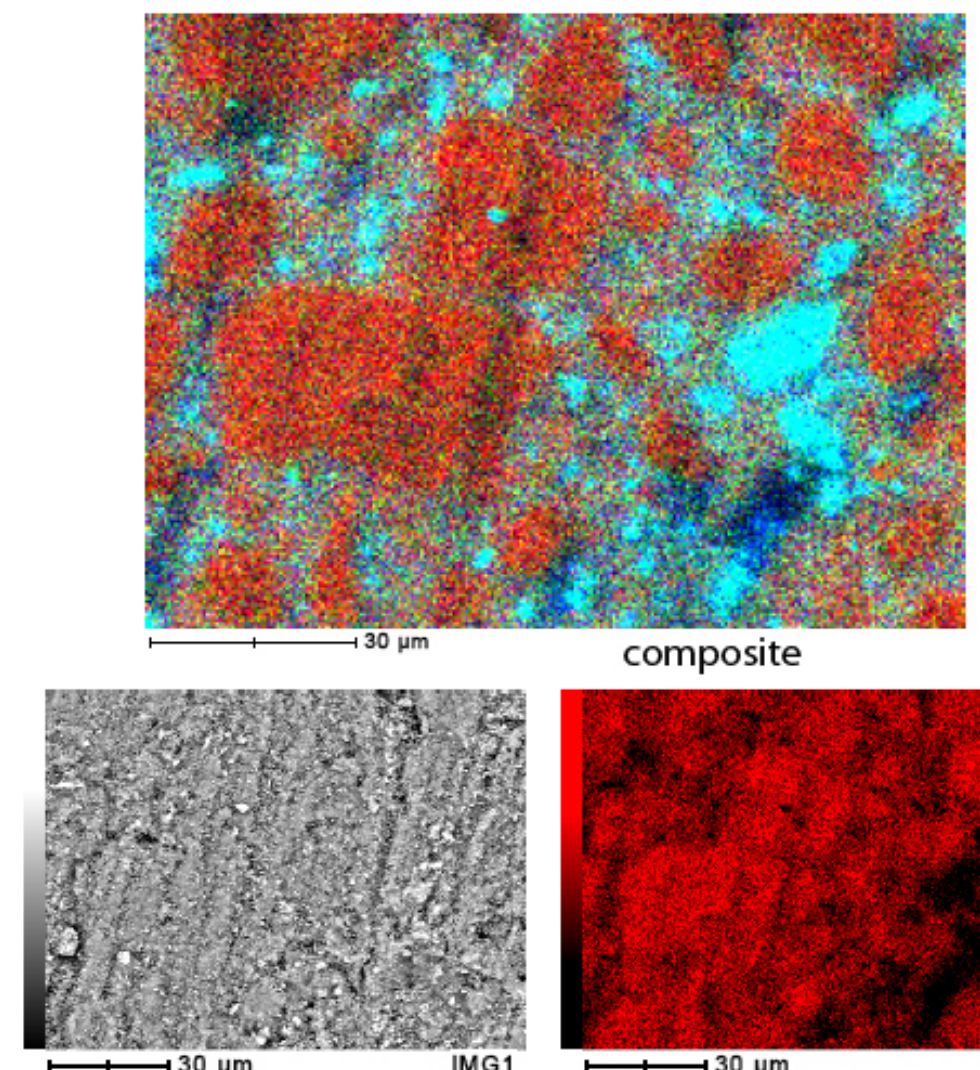

composite
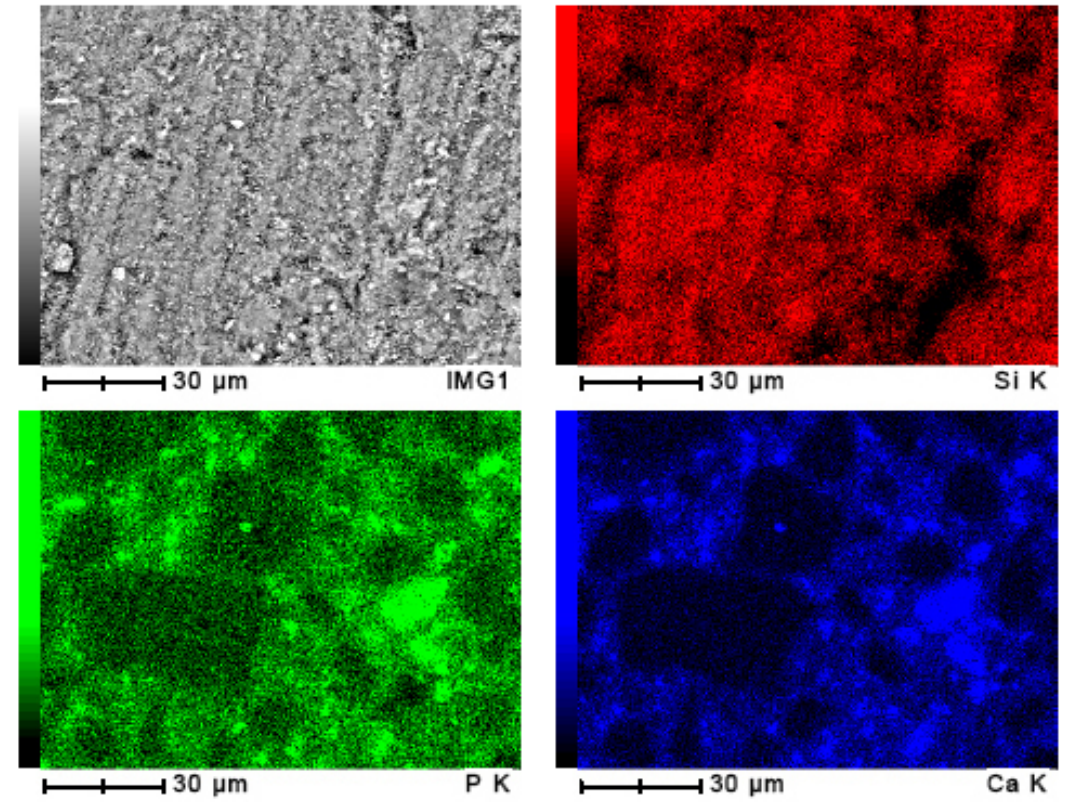

JEOL

Figure 5.64: EDS element maps of the calcium phosphate-containing geopolymer, heated to $600^{\circ} \mathrm{C}, x 1000$. 
The regions containing higher concentrations of calcium and phosphorus are shown as the blue areas in the composite map (top), the red regions in the composite map indicate the geopolymeric material itself containing mainly aluminium and silicon. EDS analysis shows that the sample is not a homogeneous mixture of geopolymer and calcium phosphate, possibly because the calcium phosphate may not have reacted with the alkaline geopolymer. Use of a finer calcium phosphate powder or more intensive mixing of the reagents may give better homogeneity. 


\subsubsection{After SBF exposure}

The micro structure of the geopolymers containing calcium phosphate is slightly changed after exposure to simulated body fluid for seven weeks, shown in this section.

The scratches seen in Figure 5.65 are from the sample preparation, but agglomerates to up to about $5 \mu \mathrm{m}$ in size are also visible.

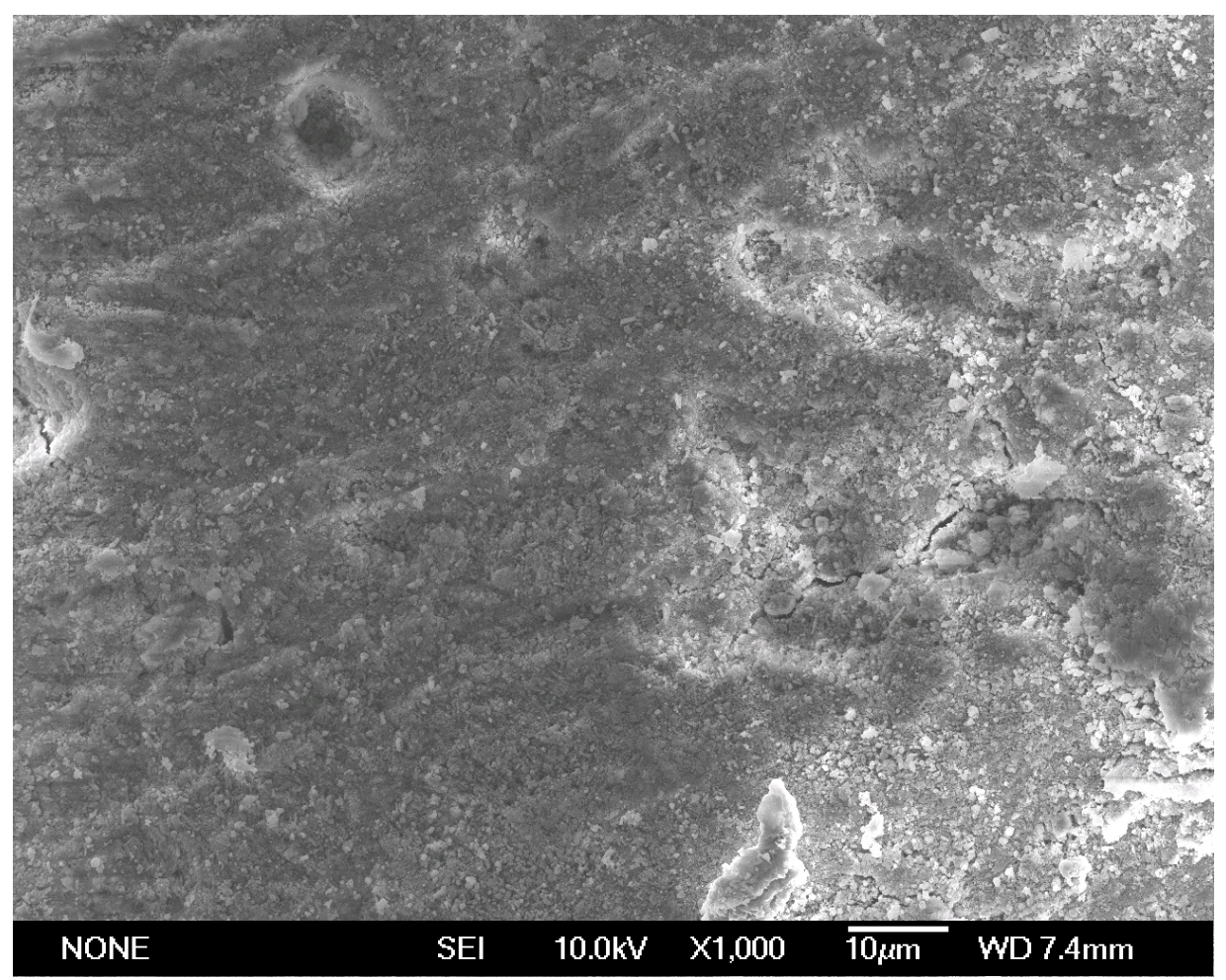

Figure 5.65: SEM micrograph of the calcium phosphate geopolymer, heated to $600^{\circ} \mathrm{C}, 7$ weeks SBF exposure, $x 1000$

The material appears relatively rough and the agglomerates rather less ball-shaped compared with the geopolymer before exposure to simulated body fluid. This geopolymer appears to be relatively porous, with the 
porosity more or less evenly distributed throughout the sample.

At higher magnifications (Figs. 5.66 and 5.67), the changes resulting from exposure to simulated body fluid become more obvious. Although there are still agglomerates present, new morphologies such as needleshaped crystals (marked 1 in Fig. 5.66) have developed. The agglomerates range in size between $<30 \mathrm{~nm}$ to $>2 \mu \mathrm{m}$, whereas the needle-shaped crystals range from $500 \mathrm{~nm}$ to $1.4 \mu \mathrm{m}$. Larger pores are present in the geopolymer, approximately $100-200 \mathrm{~nm}$ in size, together with a relatively large amount of nano porosity (pore sizes $<30 \mathrm{~nm}$ ).

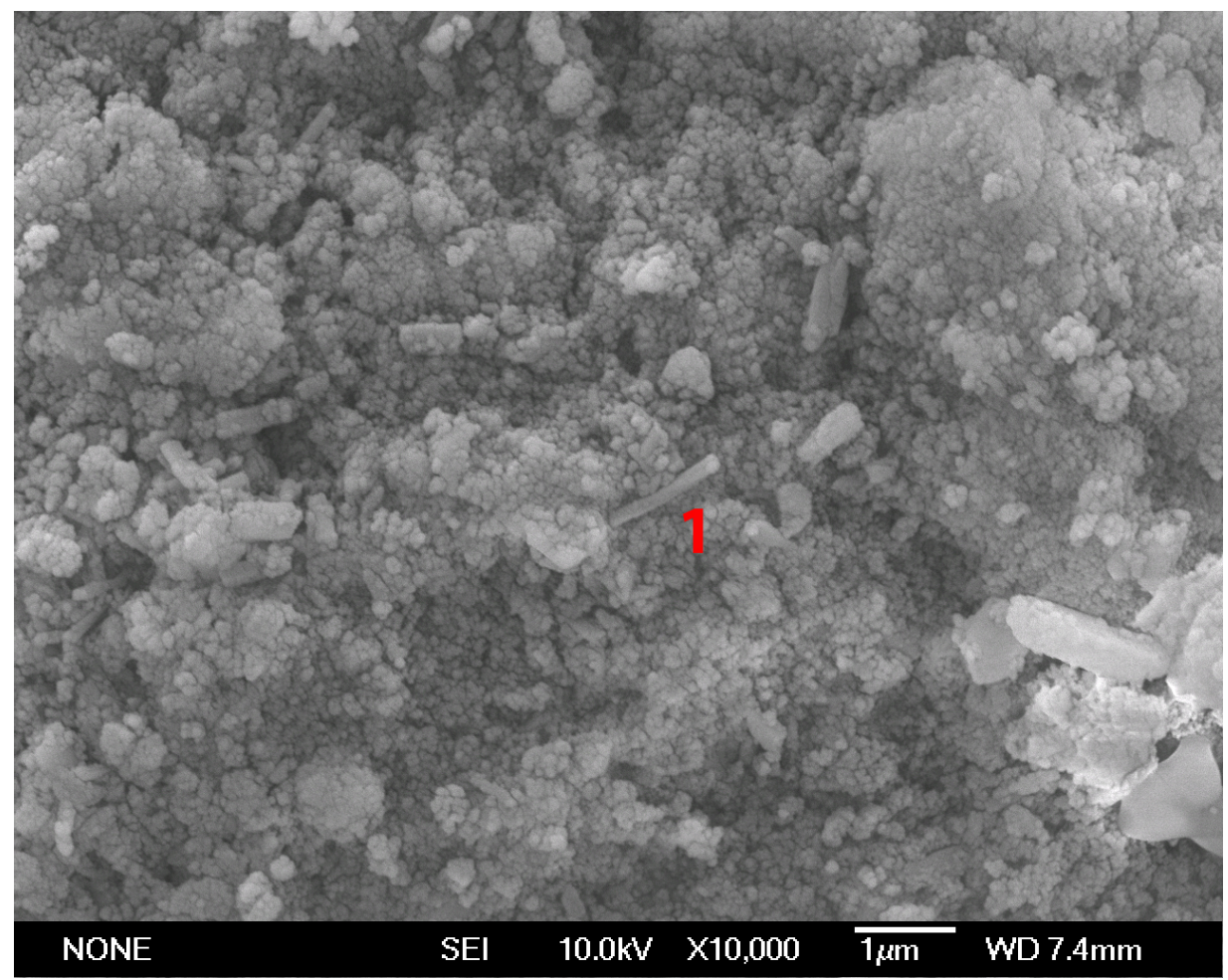

Figure 5.66: SEM micrograph of the calcium phosphate-containing geopolymer, heated to $600^{\circ} \mathrm{C}, 7$ weeks $\mathrm{SBF}$ exposure, $x 10 \mathrm{k}$ 


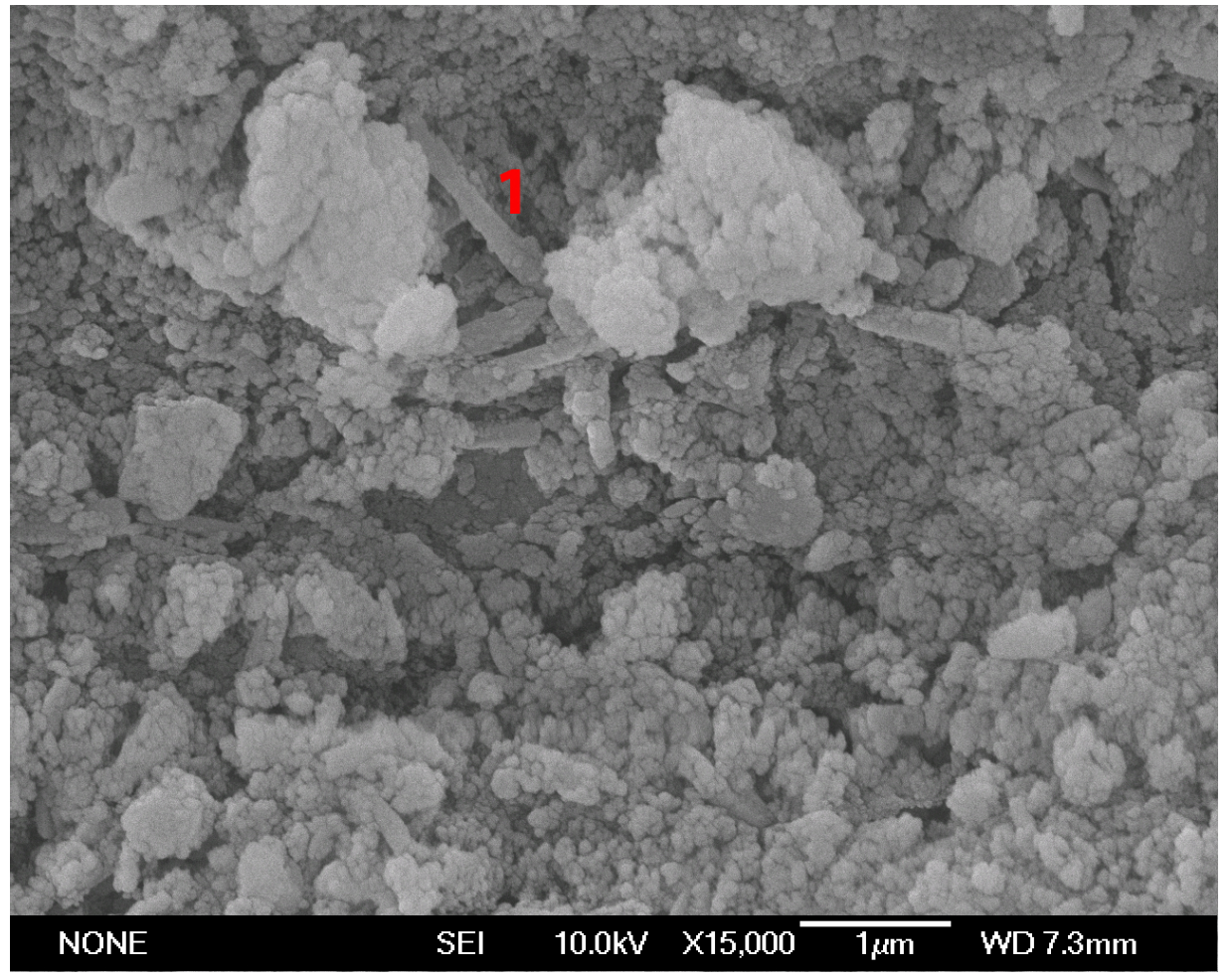

Figure 5.67: SEM micrograph of the calcium phosphate-containing geopolymer, heated to $600^{\circ} \mathrm{C}, 7$ weeks SBF exposure, $x 15 \mathrm{k}$ 
Element mapping (Fig. 5.68) shows that the element distribution is relatively homogeneous with respect to silicon, calcium and phosphorus.
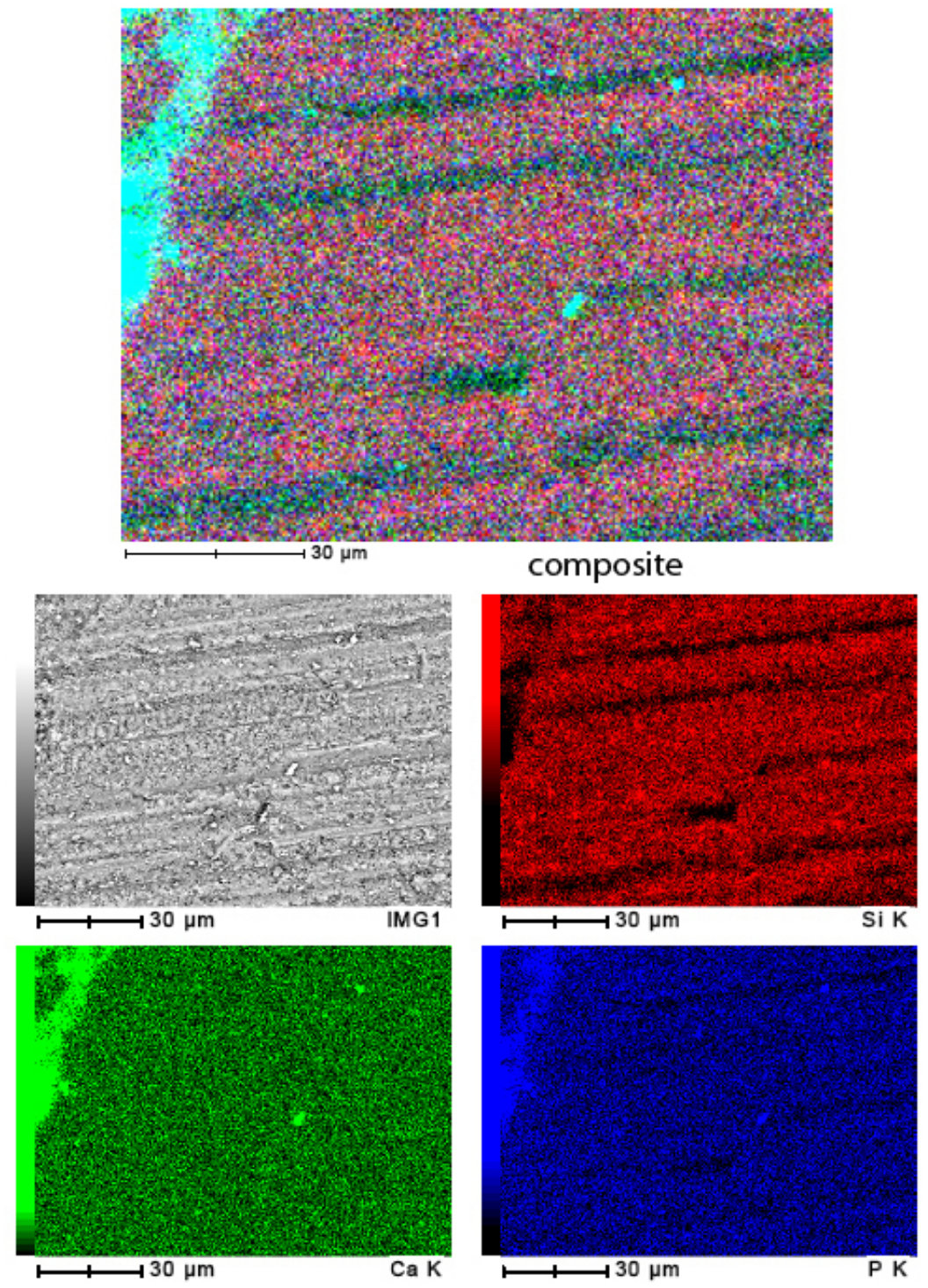

JEOL

Figure 5.68: EDS element maps of the calcium phosphate-containing geopolymer, heated to $600^{\circ} \mathrm{C}, 7$ weeks $S B F$ exposure, $x 1000$ 
Although these elements are evenly distributed, calcium and phosphorus appear to be concentrated in a scratch indicated by the greenish blue colour in the composite map (top). This may result from the presence of a softer area of calcium phosphate that was more readily damaged during grinding. Exposure of this geopolymer to SBF has eliminated the elemental inhomogeneity observed in the sample prior to SBF exposure. This is not an artefact, since a number of areas analysed by EDS all showed the same results.

A possible reason for the improved homogeneity is the exchange of elements with the compounds of the SBF with the formation of new $\mathrm{x}$ ray amorphous phases. ICP analysis indicates an exchange of aluminium from the geopolymer to the SBF, and the absorption of calcium, silicon and phosphorus from the SBF by the geopolymer (section 5.5). 

Chapter 6

\section{Conclusions}


The aim of this project was to produce aluminosilicate geopolymers with bioactive behaviour. Since such behaviour is observed in calciumcontaining compounds, geopolymer composites using several inorganic calcium compounds were synthesised. Their mechanical properties and bioactivity were tested under laboratory conditions. Because geopolymers are highly alkaline, the $\mathrm{pH}$ of these composites needed to be reduced to non-hazardous levels. This was done by using the least possible alkali in the synthesis without compromising the mechanical properties, and by heating to $550^{\circ} \mathrm{C}-600^{\circ} \mathrm{C}$. Geopolymers contain aluminium, which must be fixed in the material's structure, to prevent leaching into the body.

The phases and structures formed in the geopolymers before and after exposure to SBF were determined by $\mathrm{XRD},{ }^{27} \mathrm{Al},{ }^{29} \mathrm{Si}$ and ${ }^{43} \mathrm{Ca}$ MAS NMR, and SEM/ EDS. The tensile strength of the materials before SBF exposure was determined by diametral compression testing. Alterations of the element concentrations in the SBF during the exposure experiments were determined by ICP analysis and changes of the $\mathrm{pH}$ were determined by direct measurements.

The most important properties in a geopolymer material for bioactive applications are:

- The ability to form bioactive compounds in contact with body fluid

- Near neutral pH

- Minimal release of aluminium

- Comparable strength to current materials 
Table 6.1: Summary of the important properties of the geopolymers

\begin{tabular}{||c|c|c|c|c|c||}
\hline \hline Geopolymer & $\begin{array}{c}\text { heating } \\
\text { temp. }\end{array}$ & $\begin{array}{c}\text { HA or HCA } \\
\text { formation }\end{array}$ & $\mathrm{pH}$ & $\begin{array}{c}\text { leached } \\
\mathrm{Al}\end{array}$ & $\begin{array}{c}\text { Tensile } \\
\text { strength }\end{array}$ \\
\hline \hline \multirow{2}{*}{ Reference } & $\left({ }^{\circ} \mathrm{C}\right)$ & & & $(\mathrm{ppm})$ & $(\mathrm{MPa})$ \\
\cline { 2 - 6 } & 550 & possible $^{1}$ & 7.87 & 0.211 & 2.05 \\
\cline { 2 - 6 } & 600 & possible $^{1}$ & 7.78 & 0.135 & 1.22 \\
\hline \hline \multirow{2}{*}{$\begin{array}{c}\text { Calcium } \\
\text { hydroxide }\end{array}$} & 550 & present & 9.00 & 6.350 & 0.64 \\
\cline { 2 - 6 } & 600 & strongly present & 8.96 & 2.680 & 1.46 \\
\hline \hline \multirow{2}{*}{$\begin{array}{c}\text { Calcium } \\
\text { silicate }\end{array}$} & 550 & absent & 10.75 & 0.056 & - \\
\cline { 2 - 6 } & 600 & present & 9.30 & 0.027 & 1.38 \\
\hline \hline \multirow{2}{*}{$\begin{array}{c}\text { Calcium } \\
\text { phosphate }\end{array}$} & 550 & probable $^{1}$ & 8.12 & 0.517 & 4.17 \\
\cline { 2 - 6 } & 600 & probable $^{1}$ & 8.03 & 0.442 & 1.73 \\
\hline \hline
\end{tabular}

${ }^{1}$ : Not confirmed by XRD but suggested according to ICP, SEM and EDS results

From the results in Table 6.1 we conclude: The reference geopolymers both heated to $550^{\circ} \mathrm{C}$ and $600^{\circ} \mathrm{C}$ showed no confirmed evidence of bioactive phase formation after exposure to SBF. They produce the lowest $\mathrm{pH}$ values in the SBF and the tensile strength results are average. These samples released the second lowest amount of aluminium but the amount released dropped by $50 \%$ for the sample heated to $600^{\circ} \mathrm{C}$.

After exposure to SBF, the calcium hydroxide geopolymers showed the formation of the bone-like phases HA and HCA . They released the highest amount of aluminium whereas it was significantly lower for the sample heated to $600^{\circ} \mathrm{C}$ but still excessive. The $\mathrm{pH}$ of the SBF produced by these 
samples were not the highest but still do not meet the requirements for a bio-compatible material.

The presence of hydroxyl apatite phases after SBF exposure was confirmed for the calcium silicate sample heated to $600^{\circ} \mathrm{C}$ but this phase was absent for the sample heated to $550^{\circ} \mathrm{C}$. These samples showed the lowest leaching of aluminium but produced the highest $\mathrm{pH}$ values.

Geopolymers containing calcium phosphate showed no confirmed formation of hydroxyl apatite or hydroxyl carbonate apatite after exposure to SBF. They produced $\mathrm{pH}$ values slightly above neutral and showed the highest tensile strength. However, these samples released the second highest amount of aluminium in critical levels.

The best properties in terms of bio-compatibility are shown by the reference and the calcium phosphate-containing geopolymer, with respect to their $\mathrm{pH}$ values and their tensile strength. Both compare favourably with the commercially available Bioglass/polysulfone composites and Bioglass ${ }^{\circledR}$. The presence of bioactive phase formation could not be confirmed by XRD, however ICP, SEM and EDS results showed the absorption of calcium and phosphorus of the SBF and the formation of nano-scaled crystals rich in these elements. This probably indicates the formation of calcium phosphate phases, such as hydroxyl apatite, and therefore a degree of bioactivity. However, the release of aluminium is critical which makes them presently bio-incompatible.

The best bioactivity is shown by the geopolymers containing calcium hydroxide $\left(550^{\circ} \mathrm{C}\right.$ and $\left.600^{\circ} \mathrm{C}\right)$ or calcium silicate $\left(600^{\circ} \mathrm{C}\right)$. They show the formation of the bone-like phases HA and HCA which is confirmed by $X R D$. The release of aluminium is relatively low for the calcium silicate 
containing samples $(<0.06 \mathrm{ppm})$ but critically high for the calcium hydroxide containing geopolymers ( $>2.6 \mathrm{ppm}$ ). Both of the samples present tensile strength values comparable to Bioglass/polysulfone composites The $\mathrm{pH}$ values of the calcium hydroxide and the calcium silicate geopolymers showing the trend to drop with increased heating temperature, but are still too high.

\subsection{Future work}

These are promising results but the synthesised geopolymers are not ready to use as biomaterials yet. Further improvement is required to lower the materials $\mathrm{pH}$ values and the release of aluminium. The strength of the geopolymers should be improved to make these materials available for a wider range of biomedical applications.

To get more information about the above-mentioned synthesised materials, additional examination is suggested. ${ }^{31} \mathrm{P}$ MAS NMR could be carried out to gain more information about the environment of the phosphorus in the calcium phosphate-containing geopolymer. This could deliver information whether the phosphorus forms part of the geopolymer network structure and whether heating induces phosphate-bonding. Analysis by ${ }^{43} \mathrm{Ca}$ MAS NMR was carried out on the calcium phosphate-containing geopolymers but should also be carried out on all the other geopolymers to determine the nature of the calcium sites in their structure. To augment the available reference spectra, ${ }^{43} \mathrm{Ca}$ MAS NMR spectra should be acquired for synthetic hydroxyl apatite and hydroxyl carbonate apatite.

Another method for producing bioactive geopolymer composites may 
be to first synthesise a geopolymer without additives, then coat it with a thin layer of a calcium-containing compound, such as those used in the present work. This could be done in various ways.

By making a water-based solution containing the bioactive compound and applying it thinly to a conventional geopolymer monolith before curing, a bond to the sample surface may result. Alternatively, it may be possible to thinly sprinkle an uncured geopolymer slurry with a very finely powdered bioactive compound to achieve an attachment with the geopolymer.

These methods may reduce the amount of additive required, thereby lowering the amount of essential alkaline material. As shown in this work, a geopolymer without additives can be produced with much less alkaline reagents and therefore create a geopolymer with lower $\mathrm{pH}$. 


\section{Bibliography}

[1] K.J.D. MacKenzie. What are these things called Geopolymers? A PhysicoChemical Perspective, volume 153 of Ceramic Transations, pages 175186. Am. Ceram. Soc., 2003.

[2] J. Davidovits. Geopolymers: Inorganic polymeric new materials. J. Thermal Analysis, 37:1633-1656, 1991.

[3] H. Oudadesse, A.C. Derrien, M. Mami, S. Martin, G. Cathlineau, and L. Yahia. Aluminosilicates and biphasic HA-TCP composites: studies of properties for bony filling. Biomed. Mater., 2:59-64, 2007.

[4] S. Martin, A.C. Derrien, H. Oudadesse, D. Chauvel-Lebret, and G. Cathelineau. Implantation of aluminosilicate/ calcium phosphate materials; influence on bone formation in rabbit tibias. European Cells and Materials, 9:71-72, 2005.

[5] H. Yan, K. Zhang, C. Blanford, L. Francis, and A. Stein. In vitro hydroxycarbonate apatite mineralization of $\mathrm{CaO}-\mathrm{SiO}_{2}$ sol-gel glasses with a three-dimensionally ordered macroporous structure. Chem. Mater., 13:1374-1382, 2001.

[6] Online on Geopolymers Homepage, www.geopolymer.org. 
[7] K.J.D. MacKenzie. Applications of solid state NMR spectroscopy to ceramic research. British Ceramic Transactions, 99:231-240, 2000.

[8] W.M. Kriven, J.L. Bell, and M. Gordon. Microstructure and Microchemistry of fully-reacted Geopolymers and Geopolymer Matrix Composites, volume 153 of Ceramic Transations, pages 227-250. Am. Ceram. Soc., 2003.

[9] V.F.F. Barbosa, K.J.D. MacKenzie, and C. Thaumaturgo. Synthesis and characterisation of materials based on inorganic polymers of alumina and silica: sodium polysialate polymers. Int. J. of Inorganic Mater, 2:309-317, 2000.

[10] J. Davidovits. 30 years of successes and failures in geopolymer applications. market trends and breakthroughs. Geopolymer Conference, Melbourne, 2002.

[11] H. Oudadesse, A.C. Derrien, M. Lefloch, and J. Davidovits. MAS-NMR studies of geopolymers heat-treated for applications in biomaterials field. J. Mater. Sci., 42:3092-3098, 2007.

[12] D. Kim, H.-T. Lai, G.V. Chilingar, and T.F. Yen. Geopolymer formation and its unique properties. Environ Geol, 51:103-111, 2006.

[13] M.G. Blackford, J.V. Hanna, K.J. Pike, E.R. Vance, and D.S. Perera. Transmission electron microscopy and nuclear magnetic resonance studies of geopolymers for radioactive waste immobilization. J. Am. Ceram. Soc., 90:1193-1199, 2007. 
[14] D.S. Perera, Z. Aly, E.R. Vance, and M. Mizumo. Immobilization of $\mathrm{Pb}$ in a geopolymer matrix. J. Am. Ceram. Soc., 88(9):2586-2588, 2005.

[15] J. Black, S.W. Shalaby, and M. LaBerge. Biomaterials education: An academic viewpoint. Journal of Applied Biomaterials, 3:231-236, 1992.

[16] L.L. Hench. Bioceramics. J. Am. Ceram. Soc., 81(7):1705-1728, 1998.

[17] L.L. Hench. Bioceramics: From concept to clinic. J. Am. Ceram. Soc., 74(7):1487-1510, 1991.

[18] S.V. Dorozhkin. Calcium orthophosphate cements for biomedical application. J. Mater. Sci., 43:3028-3057, 2008.

[19] A.U.J. Yap, Y.S. Pek, R.A. Kumar, P. Cheang, and K.A. Khor. Experimental studies on a new bioactive material: HAIonomer cements. Biomaterials, 23:955-962, 2002.

[20] G. Geyer, G. Baier, and J. Helms. Epidureal application of ionomeric cement implants. experimental and clinical results. The Journal of Laryngology and Otology, 112:344-350, 1998.

[21] P. Hantson, P. Mathieu, M. Gersdorff, C.J.M. Sindic, and R. Lauwerys. Encephalopathy with seizures after use of aluminium-containing bone cement. The Lancet, 344:1647, 1994.

[22] K.J.D. MacKenzie, S. Komphanchai, and R.A. Fletcher. New Trends in the Chemistry of Inorganic Polymers for Advanced Applications, volume 28 of Ceramic Transations, pages 249-257. Ceramic Transactions, 2007. 
[23] K.J.D. MacKenzie, D.R.M. Brew, R.A. Fletcher, C.L. Nicholson, R. Vagana, and M. Schmuecker. Towards an understanding of the synthesis mechanisms of geopolymeric materials. Proc. World Geopolymer Conference, St. Quentin, Paris, 2005.

[24] K.J.D. MacKenzie, M.E. Smith, and A. Wong. A multinuclear MAS $N M R$ study of calcium-containing aluminosilicate inorganic polymers. J. Mater. Chem., 17:5090-5096, 2007.

[25] K.J.D. MacKenzie, D.R.M. Brew, R.A. Fletcher, and R. Vagana. Formation of aluminosilicate geopolymers from $1: 1$ layer lattice minerals pre-treated by various methods: a comparative study. J. Mater Sci, 42:4667-4674, 2007.

[26] A. Oyane, H.-M. Kim, T. Furuya, T. Kokubo, T. Miyazaki, and T. Nakamura. Preparation and assessment of revised simulated body fluids. J. Biomed. Mater. Res., 65A:188-195, 2003.

[27] C. Ohtsuki. How to prepare simulated body fluid $(S B F)$ and its related solutions, proposed by Kokubo and his colleagues. http: //mswebs.naist.jp/english/index.html.

[28] H. Stanjek and W. Husler. Basics of x-ray diffraction. Hyperfine Interactions, 154:107-119, 2004.

[29] Online, Bruker website, http://www.bruker-axs.de.

[30] Basics of x-ray diffraction. online: University of New Mexico - Department of Earth and Planetary Science, http://epswww.unm. edu/xrd/xrdbasics.pdf, 1999. 
[31] K.J.D. MacKenzie and M.E. Smith. Multinuclear Solid-State NMR of Inorganic Materials, volume 6 of Pergamon Materials Series, chapter 1, pages 3-18. Pergamon, 2002.

[32] K.J.D. MacKenzie and M.E. Smith. ${ }^{27} A l$ NMR, volume 6 of Pergamon Materials Series, chapter 5, pages 271-330. Pergamon, 2002.

[33] K.J.D. MacKenzie and M.E. Smith. ${ }^{29}$ Si NMR, volume 6 of Pergamon Materials Series, chapter 4, pages 201-268. Pergamon, 2002.

[34] P.F. Schmidt. Praxis der Rasterelektronenmikroskopie und Mikrobereichsanalyse. Kontakt \& Studium. 1994.

[35] JEOL LTD. A guide to scanning microscope observation. JEOL Brochure.

[36] C. Pittet and J. Lemaitre. Mechanical characterization of brushite cements: A mohr circleś approach. J. Biomed. Mater. Res., 53:769-780, 2000.

[37] Y.-C. Chou and C.-S. Chen. Determining elastic constants of transversely isotropic rocks using brazilian test and iterative procedure. Int. J. Numer. Anal. Meth. Geomech, 32:219-234, 2008.

[38] M.K. Kerber, A.A. Wereszczak, and M.G. Jenkins. Fracture Strength, chapter 4, pages 147-152. Marcel Dekker, INC, 1998.

[39] T.J. Manning and W.R. Grow. Inductively coupled plasma - atomic emission spectroscopy. The Chemical Educator, 2, 1997. 
[40] I. Odler. Special Inorganic Cements. E \& FN Spon, London and New York, 2000.

[41] R.B. Heimann. Materials science of crystalline bioceramics: A review of basic properties and applications. CMU Journal, 1:23-46, 2002.

[42] I. D. Thompson and L.L. Hench. Mechanical properties of bioactive glasses, glass-ceramics and composites. Proceedings of the Institution of Mechanical Engineers, 212(Part H):127-136, 1998.

[43] E. Bresciani, T. Barata, T.C. Fagundes, A. Adachi, M.M. Terrin, and M.F. Navarro. Compressive and diametral tensile strength of glass ionomer cements. Journal of Applied Oral Science, 4:344-348, 2004.

[44] L. Yue, M. Shui, and Z. Xu. The decomposition kinetics of nanocrystalline calcite. Thermochimica Acta, 335:121-126, 1999.

[45] L.L. Hench. Plenary Lecture, PACRIM Conference 8, Vancouver, 2009.

[46] M. Schmuecker and K.J.D. MacKenzie. Microsstructure of sodium polysialate siloxo geopolymer. Ceramics International, 31:433-437, 2005. 